\title{
Barriers to Open E-Learning in Public Administrations
}




\section{Julia Dorothée Stoffregen}

\section{Barriers to Open E-Learning in Public Administrations}

Esitetään Jyväskylän yliopiston informaatioteknologian tiedekunnan suostumuksella julkisesti tarkastettavaksi yliopiston Agora-rakennuksen auditoriossa 2 joulukuun 16. päivänä 2017 kello 16.

Academic dissertation to be publicly discussed, by permission of the Faculty of Information Technology of the University of Jyväskylä, in building Agora, auditorium 2, on December 16, 2017 at 16 o' clock.

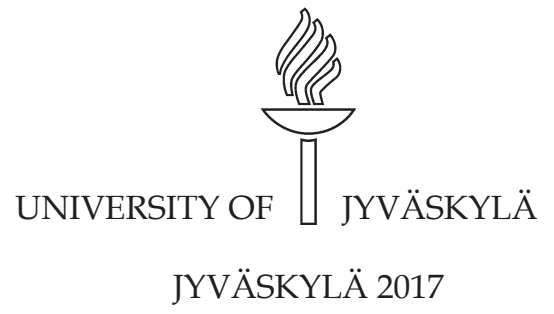




\section{Barriers to Open E-Learning in Public Administrations}




\section{Julia Dorothée Stoffregen}

\section{Barriers to Open E-Learning in Public Administrations}

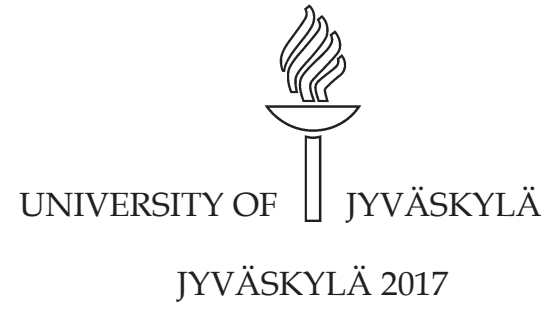


Editors

Marja-Leena Rantalainen

Faculty of Information Technology, University of Jyväskylä

Pekka Olsbo, Ville Korkiakangas

Publishing Unit, University Library of Jyväskylä

Permanent link to this publication: http:/ / urn.fi/URN:ISBN:978-951-39-7298-1

URN:ISBN:978-951-39-7298-1

ISBN 978-951-39-7298-1 (PDF)

ISBN 978-951-39-7297-4 (nid.)

ISSN 1456-5390

Copyright (C 2017, by University of Jyväskylä

Jyväskylä University Printing House, Jyväskylä 2017 


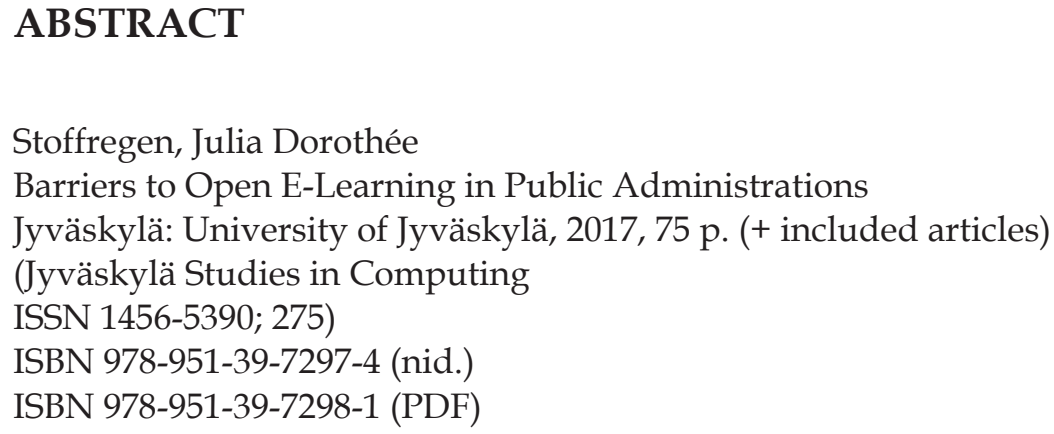

The use of Open Educational Resources (OERs) is promising as a complementary resource to traditional e-learning courses. Digital learning resources can be accessed on demand and can be developed by a wide range of employees. Thus, OERs may be suitable as a response to the changing demands of workplace learning. Despite its potential, the uptake of OER is slow. Previous research has found numerous barriers to the use and sharing of OERs, ranging from cultural to technical and organizational challenges. Research has reported barrier concepts, which elaborate on the kinds and meanings of challenges in the educational and private sector domain. Yet, it remains unclear as to why and how barriers evolve and differ across contexts.

One dedicated example is the public sector, where the need to innovate processes of knowledge management and learning is high. Besides limited budgets that restrict investment in employees' training, the ageing workforce has increased the need to find a suitable solution to document and transfer knowledge. So far, OERs are not well known in this sector. Similarly, the kinds of barriers to OERs in this specific bureaucratic context have not been elaborated from research or theoretical perspectives.

This dissertation aims at closing this research gap by elaborating on the range of barriers across European public administrations as well as answering the questions of why and how barriers evolve in a particular space and time. As a result, the thesis presents a unique theoretical perspective on barriers to OERs and their trajectories in the public sector. The dissertation provides a punctuated and adapted structural socio-technical change model which can be used to analyse how and why barriers unfold beyond public sector research. Besides the theoretical contributions, the thesis provides a contextualized barrier frame that can guide OER platform developers in assessing socio-cultural barriers and requirements that are typical to open e-learning practices in public administrations. During the field research, the thesis further provided design principles, in addition to OER guidelines, for employees in the public sector.

Keywords: OER, public sector, barrier studies, process theory perspective 
Author's

Supervisors

Reviewers

Opponents
Julia Stoffregen

Faculty of Information Technology

University of Jyväskylä, Finland; and

Department of Computer Science

Ruhr West University of Applied Sciences, Germany

Julia.stoffregen@hs-ruhrwest.de

Professor Jan Pawlowski

Faculty of Information Technology

University of Jyväskylä, Finland; and

Department of Computer Science

Ruhr West University of Applied Sciences, Germany

Professor Dr.-Ing. Jari Veijalainen

Faculty of Information Technology

University of Jyväskylä, Finland

Prof. Sirje Vikus

School of Digital Technologies

Tallinn University, Estonia

Dr. Javiera Atenas

School of Management

University College London, The United Kingdom

Dr. Markus Deimann

Institute of Learning Services

Lübeck University of Applied Sciences, Germany 


\section{ACKNOWLEDGEMENTS}

About three years ago, I moved to the Ruhrgebiet in Germany and started my dissertation as part of the EAGLE (EnhAnced Government LEarning) project. During my time here, I have gotten to known inspiring people and a great group of competent colleagues. I got the chance to work with them and to learn how to excel at research work. I am grateful for all of these experiences which will shape my future path in the academic field.

First and foremost, I would like to thank my first supervisor, Professor Jan Pawlowski, who has been with me through all the ups and downs in my research. Jan Pawlowski always found the time for domain-specific as well as other discussions and created a space for trustful collaboration. His ongoing support and positive approach to research has encouraged me greatly in the academic field. I would also like to thank my second supervisor, Professor Jari Veijalainen, for providing me with support for my dissertation. In this regard, my thanks also goes to Professor Ola Henfridsson, who shaped the final twists of the dissertation by helping with critical discussions and providing guidance in the past year. Similarly, Professor von Lucke needs a mention because he was always there to answer public-administration-specific questions.

At the University of Jyväskylä, I had the pleasure of being a part of the GLIS group, which comprised Henri Pirkkalainen, Kati Clements, Philipp Holtkamp and Tiia Stén. They supported me with the development of my dissertation and often brought me back on track whenever I headed forward too fast.

At the University of Applied Sciences Ruhr West, I would like to thank Professor Uwe Handmann and colleagues at the Institute of Computer Science, who provided me with a fantastical work space, in which I could plan, realize and analyse the results of each research step of my dissertation.

I am grateful to my colleagues of the EAGLE project, namely, Eric Ras, Eric Tobias, and Celina Raffl, as well as the participating institutes from abroad. They supported the planning and realization of certain research steps and allowed us to obtain parts of the research data from public administrations of foreign countries. In relation to this, I would like to thank the numerous participants of public administrations, who have dealt with my work, my research questions and propositions of models in dozens of interviews, workshops, validations, pilots and other discussion formats.

Last but not least, I would like to thank Andre Beblek, who was there with me throughout this eventful journey of the last few years, not to forget my family, Regina Stoffregen, Rainer Looschen and Johanna Burkert, who supported me through the highs and lows and pushed me to accomplish this work.

Thank you all very much for your time and support throughout the years!

Bottrop 29.8.2017

Julia Dorothée Stoffregen 


\section{FIGURE}

FIGURE 1: Structure of the Chapter 'Introduction' ............................................... 13

FIGURE 2: Structure of the Chapter 'Methodology' .............................................. 25

FIGURE 3: Overview of Articles According to the ADR Approach ..................... 32

FIGURE 4: Illustration of an OER................................................................... 57

\section{TABLE}

TABLE 1: Research Framework and Criteria ……................................................. 29

TABLE 2: Adapted Action Design Research Approach............................................. 32

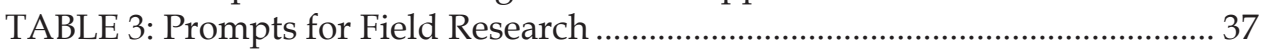

TABLE 4: Categorizing Contributions of the Dissertation ..................................... 49

TABLE 5: Excerpt of Enabler Statements ............................................................ 55

TABLE 6: Excerpt of the Design Principles............................................................... 56 


\title{
CONTENTS
}

\author{
ABSTRACT \\ ACKNOWLEDGEMENTS \\ FIGURES AND TABLES \\ CONTENTS
}

1 INTRODUCTION

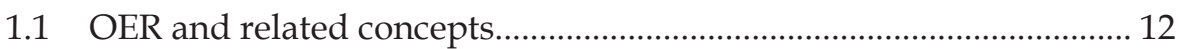

1.1.1 OER as a concept and related trends............................................. 13

1.1.2 OER barriers and related concepts ................................................. 14

1.1.3 E-learning and barriers in relation to OERs .................................. 16

1.1.4 Knowledge management and barriers in relation to OERs ...... 18

1.2 Basic models and theories ..................................................................... 20

1.2.1 Cultural and contextual models and theories ............................. 20

1.2.2 Process theories for barrier change ................................................ 22

1.3 Research objectives ............................................................................... 23

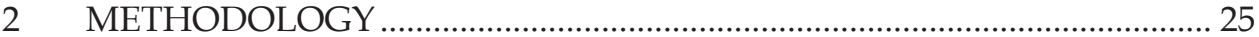

2.1 Basic foundation of the research approach ............................................ 26

2.2 Research design considerations ............................................................. 30

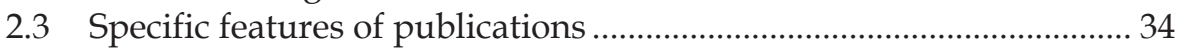

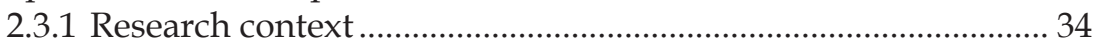

2.3.2 Methods and analysis of publications and research stages ...... 34

3 OVERVIEW OF ARTICLES ........................................................................... 38

3.1 Article I: A barrier framework for open e-learning in public

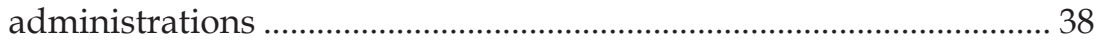

3.2 Article II: Barriers to open e-learning in public administrations: A comparative case study of the European countries Luxembourg, Germany, Montenegro and Ireland

3.3 Article III: Identifying socio-cultural factors that impact the use of Open Educational Resources in local public administrations...

3.4 Article IV: Why do relevant structural gaps to the exchange of open knowledge resources change in public administrations.

3.5 Article V: Which functional design allows for meaningful navigation through collaborative contextualization processes. 44

3.6 Article VI: How does agile software development benefit from agile OER development in public administration.......................................... 46

4 CONTRIBUTIONS, LIMITATIONS AND FUTURE WORK ......................... 48

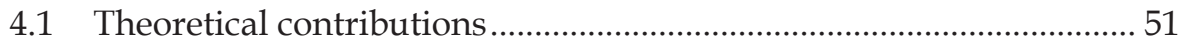

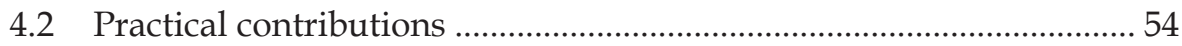

4.3 Limitations and future work ............................................................... 58 


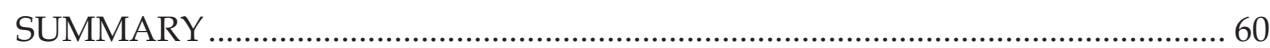

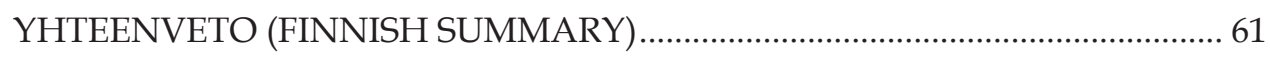

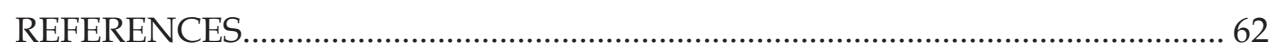




\section{ORIGINAL PAPERS}

I A Barrier Framework for open E-Learning in public administrations

II Barriers to open e-learning in public administrations: A comparative case study of the European countries Luxembourg, Germany, Montenegro and Ireland

III Identifying Socio-Cultural Factors That Impact the Use of Open Educational Resources in Local Public Administrations

IV Why do relevant structural gaps to the exchange of open knowledge resources change in public administrations

V Design for Collaborative Contextualization of Open Educational Resources

VI The Contribution of Agile Open Educational Resources towards Agile Government - an Explorative Study

Julia Stoffregen is the first author of these articles and did the majority of the work for each publication. 


\section{INTRODUCTION}

Employees in the public sector have to handle considerable amounts of digital data about persons and public services every day. They are expected to be experts with up-to-date knowledge and to be able to answer individually to citizens about their concerns (Wohlers, 2009). While the public sector is considered to move slowly given its bureaucratic cultural context, recent crises such as the entry of refugees show that rules and services may change fast and frequently. Knowing immediately about new technical requirements vis-a-vis proven practices is thus essential to providing good public services (Casalino, 2014; Davies, 2010). In this respect, the management of knowledge and learning has been a crucial topic for years (OECD, 2001, 2003; Rashman, Withers, \& Hartley, 2009). Given the ageing workforce, however, the topic has now come to the forefront (Fishenden \& Thompson, 2013; Korge \& Piele, 2014), and there is a lot of pressure to develop a smart technical solution that can help the administration successfully organize the knowledge of employees before they retire (Korge \& Piele, 2014; Talbot, 2009).

A recent approach that appears to be a solution is the use of Open Educational Resources (OERs). OERs are defined as 'any digital object[s] which can be freely accessed and used for educational purposes [using an open license]' (Pirkkalainen \& Pawlowski, 2010, p. 24, changes by the author are in parentheses). Known examples of OERs are accessible course materials of universities such as MIT (D'Antoni, 2009). The format is manifold: OERs may be in the form of videos, course concepts, quizzes or complete courses (Butcher, 2015), to mention just a few. Within public sector administrations, these formats may complement vocational training and knowledge-sharing processes. Unlike external experts who are paid to tutor employees about learning programs from time to time, OERs may be generated by lay public employees. They may note down, for example, how to process service requests most efficiently or whom to call in case of urgent services.

The internal use of OERs may thus contribute to translating the knowledge of colleagues into digital formats. Given that OERs are agnostic to domains, the accumulated knowledge may be used to create a digital memory 
of the organisation over time (Blees, Deimann, Seipel, Hirschmann, \& MuußMerholz, 2015). For newcomers or replacements, this memory is highly important to avoid slacking. Smart formats such as explainer videos, for example, can be quickly accessed on demand at the workplace. OERs thus appear to complement vocational e-learning courses by presenting an innovation in the management of knowledge and learning at the workplace (cf. Eidson, 2009; Talbot, 2009).

While the benefits of OER are appealing, experience has shown that in general, it is difficult for new technology to succeed in the public sector. Cultural factors such as bureaucracy, secrecy and seniority (cf. Stefanick \& LeSage, 2005) impede the uptake and use of new digital processes and resources. Generally, rejection or restriction of open sharing of information and knowledge across institutional contexts is observed (Langford \& Seaborne, 2003). Another such characteristic of administrative culture is disinterest in IT. For example, elearning materials were rejected as they lacked interactivity and replaced social meetings for sharing experiences (Sannia, Ercoli, \& Leo, 2009). Another characteristic of administrative contexts is understaffing. In other words, it is challenging for public employees to organize workplace learning if there are no replacements for them at the front office (Eidson, 2009).

The central questions related to the success of OERs in the public sector is thus not only, how will OERs be embedded into existing strategies, but also, how will culture- and context-specific barriers unfold. While there is a lack of knowledge about OERs in the public sector, earlier studies have identified numerous organizational, technical and cultural barriers that impeded the success of e-learning technologies (Bere, Nemeș, \& Silvestru, 2014) as well as knowledge management (Amayah, 2013). Given the novelty of OERs in the public sector, however, there are hardly any context-specific concepts that help to understand which barriers unfold and how the administration evolves over time to become open to e-learning at the workplace.

Given this lack of research on OERs with regard to both practice and theory, this dissertation elaborates on the barriers to OERs in the public sector context. The goal is to generate a conceptual model of barrier change in the public sector that can be applied in theory and practice.

\subsection{OER and related concepts}

This section elaborates on the theoretical background and main concepts of the dissertation. Studies on OERs in information system research lie at the intersection of OERs, e-learning and knowledge management. The related concepts that are published are built on models and theories about culture and context. The following sections will elaborate on the main concepts and their interactions (see Figure 1). 


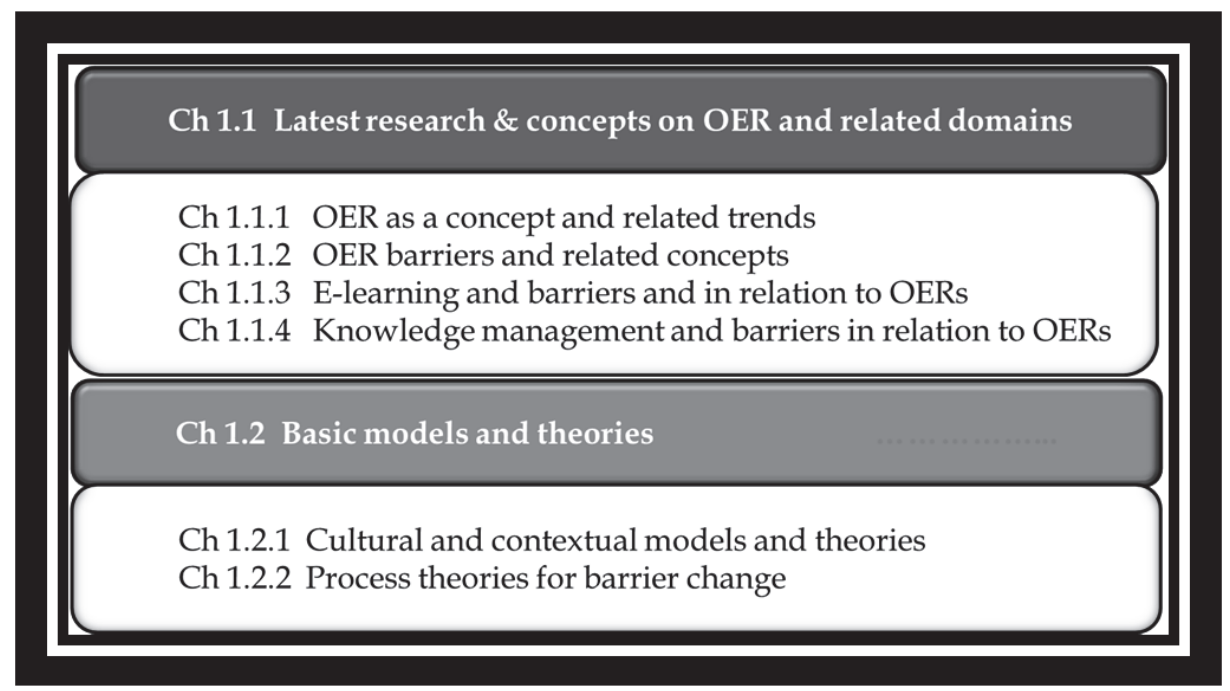

FIGURE 1: Structure of the Chapter 'Introduction'

\subsubsection{OER as a concept and related trends}

OERs represent the new trends in digitization and opening access to knowledge and electronic learning resources (Chatti, Schroeder, \& Jarke, 2012; D'Antoni, 2009; Richter \& McPherson, 2012). The overall aim is to increase access to knowledge and education (UNESCO, 2012) as well as to use, share and collaborate in the creation of knowledge, innovation and educational resources with peers across various domains (Koper, 2008; Laurillard, 2008; Pawlowski \& Richter, 2010; Pirkkalainen et al., 2010).

Despite general consent on the aim, the concept of OERs as such is malleable: In the term OER, resources may stand for 'highschool courses, university modules but also explainer videos of private persons, materials of companies as well as software and other tools or techniques used to support access to knowledge' (cf. Atkins, Brown, \& Hammond, 2007, p. 4). Hence, any digital content on individual experiences, theoretical concepts or software code may become an OER, if it is used and is free for re-use as a means of knowledge acquisition or transfer (UNESCO, 2002). The term educational covers individual and common learning processes as well as practices that allow for the sharing and transfer of knowledge to others, including consultation processes (cf. Hilton, Wiley, Stein, \& Johnson, 2010; UNESCO, 2002). Finally, the term open is highly relevant with regard to resource development and sharing of knowledge. Firstly, from a technological viewpoint, access to materials is opened due to information and communication technologies, interoperable formats and free registration with platforms (D'Antoni, 2009). Secondly, from the viewpoint of policy, openness relates to the use of open licences, such as the Creative Com- 
mons ${ }^{1}$ license, or public domains, among others. Open licences tell users under what terms OERs are allowed to share, use or match contents for their own (educational) means. Boundaries to this openness are particular components of open licenses as well as intellectual property rights that define under what terms materials can be used. Thirdly, from a philosophical point of view, OERs give individuals the freedom to choose to educate themselves, qualify and acquire knowledge as well as to decide what to do (further) with their insight (D'Antoni, 2009).

In the public sector, studies relating to the use of open or social media and tools often elaborate on open collaboration or use of open innovation processes in governments (Janssen, 2012; von Lucke \& Geiger, 2010; Mergel \& Desouza, 2013). Often, the objective is to see how open data provided by the government can supply OERs (Campbell, 2015) or lead to citizen innovations (Mergel \& Desouza, 2013). Interestingly, no publication takes the reverse perspective and asks how open e-learning and resources can benefit public sector employees.

In educational and private sector research, however, OERs as a topic is gaining much attention. Several attempts have been made to come up with a common definition for OERs that is inclusive of the e-learning, open education, courseware and teaching resources perspectives, among others (Atkins et al., 2007; Pawlowski et al., 2013; UNESCO, 2002, 2012). There have also been attempts to define core elements (UNESCO, 2002), principles of single aspects such as 'openness' (Hilton et al., 2010) and the design of OERs (Lane, 2010). Yet, there is no one particular OER concept that is common to information system research.

Besides elaborating on the concept of OERs, the focus of the latest research has started to shift to implementation-related issues such as models of OER lifecyles and processes (Downes, 2007; McGreal, 2010; Langen \& Bitter-Rijkema, 2012; Pawlowski \& Richter, 2010), programming aspects (Arimoto, Barroca, \& Barbosa, 2016; Green, Jones, Pearson, \& Gkatzidou, 2006; Richter \& Pawlowski, 2007) and the quality standards of OER repositories (Clements, Pawlowski, \& Manouselis, 2015). Moreover, the impact of OERs on higher education (Richter \& McPherson, 2012) and lifelong learning institutions (Das, 2011) has also been investigated. However, most studies have found that the uptake of OERs is slow and falls short of expectations (D'Antoni, 2009; Pawlowski, Pirkkalainen, \& Gervacios, 2013). The challenges range from organizational to technical and cultural factors (Pirkkalainen \& Pawlowski, 2014), and this is the central concern of the present dissertation. In this regard, the next section will elaborate on the barriers to implementing OERs.

\subsubsection{OER barriers and related concepts}

According to Pirkkalainen and Pawlowski (2013), a barrier is defined as '...any challenge, risk, difficulty, obstacle, restriction or hindrance that might prevent a

\footnotetext{
${ }^{1}$ https://creativecommons.org/
} 
single person, a group or an organization to reach an objective and success in a specific context when the challenge is related to acting or working in a collaborative cross border setting' (p. 5). Given the low uptake of OERs, research on the barriers to its implementation has started to increase. Initially, it was reported that there was a lack of knowledge about licensing and usage strategies related to OERs, apart from software, IT and data security risks as well as concerns about standards and policy (Atkins et al., 2007; von Lucke \& Geiger, 2010; UNESCO, 2002). Depending on the analytical model, the other barriers identified were culture-specific colours, pedagogic designs and mis-fitting role models in learning materials (Henderson, 2007), as well as the use of difficult language and domain-specific terminology (Edmundson, 2007; Richter \& Pawlowski, 2007). With the help of several case studies, Pirkkalainen and Pawlowski (2014) conducted some in-depth research and created a barrier framework based on empirical studies about the utilization of social software by workers with global knowledge. Further, from the cultural, social, technical and organizational contextual aspects, more than hundred barriers were identified (Pirkkalainen \& Pawlowski, 2014). Yet, studies indicate that many of these barriers overlap (Pirkkalainen \& Pawlowski, 2014). Although there is some systematic insight into the kinds of barriers, knowledge about culture- and contextspecific barriers to open e-learning is lacking. Thus, the question of how barriers vary across time and space remains unanswered (Blees et al., 2015; Pirkkalainen \& Pawlowski, 2014, p. 645; Richter \& McPherson, 2012).

Despite the unanswered questions about barriers, research has started to elaborate how to improve OER and overcome particular barriers. One approach in this respect is to adapt open content so as to overcome the barriers (Pawlowski \& Richter, 2010; Pirkkalainen et al., 2010). 'Adapting' means to define barriers and to adapt OERs such that the contents and formats are meaningful to learners in different contexts (Pawlowski et al., 2013). In this respect, adapting OERs can also be called 'contextualization', which highlights that cultureand context-specific factors interact and evolve into specific requirements that are related to a learner's locality and situation (Henderson, 2007; Richter \& Pawlowski, 2007).

The reported contextualization models describe how to retrieve and evaluate OERs for personal means (Edmundson, 2007; Pawlowski et al., 2013; Richter \& McPherson, 2012; Specht, 2008). An adaptation process is run, for example, over six steps, including the search for resources, validation of reusability, rewriting of courses or materials, adaptation, validation and re-publishing of materials (Richter \& Pawlowski, 2007). Moreover, different degrees of adaptation have been defined, which range from minor changes of wordings to the creation of a new resource (Edmundson, 2007; Richter \& Pawlowski, 2007; Tapanes, 2011). Another technical aspect of contextualization is the use of a metadata approach (Buzatto et al., 2009; Green et al., 2006; Pawlowski \& Richter, 2010). This approach is based on the assumption that cultural factors are defined and attached as attributes to the digital learning resource; hence, these factors function as metadata. When a learner searches for an OER, the resource is retrieved 
semi-automatically by search and filter functions according to the preferences or profile attributes of the learner (Pawlowski \& Richter, 2010; Richter \& Pawlowski, 2007).

When digital contextualization processes are run automatically, the challenge is to ensure that all integrated OERs follow the same metadata approach (reliable culture categories or taxonomies) and perform well across different platforms and search functions (Buzatto et al., 2009). Furthermore, all the culture factors linked to an OER need to be representative and relevant across contexts (Richter \& Pawlowski, 2007). In this regard, the relevance of culture- and context-specific barriers to OER is underscored (cf. Edmundson, 2007; Henderson, 2007; Richter \& Adelsberger, 2012).

Apart from adaptation models, research has also elaborated on other aspects that are considered to be critical for the success of OERs. Often, sustainability in terms of cost, technical integration into existing learning platforms and the roles of contributors are mentioned in this respect (Atkins et al., 2007; Downes, 2007). Some studies were dedicated to researching funding issues (Hylén, 2006), the development of business models (Langen \& Bitter-Rijkema, 2012) and comparison to prior movements such as free and open software sources to avoid barriers and pitfalls (Vukovic \& Martin, 2009). Technical frameworks were developed (Manisha \& Bandyopadhyay, 2009), and further studies on the quality of repositories (Clements et al., 2015) and correct use of licenses (Hylén, 2006; Hylén \& Schuller, 2007) were published. Despite these findings, authors have concluded that '...there will certainly be many more challenges ahead' (Atkins et al., 2007, p. 9). Hence, there is still a need for research into the range of barriers and how they respond to interventions.

In summary, several studies have described the barriers to OERs in the private and educational sector. While a high number of barriers have been identified, it appears that the relevance and kind of barriers differ across contexts. Furthermore, how barriers interrelate and unfold in a given space and time has not been researched so far. Models that capture these barriers are mainly in the form of a tabular format which summarizes the findings of individual case studies. Further, models that provide guidance on how to adapt OERs to overcome barriers focus on pre-defined aspects and have low value in practice (Richter \& Adelsberger, 2012; Tapanes, 2011). In this respect, there is more room for work that is dedicated to enhancing the knowledge about context-specific appearance and development of barriers. The research objectives of the dissertation are set so as to meet these needs. To provide some background, the latest research on barriers in related domains will be described in the next section.

\subsubsection{E-learning and barriers in relation to OERs}

E-learning is defined as the use of information and communication technology (ICT) to enhance education and learning processes (Kirkwood \& Price, 2013; Rosenberg, 2001). Though typically equated to online learning platforms, elearning is an umbrella term that also includes the use of mobile phones, dedi- 
cated apps, single videos, and desktop versions as either single-learning means or as media integrated in the standard classroom (cf. Rosenberg, 2001).

In the public sector, studies document that e-learning is mainly implemented as a blended approach (Bere et al., 2014). Hence, classroom or face-toface seminars are supplemented with optional or obligatory online resources (Colazzo, Molinari, \& Villa, 2009; Hârțescu, 2012; Sannia et al., 2009). The main goals of public administrations with regard to implementing e-learning are to improve the efficiency of services and to become more competitive by continuously updating their skills (Bere, Silvestru, \& Nemeș, 2013; Bere et al., 2014; Conci \& Bramati, 2007). Moreover, e-learning appears to be a cheap and easyto-implement solution which is almost free and also cost effective as employees do not have to travel anywhere to attend seminars (Langford \& Seaborne, 2003).

In the context of private organizations, the role of e-learning has been of similar interest. The use of ICT in knowledge-related processes was considered as a means of creating a learning organization (Rosenberg, 2001; Wild, Griggs, \& Downing, 2002), which represents both a metaphor and a concept of the fact that '...learning does take place in organizations during dynamic interactions amongst individuals, groups and the organization itself' (Falconer, 2006, p. 141). In the beginning, e-learning was expected to support organizational learning and to foster the documentation of explicit knowledge. Explicit knowledge is easily explicated knowledge which is ' ....articulated, codified, and communicated in symbolic form and/or natural language' (Alavi \& Leidner, 2001, p. 110). With regard to tacit knowledge that may be in the form of mental maps, beliefs, crafts and '...skills that apply to a specific context' (Alavi \& Leidner, 2001, p. 110), authors have been critical of whether information technology can foster creative activities and allow for social interaction and translation of tacit knowledge to a digital format (Falconer, 2006).

Prior to OERs, the e-learning trend was considered to facilitate access to educational resources (Deimann, 2012). However, e-learning mainly resulted in the digitization of existing materials. Moreover, access remained limited to individuals registered in courses or institutions such as universities (cf. Blees et al., 2015). The factors impeding the uptake of e-learning in public administrations, furthermore, range from social aspects such as a lack of familiarity and fear of 'mis-speaking in public' (Stefanick \& LeSage, 2005) to organisational and technical challenges, including a lack of suitable digital infrastructure and contents (Sannia et al., 2009). Moreover, managerial pitfalls boosted expenses and led to a delay in the development of platforms from scratch (Langford \& Seaborne, 2003).

By now, e-learning research has conceptualized the barriers to e-learning from different perspectives, including the pedagogical (Sannia et al., 2009; Yunus \& Salim, 2008), resource-based (Chen, 2014) and managerial perspectives (Pereira Ramos, Gouvêa, \& da-Costa, 2015). While various barriers are reported across studies, some barriers such as time and weak infrastructure appear to be commonly reported (cf. Bere et al., 2013). Recent studies, thus, recommend that new perspectives be explored to enhance knowledge in this domain, for exam- 
ple, by using a process-related perspective to identify barriers to learning and knowledge practices in the future (cf. Barette, Lemyre, Corneil, \& Beauregard, 2012; Gustavsson, 2009; Stefanick \& LeSage, 2005). However, despite this call by researchers (cf. Gustavsson, 2009; Moynihan \& Landuyt, 2009), no in-depth research has been published that provides a solid starting point for interventions. The studies reported so far either are in the form of brief reports about certain aspects (e.g. Conci \& Bramati, 2007) or provide a thorough concept of the barriers while not going beyond categorizing the findings of the study (Chen, 2014; Eidson, 2009).

Besides barriers, research on OERs and e-learning approaches has elaborated on the integration of components. While e-learning platforms and contents require tutoring by teachers or experts (Guri-Rosenblit, 2006), OERs require the contribution and collaboration of learners and evolve over time (Blees et al., 2015). Deimann (2012) concludes that OERs offer more space for social interaction than traditional e-learning courses. While the differences between elearning and OERs have been described, few studies address the conceptual aspects, such as how e-learning and OERs interrelate. It seems that OERs supplement e-learning rather than replace them, because a single resource may not be able to cover skills, abilities and knowledge as well as a well-designed curriculum and related materials (Deimann, 2012). Karunanayaka, Naidu, Rajendra, and Ratnayake (2016) report in this respect about an OER-based e-learning course where resources are designed to complement e-learning curricula. Yet, studies about the conceptual integration of OERs and e-learning are scarce. In relation to this, it is not clear which new theoretically grounded perspectives can enhance our understanding about barriers across domains and contexts.

\subsubsection{Knowledge management and barriers in relation to OERs}

Besides e-learning, studies on OERs often focus on knowledge management (Pawlowski \& Zimmermann, 2007; Pirkkalainen \& Pawlowski, 2012). Knowledge management 'involves distinct but interdependent processes of knowledge creation, knowledge storage and retrieval, knowledge transfer, and knowledge application' (cf. Alavi \& Leidner, 2001, p. 131; also see Back, 2002). Related processes, such as the handover of tasks and positions and the documentation and organization of knowledge (Alavi \& Leidner, 2001, p. 131) are focal for daily work in the public sector (OECD, 2001, 2003). In fact, some authors argue that public administrations are nothing but organisational processes of knowledge and information (Schilling, 2013).

The latest reviews and studies about innovative knowledge management and learning practices in the public sector (De Angelis, 2013; Rashman et al., 2009) demonstrate that both research about the state as well as research about the organisation of processes in practice are characterized by knowledge gaps. Single studies about the role of barriers to knowledge management have been published, for example, Amayah (2013) and Barette et al. (2012). Yet, the results are limited in terms of generalizability (cf. Amayah, 2013). According to Rash- 
man et al. (2009), future research should focus on the specific demands and conditions of the public sector in this respect:

'... public organizations constitute an important, distinctive context for the study of organizational learning and knowledge. Sector-specific features within the public sector are likely to influence organizational and inter-organizational learning processes, and further research is needed to understand the processes and contingencies which shape the nature and extent of organizational learning'. (p. 486)

Hence, future research should focus on the potential public sector-specific cultural and contextual barriers.

Besides the latest concepts, studies focusing on the interplay between OERs and knowledge management have also been reported. OERs may function as media for the storage and transfer of knowledge, such as noting down best practices in wikis or making a video on how to use an excel sheet. Developing OERs collaboratively with peers is at the same time a knowledge creation process. In this regard, authors have elaborated on the selection of promising tools that support social collaboration over distances (cf. Pirkkalainen \& Pawlowski, 2013; also see Wild et al., 2002).

Apart from OERs as a tool for innovation, studies have started to elaborate on specific aspects that allow the integration of knowledge management and open contents. One example is the technical integration of learning object repositories and knowledge management systems (Sampson \& Zervas, 2011). With regard to a conceptual review, however, the literature is scarce. With regard to knowledge management in the context of OERs, open contents seem to play an important role that extends beyond educational institutions, such as in the organization of knowledge sharing in communities of practice (Pawlowski \& Zimmermann, 2007).

In summary, research on barriers to OER and related domains in the context of the public sector is lagging behind at the moment. Furthermore, there are several open research questions and gaps in the field of information systems research that need to be addressed. This dissertation aims at closing the research gaps and increasing understanding about the barriers to OERs and their processes of change in the context of the public sector. Relevant findings reported in the literature will also be taken into account.

To develop a sound and innovative research approach to cultural and contextual barriers, a solid background about the latest models and theories is required. Therefore, the remaining section is dedicated to the relevant theoretical concepts and models related to culture, context and process. 


\subsection{Basic models and theories}

The following section provides the basic background of the culture, context and process theories that are needed to provide a sound theoretical look into the barriers to OER implementation in the public sector. In the first step, common approaches to cultural and contextual models and their relevance in public sector research are discussed. Subsequently, basic concepts that trace how barriers unfold will be presented.

\subsubsection{Cultural and contextual models and theories}

Previous studies have found that cultural factors are core barriers to the (re)use processes of OER and e-learning systems across different countries, in both the academic and sectorial domains (Richter \& McPherson, 2012). However, the definition of 'culture and cultural context factors' vary among these studies and include values, artefacts, behavioural routines, and basic assumptions, among others (Jamil, Askvik, \& Hossain, 2013; Richter, 2014). Accordingly, the term 'cultural context' is broadly defined by factors that are enmeshed and interdependent. Culture may be broadly defined as a 'programming of the mind' (Hofstede, 2001), or in more detail as '... patterns of thinking, feeling and potential acting that were learned throughout the person's lifetime' (Hofstede, Hofstede, \& Minkov, 2010), which may explain the interaction with IT (Leidner \& Keyworth, 2006). Others see culture as an amalgamation of values and beliefs shaped by practices and routines (Henderson, 2007). Context is often seen as everything around a given space and time, and thus, as a geographically bound pattern that can define the boundaries of a (cultural) group or that happens within a given time and space (Richter, 2014).

In the public sector, several studies elaborate on the role of culture and context in learning processes (Dunn \& Marinetti, 2002; Hall, Kutsch, \& Partington, 2012, Mahler, 1997; Laurillard, 2008; Swinke, 2012). Yet, there is no generalized cultural concept that can be used in the public sector (Barette et al., 2012; Beuselinck, Verhoest, \& Bouckaert, 2007; Bouckaert, 2007; Keraudren, 1996). Similarly, only a few concepts have evolved as reference models for analysing which cultural-contextual factors shape open e-learning in the private and educational domains. Some of the main approaches are presented in the following paragraphs.

One concept that is well known in research and in practice was developed by Hofstede (Hofstede, 2001; Richter, 2014). According to this concept, culture is defined as a mental program which '...partly predetermines human behavior' (Hofstede, 2001, p. 4). The programming is mainly based on six value dimensions: for example, culture is defined along pre-defined dimensions such as masculinity (-femininity) and individualism (-collectivism), among others (Hofstede, 1989; Hofstede, 1998; Hofstede et al., 2010). Researchers may use the set of pre-defined questions and guidelines for elaborating on culture differences between groups of participants on the basis of ratings. Furthermore, the differ- 
ences indicate the areas in which learners have to '...unlearn these patterns' (Hofstede, 2001, p. 3f) to advance and adapt to their current context.

A prominent concept that is considered as an alternative to Hofstede's concept in the e-learning domain is the multiple culture model (MCM, Henderson, 1996). As opposed to the definition of culture as a programming of the mind (Hofstede, 2001), culture is defined in terms of worldviews, basic assumptions and values related to learning and interactional processes (Edmundson, 2007; Henderson, 1996). According to this concept, after understanding the preferences of learners, instructional designers should develop assessment techniques and learning and interaction tools that can improve the reception of digital resources (Henderson, 1996, 2007). Unlike Hofstede's model (2001), the cultural factors of MCM are dedicated to learning contexts and extend beyond just values.

With regard to public sector studies, the cultural and contextual factors shaping e-learning cover demographical characteristics, personal expectations, individual and common experiences as well as infrastructure conditions (Chen, 2014; Eidson, 2009). There is no standard approach to defining 'culture' in the public sector, within which diverse cultural, rational or traditional definitions and levels of concepts are applied (cf. Bouckaert, 2007; Keraudren, 1996). While the cultural model of Hofstede (2001) is attractive for research given the scope of values and the current state of validation, its use in the public sector is generally questioned. Beginning with the specificity of the model, researchers claim that the model lacks structural or Weberian values (Beuselinck et al., 2007; Bouckaert, 2007; Moynihan \& Landuyt, 2009). The model is further limited to defining culture only by 'values' and excludes behavioural routines, assumptions and artefacts (cf. Richter, 2014), which may be relevant to understanding the barriers to implementing OERs in the public sector. Moreover, the models of Hofstede (2001) and Henderson (1996) are mainly focused on organisational culture or pedagogical concepts and disregard specific frames such as the barrier framework of OERs (Pirkkalainen \& Pawlowski, 2014). On the one hand, such frames focus on specific factors related to OER use (Pirkkalainen \& Pawlowski, 2014; Richter, 2014; Riege, 2005) and contribute to increasing domain specificity. On the other hand, they often lack a sound theoretical background (cf. Richter, 2014).

In summary, there is no dedicated cultural and contextual model for OER barriers in the public sector. Renowned models such as the one reported by Hofstede (2001) neglect specific 'political' values of the administrative profession (such as accountability and discretion), which appear to shape knowledge exchange in the public sector (cf. Stefanick \& LeSage, 2005). Furthermore, previous categorizations of barriers need to be assessed in order to elaborate on the meaning and interdependence of barriers across domains (Pirkkalainen \& Pawlowski, 2014; Richter \& Pawlowski, 2010). For developing a specific barrier model for the public sector, it is therefore important to consider cultural and contextual factors specific to the public sector, such as practices and social interaction (behaviour) at different (group) levels (Beuselinck et al., 2007; Boucka- 
ert, 2007). Moreover, the resulting barriers and their correspondence to commonly applied models in the educational or private sector domains need to be assessed with caution.

Following the review of culture- and context-specific theories and models, a point which still needs to be addressed is the meaning of tracing new process perspectives in research about barriers to the management of knowledge and learning (cf. Moynihan \& Landuyt, 2009). The next section will therefore present the core theories and models relevant to the dissertation.

\subsubsection{Process theories for barrier change}

Process models are explanatory concepts that explain how humans, digital artefacts and events interact and evolve over time (Pentland, 1999). The models demonstrate how, over a sequence of time, humans interact, and which kind of antecedents, incidents or consequences are influential in explaining or foreseeing changes in the interaction (Pentland, 1999; Van de Ven, 2007; Van de Ven \& Poole, 2005). Beyond identifying the present cultural and contextual barriers, such a perspective allows to elaborate on the questions of how and why barriers emerge. Furthermore, elaborating on the roots of barriers and related interventions is beneficial for research calls related to barrier influence and interrelations (Pirkkalainen et al., 2010; Richter \& Pawlowski, 2007).

One potential process model as a point of orientation is the punctuated socio-technical change model (PSIC) (Newman \& Zhu, 2007, 2009). This model is acknowledged in the information systems domain for paving the path to process-oriented analysis in technology development (cf. Ahmad, Lyytinen, \& Newman, 2011). The analytical categories address a wide but focused range of entities. Process or change, in this model, includes both social and technical factors (Lyytinen \& Newman, 2008), which makes it suitable for elaborating on the wide range of barriers to open e-learning (cf. Newman \& Robey, 1992; Pirkkalainen \& Pawlowski, 2014).

Another concept for elaborating on barrier change is the adaptive structuration theory (Giddens, 1984/2001; Meneklis \& Douligeris, 2010; Orlikowski \& Robey, 1991). The concept provides a frame for research that is shaped by sociotechnical lenses and has been used to analyse e-learning phenomena and group interactions before (cf. Bostrom \& Gupta, 2009; Stubbs, Martin, \& Endlar, 2006). It builds upon the structuration theory, which defines different modes or modalities of structuration processes, which are processes wherein social and technical realms interact and mutually shape each other (Orlikowski \& Robey, 1991).

In the private and public sector as well as educational domains, these perspectives have not been used to elaborate on barriers. Future publications may be based on previous studies on e-learning in general (Bostrom \& Gupta, 2009), as well as on recommendations on how to follow a new perspective (Barette et al., 2012; Gustavsson, 2009; Moynihan \& Landuyt, 2009; Stefanick \& LeSage, 2005). Yet, there are research gaps in terms of the barriers to open e-learning based on new theoretical perspectives. 
To summarize, research on barriers to OERs is limited in terms of cultureand context-specific barriers as well as the trajectories of their development. In particular, this research gap is observed in the public sector, which lags behind the private and educational domains. In general, theoretically engrained concepts related to barriers and their change in specific contexts are scarce. Based on this summary, the objectives of the dissertation will be provided in the following section.

\subsection{Research objectives}

This chapter elaborates on the research objectives and questions that guide the dissertation. As mentioned above, the research on barriers to OER development and use in the public sector is in its early stages. At the same time, there is a lot of interest in the barriers to OERs across different contexts. Therefore, the first motivation for this dissertation was to elaborate on the current state of knowledge about and experiences with barriers to OERs and related activities in the public sector. The corresponding research question is:

- RQ1: Which barriers appear to open e-Learning in the public sector?

Answering this question will help develop a foundational understanding about the state of knowledge related to the challenges of OERs in the context of public administrations.

As studies about barriers have shown, however, the challenges differ in relevance and presence according to cultural context (Pirkkalainen \& Pawlowski, 2014; Richter \& McPherson, 2012). To further ground the initial findings in the public sector, the following research question is assessed:

- RQ2: What are similarities and differences of barriers to open eLearning across public administrations?

Based on work related to these two research questions, a sound empirical view is provided on the state of challenges to OER use and development in the public sector. The answer to the question can be found in studies that elaborate on the barriers to knowledge management and e-learning which have been published before in the public sector (Barette et al., 2012; Eidson, 2009). The work also complements previous studies in educational and private sector domains which have elaborated on barriers to OERs, e-learning and knowledge management (Amayah, 2013; Pirkkalainen \& Pawlowski, 2010; Riege, 2005).

While allowing for empirical comparisons across contexts, the published research does not answer questions about how barriers emerge and vary across contexts. The aim of the next research question was thus to provide more in- 
sight into the significant cultural barriers to OER development and use from a theoretical point of view.

- RQ3: What are the structural gaps shaping the exchange of OER in the public sector, and why?

The question links to a core aim of the dissertation, the interest to elaborate on how barriers evolve in a given cultural context. It is essential to advance the available knowledge about barriers once they are nominally defined. Knowledge about factors related to barrier development as well as interventions can be enhanced in this regard. Accordingly, the next research question was as follows:

- RQ4: Why and how do barriers to open e-learning change?

Elaborating on the techniques and processes of OER usage and implementation from a conceptual point of view can provide insight into what to consider when developing as well as adapting OERs for a specific context. With regard to the empirical and theoretical barriers and the requirements and factors that shape how and why barriers unfold, the next research objective is to put this knowledge into action. To realize this aim, research activities should focus on translating the findings into technical design while concentrating on a specific aspect of OER contextualization:

- RQ5: Which functional design allows for meaningful navigation through collaborative contextualization processes?

Research into the questions listed so far can generate knowledge about changes in the barriers to OER development and their use in the context of public administrations from a conceptual and theoretical point of view. In the public sector, this knowledge is highly relevant, given the pressure to find a smart, agile solution for the management of knowledge and learning.

Another important step in this respect is to determine how public employees on site put OER techniques and processes into practice. Moreover, the uses of OERs in the context of recent trends and practices need to be elaborated on to validate previous findings. Accordingly, the next research question is:

- RQ6: How do the latest OER uses and development processes contribute towards the knowledge and learning practices of public employees in view of recent government reforms in theory and practice?

These questions have been addressed in articles that have been published, which present the research and results of the dissertation. The following chapter will outline the methodology employed. 


\section{METHODOLOGY}

The previous chapters presented the background of OER research in the public sector, based on which the main research objectives and questions of the dissertation were framed. This chapter discusses a suitable research approach to answer the questions. In the first part, the basic epistemological and ontological implications and the related data collection and analysis methods are discussed. In the second part, the overall approach of the dissertation based on the action design research (ADR) concept (Sein, Henfridsson, Purao, Rossi, \& Lindgren, 2011) is presented. In the third and final part, specific features of the research context and relevant studies will be presented and discussed subsequently (see Figure 2).

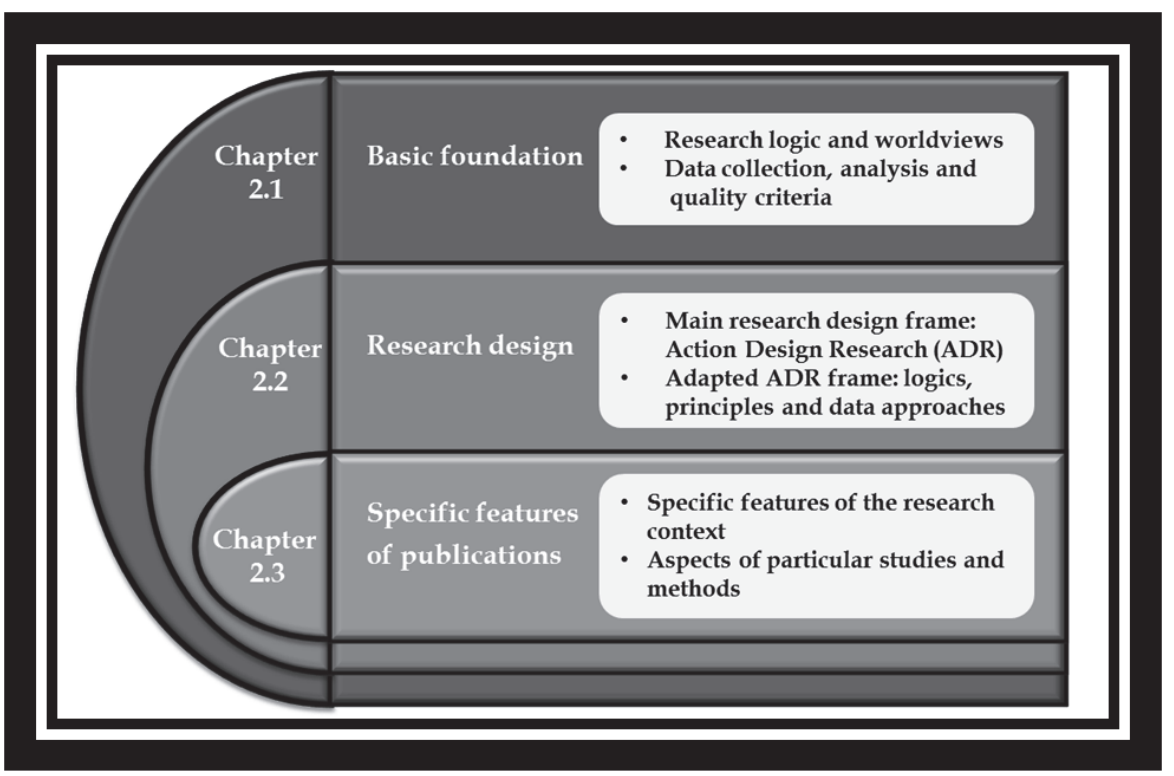

FIGURE 2: Structure of the Chapter 'Methodology' 


\subsection{Basic foundation of the research approach}

A research approach is defined as 'a plan[] and the procedures for research that span the steps from broad assumptions to detailed methods of data collection, analysis and interpretation' (Creswell, 2013, p. 3). According to the plan, it is important to understand one's assumptions and paradigms, to define procedures and to evaluate whether the chosen courses of action are suitable for realizing the research objectives (Creswell, 2013; Creswell \& Plano-Clark, 2011; Venkatesh, Brown, \& Bala, 2013).

A research objective may, on the one hand, be exploratory in nature, and involve an increase in understanding and the development of new theories about the event. On the other hand, an objective may involve testing assumptions of pre-defined concepts in order to generalize cases (Cresswell, 2013).

In this dissertation, given the infant state of current knowledge in this domain, it makes sense to explore the state of research and practice as the first step. At the same time, knowledge about barriers to OERs has been systemized in the private and educational sector before (Guri-Rosenblit, 2006; Pirkkalainen \& Pawlowski, 2014). In this regard, the aim of the dissertation is to assess the similarities and differences in findings as the second step. The evolving, systematic understanding shall extend beyond previous conceptualizations and support theories about the phenomenon. The basic aim, however, is to elaborate on the state of knowledge and practice and, thus, to present exploratory research objectives.

Based on the definition of research objectives, the corresponding research logics or worldviews need to be defined, based on ontological and epistemological assumptions (Creswell, 2013; Venkatesh et al., 2013). While there are varying definitions (cf. Creswell, 2013; Madill, Jordan, \& Shirley, 2000; Lincoln, Lynham, \& Guba, 2011), a positivist or realist worldview assumes in general that there is a single external reality that the researcher can directly measure (Creswell, 2013; Prabash, n.d.). Knowledge about truth is objective and can be collected with the help of pre-defined research steps, from inference to generalization (Prabash, n.d.). In contrast, interpretivists or constructionists consider that there is no single true reality; people need to develop or 'construct' a shared reality, knowledge and meaning. Besides extreme logics (e.g. Baghramian \& Carter, 2015; Madill et al., 2000; Williams \& Edge, 1996), another worldview that is promoted by pragmatists is that no single worldview is good enough on its own to generate understanding about a phenomenon (Creswell, 2013). That is, alternative logics need to be applied and discussed throughout a research term.

In this dissertation, certain assumptions shall be made with regard to the specific features of different public administrations and administrative levels (Rashman et al., 2009). It is important for the author to develop inter-subjective meaning and context-specific knowledge to assess how common culture context models suit public sector needs. To evaluate the shared meaning and represent- 
ativeness of models, public employees working on site are involved regularly throughout the research steps. They are considered as experts with regard to their behaviour and processes in their working context. While the specificity of research to particular contexts is recognized, the results and models shall allow comparisons across the private, educational and public domain at the same time. Associated with this is the assumption that the conceptual categories of the models are valid by themselves and for objective comparison from the perspective of the researcher. Summarizing the points, both interpretivist (constructionist) and realist (positivist) logics can be identified behind the objectives of the dissertation. Correspondingly, the approach follows the overall logic of pragmatists, while for each study, the applied or dominant perspective is defined.

This point leads to the discussion of the related logic of reasoning. For this dissertation, previous elaborations are in favour of an abductive approach. Abductive reasoning embraces inductive (from details in the field to theory) and deductive approaches (from theoretical assumptions to the field; Cresswell, 2013). Based on stunning or incomplete findings, a researcher makes their initial best guesses about suitable concepts or observations (RM, 2017). Subsequently, understanding is generated from both deductive and inductive logics as well as theoretical and practical points of view. Integrated concepts which are known in the field are seen as sensitizing frames (Blaikie, 2010) rather than a priori defined categories or inter-relations.

In this dissertation, the sensitizing frames are, for example, advanced elaborations on barriers to OER use (Pirkkalainen \& Pawlowski, 2014) as well as knowledge management (Riege, 2005). Moreover, in the public sector, previous studies on barriers to e-learning (Eidson, 2009) and knowledge management (Amayah, 2013) have to be taken into account. Incomplete observations shaping logic are the lack of knowledge on how OER trajectories evolve in the public sector and are embedded in the management of knowledge and learning. The assumptions and logics that dominate a particular publication of the dissertation can be found in the corresponding article.

Based on the decisions above, the data collection approach can be defined. Qualitative data are data interpreted from speech, observation and contextual incidents (Myers, 1997). Qualitative methods include interviews, observations and discussions, which are often used in behavioural and social sciences (Campagnolo \& Fele, 2010; Corbin \& Strauss, 1990; McNiff \& Whitehead, 2009). Quantitative data, in contrast, are numbers or counts of measureable objects that are used for generalized calculations or statistical analysis. They serve to test a hypothesis with the help of numerical thresholds and are often used in design approaches such as experiments or semi-experiments in natural science research (Creswell, 2013). A mixed-methods approach combines qualitative and quantitative data. This may generate better outcomes in terms of generalizability and validity if the joint design is defined. Cresswell (2013) suggests, for instance, that there are differences between convergent, sequential and embed- 
ded design among multi-phase studies and interventions (also see Creswell \& Plano-Clark, 2011; Venkatesh et al., 2013).

In this dissertation, one of the goals is to enhance the understanding about barriers to open e-learning in the context of public administrations. Besides exploring the research topic, another purpose of the dissertation is to validate or triangulate intersubjective accounts (Madill et al., 2000) and generalize findings across different contexts. In view of the objectives, qualitative methods will help gain an understanding of the phenomenon as the first step. As the second step, quantitative data collection methods would complement and enrich the qualitative methods. For example, content analysis (Mayring, 2010) can be used to analyse relevant barriers or incidents related to change. Another predestined approach is to conduct (quantitative) surveys (Cresswell, 2013a) which require experts to answer questions on a pre-defined scale. According to these considerations, a mixed-methods approach appears to be suitable. More precisely, an exploratory sequential mixed-methods approach (Creswell \& Plano-Clark, 2011) in which qualitative methods are dominant seems apt.

For each sequence of qualitative/quantitative research in the dissertation, methods for data collection, analysis and quality criteria have to be taken into account (Cresswell, 2013b; Cresswell \& Plano-Clark, 2011; Frank, 2006). Without elaborating on different qualitative (Corbin \& Strauss, 1990; Mayring, 2010; Trochim, 1989) and quantitative (Hair, Black, Babin, \& Anderson, 1998; Hong, Chan, Thong, Chasalow, \& Dhillon, 2013; Myers, 1997) analysis patterns, the overall quality criteria of analyses have to be addressed, including reliability, validity, and objectivity (which is preferably referred to as inter-subjectivity in qualitative studies; Madill et al., 2000). In quantitative research approaches, the calculated scales and thresholds define the quality of data and analysis. Some additional aspects of qualitative research are, for example, inter-coder reliability; exchange with experts within the research context; and corresponding selection of samples in terms of dependability, hierarchy and heterogeneity (Creswell, 2013; Frank, 2006; Kitzinger, 1994; Madill et al., 2000). Given the dominant role of humans as research subjects in information systems research, the role of ethics also needs to be discussed. To define a sound research approach, the role of the researcher in relation to the involved persons, procedural ethics and practised ethics, apart from respect for individual concerns and anonymization, needs to be taken into account (Guillemin \& Gilliam, 2004; Kretzer, 2013). The main analysis and quality criteria that have been considered in the dissertation are discussed in Table 1. 
TABLE 1: Research Framework and Criteria

\begin{tabular}{|c|c|c|}
\hline $\begin{array}{l}\text { Criterion } \\
\text { (meaning) }\end{array}$ & Principles underlying the criteria & $\begin{array}{c}\text { Conduct in } \\
\text { the dissertation }\end{array}$ \\
\hline $\begin{array}{l}\text { Reliability } \\
\text { (consistency } \\
\text { in approach, } \\
\text { transparency } \\
\text { for research- } \\
\text { ers and pro- } \\
\text { jects) } \\
\text { (Cresswell, } \\
\text { 2013; Cress- } \\
\text { well \& Pla- } \\
\text { no-Clark, } \\
\text { 2011; Frank, } \\
\text { 2006; } \\
\text { McKenzie, } \\
\text { Wood, Ko- } \\
\text { tecki, Clark, } \\
\text { \& Brey, 1999) } \\
\end{array}$ & $\begin{array}{l}\text { Defining and following consistent frames: } \\
\text { defining the research approach and logic, } \\
\text { presenting comparisons or similarities to } \\
\text { commonly known approaches to facilitate } \\
\text { tracing the approach } \\
\text { Inter-coder reliability: ensuring that ex- } \\
\text { perts and scholars obtain the same results } \\
\text { in terms of coding, given the sensitizing } \\
\text { framework } \\
\text { Appropriate methods: defining research } \\
\text { instances (such as cases) and securely ad- } \\
\text { dressing the (same) instance via qualita- } \\
\text { tive/quantitative methods } \\
\text { Appropriate converging of data: keeping } \\
\text { the research instance in mind, and using } \\
\text { reliability and validity procedures for each } \\
\text { method }\end{array}$ & $\begin{array}{l}\text { The approach and logic of } \\
\text { the research has been de- } \\
\text { fined in each publication: } \\
\text { in the case of inter-coder } \\
\text { reliability, a common } \\
\text { conduct for analysis was } \\
\text { defined. In case of differ- } \\
\text { ences, coders discussed } \\
\text { and agreed upon interpre- } \\
\text { tations; data collection } \\
\text { and analysis were based } \\
\text { on well-known frames for } \\
\text { using a replicable ap- } \\
\text { proach and accounts. }\end{array}$ \\
\hline $\begin{array}{l}\text { Validity } \\
\text { (accuracy of } \\
\text { findings and } \\
\text { methods } \\
\text { according to } \\
\text { inter- } \\
\text { subjective } \\
\text { accounts) } \\
\text { (Cresswell, } \\
\text { 2013; Cress- } \\
\text { well \& Pla- } \\
\text { no-Clark, } \\
\text { 2011; Madill } \\
\text { et al., 2000) } \\
\end{array}$ & $\begin{array}{l}\text { Triangulation (also called member- } \\
\text { checking): acquiring and comparing dif- } \\
\text { ferent perspectives, and judging to which } \\
\text { extent perspective-weighting is important } \\
\text { and valuable } \\
\text { Inter-subjectivity: defining objectivity } \\
\text { based on positivist accounts, and follow- } \\
\text { ing a transparent and logical approach to } \\
\text { reasoning based on results } \\
\text { Appropriate sampling: obtaining an ap- } \\
\text { propriate sample size and ensuring pur- } \\
\text { poseful selection based on social barriers } \\
\text { such as dependency/hierarchy and free } \\
\text { choice }\end{array}$ & $\begin{array}{l}\text { Data were iteratively ob- } \\
\text { tained, discussed and ana- } \\
\text { lysed with research peers } \\
\text { as well as experts in the } \\
\text { field; based on rankings } \\
\text { and discussions, common } \\
\text { views were agreed upon } \\
\text { sampling was conducted } \\
\text { according to the selection } \\
\text { criteria of well-known } \\
\text { methods }\end{array}$ \\
\hline $\begin{array}{l}\text { Ethics } \\
\text { (planning } \\
\text { and conduct- } \\
\text { ing research } \\
\text { with respect, } \\
\text { having a } \\
\text { sense of sus- } \\
\text { tainability } \\
\text { and sensibil- } \\
\text { ity with re- } \\
\text { gard to the } \\
\text { requirements } \\
\text { and efforts of } \\
\text { involved } \\
\text { participants) }\end{array}$ & $\begin{array}{l}\text { Procedural ethics comprises the follow- } \\
\text { ing factors: } \\
\text { Public interest: considering the influential } \\
\text { forces, informing involved participants } \\
\text { and letting them choose their own artefact } \\
\text { features, accounts and assumptions about } \\
\text { the research outputs } \\
\text { Informed consent: obtaining the consent of } \\
\text { any person involved in the research pro- } \\
\text { cesses } \\
\text { Privacy and sensibility to disclosure (mi- } \\
\text { cro-ethics): ensuring the privacy of names } \\
\text { and accounts, not only by anonymizing } \\
\text { voices, but also, for example, during } \\
\text { group discussions, defining common dis- }\end{array}$ & $\begin{array}{l}\text { Participants for data col- } \\
\text { lection were purposefully } \\
\text { selected and invited; in } \\
\text { cases where leaders se- } \\
\text { lected participants, correc- } \\
\text { tions were suggested, } \\
\text { groups were formed to } \\
\text { avoid hierarchy and de- } \\
\text { pendency (for example, } \\
\text { leaders and managers } \\
\text { were met in separate } \\
\text { workshops from lay per- } \\
\text { sonnel and employees) } \\
\text { furthermore, common } \\
\text { discussion rules were de- }\end{array}$ \\
\hline
\end{tabular}




\begin{tabular}{|l|l|l|}
\hline (Guillemin \& & cussion principles & fined and displayed for \\
Gilliam, & Accuracy/property account: giving credit & participants (such as re- \\
2004; Kitz- & to the appropriate sources for ideas and & specting accounts, avoid- \\
inger, 1994; & innovations (Myers \& Venable, 2014, p. 11) & $\begin{array}{l}\text { ing interrupting people, } \\
\text { Kretzer, } \\
\text { not disclosing anything }\end{array}$ \\
$\begin{array}{l}\text { 2013; Myers } \\
\text { \& Venable, } \\
\text { 2014) }\end{array}$ & & $\begin{array}{l}\text { said within the group } \\
\text { outside, etc.). }\end{array}$ \\
\end{tabular}

Following the discussion about basic assumptions and logics, considerations for the research design are provided.

\subsection{Research design considerations}

For a long time, Information Systems Research (ISR) studies have followed research approaches used in the natural sciences in order to produce relevant findings as well as to produce replicable data (Myers, 1997). However, the associated positivist worldview led to a neglect of the role and influence of social interaction. Therefore, researchers in information systems are now trying out qualitative approaches, and generally, there is an increase in the discussions on design choices (Myers, 1997; Orlikowski \& Baroudi, 1991). In response, suitable qualitative approaches such as netnography (Kozinets, 2007) and the soft systems method (SSM; Checkland \& Poulter, 2010) and entire socio-technical schools of thought (Williams \& Edge, 1996) have emerged. Moreover, design frameworks shaped by natural sciences have evolved, such as the design science research method (Pfeffers et al., 2007). The main framework that is well known for performing well in the natural behavioural science domain is ADR (Sein et al., 2011).

ADR is useful for research on information technology artefacts and is also sensitive to the organizational context (Sein et al., 2011). ADR relates well to the design science research method (Hevner, 2007; Pfeffers, Tuunanen, Rothenberger, \& Chatterjee, 2007) as well as action research (Cole, Purao, Rossi, \& Sein, 2005; McNiff \& Whitehead, 2009). Accordingly, the principles of this framework address the technical design processes, outputs or artefact categories and behavioural principles of research (Sein et al., 2011). ADR requires researchers to reflect on their role as human beings interacting with research subjects, as well as provides them with the framework for creating the research steps and decisions for obtaining the technical outputs within a particular place and time.

Compared to well-known qualitative approaches such as grounded methods (Strauss \& Corbin, 1998) and quantitative approaches such as the soft systems methodology (SSM) and the technology acceptance model TAM (Checkland \& Poulter, 2010; Lau \& Woods, 2009), ADR seeks to make both theoretical and practical contributions. The practical contributions are, for example, technical artefacts such as codes, design principles, conceptual models and solutions 
for a class of problems. The theoretical contributions include the systematization of knowledge about the context of action and an increased understanding of the requirements and processes of socio-technical interaction within a given time and space (Gregor, 2006; Sein et al., 2011). In this respect, the intended outcome of the ADR framework is an ensemble artefact that represents the theory ingrained in both products and ideas which are shaped by socio-technical contexts and on-site processes (cf. Sein et al., 2011, p. 41).

While ADR appears to be an innovative approach, it is a relatively new framework which has flaws, just like the frameworks that were proposed before. Given its similarity to the design science research method and action research, its flaws are also related to ethics (cf. Myers \& Venable, 2014), procedural integration and paradigmatic faultlines (Iivari \& Venable, 2009). One could argue that more established frameworks should be used in the dissertation. Yet, it can also be argued that researchers using ADR need to reflect on and define their course of action with regard to foundations.

For this dissertation, the foundations have been discussed and defined in the previous chapter. ADR appears to complement these decisions with a focus on ISR-specific research and requirements for the design processes and research aspects. First, the goals of ADR and the dissertation overlap as the dissertation aims at conceptualizing barriers and complementing previous knowledge from a theoretical viewpoint; that is, it aims to develop a theoretically engrained artefact (Sein et al., 2011). Secondly, ADR provides a framework which requires that the IT or organizational dominant point of view be defined. The dissertation follows an organization-dominant approach, where the main innovative demands stem from the organizational contexts (cf. Sein et al., 2011). Thirdly, ADR requires that the research aims be situated in a generic scheme that reflects how the work and research efforts are positioned in terms of the researchers, practitioners and end users (see Figure 3). 


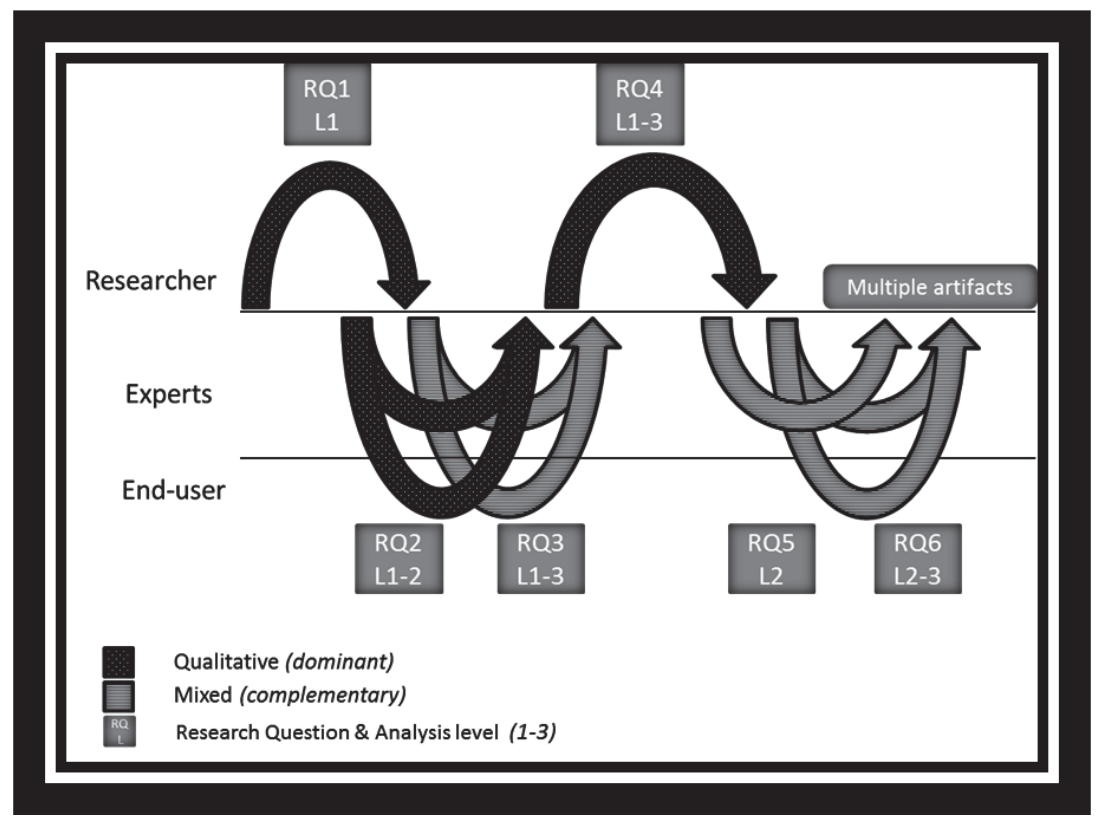

FIGURE 3: Overview of Articles According to the ADR Approach

Overall, ADR embraces the underlying paradigms and allows the embedding of decisions within the research steps. Table 2 demonstrates the course of action of the dissertation in detail as well as how the principles and decisions were integrated with regard to the choice of research methods:

TABLE 2: Adapted Action Design Research Approach

\begin{tabular}{|c|c|c|}
\hline $\begin{array}{l}\text { Stages and } \\
\text { principles }\end{array}$ & $\begin{array}{c}\text { Meaning } \\
\text { (Sein et al., 2011) }\end{array}$ & $\begin{array}{l}\text { Foundation } \\
\text { of the dissertation }\end{array}$ \\
\hline $\begin{array}{l}1 \text { Problem for- } \\
\text { mulation }\end{array}$ & $\begin{array}{l}\text { Delineate the research project in } \\
\text { terms of research question formu- } \\
\text { lation, delimitation of the class of } \\
\text { problems and earlier publications } \\
\text { and efforts in practice to solve the } \\
\text { problem, among others (p. } 41) \text {. }\end{array}$ & \multirow{3}{*}{$\begin{array}{l}\text { An initial literature review was } \\
\text { conducted to elaborate on the } \\
\text { state of published research and } \\
\text { practice. Initial interviews were } \\
\text { held with public employees, } \\
\text { based on which the initial re- } \\
\text { search questions and aims } \\
\text { were formulated. The related } \\
\text { findings can be found in RQ1 } \\
\text { as well as further publications. }\end{array}$} \\
\hline $\begin{array}{l}\text { 1.1 Inspiration } \\
\text { from practice }\end{array}$ & $\begin{array}{l}\text { Delineate the problem in the con- } \\
\text { text of the study (p. } 40) \text {. }\end{array}$ & \\
\hline $\begin{array}{l}1.2 \text { Theory- } \\
\text { ingrained arte- } \\
\text { fact }\end{array}$ & $\begin{array}{l}\text { Consider which theories exist or } \\
\text { will contribute to generalizing the } \\
\text { findings later (p. 40f.). }\end{array}$ & \\
\hline $\begin{array}{l}2 \text { Building, in- } \\
\text { tervention, and }\end{array}$ & $\begin{array}{l}\text { Undertake research and support } \\
\text { the assumptions developed in }\end{array}$ & $\begin{array}{l}\text { Research proceeds in the con- } \\
\text { text of public administrations. }\end{array}$ \\
\hline
\end{tabular}




\begin{tabular}{|c|c|c|}
\hline evaluation & $\begin{array}{l}\text { previous steps. Design an initial } \\
\text { artefact (build), place it in organi- } \\
\text { zational processes (intervene) and } \\
\text { see how the trajectory evolves } \\
\text { (evaluate) (p. 42). }\end{array}$ & \multirow{4}{*}{$\begin{array}{l}\text { The first artefact is the barrier } \\
\text { framework (artefact), for com- } \\
\text { parison of single administra- } \\
\text { tions, countries as well as dif- } \\
\text { ferent contexts. The involved } \\
\text { experts were asked to evaluate } \\
\text { the barrier framework, and the } \\
\text { suggested changes were inte- } \\
\text { grated and noted. Further } \\
\text { workshops were held to con- } \\
\text { vey knowledge and shape pro- } \\
\text { cesses (intervene). In relation to } \\
\text { this, feedback on what to } \\
\text { change or adapt in the frame- } \\
\text { work as well as process proto- } \\
\text { types (build) was collected } \\
\text { (evaluation). Steps in this re- } \\
\text { gard are published in articles } \\
\text { RQ1 and RQ5, and RQ6. }\end{array}$} \\
\hline $\begin{array}{l}2.1 \text { Reciprocal } \\
\text { sharing }\end{array}$ & $\begin{array}{l}\text { Elaborate on the faultlines of in- } \\
\text { teractions between the IT artefact } \\
\text { and social processes in the given } \\
\text { context (p. 43). }\end{array}$ & \\
\hline $\begin{array}{l}2.2 \quad \text { Mutually } \\
\text { influential roles }\end{array}$ & $\begin{array}{l}\text { Reflect on the researchers' influ- } \\
\text { ence on organizational processes } \\
\text { (p. 43). }\end{array}$ & \\
\hline $\begin{array}{l}2.3 \text { Authentic } \\
\text { and concurrent } \\
\text { evaluation }\end{array}$ & $\begin{array}{l}\text { Integrate experts from their re- } \\
\text { spective contexts into different } \\
\text { steps of the design and conduct } \\
\text { an evaluation to validate } \\
\text { knowledge, assumptions, and } \\
\text { approaches (p. } 43) \text {. }\end{array}$ & \\
\hline $\begin{array}{l}3 \text { Reflection and } \\
\text { learning }\end{array}$ & $\begin{array}{l}\text { given knowledge } \\
\text { s to a class of } \\
44)\end{array}$ & \multirow{2}{*}{$\begin{array}{l}\text { Based on knowledge about } \\
\text { existing barriers in the field, } \\
\text { the view is refined with the } \\
\text { help of theoretical frameworks } \\
\text { and approaches to generalize } \\
\text { findings both across contexts } \\
\text { and in theoretical terms. The } \\
\text { related work can be found in } \\
\text { RQ2 and RQ3. }\end{array}$} \\
\hline $\begin{array}{l}3.1 \quad \text { Guided } \\
\text { emergence }\end{array}$ & $\begin{array}{l}\text { anges relate to ex- } \\
\text { nents and which } \\
\text { consequences were } \\
\text { resolved. }\end{array}$ & \\
\hline $\begin{array}{l}4 \text { Formalization } \\
\text { of learning }\end{array}$ & $\begin{array}{l}\text { about pro- } \\
\text { concepts. } \\
\text { ciples and }\end{array}$ & \multirow{2}{*}{$\begin{array}{l}\text { The stage formalization of } \\
\text { learning is completed jointly } \\
\text { with the previous steps. Most } \\
\text { publications result in a concep- } \\
\text { tual framework of barriers in } \\
\text { practice and theory (problem } \\
\text { instance), antecedents of } \\
\text { change (solution instance) or } \\
\text { design framework of the given } \\
\text { barriers (design principles). }\end{array}$} \\
\hline $\begin{array}{l}4.1 \text { Generalized } \\
\text { outcomes }\end{array}$ & $\begin{array}{l}\text { Categorize findings into a class of } \\
\text { problems and provide related } \\
\text { solutions for future research. } \\
\text { Generalize the problem instance, } \\
\text { solution instance and design } \\
\text { principles. }\end{array}$ & \\
\hline
\end{tabular}

Table 2 indicates which research methods were applied in which step of the dissertation. The next chapter will present the specific research context and publications of the dissertations. 


\subsection{Specific features of publications}

\subsubsection{Research context}

The research context of the dissertation is the EAGLE project, which is funded by the 7th European Union Framework Programme (grant agreement No. 310806). The project has been in effect for three years and involves public administrations from the countries of Germany, Luxembourg, Montenegro and Ireland.

One goal of the project was to develop an inter-cultural open e-learning platform for public administrations. In this regard, the author coordinated and led associated work packages and tasks related to the contextualization and localization of OERs. This included identifying the requirements and conducting barrier analysis of open e-learning in all four countries, as well as designing platform features such as the website interface, contextualization steps and choice of metadata taxonomies, among others.

Given the research context, one requirement for the design is to allow for research across multiple sites or cases. Therefore, it would be interesting to understand cultural differences which require that results across cases be compared and translated into a common framework. Another requirement is to consider how researchers as well as research participants differ in their accounts about culture and relevant factors of the cultural context.

One feature of the exploratory sequential mixed-methods approach is that different studies are appraised as cases (Benbasat, Goldstein, \& Mead, 1987; Yin, 2014). The case studies could be public administrations with embedded units such as employees or leaders, depending on the research interest and question of concern. Care should be taken to ensure that the case study research was originally conducted from the positivist perspective (Benbasat et al., 1987; Yin, 2014), although an interpretative research can be pursued as well (Carson, Gilmore, Perry, \& Gronhaug, 2001).

\subsubsection{Methods and analysis of publications and research stages}

The data collection methods and analysis steps will be discussed with regard to the research stages of ADR (Sein et al., 2011) and the exploratory, case-based mixed-methods approach.

\section{Exploring barriers (Problem Formulation)}

The first step among the first publications (particularly Article I) is to explore the barriers which appear in relation to open e-learning in the public sector. In the dissertation, a basic starting point in this respect is literature reviews based on Webster and Watson (2002). Literature reviews serve to elaborate on the state of research in a field (Fink, 2014; Jesson, Matheson, \& Lacey, 2011; Okoli \& Schabram, 2010) and shed light on the appropriateness of the study objectives with regard to research gaps in the field (Fink, 2014). 
The main difficulty is designing a suitable sampling approach which ensures that relevant articles and experiences in research and practice are collected (Webster \& Watson, 2002). Another difficulty is with regard to translating findings into an analytical framework that can be used to answer the research question and is meaningful to other researchers. Ways to analyse the literature thus range from qualitative comparisons of concepts or author-oriented reports to more quantitative counts of single aspects or research instances such as words or barriers (Jesson et al., 2011; Mayring, 2010; Webster \& Watson, 2002).

In the dissertation, relevant articles were researched in ISR-specific journals such as the basket-of-eight journals (European Journal of Information Systems, Information Systems Journal, Journal of AIS, and Journal of MIS, among others) (AfIS, 2011). Moreover, the search included public administrationspecific journals based on their impact factor and the relevance of their findings on platforms such as SpringerLink and Elsevier. Hence, Public Administration, Government Information Quarterly and Journal of Public Administration Research and Theory, among others, are used in the review. The key terms were combinations of OERs, e-learning, public administration, training and learning within the time frame 2006-2013. Given the low number of results, the search was extended with the help of a full-text search with single keywords (such as training or e-learning) and a snowballing strategy.

To document and analyse the findings from the review, a sensitizing frame was developed. In a tabular format, known categories of barrier frames (Pirkkalainen \& Pawlowski, 2014), and later on, theoretical categories (Lyytinen \& Newman, 2008; Newman \& Zhu, 2008) were defined. Findings such as the barriers of each article were noted in a suitable category of the table or saved as a dedicated (new or adapted) category. In this manner, a pattern-matching process was followed (Trochim, 1989; Yin, 2014). Subsequently, the meaning, role of the barrier and their interdependence were elaborated and annotated with dedicated memos (Corbin \& Strauss, 1990). Thus, the results were analysed according to interpretative content analysis (Mayring, 2010) based on the principles of grounded methods (Corbin \& Strauss, 1990; Glaser \& Strauss, 2010).

\section{Increasing the context specificity of concepts (Building)}

Following the first article, the second publication (Article II) extended the insight of the literature review with the help of expert discussions and focus groups (Kitzinger, 1994; Merton \& Kendall, 1946; Meuser \& Nagel, 2002). Focus groups represent an invaluable approach for engaging with experts in the field and generating inter-subjective accounts from multiple perspectives (Kitzinger, 1994). Similar to interviews, focus groups follow a semi-structured pattern of questions which are discussed for a certain time. Unlike interviews, with focus groups, the goal is to observe interactions between experts and determine whether the social relations of the contexts translate into the focus group. In this respect, the aim of the dissertation is to determine how barriers are recognized and interrelated with structures such as hierarchy and lack of open communication, for example. Given this aim, the sampling of the focus group was carefully 
conducted so as to comply with the required diversity criteria, with regard to the position, gender and experience of participants. In detail, 68 employees in the public sector were involved across Germany, Luxembourg, Ireland and Montenegro. The sample included managers to lay front-office employees, elderly to young employees, as well as IT-interested to IT-averse participants; moreover, experts were also involved.

Given the sampling, common rules were defined to ensure compliance to the rules of a free discussion, irrespective of dependencies between known or unknown group members (Kitzinger, 1994). These were some of the rules that were introduced at the beginning of the workshops: (1) every statement made should be respected, (2) what is said here remains in the group, and (3) we are talking about opinions and not about people.

To ensure inter-coder reliability across the focus group leaders, the author provided a structured discussion guideline as well as a common analytical grid in which statements, notifications, and the results of discussions were noted. Analysis of these grids for each workshop was the author's responsibility. The interpretations and main results were forwarded to focus group leaders as well as workshop participants to develop a shared meaning and understanding of the context.

Besides the interpretative content analysis (Mayring, 2010), the analysis included the count and ranking of barriers according to their relevance. In this regard, the first integration of quantitative methods was realized. The count allowed for comparison of results across workshop sites as well as countries, which served the second research objective of the dissertation. Based on the results, a common, contextualized barrier framework was defined with a focus on the specific features of the countries.

\section{Increasing the context specificity of concepts (Planning, Interventions and Evaluation)}

Apart from focus groups, interviews were central data collection methods to gather insight into the barriers to open e-learning, which were used in the third publication (Article III). Interviews are interrogations of single persons, according to a predefined or semi-structured set of questions (Merton \& Kendall, 1946). On the one hand, the goal of an interview is to record the interviewee's perspective on a certain topic. On the other hand, the goal may also be to grasp their account of the completeness, conceiveness and appropriateness of a framework or concept for means of triangulation (cf. Merton \& Kendall, 1946; Meuser \& Nagel, 2002; Myers \& Newman, 2007). In all studies, an expert is defined as a person who has crucial domain knowledge, is available for the interview and has experience in the given context, which was e-learning, OERs and knowledge management in the present case (Cresswell \& Plano Clark, 2011; McKenzie et al., 1999; Meuser \& Nagel, 2002).

Eleven experts were recruited and interviewed face-to-face or by phone depending on their availability and geographical distance. The experts were asked to rank barriers based on a quantitative validation method (McKenzie et 
al., 1999). Subsequently, the experts were asked to elaborate on and contextualize their choices (qualitative validation method; McKenzie et al., 1999). Further, the findings of previous studies were assessed and contextualized. Moreover, the method allowed for the calculation of the significance of the barriers, which served the research objectives of the dissertation.

\section{Evaluating concepts in practice (Intervening and Evaluating)}

According to the research design frame of the dissertation, a main step for shaping the results of a theory-ingrained artefact is to assess its value in practice. In this regard, field research (Article 6) on seminars, workshops, pilots and agile development of OERs with employees in a public administration was applied based on the ADR principles discussed above.

To document the field research, guidelines were generated based on the studies of McNiff and Whitehead (2009) and Sein et al. (2011). For example, a field diary was created which required the author to make notes at least at the beginning and at the end of the day (McNiff \& Whitehead, 2009). The guidelines included prompts for both basic reflections and dedicated memos for observation (see Table 3).

TABLE 3: Prompts for Field Research

\section{Basic reflection}

What is my concern, what What is the situation, what How do I modify practices \begin{tabular}{l|l|l} 
is my aim, what is the aim & will/can I do about it & in light of my evaluation
\end{tabular}

of others

\section{Memos}

\begin{tabular}{|l|l|l}
\hline When did (it) happen & Where did (it) happen & What was (it) about
\end{tabular}

\begin{tabular}{|l|l|l|}
\hline Who was involved & Headcount/data needed to & Anything else considered
\end{tabular} embed the happening $\quad$ important

Furthermore, workshop participants were asked to answer questionnaires regarding their state of knowledge and competence in using OERs at the workplace to track progress. The quantitative data were used to complement the qualitative interpretations. The survey data were descriptively analysed using the statistical programme SPSS. Memos from this analysis as well as from the field were matched with the sensitizing framework, in particular, with a prototype of an agile OER implementation process (cf. Arimoto \& Barbosa, 2013; Arimoto et al., 2016). The results of the analysis were discussed with public leaders in the administration to derive an inter-subjective meaning.

So far, the core data collection and analysis processes have been described. In the following section, the articles of the dissertation will be presented. 


\section{OVERVIEW OF ARTICLES}

This section summarizes the research objectives, methods, related findings and their role in the dissertation.

\subsection{Article I: A barrier framework for open e-learning in public administrations}

Stoffregen, J., Pawlowski, J. M., \& Pirkkalainen, H. (2015). A barrier framework for open e-learning in public administrations. Computers in Human Behavior, 51, 674-684.

\section{Research objectives and methods}

The first article described the state of research and practices in open e-learning in the public sector and asked the question 'which barriers have been identified when introducing and implementing e-learning in public administration' (Stoffregen, Pawlowski, \& Pirkkalainen, 2015a, p. 674). While research on OER is advanced in the private and educational domain, only few studies have been published about OERs in public administration. Leaning on publications about previous trends such as e-learning (Bere et al., 2013; Conci \& Bramati, 2007) and related concepts (see section 1.1.3.), the main objective of this article was to lay the ground for elaborating on past experiences and what to consider in future research and practice.

Moreover, the goal was to systemize the lessons learned and go beyond single reports of challenges in single publication contexts. For this aim, an extensive literature review was conducted according to Webster and Watson (2002). To allow for comparison with findings in other domains, the study was based on the barrier framework of Pirkkalainen and Pawlowski (2014) as a sensitizing framework (Blaikie, 2010). 


\section{Findings}

Analysis of the review resulted in the creation of a list of more than forty barriers which were categorized into organizational (including the lack of resources and lack of management), social (such as conflicting values among learners, the low level of ICT skills and conflicting personal backgrounds) as well as technical barriers (such as availability of infrastructure and perceived functionality of the data). Major insights concern, for example, the relevance of managerial leadership and coordination. A lack of personal guidance and support from management as well as a lack of policy frameworks were considered as crucial challenges to introducing OERs in public administrations.

Compared to the barrier framework of other domains, no conflicting barriers were found. However, the challenges were not replicated in terms of wording, appearance or relevance. On the one hand, barriers concerning the practice of sharing information were not identified, for example, the role of language among OER users. On the other hand, barriers in the public sector stressed on assumptions that public employees' performance depends on tacit knowledge (Hazlett, McAdam, \& Beggs, 2008), which is difficult to digitize.

\section{Role in the dissertation}

The publication addressed the first research question of the dissertation (RQ1): 'What are the barriers to open e-learning in the public sector'? The study is of major importance, since the analysis provides initial insight into the state of knowledge about the topic of OERs in public administrations. Assumptions concerning the low level of research and practices which guided the beginning of the dissertations were supported.

Furthermore, the study not only allows for the systemization of barriers in the public sector, but also allows for comparison of findings to challenges that appear in other domains such as the private or educational sectors. In this regard, differences concerning the kind and relevance of barriers to OER use and development were found between the public and private sector. Accordingly, there is some support for taking cultural and contextual factors into account when studying OERs in the public sector.

Thus, the first step to conceptualize knowledge related to the design of the science research approach was taken. Based on the work of Pirkkalainen and Pawlowski (2014), the article presented a contextualized barrier framework for the public sector. 


\subsection{Article II: Barriers to open e-learning in public administra- tions: A comparative case study of the European countries Luxembourg, Germany, Montenegro and Ireland}

Stoffregen, J. D., Pawlowski, J. M., Ras, E., Tobias, E., Šćepanović, S., Fitzpatrick, D.,...Friedrich, H. (2016). Barriers to open e-learning in public administrations: A comparative case study of the European countries Luxembourg, Germany, Montenegro and Ireland. Technological Forecasting and Social Change, 111, 198-208.

\section{Research objectives and method}

The second article of the dissertation aims to explore the barriers to open elearning in public administrations at the local government level. Apart from the insights of the initial literature review, empirical data were gathered to validate the content and its value in the contextualized barrier framework (Stoffregen et al., 2016a).

In this regard, a multiple case-study was designed in the context of the EAGLE project. Data were gathered by conducting focus groups and interviews across several public administrations. Overall, 68 public employees participated in workshops that were conducted in Luxembourg, Ireland, Montenegro and Germany. To ensure inter-coder reliability, all qualitative data were translated into a reporting sheet and subjected to iterative analysis by workshop leaders and an additional reviewer.

The results of the workshops were analysed using interpretative content analysis (Mayring, 2010) as well as the pattern matching technique (Trochim, 1989; Yin, 2014). The results of the analysis were compared between the public administrations of one country, as well as between countries.

\section{Findings}

This turned out to be a well-grounded, comparative study of barriers across several European public administrations. First, the results were compared across public administrations. The findings indicated that the barriers are more common than different, despite the fact that administrations differ in terms of organizational size, recent reforms and workplace organization. Yet, while similar barriers were identified, the relevance (or prioritization of relevant barriers) differed. In the case of Montenegro, for instance, the legal and technical aspects were more important than in Germany, where the legal and political arguments for OER implementation were a matter of concern.

While context-specific barrier lists were created, a common barrier framework was developed that applies to all countries, too. This framework comprises three barrier dimensions, namely, contextual, social and technical barriers. 
Within the barrier dimensions, more than fifteen barrier categories were defined, including the quality of information, the value of information, individual concerns, usability and the lack of resources, among others. Importantly, further subcategories were defined, which provide a granular view and comparison of barriers in public administrations.

\section{Role in the dissertation}

The article addressed the research question RQ2: 'What are similarities and differences in barriers to open e-learning across public administrations?' Given the great number of participating public employees, the results of the analysis allowed for an in-depth exploration and understanding of the current practices and concerns regarding OER use and development in this context.

Since public administrations across countries were involved, a greater understanding of culture- and context-specific factors was possible. This pointed to the need for future research about the role of culture- and context-specific factors in OER use and development.

With regard to the initial publication, the aim to further validate the contextualized barrier framework was realized. The value of the barrier framework was discussed in the publication as well.

\subsection{Article III: Identifying socio-cultural factors that impact the use of Open Educational Resources in local public admin- istrations}

Stoffregen, J., Pawlowski, J. M., Ras, E., Scepanovic, S., \& Zugic, D. (2016). Identifying Socio-Cultural Factors That Impact the Use of Open Educational Resources in Local Public Administrations. International Journal of Management, Knowledge and Learning, 5(2), 167-187.

\section{Research objectives and method}

The goal of the publication is to elaborate on the barriers to OERs in public administrations systematically from a socio-cultural perspective. Previous articles have contributed to demonstrating the state of knowledge about existing barriers. Given the relevance of culture and context in the field of OER use and development (Edmundson, 2007; Henderson, 2007; Richter \& McPherson, 2012), however, there is a need for more understanding from a theoretical perspective in future research.

In this regard, an extensive literature review was conducted (Stoffregen, Pawlowski, Ras, Tobias, \& Scepanovic, 2015b), which resulted in seventeen as- 
sumptions about how cultural factors shape interactions in open e-learning systems. Subsequently, dedicated expert interviews were conducted following a mixed-methods strategy (Mckenzie et al., 1999). This provided an understanding of the intelligible meaning behind factors related to experts as well as helped to systematically elaborate on and compare the significance of sociocultural factors.

\section{Findings}

The results of the study demonstrate that six cultural factors were significant in explaining why public employees are likely to be involved in OER practices. Among the significant factors are superior's support, the social spirit of the platform and group identification, among others. These findings support previous assumptions about barriers to OER use and development as presented in previous articles. On the other hand, the findings differ from previous publications in terms of the importance of the barriers. For example, factors concerning the geographical distance between OER users, openness in discourse and regulatory frames did not appear to be of major concern.

The role of geographical distance is a finding that differs from the role of locality reported in educational and private sector research (Pirkkalainen, Jokinen, Pawlowski, \& Richter, 2014a; Pirkkalainen, Jokinen, \& Pawlowski, 2014b). However, the strength of this article is that experts also provided a qualitative explanation of why factors are (ir-)relevant. With regard to this factor, experts considered the experiences to be too scarce for evaluation.

Apart from the factors and their relevance in explaining the involvement of public employees in OER use, experts elaborated on the quality of the presented socio-cultural perspective on the topic. The results showed that experts consider the model to be comprehensive and suitable for drawing inferences for action.

\section{Role in the dissertation}

The elaborated model in this article is a major step forward for improving the state of knowledge about barriers in the public sector. It provides an overview of cultural factors and the related assumptions about their role in a given context, along with a qualitative and quantitative evaluation by experts.

The article thus contributes to the objective of developing a culturesensitive understanding of OER barriers in the public sector. Accordingly, the publication answers research question RQ3: 'What are the structural gaps shaping the exchange of OER in the public sector, and why?' 


\subsection{Article IV: Why do relevant structural gaps to the exchange of open knowledge resources change in public administrations}

Stoffregen, J., Pawlowski, J., Šcepanovic, S., Zugic, D., Moebs, S., Raffl, C.,...Müller, J. (2015, October). Why do relevant structural gaps to the exchange of open knowledge resources change in public administrations? In E-Learn: World Conference on E-Learning in Corporate, Government, Healthcare, and Higher Education (pp. 1051-1056). Association for the Advancement of Computing in Education (AACE).

\section{Research objectives and methods}

The fourth article elaborates on the barriers to OER use and development across European public administrations. While the initial aim was to define which barriers exist, the core objective is to explore how and why certain barriers unfold in a given cultural context.

Starting from the barrier analysis in previous articles, this study concentrated on expert interviews that validate the barriers and assumptions concerning how barriers unfold. Expert interviews followed a mixed-methods approach, which also allowed to clarify which aspects are significant.

The overall aim was to go beyond previous knowledge about existing barriers and take a step towards theorizing about how and why barriers unfold in a particular context. For this aim, a theoretical process perspective was applied (based on Bostrom \& Gupta, 2009; Lyytinen \& Newman, 2008), which shaped the language and focus of the research.

The analysis was based on Van de Ven (2007), who defined analytical steps to derive conceptually dense factors that shape change processes, such as barrier change in a given context.

\section{Findings}

Analysis of expert interviews brought several factors or 'incidents' to light, which shape the development of barriers (or the so-called incidents shaping structural gaps; cf. Van de Ven, 2007). Among the mentioned factors, four clusters including individual, inter-personal, organizational and time-related factors were developed.

Each incident was described in terms of its basic meaning, discrete empirical occurrence, specific appearance and consequence in a given situation as well as the memo of the context, among others. Hence, the results clarified under what context- and culture-specific situations barriers change, or in more detail, evolve, unfold or resolve, according to the experience of experts.

The crucial results of the study include the incidents, which are described in a rather detailed way. For example, among the time-related incidents, change 
in personnel and scheduling of meetings or elections were mentioned. In practice, these specific moments in time allow for the creation of interventions to foster or avoid influence on OER development and use. In theory, these moments in time provide insight, according to which certain factors shape barrier change in the given context.

\section{Role in the dissertation}

The article provided an answer to the research question RQ4: 'Why and how barriers to open e-learning change?' The core aim to provide a theoretical approach to extend the barriers to OER development and use in a given context was achieved.

Since previous articles addressed the state of current barriers, the article further provides the foundation for designing studies on barrier change in the future.

\subsection{Article V: Which functional design allows for meaningful navigation through collaborative contextualization processes}

Stoffregen, J., Pawlowski, J., Moebs, S., Traxler, J., Guerra-Correa, V., \& Prakash, A. (2016). Design for Collaborative Contextualization of Open Educational Resources. In V. Nissen, D. Stelzer, S. Straßburger, \& D. Fischer (Eds.), Multikonferenz Wirtschaftsinformatik (MKWI) 2016, 1st edition (1 volume, pp. 591-602). Ilmenau: Univ.-Verl.

\section{Research objectives and methods}

The article 'design for collaborative contextualization' strives to translate the findings of studies on barriers to OER use and development in the public sector into technical design. In this regard, the core objective is to advance knowledge about collaborative development and adaptation processes of digital learning resources in the public sector and its implications for user interfaces.

To generate practice-oriented insights, the research focus was on the following questions: (1) when do users like to add collaborative peers in the process? (2) which informational needs do users require to validate the selection of collaborative peers? and (3) which functions need to be added to allow collaborators to exchange their knowledge (how and/or what to adapt)?

To answer these questions, prototype interfaces (or mock-ups) were designed based on the LUCID approach (Logical User-Centered Interactive Design Approach; in Kreitzberg, 2008; Shneiderman, 2002). The prototype demonstrated a contextualization process that included the search for the OER, analy- 
sis of the OER, and adaptation of the OER (based on the OER lifecycle by Pawlowski and Richter [2010]).

The design was evaluated with the help of a concurrent mixed-methods approach (Creswell \& Plano-Clark, 2011). To test the usability of the mock-ups, interviewees were asked to respond to an adapted VisAWI questionnaire (Moshagen \& Thielsch, 2010). Given the different kinds of data, the analysis can be summarized as an exploratory sequential mixed-methods approach (Creswell \& Plano-Clark, 2011).

\section{Findings}

The results of the study explain the usability and aesthetics of the interface design. Furthermore, the results provide answers to the research questions as follows.

Public employees like to contact peers before, after and during the use of an OER. They expect the OER platform to perform like a social network, with the corresponding icons and buttons. While a lot of information about OER authors and OER contents is provided, public employees preferred that less information be provided and that more details be provided only on demand. Finally, public employees consider functions such as screenshots, links, videoaudio and notification sharing as crucial elements for fostering collaboration.

The findings were translated into a table describing the design principles and implications of the results. The table can be used by designers for collaborative contextualization to understand the assumptions and preferences of OER users better in the public sector.

\section{Role in the dissertation}

The article contributes to the objective of the dissertation to put conceptual knowledge about barriers into action and thus to answer research question RQ5: 'Which functional design allows for meaningful navigation through collaborative contextualization processes?' While previous articles provided conceptual insight into the barriers to OER use and development, this work demonstrates how this knowledge can inform OER development in practice.

Furthermore, the table demonstrating the design principles and their realization acts as a context-specific guideline about what factors to consider in OER development in the public sector. This contributes to the research design of the dissertation, which aims at generating conceptual knowledge and models for future research and practice. 


\subsection{Article VI: How does agile software development benefit from agile OER development in public administration}

Stoffregen, J., \& Pawlowski, J. (nn). The Contribution of Agile Open Educational Resources towards Agile Government-an Explorative Study Research Objectives. Submitted to Special Issue on Agile Government and Adaptive Governance in the Public Sector Governments, Government Information Quarterly.

\section{Research objectives and method}

The last article elaborates on the interface between OER practices and the latest, related trends in the public sector. The research objective is three-fold: The first goal is to study a recent OER practice, which is the exploration of agile methods in development steps (cf. Arimoto et al., 2016). The second goal is to perceive how the latest OER practices embedded in reforms make the government more flexible and adaptive to innovative, digital processes. In relation to this, the third goal is to shift the perspective to developments in the field and complement collected knowledge from previous publications.

Given these goals, the article elaborates on the research question 'how do OER uses contribute to knowledge and learning processes as part of agile government changes?'

To answer the question, a case study was designed in the context of the German public administration. The data collection proceeded over a year and was based on qualitative methods, including focus groups, survey interviews and semi-structured interviews (Kitzinger, 1994; Merton \& Kendall, 1946; Morgan, 1997; Myers, 1997; Yin, 2014).

\section{Findings}

The article presents an in-depth case study of OERs, which runs till the first sprint of the model. Based on the results, the article develops a reference model of agile OER implementation. The main steps of the model are a hands-on phase, requirements analysis, planning of change, releases and springs, besides trials and evaluation. Based on the results, the main focus should be the resultsoriented 'hands-on' phase, in which public employees are shown how technical artefacts such as OERs work.

Moreover, the analysis supported the use of OERs as a solution for learning processes which shortens the training and decision-making phases in development and use processes. The main benefit of using the OER at the workplace was the analysis of socio-cultural and organizational barriers with the help of the contextualized barrier framework. For public employees, this analysis can be used to define a common framework for OER development and use processes. 
Finally, the article unveils future research gaps, for example, which development roles should be covered and addressed in agile processes and which training is required to build corresponding competences in public employees.

\section{Role in the dissertation}

The results of the study contribute to putting experience and conceptual knowledge about barriers into action in the field. The results help to answer research question RQ6: 'How do the latest OER uses and development processes contribute towards the knowledge and learning practices of public employees in view of recent government reforms in theory and practice?'

In particular, the question was analysed from two perspectives: the empirical perspective of 'how does the project trajectory evolve with agile OER uses?' as well as the conceptual perspective of 'which model represents an integrated process of agile government and learning processes?'

The article presents fundamental knowledge about barriers and changes in OER use and development in the public sector as well as the latest trends in both OERs and the public sector. In this regard, the article is essential for summarizing previous work of the dissertation based on long-term exploration in a practice-based context. 


\section{CONTRIBUTIONS, LIMITATIONS AND FUTURE WORK}

This chapter discusses the main contributions of the dissertation. Overall, the dissertation provided a contextualized barrier framework to open up e-learning in the public sector. The contextualized barrier framework was validated across different countries and public sector administrations. The framework provided the basis for defining the requirements and technical design of contextualization processes. The findings were translated into an open e-learning platform as well as into a framework for the design principles of contextualization processes in the public sector. For users, guidelines on how to use, contextualize and collaboratively develop OERs were created and validated. Apart from the practical results of the initial framework, the research efforts of the dissertation have resulted in the development of a theoretical concept behind the barrier framework. The theoretical perspective allows to trace the incidents that shape changes in the barriers to open e-learning in public administrations. This perspective has been developed, discussed and published in academic and public sector contexts.

According to the ADR approach (Sein et al., 2011), these results can be categorized into three different types of contributions (Table 4). 
TABLE 4: Categorizing Contributions of the Dissertation

\begin{tabular}{|c|c|}
\hline $\begin{array}{c}\text { Category } \\
\text { (Sein et al. } \\
\text { 2011) }\end{array}$ & Results and references of the dissertation \\
\hline $\begin{array}{l}\text { Methods, } \\
\text { models, } \\
\text { concepts, } \\
\text { design } \\
\text { principles }\end{array}$ & $\begin{array}{l}\text { Concepts: } \\
\text { - A contextualized barrier framework (Stoffregen et al., 2015a) which } \\
\text { provides a list of relevant barriers for the public sector, extends pre- } \\
\text { vious frameworks (Henderson, 1997; Pirkkalainen \& Pawlowski, } \\
\text { 2014) and allows for comparison between public and private sector } \\
\text { barriers } \\
\text { - A comparative, contextualized barrier framework (Stoffregen et al., } \\
\text { 2016a) which allows to assess the requirements and assumptions re- } \\
\text { lated to barriers across different public administrations in detail } \\
\text { Theoretical developments } \\
\text { - A cultural theory perspective of the barrier framework (Stoffregen, } \\
\text { Pawlowski, Ras, Scepanovic, \& Zugic, 2016b) } \\
\text { - Theoretical model: A process perspective of barrier change based on } \\
\text { the barrier framework for the public sector which defines typical in- } \\
\text { cidents such as time-related and person-centred incidents and how } \\
\text { barriers unfold (Stofffegen \& Pawlowski [under review]; Stoffregen } \\
\text { et al., 2016c) } \\
\text { Design principles: } \\
\text { - Principles for designing collaborative contextualization of OERs } \\
\text { which range from the use of words and icons to the layout and re- } \\
\text { quired training and in/output capabilities (Stoffregen et al., 2016c) }\end{array}$ \\
\hline $\begin{array}{l}\text { Context- } \\
\text { specific } \\
\text { artefacts }\end{array}$ & $\begin{array}{l}\text { Design of the contextualization process (EAGLE) } \\
\text { - Design of the contextualization process on the IT platform (Stof- } \\
\text { fregen et al., 2016c) and related choice of metadata which are crucial } \\
\text { for contextualization processes (cf. Pawlowski \& Richter, 2007; Pra- } \\
\text { kash et al., 2014). }\end{array}$ \\
\hline $\begin{array}{l}\text { Utility for } \\
\text { users }\end{array}$ & $\begin{array}{l}\text { Guidelines: } \\
\text { - Specific open learning materials for users on how to use, how to } \\
\text { contextualize and how to collaboratively generate OERs, with mate- } \\
\text { rials developed for the EAGLE platform and beyond (Link to the } \\
\text { OER). } \\
\text { Significance of barriers: } \\
\text { - Discussion and agreement between experts and users on the signifi- } \\
\text { cance of the elaborated barriers and models for the public sector } \\
\text { (Stoffregen et al., 2016b). } \\
\text { Schooling concepts } \\
\text { - Integration of OERs in existing processes and knowledge manage- } \\
\text { ment concepts on the basis of the barrier framework and future pro- } \\
\text { jects (Link to the OER) }\end{array}$ \\
\hline
\end{tabular}

The results presented in the table cover practical as well as theoretical artefacts, as aspired in information systems research (Gregor \& Hevner, 2013; Sein et al., 2011). Yet, the kind of contributions in information systems research needs to be assessed in more detail. The ADR framework does not provide a 
differentiation system to classify practical or theoretical outcomes, but Gregor and Hevner (2013) have classified contributions with regard to the recipients and maturity of the results for a given domain according to the nature of artefacts (the theoretical level, abstract solutions and type of practical results). The categories are as follows (definitions adapted and shortened from Gregor and Hevner [2013, p. 345]):

- Invention: New solutions for new problems, new research opportunities, application domain and solution (low maturity)

- Improvement: New solutions for known problems, research opportunities and application domain (high maturity), and solution (low maturity)

- Exaptation: Extending known solutions to new problems, research opportunities, and application domain (low maturity), and solution (high maturity)

- Routine Design: Applying known solutions to known problems which make no major knowledge contribution

With regard to contributions to theory, further considerations such as the scope, components and maturity, for example, need to be discussed. A wellknown classification for theories in information systems research is provided by Gregor (2006). She defines a taxonomy as well as structural components of results that cover overarching theory components (1), components contingent to theory purposes (2), as well as theory purposes (3), as shown in detail below:

1. Overaching theory components

1.1. Means of representation, such as verbal or graphical artefacts

1.2. Constructs, such as terms, boundaries and differentiation

1.3. Statement of relationships, such directional influence

1.4. Scope, with regard to the generalizability and contingency of assumptions

2. Components contingent to theory purposes

2.1. Kind of explanations or statements provided for research

2.2. Kind of propositions or hypothesis; qualifying empirical research

3. Theory purposes

3.1. Analysing and describing the phenomenon as such

3.2. Explaining by defining how, why and when things happen

3.3. Predicting inter-alia statements of future happenings

3.4. Prescribing by acting upon or stating the method for prescribing action

The mentioned categories and criteria will help to evaluate the results of the dissertation in the following sections. Gregor's categories (2006) mentioned above will be referred to by the same numbers as above, and Gregor and Hevner's (2013) categories will also be referred to. 


\subsection{Theoretical contributions}

\section{Defining the boundaries of the phenomenon}

The first step of the dissertation was to define which culture- and contextspecific challenges to open e-learning exist in public administrations. The barriers are elaborated, described and represented in words and tables (1.1.). The findings differ between three dimensions (social, technical and contextual barriers), and further categories and sub-categories which address both observational and conceptual terms are also presented (1.2.). The examples are a lack of finances, a lack of infrastructure, and the value of information, among others (Stoffregen et al., 2015a). With the help of these categories, the framework systematically evaluates challenges to open e-learning in the public sector. The influence of barriers on open e-learning as well as their interdependence is addressed, and related propositions for future research are provided (1.3.). The boundaries of the frame are well defined with respect to the particular research context, which is public administrations. In this regard, similarities and differences in findings related to the barriers in private and educational sectors are clarified (1.4. and 2.1.). The evaluation of findings is based on expert feedback and discussions (2.2.); yet, barriers found in research and practice were translated into requirements for platform design as well as enabler statements to be used in implementation strategies (Stoffregen, 2015c). In this regard, testable propositions as well as prescriptions were derived from the frame (2.2.).

Summarizing these points according to Gregor (2006) shows that the critical structural components of a theory are covered. As the contextualized framework is one of the first systematic barriers to open e-learning in the public sector (cf. Barette et al., 2012; Eidson, 2009; Peirreira et al., 2015), the frame provides the initial foundation of a theory that allows for analysis of the phenomenon and its translation it into a descriptive artefact.

From the ADR perspective, an important point is that the conceptualized barrier framework evolved as a theoretically engrained concept with regard to previous frames in the domain (Bouckaert, 2007; Henderson, 1996; Pirkkalainen \& Pawlowski, 2014). As indicated before, the work allowed for comparisons of which barriers are reproduced or which challenges are unique to particular contexts; correspondingly, which solutions may be transferred across contexts was discussed (cf. Beuselinck et al., 2007; Bouckaert, 2007). Moreover, known barrier frames and categories were translated into a new context. They were extended with new challenges, such as the role of multilingual settings. Moreover, the research demonstrated that the relevance of barriers differs across contexts, just as observed in the case of social interaction, which is crucial in the public sector. Based on the criteria of Gregor and Hevner (2013), the artefact qualifies as an exaptation, as it exploits new research 
opportunities and takes a first step towards ensuring the maturity of an application domain of a barrier model for the public sector.

\section{Increasing domain specificity}

In order to strengthen the maturity of the contextualized barrier frame for open e-learning in the public sector, the second step was to elaborate on the similarities and differences of barriers across different public sector administrations. In four European countries, including Germany, Luxembourg, Ireland and Montenegro, participants were carefully selected at the local government level to participate in expert interviews. While the selected countries were at different maturity levels with regard to the state of vocational training, familiarity with e-learning programs, range of core actors and state of recent reforms, the selected participants ranged from lay personnel to public administration leaders and key stakeholders such as advisors for learning practices and reforms. In this respect, the replication strategy (Carson et al., 2001) was used, in which a wide range of different empirical contexts are included to refine the contextualized barrier framework (1.4. and 2.1.).

The work of one publication generated an in-depth analysis that was used to define a set of similar and different barriers for the involved public sector contexts (1.4.). To generate a granular comparison, the main dimensions, barrier categories and sub-categories from the initial contextualized barrier framework were addressed. In addition, striking similarities and unique barriers were defined. For example, structural characteristics such as reforms and training strategies did not appear to shape the communication and use of Open Educational Resources (2.2). Moreover, the lack of personnel dedicated to organizing open e-learning platforms was a paramount challenge. Some of the unique context-specific barriers were concerns about competition (Germany), the need for quality checks along the hierarchy before publication (Luxembourg), and unique job rotation processes (Ireland), all of which led to added emphasis in the corresponding domain or the addition of barriers to open e-learning.

The work of a second publication further elaborated on the significance of barriers (2.1). Based on a mixed-methods validation approach (McKenzie et al., 1999), the factors IT infrastructure, independence in choice of learning at the workplace, spirit of the platform as well as format of media, among others, appeared as significant factors that explained why public employees use OERs. Moreover, experts elaborated on how barriers interdependend, such as the role of infrastructure, calm rooms, the position and area of work of respective learners (1.3). Finally, experts had a positive opinion of the model, and they started generating inferences for interventions in their own public administrations (2.2). For example, experts drew inferences from cultural factors such as openness in discourse, and made assumptions about how to sensitize public employees to the use of open e-learning materials. 
Hence, the practicability of the contextualized barrier frame for empirical contexts was also highlighted.

To summarize these points, the second and third publication of the dissertation contained advanced findings regarding the contingency of assumptions as well as the generalizability and propositions of barriers to open elearning in the public sector (Gregor, 2006). In this regard, it was possible to further refine a theory for analysing cultural and contextual barriers and their changes in a given space and time. Yet, another crucial result is that contextspecific characteristics were defined and evaluated, which also shed light on when and why culture- and context-specific factors emerge as crucial barriers. Experts further elaborated on the direction of influence, interdependencies and related interventions in their particular contexts. Thus, important accounts about the relationship of barrier constructs and hypotheses for future empirical research were defined (article 3 and article 4). Hence, the essential components of an explanatory theory are addressed, which clarify when and why certain relevant barriers evolve.

Categorizing these results according to the framework of Gregor and Hevner (2013) led to the identification of the components of a new frame regarding the significance of challenges, the definition of context-specific characteristics shaping the relevance of barriers as well as their contingent change processes. In this respect, both an improvement of the previous exaptation (initial contextualized barrier framework) as well as an invention was achieved, which generated new research opportunities such as, for example, quantitative research on barrier constructs and interdependencies.

\section{Innovating research on barriers - theorizing on the barriers to OERs}

While previous results contribute innovative components to the contextualized barrier framework, an essential step to extend previous research and practice beyond the public sector boundaries is to elaborate further on the interdependence and trajectory of barrier change (see section 1.1.3). So far, the literature has elaborated on the existence and categorization of barriers (Pirkkalainen \& Pawlowski, 2014; Riege, 2005), while claims to shed new perspectives on the phenomenon were published years before (Moynihan \& Landuyt, 2009). The third step to innovating research on barriers was thus to translate and validate previous findings.

By discussing suitable theoretical perspectives, the fourth and forthcoming article (Stoffregen \& Pawlowski, under review) contributes to an extended, punctuated socio-technical change model (Lyytinen \& Newman, 2008) in which antecedents to changes in barriers appear (which refers to their emergence or disappearance). With the help of a mixed-methods validation approach (McKenzie et al., 1999), four constructs for antecedents and incidents were defined (2.1 and 1.2). They provide a unique perspective on the phenomenon of open e-learning in the public sector as they increase the granular- 
ity of assumptions about constructs (1.2 and 2.2), for example, time-related antecedents such as age ranges as well as unique dates shaping the use of OERs. Furthermore, the findings support previous assumptions in the literature about barriers, their relevance and emergence (2.1 and 1.4). For example, incidents related to the construct change of personnel, such as the rotation of employees, appear to have a positive effect on OER use processes by increasing the habitualization of learning processes and knowledge exchange.

To summarize the points, the publication contributes some essential components for developing an explanatory theory (cf. Gregor, 2006). In particular, this work further refines previous assumptions about how and why barriers evolve with respect to the question of when processes occur (i.e. which antecedents and incidents have to be taken into account). This insight goes beyond other published studies aiming at developing exploratory and explanatory models. Examples in the latest research can be found in Peireira et al. (2015), who elaborated on the factors shaping continuous e-learning uses, or Eidson (2009), who defines barriers or influences without specifying context-specific contingencies and change processes (cf. Peireira et al., 2015).

According to the categories of Gregor and Hevner (2013), the mentioned results of the dissertation can be categorized as an invention given that a new, theoretically sound concept for new and context-specific barriers was created, discussed, embedded and differentiated with regard to the latest research in the public, private and educational sectors.

In conclusion, essential components and steps towards innovating theoretical perspectives and models for barriers and their changes in relation to open e-learning in the public sector were generated. As will be discussed in the section on future work, the results offer a basis for quantitative research and model development, which is scarce at this point of time. Yet, the dissertation focuses on a sound mixed-methods approach to build a research basis. While reflecting and appraising the systematic steps towards the theoretical contributions, a few practical outcomes have been mentioned. In the following section, these practical aspects will be addressed in more detail.

\subsection{Practical contributions}

Practical contributions cover results that are meaningful to practitioners in their respective contexts. In particular, the dissertation generated a conceptual barrier framework, a model of barrier incidents and change, as well as a list of design requirements and principles and user guidelines.

Beginning with the IT-centric results (cf. Gregor \& Hevner, 2013; Sein et al., 2011), the development of the contextualized barrier framework was integrated with the IT artefact design, requirements engineering and development processes. Firstly, the elaboration and list of barriers were used during the requirements elicitation jointly among public sector and online media (peda- 
gogy) experts and researchers. In the EAGLE project (see section 2.3.1), these practitioners used the frame to develop enabler statements and interventions. Hence, statements on how to intervene and to improve (enable) the use of OERs were created for each barrier. Based on the discussions, the enabler statements were then transferred to developers who created the open elearning platform. Examples of the statements are provided in Table 5 (the text is adapted and stems from the deliverable of Stoffregen et al. [2015c]):

TABLE 5: Excerpt of Enabler Statements

\begin{tabular}{|c|c|c|}
\hline Action goal & Intervention & Enabler statement (follow up) \\
\hline \multirow{4}{*}{$\begin{array}{l}\text { Enhance manage- } \\
\text { rial organization } \\
\text { and change man- } \\
\text { agement }\end{array}$} & \multirow{2}{*}{$\begin{array}{l}\text { Lobby for political } \\
\text { support for learning } \\
\text { and for EAGLE at a } \\
\text { central level }\end{array}$} & $\begin{array}{l}\text { A training process and facilities for edu- } \\
\text { cational/training activities are intro- } \\
\text { duced. }\end{array}$ \\
\hline & & $\begin{array}{l}\text { An overview of programs and courses to } \\
\text { attend in everyday life is provided. }\end{array}$ \\
\hline & $\begin{array}{l}\text { Support change man- } \\
\text { agement }\end{array}$ & $\begin{array}{l}\text { Guidelines are in place to guide manage- } \\
\text { rial changes. }\end{array}$ \\
\hline & $\begin{array}{l}\text { Encourage the stream- } \\
\text { lining of EAGLE }\end{array}$ & $\begin{array}{l}\text { EAGLE is introduced as a complemen- } \\
\text { tary learning offer. }\end{array}$ \\
\hline \multirow{3}{*}{$\begin{array}{l}\text { Enhance } \\
\text { knowledge about } \\
\text { technology- } \\
\text { enhanced learn- } \\
\text { ing }\end{array}$} & \multirow[t]{3}{*}{$\begin{array}{l}\text { Enhance understand- } \\
\text { ing about the benefits } \\
\text { of e-learning }\end{array}$} & $\begin{array}{l}\text { Advice is given about the long-term use, } \\
\text { cost benefit and gap-trend analysis of e- } \\
\text { learning. }\end{array}$ \\
\hline & & $\begin{array}{l}\text { A booklet to delimit the scope and mean- } \\
\text { ing of OER, OER characteristics, re- } \\
\text { sources and types of learning, its relation } \\
\text { to knowledge management, and poten- } \\
\text { tial for experience exchange is devel- } \\
\text { oped. }\end{array}$ \\
\hline & & $\begin{array}{l}\text { Guidelines are in place which delimit the } \\
\text { efforts to define the targets and goals of } \\
\text { open e-learning. }\end{array}$ \\
\hline \multirow{3}{*}{$\begin{array}{l}\text { Develop a regula- } \\
\text { tory frame for } \\
\text { OERs and learn- } \\
\text { ing }\end{array}$} & \multirow[t]{3}{*}{$\begin{array}{l}\text { Advise about regula- } \\
\text { tory frames for OER }\end{array}$} & $\begin{array}{l}\text { A framework for collaboration and } \\
\text { learning is introduced. }\end{array}$ \\
\hline & & $\begin{array}{l}\text { A legal framework on open resources is } \\
\text { devised. }\end{array}$ \\
\hline & & The CC license and IP charter is adopted. \\
\hline \multirow[t]{2}{*}{$\begin{array}{l}\text { Establish a learn- } \\
\text { ing environment } \\
(\mathrm{LEV})\end{array}$} & \multirow[t]{2}{*}{$\begin{array}{l}\text { Advise about learning } \\
\text { policies }\end{array}$} & $\begin{array}{l}\text { LEV policies are provided (fixed time } \\
\text { slots, space and the right to learn at the } \\
\text { workplace is established). }\end{array}$ \\
\hline & & $\begin{array}{l}\text { Policies are made in accordance with the } \\
\text { accessibility guidelines. }\end{array}$ \\
\hline \multirow[t]{2}{*}{$\begin{array}{l}\text { Establish a quality } \\
\text { committee }\end{array}$} & \multirow{2}{*}{$\begin{array}{l}\text { Develop a highly nec- } \\
\text { essary certification of } \\
\text { contents that is valid, } \\
\text { reliable, and authentic }\end{array}$} & $\begin{array}{l}\text { Guidelines are in place to certify the } \\
\text { OER. }\end{array}$ \\
\hline & & $\begin{array}{l}\text { A committee is in place to validate OER } \\
\text { authenticity. }\end{array}$ \\
\hline
\end{tabular}


Besides providing general guidance on requirements elicitation, the contextualized barrier framework was used for specific tasks such as considering how user-friendly navigation based on metadata choices and visualization can be achieved. On the one hand, developers and researchers decided that the metadata should be based on standards such as InLOC (Integrating Learning Outcomes and Competences ${ }^{2}$ ) and $\mathrm{LOM}^{3}$ (Prakash et al., 2014). The relevance, choice and formulation of metadata were then inspired by the contextualized barrier frame. On the other hand, the contextualized barrier framework was used for orientation of the design of culture- and context-specific use and adaptation processes of OERs (Article 5). While common design standards and patterns were used as a basis, such as those by Nielsen (1994), Hetsevich (2014) or Shneiderman (2002) and Galitz (2007), specifications were made with regard to the contextualized barrier framework, for example, its use in the translation of principles into a public sector-specific design. An excerpt of the frame is provided in Table 6 (the text is adapted and stems from Stoffregen et al. [2016c]):

TABLE 6: Excerpt of the Design Principles

\begin{tabular}{|c|c|c|}
\hline $\begin{array}{c}\text { Specific design princi- } \\
\text { ples }\end{array}$ & Argumentation of the design choice & Implications \\
\hline \multicolumn{3}{|c|}{ Use of words and icons } \\
\hline $\begin{array}{l}\text { A.Consistency } \\
\text { o Maintain consistency } \\
\text { in design and textual } \\
\text { devices (e.g. Het- } \\
\text { sevich, 2014) } \\
\text { B.Wording } \\
\text { o Use linguistically clear } \\
\text { elements (e.g. Het- } \\
\text { sevich, 2014) } \\
\text { C.Usability } \\
\text { o Use language that is } \\
\text { appropriate for in- } \\
\text { creasing usability (e.g. } \\
\text { Nielsen, 1994) }\end{array}$ & $\begin{array}{l}\text { Consistency is achieved by using } \\
\text { consistent fonts and colour (shades } \\
\text { of blue, light yellow, and light red). } \\
\text { The navigation function is on the } \\
\text { top, with the wordings in page la- } \\
\text { bels/fonts/buttons reflecting the } \\
\text { results of GOMS (cf. Galitz, 2007, p. } \\
\text { 139; Oracle, 2010). } \\
\text { The use of words and textual } \\
\text { learning contents needs to be low. } \\
\text { The platform is used across coun- } \\
\text { tries, so several languages are con- } \\
\text { figured. Therefore, linguistically } \\
\text { unambiguous terms are chosen, } \\
\text { such as 'peer space', 'manage' or } \\
\text { 'communicate', 'trace', 'editing', } \\
\text { 'preview' and 'publish'. }\end{array}$ & $\begin{array}{l}\rightarrow \text { Linguistic terms: } \\
\text { use more icons and } \\
\text { familiar wordings, } \\
\text { such as the icons } \\
\text { for share, log in, } \\
\text { save, and search, } \\
\text { and the words } \\
\text { 'share', 'invite', } \\
\text { 'add', 'colleague', } \\
\text { and 'collabo- } \\
\text { rate' / chat'. } \\
\rightarrow \text { Based on the } \\
\text { design of mobile } \\
\text { phones and social } \\
\text { media platforms }\end{array}$ \\
\hline
\end{tabular}

The dissertation produced theoretically engrained artefacts that were used to create design concepts and technology. The recipients ranged from researchers discussing and developing technical principles and making design choices, to developers programming the platform for users. According to Gregor and

\footnotetext{
2 http://www.cetis.org.uk/inloc/Home.

${ }^{3}$ https:// standards.ieee.org/findstds/standard/1484.12.1-2002.html.
} 
Hevner (2013), artefacts qualify as exaptations, as common design approaches are refined to create new contexts and application domains.

In addition to the mentioned artefacts, two other results need to be mentioned. On the one hand, the presented enabler statements and validations of the barrier models above were used for the definition of interventions (for example, the training of public employees or investment in technology). While some statements are already presented in Table 4, further interventions concern elaborations with practitioners on how to introduce OERs to existing strategies such as knowledge management frameworks. One well-placed publication in this respect elaborates on agile OER processes, highlighting the contribution of digital knowledge resources to the latest agile reform processes (Article 6). The elaboration resulted in the creation of a reference model of agile OER implementation, with the goal being to support knowledge and learning processes as part of agile government projects. The steps include a hands-on (practicedevelopment) phase, a needs/requirements analysis, planning of change, trial and evaluation, among others (Stoffregen \& Pawlowski, submitted).

Besides academic and programming recipients, the results of the research have led to the creation of OERs which explain how to use, collaborate and contextualize OERs to the culture- and context-specific preferences of users (see for example, Figure 4).

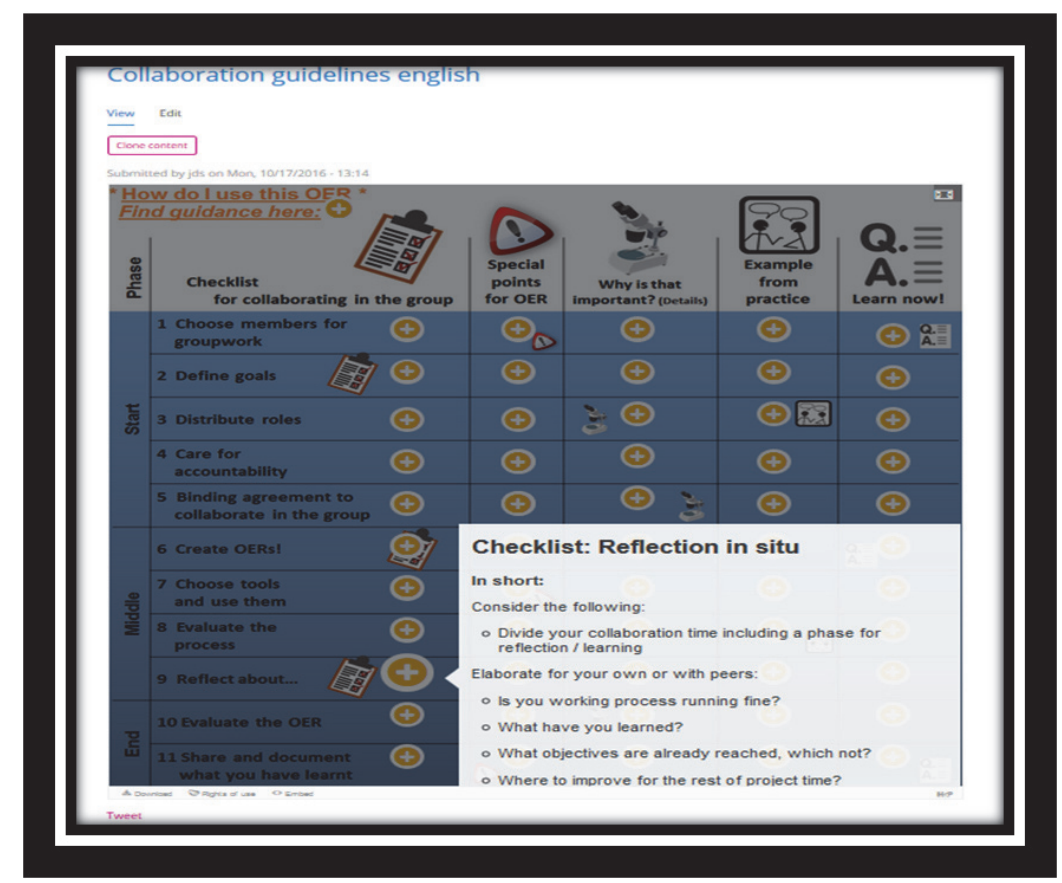

FIGURE 4: Illustration of an OER

Another user-oriented result is an OER-supported knowledge management concept which resulted from collaboration among public employees. Pub- 
lic employees used the contextualized barrier framework to analyse challenges vis-a-vis their present knowledge management processes and strategies. Given that the demographic change in public administrations has led to increasing pressure to identify innovative solutions, interest in this OER is high across different federal states in Germany.

The concept is openly available and has received positive feedback from public employees. Furthermore, interest in using the OER-supported knowledge management concept, including interest in being trained with respect to this framework, supports the relevance of the contextualized barrier framework and shows that the dissertation has generated innovative solutions for the management of knowledge and learning.

\subsection{Limitations and future work}

The previous section has elaborated on the theoretical and practical contributions of the dissertation. Yet, several limitations have to be clarified with regard to the study design and future research.

Beginning with the study design, the dissertation has followed a mixedmethods approach to generate an understanding and theoretically founded concepts that elaborate on the barriers to OERs in the public sector. Given the infant stage of research in this context, qualitative methods were dominant as they help to develop an initial understanding of the phenomenon. While the dissertation provided some in-depth insight and a systematic analysis, it lacks quantitative findings concerning the structural analysis of factors, for example. Although significance has been calculated for particular factors, more work is required to quantify the influence of barriers on OER use and development. However, although the dissertation is limited with regard to quantitative, statistical methods, the research has generated rich insight as well as models that can be used as a basis for how to structure multi-level models. Thus, recommendations for future work should focus on strengthening quantitative approaches to analyse the role and development of barriers and antecedents to OERs in the public sector.

With regard to the analysis and development of OERs in the public sector, another limitation of the dissertation is the duration of the study term. While data for some studies have been gathered over several months to a year, the results of some publications were based on interviews of purposefully selected experts and practitioners on site. Hence, while a high amount of qualitative data were generated and analysed, the findings need to be further strengthened, and the initial steps towards process-oriented models of OER barriers will require the planning and realization of a longitudinal study in this specific context.

Another limitation is the generalizability of the results. On the one hand, the careful sampling and selection of cases and experts throughout the dissertation is indicative of the generalizability of results across local governments in 
the European Union. Given the successive use and validation of the contextualized barrier frame, the positive feedback of practitioners and academics to the results of the dissertation support the generalizability of outcomes across different contexts. On the other hand, the contextualized barrier framework has not been assessed at different levels of government. Moreover, how meaningful the framework is for countries beyond the European Union as well as beyond English- and German-speaking cultural contexts is yet to be assessed.

Besides the limitations of the study, further considerations about future research and recommendations for practice need to be addressed. While the contextualized barrier frame has been used to enhance understanding about (socio-technical) requirements, to generate enabler statements and inform design choices, its use for practitioners is yet to be investigated. In general, more information is required, such as guidelines on how to use the contextualized barrier framework in the course of everyday OER use and development processes. More specifically, which interventions related to the antecedents or incidents of change have proven to work best in a given context needs to be further specified.

To summarize all the points mentioned, there is more room for investigation into the phenomenon of OERs in the public sector. Practice-oriented research is required to understand how models work in different contexts over time. From a theory-guided perspective, more research on the influences and interdependences of related factors needs to be conducted. Moreover, opposing theses about the nature and kind of barriers need to be tested in this respect. Hence, according to Gregor (2006), there is still scope for developing, explaining and predicting theories in future research. Given that the dissertation presented the recommended steps to be implemented before the testing of predicting models and theories (namely, analysing, describing and developing the initial components of explaining theories), the results and contributions of the dissertation can be used as sensitizing frames for future work. 


\section{SUMMARY}

Using OERs in processes of knowledge management and learning is a new trend which is about to be presented in the public sector. The use of OERs and related strategy development face several barriers in the form of technical, socio-cultural and organizational challenges, which impede the uptake and use of these digital learning resources. This dissertation has elaborated on the sociotechnical barriers in the specific cultural context of public administrations. One result is the contextualized barrier frame, which has shown that the kind and relevance of barriers to OERs differ among public administrations as well as among other educational or private sector domains. Moreover, the dissertation has elaborated on the incidents that shape how and why barriers unfold in the public sector. The related PSIC model demonstrates barrier trajectories and allows researchers and practitioners to design interventions and implementation strategies in view of forthcoming challenges.

One of the challenges is the low interest in OERs, given their impact on face-to-face exchanges and related social interactions among colleagues in a public administration. In particular, elderly employees, who have low confidence in using new technology, such as OER authoring tools, prefer personal contact and are wary of documenting their knowledge in OER formats. With the help of the contextualized barrier framework of the thesis, barriers related to the lack of social interaction can be assessed. With the help of the PSIC model, related trajectories and incidents of change, such as improvements in the barrier, can be traced back and assessed for future interventions. One example of an intervention is to design a blended OER creation strategy wherein elderly public employees can team up with other employees (maybe trainees) and meet and talk about their experiences on the job. The younger employee can then document the exchanges in an OER format and assess the report together with the elderly employee. In this way, social interaction together with OERenhanced knowledge exchange can be realized. OER developers can furthermore gain experience in creating and evaluating the quality of their materials. Besides the mentioned examples, the field research across European public administrations resulted in collaboration with OER platform developers. Thereby, the contextualized barrier framework of the dissertation has been used to guide the requirements elicitation as well as the design of contextualization processes (which describe the adaptation of learning materials for particular learning needs and contexts).

In summary, the dissertation has produced theoretically engrained models of barriers to OERs in the public sector. The in-depth research has allowed the use and validation of the models in the research context. Yet, the research on barrier change is at its infancy stage. The outcomes of the dissertation provide a basis for further inquiry into the trajectories and future explanatory research on the barriers to OERs and their trajectories in special cultural contexts. 


\section{YHTEENVETO (FINNISH SUMMARY)}

Avointen oppimateriaalien käyttö on lupaava tapa täydentää perinteisiä verkkokursseja. Sähköisiin oppimateriaaleihin pääsee halutessaan käsiksi mistä vain ja niillä voi olla useita tekijöitä. Avoimet oppimateriaalit voisivat vastata työpaikkaoppimisen vaihtuviin tarpeisiin. Riippumatta avointen oppimateriaalien potentiaalista, niitä hyödynnetään vain vähän. Aikaisemmat tutkimukset ovat havainneet useita esteitä avointen oppimateriaalien käyttämiselle ja jakamiselle vaihdellen kulttuurillisista teknisiin ja organisatorisiin esteisiin. On tutkittu estetyyppejä ja niiden merkitystä sekä koulutus- että yksityisellä sektorilla. Kuitenkin on edelleen epäselvää, miten nämä esteet kehittyvät ja eroavat erilaisissa ympäristöissä.

Yksi julkisen sektorin erityinen esimerkki liittyy tilanteeseen, jossa on tarvetta innovoida tiedonjakelun prosesseja ja oppiminen on nopeaa. Sen lisäksi, että työntekijöiden oppimiseen varatut määrärahat ovat rajalliset, ikääntyvien työntekijöiden osaamisen dokumentointiin ja siirtämiseen nuoremmille on kasvava paine. Toistaiseksi avoimet oppimateriaalit eivät ole tunnettuja tällä sektorilla. Samoin, tällä alalla esteitä avointen oppimateriaalien käytölle ei ole tutkittu.

Tämän väitöskirjan tavoitteena on vastata tähän tutkimusongelmaan, tutkien erityisesti eurooppalaisten julkishallinnon erityyppisiä esteitä ja vastaten kysymyksiin miksi ja miten esteet kehittyvät tietyssä ajassa ja paikassa. Tutkimustuloksena tämä väitöskirja esittää ainutlaatuisen teoreettisen perspektiivin avointen oppimateriaalien esteille ja niiden kehittymiselle julkisen sektorin alueella. Tämä väitös tuottaa täsmentävän ja räätälöivän sosio-teknologisen muutoksen mallin, jota voidaan hyödyntää analysoimaan miten ja miksi haasteita syntyy myös julkisen sektorin tutkimuksen ulkopuolella.

Teoreettisten vaikutusten lisäksi tämä väitöskirja tarjoaa kontekstualisoidun haasteviitekehyksen, joka voi auttaa avointen oppimateriaalien jakelualustojen kehittäjiä arvioimaan sosio-kulttuurillisia haasteita ja vaatimuksia, jotka ovat tyypillisiä avoimen oppimisen käytänteille julkishallinnoissa. Kenttätutkimusten aikana tämä väitöskirjatyö tarjosi myös avointen oppimateriaaliohjeistuksien lisäksi oppimateriaalien suunnitteluperiaatteita julkishallinnossa työskenteleville. 


\section{REFERENCES}

AfIS [Association for Infomation Systems]. (2011). Senior Scholars' Basket of Journals. Retrieved from http://aisnet.org/?SeniorScholarBasket.

Ahmad, A., Lyytinen, K., \& Newman, M. (2011). The evolution of process models in IS research: From a punctuated social process model to a socio-technical process model. Proceedings from the European Conference on Information Systems (ECIS) 2011, Paper 161.

Alavi, M., \& Leidner, D. E. (2001). Review: Knowledge management and knowledge management systems: Conceptual foundations and research issues. MIS Quarterly, 107-136.

Amayah, A. T. (2013). Determinants of knowledge sharing in a public sector organization. Journal of Knowledge Management, 17(3), 454-471.

Arimoto, M. M., \& Barbosa, E. F. (2013). Towards the establishment of an agile method for OERs development and delivery. Frontiers in Education Conference, IEEE, 541-547.

Arimoto, M., Barroca, L., \& Barbosa, E. (2016). AM-OER: An Agile Method for the Development of Open Educational Resources. Informatics in Education, 15(2).

Atkins, D. E., Brown, J. S., \& Hammond, A. L. (2007). A review of the open educational resources (OER) movement: Achievements, challenges, and new opportunities, Creative Common (pp. 1-54). Retrieved from https://pdfs.semanticscholar.org/8d16/858268c5c15496aac6c880f9f50afd9 640b2.pdf.

Back, A. (2002). Combining E-Learning and Knowledge Management. (ELearning und Wissensmanagement zusammenführen). In A. Hohenstein, \& K. Wilbers (Eds.), Handbuch E-Learning: Expertenwissen aus Wissenschaft und Praxis (pp. 1-12). Köln: Verlag Deutscher Wirtschaftsdienst.

Baghramian, M., \& Carter, J. A. (2015). Relativism. In Zalta, E. N. (Ed.), The Stanford Encyclopedia of Philosophy, Summer 2017 edition. Retrieved from https:// plato.stanford.edu/archives/sum2017/entries/relativism/.

Barette, J., Lemyre, L., Corneil, W., \& Beauregard, N. (2012). Organizational Learning Facilitators in the Canadian Public Sector. International Journal of Public Administration, 35(2), 137-149.

Benbasat, I., Goldstein, D. K., \& Mead, M. (1987). The Case Research Strategy in Studies of Information Systems. MIS Quarterly, 11(3), 369-386.

Bere, R. C., Nemeș, L., \& Silvestru, C. I. (2014). Challenges and Opportunities in Knowledge sharing in e-Learning programs for public administration (pp. 461-469). Proceedings from the 10 $10^{\text {th }}$ International Scientific Conference eLearning and Software for Education. Bucharest, April 25-26, 2014. 
Bere, R., Silvestru, C., \& Nemeș, L. (2013). E-Learning Platform for Public Administration-Case Study (pp. 486_491). Proceedings from The 9th International Scientific Conference eLearning and software for Education. Bucharest, April 25-26, 2013.

Beuselinck, E., Verhoest, K., \& Bouckaert, G. (2007). Chapter 4: Reforms of Central Government Coordination in OECD-Countries: Culture as Counterforce For Cross-National Unifying Processes? In K. Schedler, \& I. Proeller (Eds.), Cultural Aspects of Public Management Reform (vol. 16, pp. 77-115). Amsterdam [u.a.]: Elsevier JAI, Emerald Group Publishing Limited (Research in Public Policy Analysis and Management).

Blaikie, N. W. H. (2010). Designing social research: the logic of anticipation. Cambridge: Polity.

Blees, I., Deimann, M., Seipel, H., Hirschmann, D., \& Muuß-Merholz, J. (2015). Whitepaper Open Educational Resources (OER) in lifelong-learning: State of the art and potentials. Whitepaper Open Educational Resources (OER) in Weiterbildung/Erwachsenenbildung: Bestandsaufnahme und Potenziale (pp. 3-98). Retrieved from http://open-educational-resources.de/wpcontent/uploads/sites/4/2015/02/Whitepaper-OER-Weiterbildung2015.docx.

Bostrom, R. P., \& Gupta, S. (2009). Technology-mediated learning: A comprehensive theoretical model. Journal of the Association for Information Systems, 10(9), 686-714.

Bouckaert, G. (2007). Cultural characteristics from public management reforms worldwide. In K. Schedler, \& I. Proeller (Eds.), Cultural Aspects of Public Management Reform (pp. 29-64). Amsterdam [u.a.]: Elsevier JAI, Emerald Group Publishing Limited (Research in Public Policy Analysis and Management).

Butcher, N. (2015). A basic guide to open educational resources (OER). In Kanwar, A., \& Uvalić-Trumbić, S. (Eds.): A Basic Guide to Open Educational Resources (OER). Vancouver [u.a.]: Commonwealth of Learning and UNESCO.

Buzatto, D., Anacleto, J. C., Dias, A. L., Silva, M. A. R., Villena, J., \& de Carvalho, A. (2009). Filling out learning object metadata considering cultural contextualization. Systems, Man and Cybernetics (p. 424-429). Proceedings from IEEE International Conference on Systems, Man and Cybernetics [SMC 2009].

Campagnolo, G. M., \& Fele, G. (2010). From specifications to specific vagueness: how enterprise software mediates relations in engineering practices. Engineering Studies, 2(3), 221-243.

Campbell, L. (2015). Open Silos? Open data and OER. Retrieved from https:/ / lornamcampbell.wordpress.com/2015/06/08/open-silos-opendata-and-oer/. 
Carson, D., Gilmore, A., Perry, C., \& Gronhaug, K. (2001). Case-based Research. In D. Carson, A. Gilmore, C. Perry, \& K. Gronhaug (Eds.), Qualitative Marketing Research (pp. 92-113). London: SAGE Publications Ltd.

Casalino, N. (2014). Learning to Connect: a Training Model for Public Sector on Advanced E-Government Services and Inter-Organizational Cooperation. International Journal of Advanced Corporate Learning, 7(1), 24-31.

Chatti, M., Schroeder, U., \& Jarke, M. (2012). LaaN: Convergence of Knowledge Management and Technology-Enhanced Learning. IEEE Transactions on Learning Technologies, 5(2), 177-189.

Checkland, P., \& Poulter, J. (2010). Soft systems methodology. In M. Reynolds, \& S. Holwell (Eds.), Systems approaches to managing change: A practical guide (pp. 191-242). London: Springer Verlag.

Chen, T. L. (2014). Exploring e-Learning Effectiveness Perceptions of Local Government Staff Based on the Diffusion of Innovations Model. Administration and Society, 46(4), 450-466.

Clements, K., Pawlowski, J. M., \& Manouselis, N. (2015). Open educational resources repositories literature review-Towards a comprehensive quality approaches framework. Computers in Human Behavior, 51, 1098-1106.

Colazzo, L., Molinari, A., \& Villa, N. (2009). Lifelong Learning and Virtual Communities in the Public Administration: A Case Study in Italy. International Journal of Advanced Corporate Learning, 2(3), 5-11.

Cole, R., Purao, S., Rossi, M., \& Sein, M. K. (2005). Being Proactive: Where Action Research Meets Design Research. 26 ${ }^{\text {th }}$ ICIS Proceedings, Las Vegas, USA: AIS, 2005.

Conci, A., \& Bramati, C. (2007). E-Learning In Public Administration. SLOOP: Sharing Learning Objects in an Open Perspective, 81-85.

Corbin, J. M., \& Strauss, A. (1990). Grounded theory research: Procedures, canons, and evaluative criteria. Qualitative Sociology, 13(1), 3-21.

Creswell, J. W. (2013). Research design: Qualitative, quantitative, and mixed methods approaches [u.a.]. London: Sage Publications.

Creswell, J. W., \& Plano-Clark, V. L. (2011). Designing and conducting mixed methods research, $2^{\text {nd }}$ edition. USA: Sage Publications Ltd.

D'Antoni, S. (2009). Open Educational Resources: reviewing initiatives and issues. Open Learning. The Journal of Open, Distance and e-Learning, 24(1), 310.

Das, A. K. (2011). Emergence of open educational resources (OER) in India and its impact on lifelong learning. Library Hi Tech News, 28(5), 10-15.

Davies, T. (2010). Open data, democracy and public sector reform. A look at open government data use from data.gov.uk. (unpublished Master's thesis). University of Oxford, Oxford. Retrieved from 
http:// practicalparticipation.co.uk/odi/report/wp-

content/uploads/2010/08/How-is-open-government-data-being-used-inpractice.pdf.

De Angelis, C. T. (2013). A Knowledge Management and Organizational Intelligence Model for Public Administration. International Journal of Public Administration, 36(11), 807-819.

Deimann, M. (2012). Open Education: Offene Bildung und offenes Lernen-mehr als nur eine Alternative für E-Learning. Handbuch E-Learning, Köln. Retrieved from https://www.researchgate.net/profile/Markus_Deimann2/publication/ 259784191_Offene_Bildung_und_offenes_Lernen_-_mehr_als_nur_eine_Alternative_fur_ELearning/links/542126110cf241a65a1e629b/Offene-Bildung-und-offenesLernen--mehr-als-nur-eine-Alternative-fuer-E-Learning.pdf.

Downes, S. (2007). Models for sustainable open educational resources. Interdisciplinary Journal of E-Learning and Learning Objects, 3(1), 29-44.

Dunn, P., \& Marinetti, A. (2002). Cultural adaptation: necessity for e-learning. LineZine. Retrieved from http://www.linezine.com/7.2/articles/pdamca.htm.

Edmundson, A. (2007). Globalized e-learning cultural challenges. Hershey, PA: IGI Global.

Eidson, L. A. K. (2009). Barriers to E-Learning Job Training: Government Employee Experiences in an Online Wilderness Management Course. Thesis, Dissertations, Professional Papers, University of Montana, Paper 86.

Falconer, L. (2006). Organizational learning, tacit information, and e - learning: a review. The Learning Organization, 13(2), 140-151.

Fink, A. (2014). Conducting research literature reviews: from the Internet to paper. [u.a.] London: Sage Publications.

Fishenden, J., \& Thompson, M. (2013). Digital government, open architecture, and innovation: why public sector IT will never be the same again. Journal of Public Administration Research and Theory, 23(4), 977-1004.

Frank, U. (2006). Towards a pluralistic conception of research methods in information systems research (edited by ICT-Research Report, No. 7). Provided in Cooperation with University Duisburg-Essen, Institute for Computer Science and Business Information Systems (ICB). Retrieved from http:/ / hdl.handle.net/10419/58156.

Galitz, W. O. (2007). The Essential Guide to User Interface Design. An Introduction to GUI Design Principles and Techniques. Indianapolis: Wiley Publications.

Giddens, A. (1984/2001). The constitution of society: Outline of the theory of structure. Berkeley: CA: University of California Press. 
Glaser, B. G., \& Strauss, A. (2010). Grounded theory: Strategien qualitativer Forschung. Bern: Huber.

Green, S., Jones, R., Pearson, E., \& Gkatzidou, S. (2006). Accessibility and adaptability of learning objects: responding to metadata, learning patterns and profiles of needs and preferences. Research in Learning Technology, 14(1), 117-129.

Gregor, S. (2006). The Nature of Theory in Information Systems. Management Information Systems Quarterly, 30(3), 611-642.

Gregor, S., \& Hevner, A. R. (2013). Positioning and presenting design science research for maximum impact. Management Information Systems Quarterly, $37(2), 337-355$.

Guillemin, M., \& Gilliam, L. (2004). Ethics, Reflexivity, and "Ethically Important Moments" in Research. Qualitative Inquiry, 10(2), 261-280.

Guri-Rosenblit, S. (2006). Eight paradoxes in the implementation process of elearning in higher education. Distances et saviors, 4(2), 155-179.

Gustavsson, M. (2009). Facilitating expansive learning in a public sector organization. Studies in Continuing Education, 31(3), 245-259.

Hair, J. F., Black, W. C., Babin, B. J., \& Anderson, R. E. (1998). Multivariate data analysis. A Global Perspective. Upper Saddle River, NJ: Prentice hall.

Hall, M., Kutsch, E., \& Partington, D. (2012). Removing The Cultural And Managerial Barriers In Project-To-Project Learning: A Case From The UK Public Sector. Public Administration, 90(3), 664-684.

Hârțescu, I. (2012). A Case Study of Implementing Blended Learning Courses in Public Administration (pp. 497-503). Proceedings from the $8^{\text {th }}$ International Scientific Conference for eLearning and Software for Education. Bucharest, April 26-27, 2012.

Hazlett, S. A., McAdam, R., \& Beggs, V. (2008). An exploratory study of knowledge flows: A case study of Public Sector Procurement. Total Quality Management \& Business Excellence, 19(1-2), 57-66.

Henderson, L. (1996). Instructional design of interactive multimedia: A cultural critique. Educational Technology Research and Development, 44(4), 85-104.

Henderson, L. (2007). Theorizing a multiple cultures instructional design model for e-learning and e-teaching. In A. Edmundson (Ed.), Globalized e-learning cultural challenges (pp. 130-153). Hershey, PA: IGI Global.

Hetsevich, I. (2014). How To Improve eLearning Course Design Usability By Adopting The 10 Usability Heuristics. eLearning Industry. Retrieved from http://elearningindustry.com/how-to-improve-elearning-course-designusability-by-adopting-the-10-usability-heuristics.

Hevner, A. R. (2007). A three-cycle view of design science research. Scandinavian Journal of Information Systems, 19(2), 87-92. 
Hilton, III.J., Wiley, D., Stein, J., \& Johnson, A. (2010). The four 'R's of openness and ALMS analysis: frameworks for open educational resources. Open Learning, 25(1), 37-44.

Hofstede, G. (1989). Organising for cultural diversity. European Management Journal, 7(4), 390-397.

Hofstede, G. (1998). Attitudes, Values and Organizational Culture: Disentangling the Concepts. Organization Studies, 19(3), 477-493.

Hofstede, G. (2001). Culture's consequences. comparing values, behaviors, institutions, and organizations across nations. Thousand Oaks, CA. [u.a.]: Sage Publications.

Hofstede, G., Hofstede, G.-J., \& Minkov, M. (2010). Cultures and Organizations: Software of the Mind, $3^{\text {rd }}$ edition. McGraw-Hill, USA.

Hong, W., Chan, F. K. Y., Thong, J. Y. L., Chasalow, L. C., \& Dhillon, G. (2013). A framework and guidelines for context-specific theorizing in information systems research. Information Systems Research, 25(1), 111-136.

Hylén, J. (2006). Open educational resources: Opportunities and challenges. Proceedings of Open Education, 49-63.

Hylén, J., \& Schuller, T. (2007). Giving knowledge for free. Organisation for Economic Cooperation and Development. The OECD Observer, 263.

Iivari, J., \& Venable, J. (2009). Action research and design science research-seemingly similar but decisively dissimilar (pp. 1-13). ECIS 2009 Proceedings, paper 73.

Jamil, I., Askvik, S., \& Hossain, F. (2013). Understanding Administrative Culture: Some Theoretical and Methodological Remarks. International Journal of Public Administration, 36(13), 900-909.

Janssen, K. (2012). Open Government Data: Right to Information 2.0 or its Rollback Version? ICRI Research Paper, 8. Retrieved from https:/ / papers.ssrn.com/sol3/papers.cfm?abstract_id=2152566.

Jesson, J., Matheson, L., \& Lacey, F. M. (2011). Doing your literature review: traditional and systematic techniques. London [u.a.]: Sage Publications.

Karunanayaka, S. P., Naidu, S., Rajendra, J. C. N., \& Ratnayake, H. U. W. (2016). Designing Reflective Practice in the Context of OER-based e-Learning. Journal of Learning for Development, 4(2).

Keraudren, P. (1996). In search of culture: Lessons from the past to find a role for the study of administrative culture. Governance, 9(1), 71-98.

Kirkwood, A., \& Price, L. (2013). Technology-enhanced learning and teaching in higher education: what is 'enhanced' and how do we know? A critical literature review. Learning, Media and Technology, 39(1), 6-36. 
Kitzinger, J. (1994). The methodology of focus groups: the importance of interaction between research participants. Sociology of Health and Illness, 16(1), 103-121.

Koper, R. (2008). Open Source and Open Standards. In M. J. Spector, M. D> Merrill, van J. Merriënboer, \& M. P. Driscoll (Eds.), Handbook of Research on Educational Communications and Technology, $3^{\text {rd }}$ edition (pp. 355-365). Taylor \& Francis e-Library, 2008.

Korge, G., \& Piele, C. (2014). Study Learning Elderly: Learning contexts for elderly in public sectors (Studie Lernen Ältere: Lernsettings für ältere Verwaltungsmitarbeitende. Im Auftrag der BB Bank Stiftung). Fraunhofer-Institut für Arbeitswirtschaft und Organisation IAO, Stuttgart.

Kozinets, R. V. (2007). Netnography 2.0. In R. Belk, R. (Ed.), Handbook of qualitative research methods in marketing (pp. 129-142). Cheltenham, UK: Edward Elgar Publishing Ltd.

Kretzer, S. (2013). Working paper for concept-development of anonymization and pseudonymisation in quality-servicing. (Arbeitspapier zur Konzeptentwicklung der Anonymisierungs-/Pseudonymisierung in Qualiservice). Retrieved from http://www.qualiservice.org/fileadmin/templates/qualiservice/Anony misierungskonzept_Arbeitspapier.pdf.

Lane, A. (2010). Designing for innovation around OER. Journal of Interactive Media in Education, 1, 1-10.

Langen, F. H.T. de, \& Bitter-Rijkema, M. E. (2012). Positioning the OER Business Model for Open Education. European Journal of Open, Distance and $e$ Learning, 15(1).

Langford, J., \& Seaborne, K. (2003). To click or not to click: E - learning for the public sector. Canadian Public Administration, 46(1), 50-75.

Lau, S.-H., \& Woods, P. C. (2009). Understanding learner acceptance of learning objects: The roles of learning object characteristics and individual differences. British Journal of Educational Technology, 40(6), 1059-1075.

Laurillard, D. (2008). Open teaching: The key to sustainable and effective open education. In T. Iiyoshi, \& M. S. V. Kumar (Eds.), Opening up education: The collective advancement of education through open technology, open content, and open knowledge (pp. 319-336). USA: MIT Press.

Leidner, D., \& Kayworth, T. (2006). Review: A Review of Culture in Information Systems Research: Toward a Theory of Information Technology Culture Conflict. Management Information Systems Quarterly, 30(2), 357-399.

Lincoln, Y. S., Lynham, S. A., \& Guba, E. G. (2011). Paradigmatic controversies, contradictions, and emerging confluences, revisited. The Sage Handbook of Qualitative Research, 4, 97-128. 
Lucke, J. von, \& Geiger, C. P. (2010). Open Government Data- freely available data of the public sector (Open Government Data-Frei verfügbare Daten des öffentlichen Sektors). Gutachten, Deutsche Telekom Institute for Connected Cities, Zeppelin University, Friedrichshafen. Retrieved from https://www.zu.de/institute/togi/assets/pdf/TICC-101203OpenGovernmentData-V1.pdf.

Lyytinen, K., \& Newman, M. (2008). Explaining information systems change: a punctuated socio-technical change model. European Journal of Information Systems, 17(6), 589-613.

Madill, A., Jordan, A., \& Shirley, C. (2000). Objectivity and reliability in qualitative analysis: Realist, contextualist and radical constructionist epistemologies. British Journal of Psychology, 91(1), 1-20.

Mahler, J. (1997). Influences of organizational culture on learning in public agencies. Journal of Public Administration Research and Theory, 7(4), 519-540.

Manisha, n.n., \& Bandyopadhyay, T. (2009). A case study on content sharing by leveraging open educational resources framework. 2009 International Workshop on Technology for Education (T4E 2009).

Mayring, P. (2010). Qualitative content analysis (Qualitative Inhaltsanalyse), 11th edition. Weinheim/Basel: Beltz Verlag.

McGreal, R. (2010). Approaches to OER development. Open ED 2010 Proceedings. Barcelona: UOC, OU, BYU. Retrieved from http://hdl.handle.net/10609/5083.

McKenzie, J. F., Wood, M. L., Kotecki, J. E., Clark, J. K., \& Brey, R. A. (1999). Establishing Content Validity: Using Qualitative and Quantitative Steps. American Journal of Health Behavior, 23(4), 311-318.

McNiff, J., \& Whitehead, J. (2009). You and Your Action Research Project. New York: Routledge. Retrieved from http:/ / dx.doi.org/10.4324/9780203871553.

Meneklis, V., \& Douligeris, C. (2010). Bridging theory and practice in egovernment: A set of guidelines for architectural design. Government Information Quarterly, 27(1), 70-81.

Mergel, I., \& Desouza, K. C. (2013). Implementing Open Innovation in the Public Sector: The Case of Challenge.gov. Public Administration Review, 73(6), 882-890.

Merton, R. K., \& Kendall, P. L. (1946). The Focused Interview. American Journal of Sociology, 51(6), 541-557.

Meuser, M., \& Nagel, U. (2002). Expertinterviews- commonly used despite scarce reflections. (ExpertInneninterviews - vielfach erprobt, wenig bedacht). In A. Bogner, B. Littig, \& W. Menz (Eds.), Das Experteninterview. Theorie, Methode, Anwendung (pp. 71-93). Wiesbaden: Verlag für Sozialwissenschaften. 
Morgan, D. L. (1997). Planning And Research Design For Focus Groups. Focus Groups as Qualitative Research (edited by SAGE Publications Inc.). Thousand Oaks, London: SAGE Publications.

Moynihan, D. P., \& Landuyt, N. (2009). How Do Public Organizations Learn? Bridging Cultural and Structural Perspectives. Public Administration Review, 69(6), 1097-1105.

Myers, M. D. (1997). Qualitative Research in Information Systems. Management Information Systems Quarterly, MISQ Discovery, archival version. Retrieved from http://www.qual.auckland.ac.nz/.

Myers, M. D., \& Newman, M. (2007). The qualitative interview in IS research: Examining the craft. Information and Organization, 17(1), 2-26.

Myers, M. D., \& Venable, J. R. (2014). A set of ethical principles for design science research in information systems. Information and Management, 51(6), 801-809.

Newman, M., \& Robey, D. (1992). A social process model of user-analyst relationships. Management Information Systems Quarterly, 16(2), 249-266.

Newman, M., \& Zhu, S. (2007). Process Modeling Information Systems Development: The SellCo Case. In T. McMaster, D. Wastell, E. Ferneley, \& J. DeGross (Eds.), IFIP International Federation for Information Processing (pp. 63-81). Boston: Springer Publications.

Newman, M., \& Zhu, S. (2009). Punctuated process modelling of information systems development: An illustration from a mid-sized enterprise. Communications of the Association for Information Systems, 24(39), 673-701.

Nielsen, J. (1994). Enhancing the explanatory power of usability heuristics (pp. 152-158). Proceedings of the SIGCHI Conference on Human Factors in Computing Systems. ACM in Boston, MA.

OECD (2001). [Organisation for Economic Co-operation and Development]. Knowledge management: Learning-by-comparing experiences from private firms and public organisations. [Public Management Service, Public Management Committee]. HRM Working Party meeting Paris, 25-26 June 2001. Summary Record of the High Level Forum held in Copenhagen, 8-9 February 2001. JT00109192.

OECD (2003). [Organisation for Economic Co-operation and Development]. The Learning Government: Introduction and draft results of the survey of knowledge management practices in ministries/departments/agencies of central government. 27th Session of the Public Management Committee; original format, $1-54$.

Okoli, C., \& Schabram, K. (2010). A guide to conducting a systematic literature review of information systems research. Sprouts: Working Papers on Information Systems, 10(26). 
Oracle. (2010). [Oracle Corporation]. Chapter 6: Application Design Principles: Common Desktop Environment: Style Guide and Certification Checklist. Retrieved from https://docs.oracle.com/cd/E19455-01/806-2915/6jc3nftni/index.html.

Orlikowski, W. J., \& Baroudi, J. J. (1991). Studying information technology in organizations: Research approaches and assumptions. Information Systems Research, 2(1), 1-28.

Orlikowski, W. J., \& Robey, D. (1991). Information technology and the structuring of organizations. Information Systems Research, 2(2), 143-169.

Pawlowski, J. M., \& Zimmermann, V. (2007). Open content: a concept for the future of e-learning and knowledge management. Mehr Wissen-mehr Erfolg, 265-274.

Pawlowski, J. M., Pirkkalainen, H., \& Gervacios, J. L. (2013). Contextualization of Open Educational Resources in Asia and Europe. e-ASEM, Collaborative Research, 96-134.

Pawlowski, J. M., \& Richter, T. (2010). A methodology to compare and adapt ELearning in the global context. In M. H. Breitner, F. Lehner, J. Staff, \& U. Winand, U. (Eds.), E-Learning 2010 (pp. 3-13). Berlin [u.a]: Physica-Verl. Retrieved from http://dx.doi.org/10.1007/978-3-7908-2355-4_1.

Peireira, F. A. D. M., Ramos, A. M. S., Gouvêa, M. A., \& da-Costa, M. F. (2015). Satisfaction and continuous use intention of e-learning service in Brazilian public organizations. Computers in Human Behavior, 46(0), 139-148.

Pentland, B. T. (1999). Building Process Theory with Narrative: From Description to Explanation. The Academy of Management Review, 24(4), 711-724.

Pfeffers, K., Tuunanen, T., Rothenberger, M. A., \& Chatterjee, S. (2007). A Design Science Research Methodology for Information Systems Research. Journal of Management Information Systems, 24(3), 45-77.

Pirkkalainen, H., Jokinen, J. P. P., \& Pawlowski, J. M. (2014b). Understanding Social OER Environments - A Quantitative Study on Factors Influencing the Motivation to Share and Collaborate. Learning Technologies, IEEE Transactions, 7(4), 388-400.

Pirkkalainen, H., Jokinen, J., Pawlowski, J., \& Richter, T. (2014a). Overcoming Cultural Distance in Social OER Environments (authors version). In S. Zvacek, R. Restivo, J. Uhomoibhi, \& M. Helfert (Eds.), CSEDU 2014: Proceedings of the 6th International Conference on Computer Supported Education (pp. 1-10). SCITEPRESS-Science and Technology Publications.

Pirkkalainen, H., \& Pawlowski, J. M. (2010). Open educational resources and social software in global e-learning settings. Sosiaalinen Verkkooppiminen. IMDL, Naantali, 23-40. 
Pirkkalainen, H., \& Pawlowski, J. M. (2012). Global Social Knowledge Management: The Future of Knowledge Management Across Borders? (pp. 1-10). Proceedings of the European Conference on Knowledge Management, June 2012, Spain.

Pirkkalainen, H., \& Pawlowski, J. M. (2013). Global Social Knowledge Management: From Barriers to the Selection of Social Tools. Electronic Journal of Knowledge Management, 11(1), 3-17.

Pirkkalainen, H., \& Pawlowski, J. M. (2014). Global social knowledge management-understanding barriers for global workers utilizing social software. Computers in Human Behavior, 30, 637-647.

Pirkkalainen, H., Thalmann, S., Pawlowski, J. M., Bick, M., Holtkamp, P., \& Ha, $\mathrm{K}-\mathrm{H}$. (2010). Internationalization processes for open educational resources. Workshop on Competencies for the Globalization of Information Systems in Knowledge-Intensive Settings, ICSOB.

Prabash, E. (n.d.). Interpretivism and Postivism (Ontological and Epistemological Perspectives). Research Paradigms and Approaches. Retrieved from https:// prabash78.wordpress.com/2012/03/14/interpretivism-andpostivism-ontological-and-epistemological-perspectives/

Prakash, A., Kumar Rajaguru, S., Damjanovic-Behrendt, V., Glachs, D., Strohmeier, F., Pawlowski, J.,...Tobias, E. (2014). Deliverable No. D5.1. OER-LP Design Principles. Retrieved from http:/ / www.eagle-learning.eu/.

Rashman, L., Withers, E., \& Hartley, J. (2009). Organizational learning and knowledge in public service organizations: A systematic review of the literature. International Journal of Management Reviews, 11(4), 463-494.

Richter, T. (2014). Culture-oriented research in information systems research: development of a tool to demarcate cultural-context of research and to elaborate descriptive, contextually suitable cultural models (Kulturorientierte Forschung in der Wirtschaftsinformatik: Entwicklung eines Werkzeugs zur Abgrenzung kultureller Forschungskontexte und zur Ermittlung kontextuell passender Kulturbeschreibungsmodelle) (Unpublished thesis). University of Duisburg-Essen, Germany.

Richter, T., \& Adelsberger, H. (2012). On the myth of a general national culture. Making Specific Cultural Characteristics of Learners in Different Educational Contexts in Germany Visible (pp. 105-120). Proceedings from Cultural Attitudes Towards Communication and Technology 2012. Murdoch University, Murdoch.

Richter, T., \& McPherson, M. (2012). Open educational resources: education for the world? Distance Education, 33(2), 201-219.

Richter, T., \& Pawlowski, J. M. (2007). The need for standardization of context metadata for e-learning environments. Proceedings of the e-ASEM Conference, Seoul, Korea. 
Riege, A. (2005). Three-dozen knowledge-sharing barriers managers must consider. Journal of Knowledge Management, 9(3), 18-35.

Research Methodology. (2017). [RM]. Research Approach. Retrieved from http://research-methodology.net/research-methodology/researchapproach/.

Rosenberg, M. J. (2001). E-learning: Strategies for delivering knowledge in the digital age. New York: McGraw-Hill.

Sampson, D. G., \& Zervas, P. (2011). A Workflow for Learning Objects Lifecycle and Reuse: Towards Evaluating Cost Effective Reuse. Educational Technology \& Society, 14(4), 64-76.

Sannia, M., Ercoli, G., \& Leo, T. (2009). Evaluation of Virtual Learning Environment for the Professional Training in Public Administration. International Journal of Advanced Corporate Learning, 2(1), 50-55.

Schilling, P. (2013). Reflection in politics and leading positions is a success factor for new public management reforms. (Tiefgreifendes Umdenken in Politik und Führungsebene ist ein Erfolgsfaktor der Verwaltungsmodernisierung. Abstraktion und Applikation). In E. Schweighofer, F. Kummer, W., \& Hötzendörfer (Eds.), Tagungsband des 16. Internationalen Rechtsinformatik Symposions. Retrieved from http://www.jusletter-it.eu (Österreichische Computergesellschaft 2013).

Sein, M. K., Henfridsson, O., Purao, S., Rossi, M., \& Lindgren, R. (2011). Action Design Research. Management Information Systems Quarterly, 35(1), 37-56.

Shneiderman, B. (2002). User Interface Design. [Deutsche Ausgabe]. Bonn: MITPVerlag.

Specht, M. (2008). Designing Contextualized Learning. In H. H. Adelsberger, n.n., J. M. Pawlowski, \& D. G. Sampson (Eds.), Handbook on Information Technologies for Education and Training (pp. 101-111). Heidelberg: Springer (International Handbooks on Information Systems).

Stefanick, L., \& LeSage, E. Jr. (2005). Limitations to developing virtual communities in the public sector: a local government case study. Canadian Public Administration, 2, 231-250.

Stoffregen, J., \& Pawlowski, J. (submitted). The Contribution of Agile Open Educational Resources towards Agile Government - an Explorative Study Research Objectives. Submitted to: Special Issue on Agile Government and Adaptive Governance in the Public Sector Governments, Government Information Quarterly.

Stoffregen, J., \& Pawlowski, J. (under review). Theorising about Barriers to Open E-Learning Systems in Public Administrations. Technological Forecasting and Social Change. 
Stoffregen, J., Pawlowski, J. M., \& Pirkkalainen, H. (2015a). A Barrier Framework for open E-Learning in public administrations. Computers in Human Behavior, 51, 674-684.

Stoffregen, J., Pawlowski, J. M., Ras, E., Scepanovic, S., \& Zugic, D. (2016b). Identifying Socio-Cultural Factors That Impact the Use of Open Educational Resources in Local Public Administrations. International Journal of Management, Knowledge and Learning, 5(2), 167-187.

Stoffregen, J., Pawlowski, J. M., Ras, E., Tobias, E., Šćepanović, S., Fitzpatrick, D.,...Moebs, S. (2016a). Barriers to open e-learning in public administrations: A comparative case study of the European countries Luxembourg, Germany, Montenegro and Ireland. Technological Forecasting and Social Change, 111, 198-208.

Stoffregen, J., Pawlowski, J., Moebs, S., Traxler, J., Guerra-Correa, V., \& Prakash, A. (2016c). Design for Collaborative Contextualization of Open Educational Resources. In V. Nissen, D. Stelzer, S. Straßburger, \& D. Fischer (Eds.), Multikonferenz Wirtschaftsinformatik (MKWI) 2016, 1' edition (pp. 591-602). Ilmenau: Univ.-Verl. Ilmenau.

Stoffregen, J., Pawlowski, J. M., Ras, E., Tobias, E., Friedrich, H., Schilling, P.,...Mehigan, T. (2015c). Deliverable No. D2.2.A. Requirements documentation and recommendations with Accessibility Guidelines. Retrieved from http://www.eagle-learning.eu/.

Stoffregen, J., Pawlowski, J. M., Ras, E., Tobias, E., \& Scepanovic, S. (2015b). Deliverable D7.1. Cultural Model Design and Contextualization Processes. Retrieved from http:/ / www.eagle-learning.eu/.

Strauss, A., \& Corbin, J. (1998). Grounded Theory Methodology. An Overview. In N. K. Denzin, \& Y. S. Lincoln (Eds.), Handbook of qualitative research (pp. 273-285). Thousand Oaks, CA: Sage Publications.

Stubbs, M., Martin, I., \& Endlar, L. (2006). The structuration of blended learning: putting holistic design principles into practice. British Journal of Educational Technology, 37(2), 163-175.

Swinke, T. (2012). A unique, culture-aware, personalized learning environment (pp. 1-7). Proceedings from the 15th International Conference on Interactive Collaborative Learning (ICL). Austria.

Talbot, J. (2009). Delivering Distance Education For The Civil Service In The Uk: The University of Chester's Foundation for Government programme. In S. Marshall, W. Kinuthia, \& W. Taylor, W. (Eds.), Bridging the knowledge divide: Educational technology for development (pp. 77-96). Charlotte, NC: Information Age Publishing. Note: Authors version.

Tapanes, M. A. (2011). Revision and Validation of a Culturally-Adapted Online Instructional Module Using Edmundson's CAP Model: A DBR Study. Retrieved from http://scholarcommons.usf.edu/etd/3376. 
Trochim, W. M. K. (1989). Outcome pattern matching and program theory. Evaluation and Program Planning, 12(4), 355-366.

United Nations Educational, Scientific and Cultural Organization. 2002. Forum on the Impact of Open Courseware for Higher Education in Developing Countries. Final Report. (CI-2002/CONF.803/CLD.1).

United Nations Educational, Scientific and Cultural Organization. 2012. Paris OER Declaration. World OER Congress, Paris, June 2012.

Van de Ven, A. H. (2007). Engaged scholarship: a guide for organizational and social research: a guide for organizational and social research. Oxford: University Press.

Van de Ven, A. H., \& Poole, M. S. (2005). Alternative approaches for studying organizational change. Organization Studies, 26(9), 1377-1404.

Venkatesh, V., Brown, S. A., \& Bala, H. (2013). Bridging the qualitativequantitative divide: Guidelines for conducting mixed methods research in information systems. Management Information Systems Quarterly, 37(1), 2154 .

Vukovic, B., \& Martin, C. (2009). Free and Open Source Software (FOSS) and OER. Part I - An introductory note. In S. D'Antoni, \& C. Savage (Eds.), Open educational resources: conversations in cyberspace (pp. 105-124). Paris: United Nations Educational, Scientific and Cultural Organization.

Webster, J., \& Watson, R. (2002). Analyzing the past to prepare for the future: Writing a literature review. Management Information Systems Quarterly, 26(2), xiii-xxiii.

Wild, R. H., Griggs, K. A., \& Downing, T. (2002). A framework for e - learning as a tool for knowledge management. Industrial Management and Data Systems, 102(7), 371-380.

Williams, R., \& Edge, D. (1996). The social shaping of technology. Research Poli$c y, 6,865-899$.

Wohlers, T. E. (2009). The Digital World of Local Government: A Comparative Analysis of the United States and Germany. Journal of Information Technology and Politics, 6(2), 111-126.

Yin, R. K. (2014). Case study research: Design and methods. Thousand Oaks, CA: Sage Publications.

Yunus, Y., \& Salim, J. (2008). Framework for the evaluation of e-learning in Malaysian Public Sector from the pedagogical perspective. IEEE, International Symposion on Information Technology, 3, 1-8. 


\section{ORIGINAL PAPERS}

A Barrier Framework for open E-Learning in public administrations.

by

Stoffregen, J., Pawlowski, J. M., \& Pirkkalainen, H., 2015

Computers in Human Behavior vol 51, 674-684.

Reproduced with kind permission by Elsevier. 


\title{
A Barrier Framework for open E-Learning in public administrations
}

\author{
Julia Stoffregen $^{\mathrm{a}, *}$, Jan M. Pawlowski ${ }^{a}$, Henri Pirkkalainen ${ }^{\mathrm{b}}$
}

${ }^{a}$ Ruhr West University of Applied Sciences, Germany

${ }^{\mathrm{b}}$ University of Jyväskylä, Finland

\section{A R T I C L E I N F O}

Article history:

Available online 12 January 2015

\section{Keywords:}

Open education

Open Educational Resources

E-Learning

Public Administrations

\begin{abstract}
A B S T R A C T
E-Learning and openness in education are receiving ever increasing attention in businesses as well as in academia. However, these practices have only to small extent been introduced in public administrations. The study addresses this gap by presenting a literature review on Open Educational Resources [OER] and $\mathrm{E}$-Learning in the public sector. The main goal of the article is to identify challenges to open E-Learning in public administrations. Experiences will be conceptualized as barriers which need to be considered when introducing open E-Learning systems and programs in administrations. The main outcome is a systematic review of lessons learned, presented as a contextualized Barrier Framework which is suitable to analyze requirements when introducing E-Learning and OER in public administrations.
\end{abstract}

(c) 2014 Elsevier Ltd. All rights reserved.

\section{Introduction}

E-Learning is a domain which covers the integration of Information and Communication Technology (ICT) in educational environments (e.g. Guri-Rosenblit, 2006). The wide spread take-up of ICT, the coverage and resulting access to the Internet, have enabled the convergence of E-Learning to daily practices of educational institutions (Bates, 2005). E-Learning is often connected or used interchangeably with Technology Enhanced Learning [TEL], distance, online or virtual learning environments (Guri-Rosenblit, 2006) and has been mainly researched in the context of schools and higher education. The digitalization of educational resources and learning materials has enabled the re-use of these resources across countries and scholarly domains (Richter \& McPherson, 2012). Such re-use has also enabled the emergence of different forms of collaborative learning and authorship of teaching resources (Pirkkalainen \& Pawlowski, 2014b). A related concept in this respect is Open Educational Resources [OER]: contents, information and learning resources are shared to enhance knowledge and create new resources collaboratively via technological means (e.g. D’Antoni, 2009).

Also in the public sector, there is an increasing need and interest to create, enhance and share knowledge (OECD, 2001, 2003). In times of the knowledge society and on-going digitization of administrations, it is therefore surprising that collaborative E-Learning and the role of OER seem to have been neglected. Associated to

\footnotetext{
* Corresponding author.

E-mail addresses: j.stoffregen@hs-ruhrwest.de (J. Stoffregen), jan.pawlowski@hs-ruhrwest.de (J.M. Pawlowski), henri.j.pirkkalainen@jyu.fi (H. Pirkkalainen).

e-Government or knowledge management reforms, E-Learning has already been introduced in few administrations (Yunus \& Salim, 2008; e.g. Bere, Silvestri, \& Nemeş, 2014; Chen, 2014). Only few cases indicate, however, that learning and knowledge resources have become 'open', meaning that they are collaboratively developed, re-used or shared (cf. Hilton, Wiley, Stein, \& Johnson, 2010). Furthermore, no concept has been developed in the studies, which systematically captures insights and experienced challenges of the phenomenon.

Why did open E-Learning gain only marginal attention in the public sector? This question inspires our inquiry. It is salient to explore:

(1) What is the status of (open) E-Learning in public administrations from research and practice perspectives?

(2) Which barriers have been found when introducing and implementing E-Learning?

Answering these questions will enhance the understanding of the challenges in the implementation processes of E-Learning and OER. Due to the limited number of studies in the public sector, the review will further contribute to close the research gap and systemize experiences on the development and use of open E-Learning (cf. Yunus \& Salim, 2008). To systemize findings of the literature review, this study extends the Barrier Framework [BF] for E- and OER learning (Pirkkalainen \& Pawlowski, 2014a) and will thus derive at a contextualized Barrier Framework [cBF] for public administrations. Not to anticipate findings, the cBF will consist of three dimensions (context/organizational, individual, technical barriers) and will address to more than forty challenges to consider in the domain. 
The paper is structured as follows. In a first step, the background literature and concepts of open E-Learning will be reviewed. In a second step, studies on barriers to E-Learning in related domains will be explained. Building upon this background, the method for answering the research questions (systematic literature review) will be defined. In the end, the findings and implications for future research on open, collaborative E-Learning systems in the public sector will be discussed.

\section{Background literature and concepts}

\subsection{Open E-Learning in public administrations?}

Efficient learning and knowledge management concepts are necessary as part of Lifelong Learning for individual and organizational spaces (Punie, 2007). In this respect, not only the private but also the public sector is required to increase performance and implement organizational learning and knowledge management practices (Langford \& Seaborne, 2003; OECD, 2001; Rashman, Withers, \& Hartley, 2009).

To cope with this situation, several European countries like Italy or Romania, as well as Canada (Stefanick \& LeSage, 2005) and Brazil (e.g. Bere et al., 2014) have introduced E-Learning solutions for public administrations. In some cases, E-Learning is considered as a relevant program to learn at the workplace and to attract employees (Langford \& Seaborne, 2003). Virtual learning environments are promoted to suit the learning needs of the public sector which is shaped by changing contents and dynamic knowledge (Conci \& Bramati, 2007; Talbot, 2009). E-Learning is even argued to be more flexible regarding individual preferences and time to spend for learning (Bere, Silvestri, \& Nemeş, 2013). Thus, it is less inclined to interrupt civil servants from work (Hârţescu, 2012; Talbot, 2009). In some cases, E-Learning is seen as an enabler for the inclusion of geographically dispersed learners; for instance, when training programs address to a range of distant municipalities (Colazzo, Molinari, \& Villa, 2009).

Yet, E-Learning is not solely implemented to meet preferences and learning needs of civil servants. One platform developed by the World Bank (Blindenbacher \& Nashat, 2010) aims to facilitate collaboration in the area of public-private partnership and infrastructure projects. Other E-Learning solutions are developed on a domestic level for economic means. E-Learning is often assumed to provide a quick and cost efficient solution to increase performance in the sector (Langford \& Seaborne, 2003; Yunus \& Salim, 2008). Technology enhanced learning may increase digital competences and raise competitive advantages in terms of efficiency and quality of service provision, for example (Bere et al., 2013, 2014; Conci \& Bramati, 2007; Hârţescu, 2012; Langford \& Seaborne, 2003; Sannia, Ercoli, \& Leo, 2009). Following Langford and Seaborne (2003, p. 52), however, these promises on E-Learning tend to be accepted without a thorough assessment. So which lessons can be learned and what has been achieved in view of the above outlined objectives?

Summarizing the studies, most initiatives apart Chen (2014) have established blended E-Learning programs. Hence, E-Learning in the public sector tends to result in a combination of online sessions (or providing digital learning resources) and face to face classes, while putting emphasis on the later scenario and guided tutoring (Conci \& Bramati, 2007; Langford \& Seaborne, 2003).

Study results reflect on the range of evolving artifacts and programs. Often projects start off with few resources like online guides for e-Government portals and manuals for specific administrative procedures (Conci \& Bramati, 2007). Over time, the platforms offer textual e-resources such as case studies and linked data, as well as interactive forums and online tests. Face to face seminars, in contrast, cover practical sessions like role playing (Bere et al., 2014; Blindenbacher \& Nashat, 2010). Interestingly, similarities regarding the provided subject courses can be found. In most initiatives, language and ethics courses are offered online. Furthermore, learning contents cover soft skills, management and strategy issues as well as emergency procedures (Bere et al. 2013, 2014; Conci \& Bramati, 2007; Langford \& Seaborne, 2003; Sannia et al., 2009; Talbot, 2009).

Though reporting on the range of courses, few cases specify on the kind of mediating technologies (see Blindenbacher \& Nashat 2010; Butler, Feller, Pope, Emerson, \& Murphy, 2008; Conci \& Bramati, 2007). Correspondingly, the use of social media and collaboration tools like wikis is weakly reflected. Blindenbacher and Nashat (2010, p. 154) promote that the World Bank initiative is the first to integrate social media in training efforts. Given the vague elaboration on technologies, however, the role of collaboration tools and social networks is unclear. In addition to that, one can only infer how far evolving solutions refer to 'Open Educational Resources'. According Hilton et al. (2010), 'openness' of OER can be defined by the use of open source solutions which facilitate to share and collaborate on educational resources. ${ }^{1}$ Another criterion is the choice of design principles which enable to re-use, re-distribute, revise and remix OER (cf. Hilton et al., 2010). These criteria are not mutually exclusive (cf. Lane, 2010; McGrath, 2008) and can both be perceived in the public sector. In cases from Argentina, open source applications are developed (cf. Bere et al., 2014) and in cases from Italy, learning resources are not only open source but can be created both individually or through collaboration without restriction or fees (Colazzo et al., 2009; Conci \& Bramati, 2007).

Overall, these aspects shed some light on E-Learning projects in the public sector. Still, most authors concentrate on their cases and particular aspects. In addition to a focused elaboration, experiences made are resumed on a high level. Conci and Bramati (2007. p. 84), for instance, conclude that participants have gained a deeper understanding of the creation and management phases of an E-Learning system. Yet, authors neglect to illustrate the nature of the (managerial) use of the systems more precisely. A step towards capturing challenges of E-Learning in a comparative way can be found in Bere et al. (2014). Authors assess E-Learning systems, courses, methodologies and potential challenges in Brazil, Romania, Italy, Argentina and USA. Unfortunately, authors neither compare nor synthesize the findings. As a result, also their recommendations remain on a high level.

Another, more detailed study of challenges is made by Eidson (2009). She focuses on a single training center and elaborates in a qualitative approach on challenges and how civil servants perceive E-Learning (Eidson, 2009, p. 152f.). Another study to highlight is by Colazzo et al. (2009) who reflect on their experiences as developers. This study sheds some light on difficulties when transferring a Learning Management System from academic to administrative contexts. Interestingly, authors indicate that the adaptation covers not only the interface but the functionality of the system as well as metaphors and practices among developers (Bere et al., 2013; Langford \& Seaborne, 2003). But whether (and which) particular challenges and adaptations are unique to the administrative context remains unexplained.

Based on the scoping of studies above, it appears that challenges are hardly captured and systematically assessed. Exceptions are Chen (2014) and Eidson (2009); or some studies on pedagogical design of E-Learning platforms (e.g. Sannia et al., 2009). The latter, however, miss to consider potential challenging factors or lessons learned (cf. Sannia et al., 2009; Yunus \& Salim, 2008). Insight on

${ }^{1}$ Open source means the code and documentation of educational technologies is released and can be amended individually (Koper, 2008). 
practices and experiences gained in the development, implementation or use of open E-Learning-systems remains vague (cf. Yunus \& Salim, 2008). In view of this problematic, a systematic review and analysis of barriers in the administrative sphere is needed to enhance research on open E-Learning in the public sector. The
understanding, whether and which barriers in socio-cultural contexts shape the transfer of E-Learning systems, could be enhanced. A thorough literature review would also focus on practices and concepts surrounding E-Learning activities in the public sector. Indeed, only few authors categorize E-Learning in conceptual terms like Langford and Seaborne (2003, p. 53). In this vein, the research interest (to perceive what is the status of (open) E-Learning in public administrations) requires to reflect which underlying theoretical concepts shape the approaches and related domains so far. Thereby, implications of referenced concepts for the forthcoming review will be defined.

\subsection{Concepts and barrier studies in related domains}

In the following, we briefly discuss studies which are conceptually related to barrier studies (including e-Government cases) and need to be taken into account. One extensive study which provides a descriptive and statistical analysis of E-Learning challenges in public administrations is made by Chen (2014). The analysis orients on the diffusion of innovation model (Chen (2014) referring to Rogers (1995)) which measures the influence of perceived effectiveness, prior conditions, attitudes and perceived characteristics of E-Learning on (E-Learning) practices (Chen, 2014, pp. 454456). Despite defining influencing factors, like the ease of use, recognition of employees and friends, however, factors are resumed only on a compound level (cf. Chen, 2014, p. 459). Furthermore, the study neglects managerial and policy aspects and thus provides no specific concept to capture challenges in this respect. Interestingly, considerations about managerial and policy barriers are not covered in the notable study of Eidson (2009) either. The study orients upon a framework from the educational context ${ }^{2}$ and sheds light on barriers in the dimensions work environment, personal characteristics, aspects of online course designs and technology in the public sector.

Apart from these more elaborated studies in the public sector, the above discussed cases tend to align the introduction of ELearning to recent reforms such as e-Government and knowledge management [KM] (cf. Amayah, 2013; OECD, 2003; Talbot, 2009; Yunus \& Salim, 2008). In these domains, general conceptual guidance to elaborate on the new phenomenon could be found. For example, Ebrahim and Irani (2005) proposed a framework for eGovernment adoption that elaborates on barriers to implementation processes of information and knowledge management systems. The authors provide a comprehensive e-Government architecture sketch and match different technologies and applications to administrative processes and layers (Ebrahim \& Irani, 2005, pp. 596-600). Potential challenges are discussed in the categories IT infrastructure, security privacy, IT skills, organizational issues and costs (Ebrahim \& Irani, 2005, pp. 601-606). Unfortunately, barriers are detached from the architecture layers so whether a technical artifact evokes particular challenges remains open for discussion. Furthermore, the elaboration of barriers focuses more on technical but socio-cultural aspects such as collaboration and sharing cultures. The meaning of culture is not defined; yet, it appears to be associated to strategic management of change, and to authority and power (Ebrahim \& Irani, 2005). For example, the findings point out that the sharing of data as well

${ }^{2}$ Framework: situational, institutional, dispositional, epistemological, technological categories (Eidson, 2009). as collaboration among departments can be shaped by organizational culture (Ebrahim \& Irani, 2005, p. 605).

A more thorough elaboration on the role of culture in e-Government can be followed in Margetts and Dunleavy (2002). The authors match selected values like uniformity of administration to cultural myth models (Margetts \& Dunleavy (2002, p.2.) citing Thompson et al. (1990)). Interestingly, collaboration or interaction online is perceived rather between public employees and customers (Margetts \& Dunleavy, 2002, p. 1). Hence, the study emphasizes the importance of cultural barriers but is focused on a supply and demand perspective.

Apart from recent reforms, studies associate E-Learning strategies to KM strategies (e.g. Conci \& Bramati, 2007). In the public administration field, several reviews have been conducted to answer how and which concepts from the private sector and field of information systems have been received (e.g. Kennedy \& Burford, 2013). Findings emphasized that a wide range of theoretical concepts and paradigms has been taken up (cf. Alavi \& Leidner, 2001; Baskerville \& Dulipovici, 2006; Kennedy \& Burford, 2013: Rashman et al., 2009). ${ }^{3}$ However, authors find that taking up new approaches to KM lags behind: Knowledge in public sector studies is often perceived as a static, tangible resource (Ferguson, Burford, \& Kennedy, 2013, 175f.). Kennedy and Burford (2013) support this point with regard to learning conceptions and knowledge ${ }^{4}$ and Rashman et al. $(2009)^{5}$ for organizational learning concepts in the public sector. Maybe as a corollary, several advanced KM- and organizational learning concepts appear to be neglected in the study of open and collaborative E-Learning systems.

One study which could enrich considerations in this respect can be found in Chatti, Schroeder, and Jarke (2012) ${ }^{6}$ The authors elaborate on the convergence of E-Learning and KM activities as 'two sides of the same coin' (Chatti et al., 2012, pp. 181-186) and put emphasis the role of interpersonal collaboration. New learning environments including the integration of social networks will be crucial for forthcoming trends in collaborative E-Learning. Another approach to capture knowledge sharing barriers is developed by Riege (2005). He summarizes barriers on the individual, organizational and technical level (Riege, 2005, pp. 23-29). The list was derived in order to facilitate a structured review of studies with similar goals. However, the author directs attention to the point that barriers and managerial strategies may differ across different research contexts such as the private and public sector (Riege, 2005, p. 31).

The forthcoming analysis will take care about previous studies as well as Riege's (2005) note about conducting barrier studies. An initial response at this point is the Barrier Framework by Pirkkalainen and Pawlowski (2013, 2014a). The concept has been proposed as an alternative to focused domain approaches. The BF integrates various research contexts and summarizes challenges in the development and use of OER and E-Learning on various dimensions. To elaborate the background and recent streams of E-Learning apart from the public sector, the following section will sketch developments and recent studies in the E-Learning domain.

\footnotetext{
${ }^{3}$ Kennedy and Burford (2013, p. 164) have found no reference for the category knowledge creation and development in public sector literature.

${ }^{4}$ Aspects cover: organizational learning, -knowledge, knowledge transfer, -sharing -creation (Kennedy \& Burford, 2013, p. 165).

${ }^{5}$ Aspects cover: organizational learning, -knowledge, a definition of organization; a focus on the locus of learning, for example, as groups, individual, or networks (Rashman et al., 2009, pp. 472ff.).

(Rashman et al., 2009, pp. 472ff.). nont maturity.
} 


\subsection{Barriers to the development and use of open E-Learning}

In the field of information systems, studies on E-Learning initially concentrated on the development and use of systems and resources in the educational context. Apart from learning and content management systems, the role and development of web 2.0 applications like wikis, blogs or podcasts have gained relevance as well (Chatti et al, 2012). In this context, the role of Open Educational Resources (OER) is an emerging research focus. Given a higher reach of resources to learners, open E-Learning reflects the aim to make educational resources accessible on a global scale (D'Antoni, 2009; Koper, 2008; Pawlowski, Pirkkalainen, Gervacios, Nordin, \& Embi, 2013). Digital resources can be shared, re-used and collaboratively created across different countries and cultures (Laurillard, 2008; Pawlowski et al., 2013).

Yet, the contextualization of OER has raised concerns. The adaptation of open E-Learning systems for local contexts has often failed so resources are not used in many projects (Pawlowski et al. 2013; Specht, 2008). Open E-Learning Resources are not meaningful to learners if the digital learning objects and practices fail to embody socio-cultural characteristics (Chatti et al., 2012; Richter \& McPherson, 2012). Correspondingly, research efforts are directed to define how socio-cultural contexts influence the use and development of open E-Learning systems and resources (cf. Henderson, 2007; Richter \& Adelsberger, 2012).

In this context, Pirkkalainen and Pawlowski (2013, p. 5) proposed a Barrier Framework (BF) to provide guidance to alleviate barriers and challenges in the development and contextualization of open E-Learning systems. More precisely, the BF was derived through studies on difficulties which appear in the conduct, development or implementation of virtual learning systems, global collaboration - or knowledge management systems (Pirkkalainen \& Pawlowski, 2013, 2014a). To illustrate the challenges which appear in a range of contexts: organizational obstacles may be a lack of policy regulations or a poor technical fit of systems to workplaces which impede the implementation of learning environments (Pirkkalainen \& Pawlowski, 2014a: Pirkkalainen \& Pawlowski, 2014b, pp. 640f.). Technical barriers can include the interoperability among technical infrastructures (Pirkkalainen \& Pawlowski, 2014a, pp. 642, 644). On the social level, the lack of digital skills often impedes the adoption of open E-Learning. To establish collaborative learning environments also a lack of corporate incentives may be a barrier to the exchange of knowledge (Pirkkalainen \& Pawlowski, 2014a, p. 642). Moreover, cultural barriers such as perceived social distance can impede the interaction between colleagues or learners in distributed teamwork (Pirkkalainen \& Pawlowski, 2014a, p. 642).

So far, a review of studies and challenges to open E-Learningsystems in public administrations has been provided as well as a background of studies in related domains and the field of information systems. In view of the range of approaches, the Barrier Framework appears as the most conclusive conceptual frame. Based on an extensive literature review, the BF subsumes the findings of studies in related domains discussed in the previous chapter. Indeed, the BF was proposed to guide to a systemized approach to explore challenges of open, collaborative E-Learning across several domains. Given the comprehensive documentation of experienced barriers, the $\mathrm{BF}$ directs attention to the scope of potential problems. This is an important feature to sensitize exploratory research in unfamiliar contexts (Richter, 2014), such as the public sector. In this respect, it will be considered in the methodological chapter, how build upon and extend the BF to answer the research question of this study in a structured and systemized manner.

\section{Methodology: designing a Barrier Framework for the public} administration context

\subsection{Research logic and approach}

Following the initial review, what is the status of (open) E-Learning in public administrations from research and practice perspectives, the research question for the following analysis is: "Which barriers have been found when introducing and implementing E-Learning?" The research question will be answered by a systematic literature review (Webster \& Watson, 2002). The focus of analysis is experiences revolving around the development use and design of open E-Learning [OER and E-Learning] in the public sector. The goal is to systemize experiences and lessons learned in the domain as barriers, whereby the analysis will orient upon and adapt the Barrier Framework (Pirkkalainen \& Pawlowski, 2014a). We define open E-Learning as 'any ICT supported learning, education or training processes making use of OER' and OER as 'any digital object which can be freely accessed, modified and (re-)used for these purposes' (adapted from Pirkkalainen \& Pawlowski, 2010, 23f.)

In line with the goals of the study, to explore the barriers to open and collaborative E-Learning in public administrations on the one hand and to provide for a systematic approach on behalf of the Barrier Framework (Pirkkalainen \& Pawlowski, 2014a) on the other hand, the research logic follows an abductive approach (Blaikie, 2010, pp. 89-92). Hence, the original BF dimensions provide a frame to sensitize the review of the literature. Novel or alternative findings will lead to adapt the original dimensions and thus to develop a contextualized Barrier Framework. Further considerations on this point will be discussed subsequently.

\subsection{Crafting the basis for adapting the Barrier Framework}

The choice of a concept for orientation can be justified if the frame contributes to guide and systemize the inquiry of a nove phenomenon (cf. Frank, 2006, p. 52). The units of analysis should be abstract and cover a wide range of instances (Frank, 2006, p. 52). The related scales, dimensions and implications should appear adaptable in a first view (Richter, 2014, p. 148). The unit of analysis in the BF are barriers, which are not limited to a particular focus but include 'any challenges in the diffusion and appropriation process of technologies' (Pirkkalainen \& Pawlowski, 2013, p. 5). While the range of barriers allows for a detailed and systemized review the dimensions enable to categorise barriers on a more abstract level. The dimensions cover four perspectives: The organizational and contextual dimension covers obstacles in the more current environment, situations and tasks in the workplace (cf. Evaristo, 2007 p.208). The social dimension covers individual and group related challenges (Pirkkalainen \& Pawlowski, 2014a, p. 642). The technical dimension embraces difficulties related to technical artifacts and their characteristics (Pirkkalainen \& Pawlowski, 2014a, pp. 642 644). The cultural dimension covers barriers which relate to particular characteristics of the workforce. With hindsight to scoped experiences in the public sector, do the dimensions of the $\mathrm{BF}$ appear to be adaptable? Barriers such as the lack of time to learn (cf. Butler et al., 2008, p. 88; Pirkkalainen \& Pawlowski, 2014a, p. 641) as well as more elaborated categories in the study of Eidson can be subsumed (cf. category 'technological/technology barrier' in Eidson, 2009, p. 179f., and 'technical dimension' in Pirkkalainen \& Pawlowski, 2014a, p. 644). In a first view, the BF thus seems to be a suitable frame for the research aim.

To evaluate the quality of the evolving contextualized Barrier Framework (as well as the choice to orient on the BF respectively) the results of the study can be compared to similar abstract studies 
in the field (cf. Frank, 2006, p. 55). Furthermore, the contextualized $\mathrm{BF}$ needs to be discussed with regard to critique about previous studies in the last chapter. For the original Barrier Framework these considerations can be reviewed Pirkkalainen and Pawlowski (2014a). In this study, the considerations will be taken up in the discussion again. Following the outline of our analytical logic and approach, the study design for the systematic literature review will be defined.

\subsection{Study design of the systematic literature review}

Conducting a complete literature review requires that several points are defined and reported. They include the boundaries of topical themes, choice and characteristics of selected journals, conduct and keywords of the search, characteristics of the sampled outcome and selection of articles (Webster \& Watson, 2002, p. xvf.). In this study, mainly western and English speaking journals have been selected like journals from the Senior Scholar Basket in Information Systems. ${ }^{7}$ The selection of journals for public administration was oriented on the impact factor (2012) as well as on a recent review of public administration journals (Van de Walle \& Van Delft, 2014). ${ }^{8}$ The initial keywords of the literature search were: E(-)Learning, online learning, OER, and open educational resource respectively which resulted in zero findings. Therefore, the review was systematically extended to the combinations: learning AND public administration/organis(z)ation; training AND public administration/organis(z)ation; open resource AND public administration/ (organis(z)ation); as well as the term 'learning Government'. Keywords were searched in the title, abstract and text wherefore further selection criteria were needed to delimit the scope of retrieved papers. Screening the title, abstract and initial body of findings, papers were selected if they address the use technology and social software in training, professional advancement, and learning activities at least in parts of the paper.

To complete the review (given the dispersed nature of literature (on E-Learning) in the public sector (see Rashman et al., 2009)) the initially presented literature has been reviewed for further references. In this manner, thirty articles from selected journals were integrated for the analysis. They embrace both qualitative and quantitative studies and experiences from various countries and administrations.

Having the sample at hand, the structured review has been conducted, focusing on barriers as the units of analysis (cf. Webster \& Watson, 2002, p. xvii). Outlined in the previous section, the synthesis of findings was oriented on the Barrier Framework (Pirkkalainen \& Pawlowski, 2014a). As will be discussed, some findings in the literature review went beyond the original BF and demanded the adaptation of initial dimensions.

Concerning the analysis, it is important to note that caution was taken to capture experienced barriers in studies. In presenting and discussing results of studies in the public sector, however, authors often included findings from private sector literature to support or align findings (cf. Rashman et al., 2009). For being able to integrate results, some findings were therefore noted as 'demanded' or 'assumed' challenges in a detailed table of analysis (available on demand). Another difficulty to note was that studies converted

${ }^{7}$ See http://www.aisnet.org/?SeniorScholarBasket.

8 Journals, a star outlines articles were chosen from: *European Journal of Information Systems, Information Systems Journal, Information Systems research, Journal of AIS, Journal of Information Technology. Journal of MIS, *Journal of Strategic Information Systems, MIS Quarterly: and for public administrations: "Journal of Public Administration Research and Theory, *Journal of European Public Policy. Journal of Policy Analysis and Management, Governance, Journal of Social Policy, Journal of European Social Policy, Environment and Planning (C), Transforming Government, *Public Administration Review, *Journal of Information Technology and Politics, International Public Management Journal. challenges into recommendations and success-factors (similarly noted in Kennedy \& Burford, 2013). For being able to integrate and synthesize results as 'barriers' it was decided that success factors which responded to experienced difficulties were integrated into the contextualized Barrier Framework while general recommendations were tried to be separated.

The following chapter will now present the findings of the review and analysis to answer which barriers were found in the introduction and implementation of open E-Learning in the public sector.

\section{Results of the review: contextualizing the Barrier Framework}

\subsection{Associated concepts}

Several barriers have been found in the introduction and development open E-Learning-systems and associated studies in the public sector. During the review no new, overarching concept to systemize the findings across papers has been found. For example, Kang, Kim, and Chang (2008) distinguish between organizational and individual aspects and characteristics of knowledge. Gil-Garcia, Chengalur-Smith, and Duchessi (2007) differ between technical, organizational, political and legal aspects. Apart from Yang and Maxwell (2011), however, who differ between interpersonal, -organizational, and intra-organizational challenges, the categories defined in studies were not used to aggregate findings into clusters or dimensions.

A further point to outline is the use of 'culture' in the studies. Culture has often been outlined as critical factor (e.g. OECD, 2003 ) but the construct is hardly defined. Stefanick and LeSage (2005, p. 247) outline that anonymity, neutrality and occupational principles are constraining the use of virtual platforms. Otherwise findings remain on a high level, like the idea that learning is facilitated when the global culture is right (Sannia et al., 2009). Related to conceptual vagueness, there are conflicting conceptions about context, structure and culture. Phang, Kankanhalli, and Ang (2008) define culture as the 'context for organizational change'. Yang and Maxwell (2011) differ between context (as structure) and culture but find that factors of both dimensions are intertwined. Moreover, there are differences in the nature of cultural influence. While the OECD (2003) conceives culture as a factor which influences implemented programs, Schout (2009) and De Angelis (2013) see culture or cultural change rather as an outcome.

Overall, the review of selected articles has not unveiled a conflicting or competing concept to the Barrier Framework. Instead, the conceptual ambiguity and variance of factors underscores the importance to explore and further systemize research in this domain. In this regard, the initial construct of the Barrier Framework was maintained for orientation in the analytical phase while it was revised once the review was completed. The outcome is a contextualized Barrier Framework which is clustered in the three dimensions. They cover contextual/organizational, social and technical perspectives while cultural aspects were merged into these categories. In the following, the findings will be presented and described.

\subsection{Dimension 1: context barriers}

From the organizational perspective, one barrier category which poses a major challenge is the lack of resources to realize projects (E-Learning). One subcategory is the lack of finances which can lead to an unconscious orientation upon E-Learning as a "cost effective solution' though required investments may actually be high (Langford \& Seaborne, 2003). Also, a lack of budget can impede the realization because investments are delayed (Gil-Garcia et al, 
2007). Another subcategory of the lack of resources in E-Learning is the lack of time. Since employees have a high workload, they face difficulties to conduct learning sessions during work (Hazlett, Mcadam, \& Beggs, 2008; Langford \& Seaborne, 2003). Correspondingly, dedicated time is needed to avoid that learning activities are transferred to the home space (Eidson, 2009). A further subcategory regarding resources refers to the lack of personnel due to retirement (OECD, 2001) and/or staff rotation (Ferguson et al., 2013). This appears to be interrelated with the fear to lose knowledge, if it is not (digitally) captured and shared (Butler et al., 2008). Finally, the lack of resources has been found with regard to a lack of (educational) contents (Sannia et al., 2009; Schweik, Mergel, Sandfort, \& Zhao, 2011). Projects often start off with a limited base of digitized, educational materials (Langford \& Seaborne, 2003). Sustaining this problematic is that potential existing E-Learning platforms do not offer resources in the right language (Bere et al., 2013).

A second category of barriers from an organizational perspective is the managerial coordination on a policy level. This barrier embraces the lack of regulatory frameworks for collaboration with other organizations (Hazlett et al., 2008; OECD, 2001) as well as the lack of coordinated implementation (Gil-Garcia et al., 2007). For example, deadlines or agreements on intermediate steps are neither made and held (Langford \& Seaborne, 2003; Mahler, 1997) nor is adequate time granted to realize the goals (Gil-Garcia et al., 2007). Another subcategory of barriers that several studies have pointed to is the lack of systemized training offers. To establish systemized training practices can require a corresponding regulatory framework which is often not provided (Hazlett et al., 2008; Kang et al., 2008). Closely related to that, another subcategory of barriers that studies have outlined is the lack of policy for providing rewards and incentives. The policies either give employees the right to share knowledge (Langford \& Seaborne, 2003; Sannia et al., 2009) or may perform as an enabling and motivating factor (Bere et al., 2013; Kang et al., 2008).

A third category of barriers summarizes aspects of managerial culture. Compared to barriers of managerial (policy) coordination, this category relates to established practices and enacted (administrative) structures. For example, the hierarchy in administrations is one subcategory which includes bureaucratic processes. Both aspects appear to impede learning processes and the sharing of knowledge (Hazlett et al., 2008; OECD, 2003; Yang \& Maxwell, 2011). A further, major barrier which was outlined in this respect is the lack of leadership in the public sector. The implementation phase of initiatives appears to be challenged by a lack of senior support (Askim, Johnsen, \& Christophersen, 2008; Gil-Garcia et al., 2007; OECD, 2001, 2003). Later, a lack of assigned responsibilities to organize learning programs is an important barrier to consider (Hazlett et al., 2008) including a lack of tutors on the established platforms (Langford \& Seaborne, 2003; Sannia et al., 2009).

A fourth category is the perceived technological fit of evolving technical systems. One barrier to E-Learning in this respect is the concern about sustainability of technological artefacts. Most authors describe sustainability of technology as a requirement in the public sector (Bere et al., 2013; Colazzo et al., 2009). This requirement may be related to bad experiences (where externals 'came, build and left' (Stefanick \& LeSage, 2005, p. 247)), which now impede to devote resources and commitment to new systems (Stefanick \& LeSage, 2005). Another subcategory in terms of technological fit that authors have found is the lack of evidence-based success of E-Learning systems. Generally, the outcome and benefit of E-Learning is difficult to measure (Langford \& Seaborne, 2003). In the public sector, however, there is a requirement to justify investments in order to avoid that public money is wasted (Conci \& Bramati, 2007). For example, a critical mass of employees needs to be reached and needs to benefit from the investment (Stefanick \& LeSage, 2005). The following table summarizes our results (see Table 1).

\subsubsection{Intermediate results}

While a discussion of findings will be conducted in the next chapter, first adaptations can be perceived with regard to the initial Barrier Framework. It appears that a more fine-grained approach to policies and the coordination of implementation steps is needed. This reflects a particular 'political and policy perspective' (Yang \& Maxwell, 2011, p. 170) of sectorial studies (similarly in Rashman

Table 1
Context barriers

\begin{tabular}{|c|c|c|c|}
\hline Perspective & Barrier level, category & Barrier subcategory & Authors \\
\hline \multirow[t]{11}{*}{ Organizational } & \multirow[t]{4}{*}{ Lack of resources } & Lack of finances & $\begin{array}{l}\text { Askim et al. (2008), Bere et al. (2013), Ferguson et al. (2013), Gil-Garcia et al. } \\
\text { (2007), Ebrahim and Irani (2005), Langford and Seaborne (2003), Moynihan and } \\
\text { Landuyt (2009), OECD (2001, 2003) }\end{array}$ \\
\hline & & $\begin{array}{l}\text { Lack of time (to use, evaluate } \\
\text { resources) }\end{array}$ & $\begin{array}{l}\text { Bere et al. (2013), Hazlett et al. (2008), Langford and Seaborne (2003), Eidson } \\
\text { (2009) }\end{array}$ \\
\hline & & Lack of personnel (incl. turnover rates) & $\begin{array}{l}\text { Butler et al. (2008), Ferguson et al. (2013), OECD (2001), Talbot (2009), Ebrahim } \\
\text { and Irani (2005) }\end{array}$ \\
\hline & & $\begin{array}{l}\text { Lack of contents (incl. misfit of } \\
\text { language) }\end{array}$ & $\begin{array}{l}\text { Bere et al. (2013), Langford and Seaborne (2003), Talbot (2009), Sannia et al. } \\
\text { (2009), Schweik et al. (2011) }\end{array}$ \\
\hline & \multirow[t]{4}{*}{$\begin{array}{l}\text { Management } \\
\text { coordination (policy) }\end{array}$} & Lack of regulatory (policy) frameworks & $\begin{array}{l}\text { Bere et al. (2013), Hazlett et al. (2008), Ebrahim and Irani (2005), OECD (2003), } \\
\text { Gil-Garcia et al. (2007) }\end{array}$ \\
\hline & & $\begin{array}{l}\text { Mis-coordination/break-down of } \\
\text { implementation }\end{array}$ & $\begin{array}{l}\text { Gil-Garcia et al. (2007), Langford and Seaborne (2003), Moynihan and Landuyt } \\
\text { (2009), OECD (2001, 2003), Stefanick and LeSage (2005), Phang et al. (2008), } \\
\text { Talbot (2009) }\end{array}$ \\
\hline & & $\begin{array}{l}\text { Lack of systemized training offers (incl. } \\
\text { KM practices) }\end{array}$ & Butler et al. (2008), Hazlett et al. (2008), Kang et al. (2008) \\
\hline & & $\begin{array}{l}\text { Lack of rewards (nature of reward, } \\
\text { contribute, incentivise) }\end{array}$ & $\begin{array}{l}\text { Bere et al. (2013), OECD (2003), Yang and Maxwell (2011), Schweik et al. (2011), } \\
\text { Kang et al. (2008) }\end{array}$ \\
\hline & \multirow{2}{*}{$\begin{array}{l}\text { Managerial culture } \\
\text { (practices, enacted } \\
\text { structure) }\end{array}$} & $\begin{array}{l}\text { Hierarchy (incl. organisational } \\
\text { structure) }\end{array}$ & Hazlett et al. (2008), Yang and Maxwell (2011), OECD (2003) \\
\hline & & $\begin{array}{l}\text { Lack of leadership (incl. senior support, } \\
\text { assigned responsibilities, tutors/ } \\
\text { organizer) }\end{array}$ & $\begin{array}{l}\text { Sannia et al. (2009), Langford and Seaborne (2003), Hazlett et al. (2008), Yang and } \\
\text { Maxwell (2011), Talbot (2009), OECD (2003), Gil-Garcia et al. (2007), Askim et al. } \\
\text { (2008), Kang et al. (2008), Ebrahim and Irani (2005) }\end{array}$ \\
\hline & $\begin{array}{l}\text { Perceived technology } \\
\text { fit }\end{array}$ & $\begin{array}{l}\text { Sustainability of technical artefacts } \\
\text { Lack of evidence-based success (fear } \\
\text { incompatibility with work practices) }\end{array}$ & $\begin{array}{l}\text { Colazzo et al. (2009), Bere et al. (2013), Stefanick and LeSage (2005) } \\
\text { Langford and Seaborne (2003), Butler et al. (2008), Stefanick and LeSage (2005) }\end{array}$ \\
\hline
\end{tabular}


et al., 2009, p. 465). Emphasis is further put on the lack of assigned responsibilities to guide or tutor (E-)learning efforts of employees. Lessons learned in this respect will be discussed later on.

\subsection{Dimension 2: social barriers}

In the social dimension, the first perspective focuses on interrelational barriers and challenges. One category in this respect is values on the national level. Subcategories which appeared in the studies are differences in ethnic and national beliefs as well as a related, common understanding about openness of contents (Talbot, 2009). Both aspects are important for E-Learning activities to succeed but may be impeded due diverging assumptions about learning practices or the meaning of collaboration processes (Blindenbacher \& Nashat, 2010; Talbot, 2009).

The barrier lack of common understanding has been found on the organizational level as well (Talbot, 2009). If understanding about processes of information-, knowledge sharing and learning diverge, or these words are used synonymously, misunderstandings can occur about the conduct and means of interaction (Hazlett et al., 2008). A further subcategory of barriers on the organizational level refers to the lack of encouragement to share and collaborate among employees. For example, principles like anonymity or the fear to mis-speak in public (Stefanick \& LeSage, 2005, p. 244) shape how employees retrieve and share their knowledge in an online environment (Hazlett et al., 2008). Encouraging to share knowledge may appear to relate to the previous category 'managerial leadership' in a first view. In this barrier dimension, however, the challenge relates to a symbolic, interrelational meaning; the support needs to be communicated and demonstrated within the administration (Amayah, 2013; Askim et al., 2008; Kang et al., 2008). An additional subcategory of barriers is the (current) organizational practice and routines to learning practices. Butler et al. (2008) outline that sharing knowledge among employees is mostly done within groups which have clear boundaries, distributed roles and responsibilities. New learning programs which require to change the groups and routines may then lead to resistance (Phang et al., 2008).

A third category of barriers in the social dimension relates to individual concerns. A subcategory in this respect is socialization. The term stands for the fear to loose social contacts among colleagues when (personal) exchange during learning activities becomes technically mediated (Sannia et al., 2009). Implementing E-Learning systems, several authors have also found that one barrier is the preference for face to face learning (Bere et al., 2013). Hazlett et al. reason that learning practices are shaped by 'a people intensive staff culture', people carry the knowledge and thus require personal interaction for the exchange (Hazlett et al., 2008 , pp. 60f.). Another subcategory in this regard is the concern about misunderstanding colleagues due to the loss of information richness. Individuals fear to get hold of experiential and tacit knowledge if collaboration shifts to virtual platforms (Bushouse et al., 2011; Butler et al., 2008)

A fourth category of barriers is related to the characteristics and value of information and knowledge. One subcategory in this vein is a lack of mutual trust; employees have concerns about sharing information within the organization (OECD, 2003). An additional subcategory in this vein is the conception that information and knowledge is power. People fear to lose their position (Amayah, 2013; De Angelis, 2013) and thus, they are not apt to share what they know about best practices, for example.

A further category of the social dimension is the quality of information. The subcategory lack of quality may appear to be related to the 'value of information' in a first view. Yet, this aspect is more focused on the nature of digital, online information as such.
For example, employees may have a low perception of the credibility of available resources online (Stefanick \& LeSage, 2005; Talbot, 2009). Related to this, employees take precaution to trust in information whose quality they can hardly assess. So they mistrust information irrespective of the origin (Yang \& Maxwell, 2011).

Apart from the inter-relational perspective, another main category to approach barriers on the social dimension relates to skills. Findings in the literature could be separated into barriers of the category ICT skills and knowledge about open E-Learning more generally. The first category refers to a low level of objective competence levels (Yang \& Maxwell, 2011). Examples in this respect are skills to complete computer analysis; application integration and web interface development to establish the systems (cf. Ebrahim \& Irani, 2005, p. 60f). The second subcategory addresses more to the low familiarity with frameworks like IPR issues (De Angelis, 2013) as well as technical practices of the applications (Bere et al., 2013; Langford \& Seaborne, 2003). The latter category has particular relevance for open E-Learning. A lack of knowledge about virtual learning platforms can lead to resistance of change. For example, if prospective users are unclear which time is needed to learn when using virtual learning environments, concerns raise as to whether enough work-time is available and whether employees may be confronted with higher workloads (Phang et al., 2008; Sannia et al., 2009).

Finally, a last perspective of barriers refers to challenges related to cognitive and personal backgrounds. Yang and Maxwell (2011) found that diversity of backgrounds including the lack of common identity and knowledge backgrounds impede an on-going collaboration. Another subcategory in this respect is differences in curricula and training programs which are developed (Askim et al., 2008) and complicate a joint approach among employees and providers. Another barrier to collaboration and exchange in this category is the orientation to experts or experienced colleagues more generally. Civil servants often prefer to orient on experts and receive feedback of close peers instead of lay persons and general colleagues (Eidson, 2009; Talbot, 2009). Interestingly, studies have also pointed that there is mistrust to collaborate with external persons, like consultants. This barrier appears to be related to failed promises about the sustainability of technology projects (cf. Langford \& Seaborne, 2003). Employees in the public sector fear that external guidance will fail to develop a technical solution which captures their experience-based-knowledge; in turn, the mistrust impedes the implementation of further projects in this domain (cf. Langford \& Seaborne, 2003). The following table summarizes our results (see Table 2).

\subsubsection{Intermediate results}

Initial differences to the general Barrier Framework can be found. Firstly, there was no reported concern about the misuse of information, so people fear that available information lead to repercussions and deception (cf. Pirkkalainen \& Pawlowski, 2014a, p. 644). Secondly, no concern about breaking laws was named, for instance, regarding the role and meaning of copyrights or intellectual property. Thirdly, the role of multi-lingual settings was not mentioned as a potential barrier, similarly as a potential unwillingness to shift from own to new perspectives and experience based ideas. The Barrier Framework is sensible to these cultural barriers to collaboration. In this vein, another barrier which appears to be neglected is the perceived geographic and temporal distance in studies in the public sector.

Apart from the neglected aspects, studies in the public sector put emphasis on the role of socialization and conception of knowledge as tacit and people intensive (Hazlett et al., 2008). Related to this, the studies noted a clear preference to face to face learning. The formation of delimited communities which have boundaries and share a purpose of learning and sharing knowledge seems to 
Table 2

\begin{tabular}{|c|c|c|c|}
\hline Perspective & Barrier level, category & Barrier subcategory & Authors \\
\hline \multirow[t]{11}{*}{$\begin{array}{l}\text { Inter-relational } \\
\text { aspects }\end{array}$} & \multirow[t]{2}{*}{ Values on the national level } & $\begin{array}{l}\text { Differences national, ethnic background (values, } \\
\text { beliefs) }\end{array}$ & Talbot (2009) \\
\hline & & $\begin{array}{l}\text { Lack of common understanding (incl. practices and } \\
\text { open content) }\end{array}$ & $\begin{array}{l}\text { Talbot (2009), Blindenbacher and Nashat } \\
\text { (2010) }\end{array}$ \\
\hline & \multirow[t]{3}{*}{ Values on the organizational level } & $\begin{array}{l}\text { Lack of common understanding (incl. KM practices, } \\
\text { meaning of open content) }\end{array}$ & $\begin{array}{l}\text { Hazlett et al. (2008), OECD (2003), Stefanick } \\
\text { and LeSage (2005) }\end{array}$ \\
\hline & & $\begin{array}{l}\text { Lack of encouragement to share knowledge and } \\
\text { collaborate (incl. symbolic managerial support) }\end{array}$ & $\begin{array}{l}\text { Amayah (2013), Kang et al. (2008), Talbot } \\
\text { (2009), Eidson (2009) }\end{array}$ \\
\hline & & Organizational practice/approach to learning & $\begin{array}{l}\text { Butler et al. (2008), Askim et al. (2008), Phang } \\
\text { et al. (2008), Eidson (2009) }\end{array}$ \\
\hline & \multirow[t]{2}{*}{$\begin{array}{l}\text { Individual concerns (incl. } \\
\text { communication/collaboration/language } \\
\text { issues) }\end{array}$} & $\begin{array}{l}\text { Socialization (incl. loss of communication with } \\
\text { colleagues) }\end{array}$ & $\begin{array}{l}\text { Bere et al. (2013), Sannia et al. (2009), Hazlett } \\
\text { et al. (2008), Stefanick and LeSage (2005), } \\
\text { Amayah (2013), Blindenbacher and Nashat } \\
\text { (2010), Eidson (2009) }\end{array}$ \\
\hline & & $\begin{array}{l}\text { Misunderstandings (rel. loss of information } \\
\text { richness i.e. to see, hear, interact directly) }\end{array}$ & $\begin{array}{l}\text { Butler et al. (2008), OECD (2003), Bushouse } \\
\text { et al. (2011), Hazlett et al. (2008), Gil-Garcia } \\
\text { et al. (2007) }\end{array}$ \\
\hline & \multirow[t]{2}{*}{$\begin{array}{l}\text { Value of information and knowledge } \\
\text { (incl. characteristics) }\end{array}$} & $\begin{array}{l}\text { Lack of mutual trust (incl. reciprocity between } \\
\text { colleagues) }\end{array}$ & OECD (2003), Amayah (2013) \\
\hline & & $\begin{array}{l}\text { Conception information and knowledge is power } \\
\text { (rel. loss of power due to sharing with colleagues) }\end{array}$ & De Angelis (2013), Amayah (2013) \\
\hline & \multirow[t]{2}{*}{ Quality of information } & Lack of quality & $\begin{array}{l}\text { Stefanick and LeSage (2005), Schweik et al. } \\
\text { (2011) }\end{array}$ \\
\hline & & $\begin{array}{l}\text { Trust in information (incl. assessing quality is hard; } \\
\text { relying on few nr. of people to contribute) }\end{array}$ & Talbot (2009), Yang and Maxwell (2011) \\
\hline \multirow[t]{3}{*}{ Skills } & ICT skills & $\begin{array}{l}\text { Low level of objective ICT skills (incl. competence } \\
\text { levels) }\end{array}$ & $\begin{array}{l}\text { Bere et al. (2013), Langford and Seaborne } \\
\text { (2003), Yang and Maxwell (2011), Butler et al. } \\
\text { (2008), Phang et al. (2008), Gil-Garcia et al. } \\
\text { (2007), Ebrahim and Irani (2005) }\end{array}$ \\
\hline & \multirow[t]{2}{*}{ Lack of knowledge open E-Learning } & $\begin{array}{l}\text { Low familiarity frameworks (incl. IPR, details and } \\
\text { awareness of OER) }\end{array}$ & De Angelis (2013), Ebrahim and Irani (2005) \\
\hline & & $\begin{array}{l}\text { Low familiarity technical practice (incl. concerns } \\
\text { about efforts to invest) }\end{array}$ & $\begin{array}{l}\text { Phang et al. (2008), Bere et al. (2013), Sannia } \\
\text { et al. (2009), Butler et al. (2008) }\end{array}$ \\
\hline \multirow[t]{3}{*}{$\begin{array}{l}\text { Cognitive } \\
\text { preferences }\end{array}$} & \multirow[t]{3}{*}{ Cognitive, personal backgrounds } & Diversity of backgrounds & $\begin{array}{l}\text { Conci and Bramati (2007), Yang and Maxwell } \\
\text { (2011), Hazlett et al. (2008) }\end{array}$ \\
\hline & & Differences in curricula & $\begin{array}{l}\text { Askim et al. (2008), Blindenbacher and Nashat } \\
\text { (2010) }\end{array}$ \\
\hline & & $\begin{array}{l}\text { Orientation to experts (incl. experienced peers in } \\
\text { the sector) }\end{array}$ & $\begin{array}{l}\text { Talbot (2009), Eidson (2009), Langford and } \\
\text { Seaborne (2003) }\end{array}$ \\
\hline
\end{tabular}

be an important factor for collaborative learning (Moynihan \& Landuyt, 2009; Stefanick \& LeSage, 2005). Apart from that, a common finding to note is the perceived, low level of ICT skills and knowledge about virtual platforms in the sector.

\subsection{Dimension 3: technical barriers}

In the technical dimension, the first kinds of barriers are perceived from an organizational perspective. One category is the low availability of technology which embraces the subcategories shortage of appropriate infrastructure and software (Langford \& Seaborne, 2003). Another subcategory is the low quality of broadband connections which impede the interconnectivity among administrations (Stefanick \& LeSage, 2005). Another barrier is the low interoperability of systems which challenges the realization of virtual platforms and sharing practices. On the one hand, this refers to multi-platform settings. Ebrahim and Irani (2005) point out that most administrations keep their systems and data in a locally stored and managed network. On the other hand, the low interoperability is related to the lack of interoperable applications. The sheer range and variety of technical systems and artifacts impedes the sharing of digital information (Gil-Garcia et al., 2007; Yang \& Maxwell, 2011). Related to this aspect is the category of technical conceptual differences. This embraces a lack of common data references, definitions, and channels which impede a data and information exchange via technical means (Gil-Garcia et al., 2007). Last but not least, a category of technical barriers from the organizational perspective are concerns about security and privacy. One subcategory is concerns about reliability and security of systems. During the implementation and development also particular security rights need to be taken into account, to provide a secure and legitimate processing of information (Ebrahim \& Irani, 2005). The other subcategory relates to legitimacy and rights to use technical systems such as the demand of keeping confidentiality of data (Gil-Garcia et al., 2007; OECD, 2003).

Shifting from the organizational to the social perspective, further barriers can be found. A first category of barriers is the perceived functionality of the system. A requirement for individual learners appears to be that the availability of (performance) data is constrained to dedicated persons (Yang \& Maxwell, 2011). Related to this is the demand to restrict the access to online resources and platforms in technical manner (Moynihan \& Landuyt, 2009). Apart from the functionality, a set of barriers that was found are requirements towards usability of the systems. Subcategories refer to interface usability (Bere et al., 2013) as well as bugs in the system which appear as a major challenge to employees in the adoption of platforms (Eidson, 2009). Associated to this is that a low processing information may impede the use of a system (Yang \& Maxwell, 2011).

A final category of barriers to consider on the technical dimension is the digital divide. In the studies, this barrier appears in form of demographic challenges (Ferguson et al., 2013; OECD, 2001). Elderly either feel to be left behind or appear to be weakly interested in the use of the platform. Another, more general 
Table 3

Technical barriers.

\begin{tabular}{|c|c|c|c|}
\hline Perspective & Barrier level, category & Barrier subcategory & Authors \\
\hline \multirow[t]{6}{*}{ Organizational } & \multirow[t]{2}{*}{ Availability } & $\begin{array}{l}\text { Shortage of appropriate infrastructure } \\
\text { (incl. software) }\end{array}$ & $\begin{array}{l}\text { Langford and Seaborne (2003), Stefanick and LeSage (2005), Butler et al. } \\
\text { (2008) }\end{array}$ \\
\hline & & Lack of broadband & Stefanick and LeSage (2005) \\
\hline & \multirow[t]{2}{*}{ Interoperability } & $\begin{array}{l}\text { Multi-platform settings (incl. legacy } \\
\text { systems, infrastructure) }\end{array}$ & Ebrahim and Irani (2005) \\
\hline & & $\begin{array}{l}\text { Lack of interoperable applications (incl. } \\
\text { tools, software, systems) }\end{array}$ & $\begin{array}{l}\text { Yang and Maxwell (2011), Gil-Garcia et al. (2007), Butler et al. (2008), } \\
\text { Colazzo et al. (2009), Ebrahim and Irani (2005) }\end{array}$ \\
\hline & $\begin{array}{l}\text { Technical conceptual } \\
\text { differences }\end{array}$ & $\begin{array}{l}\text { Lack of common references (incl. concepts, } \\
\text { references, taxonomy) }\end{array}$ & Gil-Garcia et al. (2007), Ebrahim and Irani (2005) \\
\hline & $\begin{array}{l}\text { Concerns about privacy } \\
\text { and security }\end{array}$ & $\begin{array}{l}\text { Reliability and security } \\
\text { Legitimacy, rights and rules }\end{array}$ & $\begin{array}{l}\text { Yang and Maxwell (2011), OECD (2003) } \\
\text { Gil-Garcia et al. (2007), Ebrahim and Irani (2005), Blindenbacher and Nashat } \\
\text { (2010) }\end{array}$ \\
\hline \multirow[t]{5}{*}{ Social } & \multirow[t]{2}{*}{ Perceived functionality } & Availability (visibility) of data & Yang and Maxwell (2011) \\
\hline & & $\begin{array}{l}\text { Restrict the of use of systems (incl. access } \\
\text { to platforms) }\end{array}$ & Moynihan and Landuyt (2009), Ebrahim and Irani (2005) \\
\hline & \multirow{3}{*}{$\begin{array}{l}\text { Usability/system } \\
\text { quality } \\
\text { Digital divide }\end{array}$} & $\begin{array}{l}\text { Perceived interface usability } \\
\text { Bugs in the system (incl. slow responses) }\end{array}$ & $\begin{array}{l}\text { Bere et al. (2013), Eidson (2009), Blindenbacher and Nashat (2010) } \\
\text { Yang and Maxwell (2011), Eidson (2009) }\end{array}$ \\
\hline & & Demographic challenges & Hazlett et al. (2008), OECD (2001), Ferguson et al. (2013) \\
\hline & & $\begin{array}{l}\text { Unbalanced technological usage and } \\
\text { expertise }\end{array}$ & Moynihan and Landuyt (2009), OECD (2003) \\
\hline
\end{tabular}

subcategory is the distribution of expertise among employees which can lead to a split within groups into advanced and laggards in the administrative context (Moynihan \& Landuyt, 2009). The following table summarizes our results (see Table 3 ).

\subsubsection{Intermediate results}

One interesting point to note is the demand to restrict the access and visibility of information and online resources in systems. A system appears to be functional if it organizes access and provides resources to particular dedicated persons (cf. Moynihan \& Landuyt, 2009, p. 1099). Another interesting point is that only few studies have reported (and can be referenced) for experiences with technical challenges apart from Ebrahim and Irani (2005). This finding may indicate that research in the domain is not mainly concentrated on technical issues but includes consideration of socially and behavioral aspects of technology use (cf. OECD, 2003).

\section{Discussion}

In the previous section we have systemized the experiences made in the use and development of open E-Learning in the public sector. Findings have been classified in the dimensions: organizational/context, social, and technical dimension as presented in the contextualized Barrier Framework [cBF] above. Notable points have already been outlined after each table and barrier dimension. Yet, several points require a close discussion.

Beginning with lessons learned for managing the introduction of open E-Learning, the importance of leadership and coordination of implementation processes needs to be emphasized. Not only it is important to establish policy frameworks (cf. OECD, 2003) but also the support of senior levels as well as tutors on the platform is required (Gil-Garcia et al., 2007). Compared to similar elaborated studies like Chen (2014) these points both take up and extend considerations on legal and managerial requirements when introducing E-Learning in public administration contexts (Chen, 2014, pp. 462f.). Regarding lessons learned for facilitating an open, collaborative E-Learning system one can refer to the social dimension where barriers can be derived from different perspectives as well as on different levels (from a national to the individual level). For example, the lack of encouraging employees to share knowledge needs to be provided for. At the same time, individual dispositions and routines to share knowledge and information with colleagues need to be attuned to open collaboration (Amayah, 2013). Com- pared to similar abstract studies, these points enrich understanding about dispositions and potential reasons of weak online interaction (cf. Eidson, 2009, p. 179).

Overall to systemize the lessons learned enables both to extend and provide new insight on barriers in the use and development of open E-Learning platforms. On base of the detailed barriers as well as the three more common dimensions, the research question 'which barriers appear to open E-Learning in the public sector' can thus be answered in a detailed, as well as a more general manner.

Further to discuss is the quality of the (contextualized) BF for guiding research in this domain. Firstly, the $\mathrm{CBF}$ enables to accommodate findings from different countries (e.g. Bere et al., 2014) as well as learning scenarios (cf. Chen, 2014; Conci \& Bramati, 2007). Secondly, the cBF allows comparing barriers to those which are known in the private and educational context. Similarities can be found regarding the technical barriers such as interoperability of technical settings (Ebrahim \& Irani, 2005; Pirkkalainen \& Pawlowski, 2014a, p. 644). Also differences and knowledge gaps can be identified which need to be further explored. The first example is the role of collaborative incentive and rewards (Pirkkalainen \& Pawlowski, 2014a, pp. 641f.). While the assumption is shared that incentives to collaborate can have a positive effect, there is conflict about the nature of incentives. In the public sector, Phang et al. (2008) emphasize that salaries and promotion can be positive factor while others emphasize the contrary due to varying experiences (Yang \& Maxwell, 2011). Addressing to an open research question in the information systems field (Alavi \& Leidner, 2001, p. 127) the contradictory findings may inform and inspire research about the meaning and nature of incentives for collaboration. The second example is related to the role of collaborative learning, too. Orienting on the BF (Pirkkalainen \& Pawlowski, 2014a) sensitizes that the studies in the public sector have not reported about barriers such as the perceived geographic and temporal distance. This point may be a corollary of the finding, that apart from Blindenbacher and Nashat (2010), E-Learning is often implemented as a domestic solution. As a consequence, a particular research focus will be to explore cross-national and crossadministrative collaboration on open E-Learning environments more precisely.

Resuming these points, the $\mathrm{CBF}$ enables to research and compare findings across different contexts and domains. In this vein, the $\mathrm{CBF}$ can stand the critique that previous studies have been focused on particular aspects (Chen, 2014; Eidson, 2009). The 
comparison and adaptation of the $\mathrm{CBF}$ further supports that the original frame is a suitable concept to guide and sensitize research on barriers on a detailed as well as more general level. As it was pointed out, the comparison enables to allocate future research themes, like the role of rewards as well as cross-national collaboration in open E-Learning. In view of these points, the choice and quality of the (contextualized) BF to guide and systemize research on open E-Learning in the public sector can be supported (cf. Frank, 2006, pp. 52f., 55; Richter, 2014, p. 147f.).

The value of the contextualized Barrier Framework [CBF] in applied settings is about to be evaluated by authors in the project EAGLE (EnhAnced Government LEarning). ${ }^{9}$ The project strives to develop an open and collaborative technology enhanced learning platform across public administration sectors and in four European countries. In this empirical context the BF is used to explore which factors in the socio-cultural contexts of public administrations need to be considered in open E-Learning projects. From the current state of the project, the $\mathrm{BF}$ is found well equipped to guide the requirements engineering phase and point out which barriers are of priority for the implementation of systems. Yet, it needs to be traced over time how an applied cBF enhances not only exploratory but explanatory research about the introduction and use of open and collaborative E-Learning systems.

One limitation of the study in this respect is that interventions or more generally how to respond to barriers requires more elaboration. Recommendations from the studies in this paper can be clustered to train the managers and tutors for a successful realization of E-Learning platforms (Bere et al., 2013; Sannia et al., 2009). Another cluster advises to keep expectations about implementation processes modest (Eidson, 2009; Gil-Garcia et al., 2007; Langford \& Seaborne, 2003). Not at last, recommendations focus on the adaptation of E-Learning platform regarding the number of users (Bere et al., 2013, 2014) as well as available courses and materials (Conci \& Bramati, 2007; Eidson, 2009; Langford \& Seaborne, 2003).

In the end, the results and discussions about the cBF allow to support that the goal has been achieved to explore open and collaborative E-Learning in the public sector. We reviewed experiences and lessons learned from studies in the sector so far and correspondingly systemized which barriers are to consider in the introduction, use and development of related projects. The contextualized Barrier Framework for open E-Learning in the public sector can guide to develop and systemize research efforts about current and future collaborative E-Learning environments. A set of corresponding findings will contribute to validate the cluster of barrier dimensions and will further refine insights of particularities of the public sector. Experiences made in the project EAGLE, for instance, will contribute to this aspect in the future.

\section{Conclusion}

The study has elaborated on barriers to the use and development of open E-Learning in the public sector. A contextual Barrier Framework has been developed which outlines more than 40 barriers to consider in the organizational context, social and technical dimension. As the research domain 'open E-Learning in public administrations' is infancy, a broad reflection of underlying, and received concepts in studies of related domains as well as in the field of information systems has been made. Compared to previous approaches, the contextualized Barrier Framework enables to systematically explore and understand which barriers may challenge the implementation and use of open E-Learning in the public sector. Having the set of potential barriers in view can also lead to sys-

${ }^{9}$ See http://www.eagle-learning.eu/. temize future investigations as well as the development of interventions to facilitate the realization of open E-Learning projects. Further examination is needed in this respect, and will have to focus on the cluster and nature of barriers as well as the clarity of the concept and interventions.

\section{Acknowledgement}

This research has been co-funded by the European Union within the Seventh Framework Programme, FP7-ICT, grant agreement no: 619347, (cf. http://www.eagle-learning.eu/).

\section{References}

Alavi, M., \& Leidner, D. E. (2001). Review: Knowledge management and knowledge management systems: Conceptual foundations and research issues. MIS Quarterly, 107-136.

Amayah, A. T. (2013). Determinants of knowledge sharing in a public secto organization. Journal of Knowledge Management, 17(3), 454-471.

Askim, J.. Johnsen, A.. \& Christophersen, K. A. (2008). Factors behind organizationa learning from benchmarking: Experiences from Norwegian municipa benchmarking networks. Journal of Public Administration Research and Theory, 18(2), 297-320

Baskerville, R., \& Dulipovici, A. (2006). The theoretical foundations of knowledge management. Knowledge Management Research \& Practice, 4(2), 83-105.

Bates, A. T. (2005). Technology, E-Learning and distance education. Routledge.

Bere, R., Silvestri, C., \& Nemeș, L. (2013). E-learning platform for public administration-case study. In Conference proceedings of "eLearning and Software for Education" (eLSE): The 9th international scientific conference elearning and software for education (pp. 486-492). B

ere, R. Silvestri, C. Nenes, L. (2014). Challenges and Opportumities in Knowledge , R., Silvestri, C., Nemeş, L. (2014). Challenges and Opportunities in Knowledg sharing in E-Learning programs for public administration. In eLearning and and software for education (pp. 461-469). Bucharest, April 25-26, 2014. http: dx.doi.org/10.12753/2066-026X-14-212.

Baikie N. W. H. (2010). Designing social research: The logic of anticipation. Cambridge: Polity.

Blindenbacher, R \& Nashat, B. (2010). The black box of governmental learning: The learning spiral-A concept to organize learning in governments. World Bank Publications [Chapter 9, 10].

Bushouse, B. K., Jacobson, W. S., Lambright, K. T., Llorens, J. J., Morse, R. S., \& Poocharoen, O. O. (2011). Crossing the divide: Building bridges between public administration practitioners and scholars. Journal of Public Administration Research and Theory, 21(suppl 1), i99-i112.

Butler, T., Feller, J., Pope, A., Emerson, B., \& Murphy, C. (2008). Designing a core IT artefact for knowledge management systems using participatory action research in a government and a non-government organisation. The Journal of Strategic Information Systems, 17(4), 249-267. http://dx.doi.org/10.1016 j.jsis.2007.10.002.

Chatti, M. A., Schroeder, U., \& Jarke, M. (2012). LaaN: Convergence of knowledge management and technology-enhanced learning. Learning Technologies, IEE Transactions On, 5(2), 177-189.

Chen, T.-L. (2014). Exploring E-Learning effectiveness perceptions of local government staff based on the diffusion of innovations model. Administratio \&

Colazzo, L., Molnari, A., \& Villa, N. (2009). Lifelong learning and virtua Journal of Advanced Corporate Learning. 2(3). 5-11.

Conci, A. Bramati, C. (2007). E-learning in public administration. In SLOOP. Sharing learning objects in an open perspective (pp. 81-85)<https://www academiaedu/ learning objects in an open perspective (pp. 81-85)<https://Ww

D'Antoni, S. (2009). Open educational resources: Reviewing initiatives and issues. Open Learning: The Journal of Open, Distance and E-Learning, 24(1), 3-10. http:| dx.doi.org/10.1080/02680510802625443.

De Angelis, C. T. (2013). A knowledge management and organizational intelligence model for public administration. International Journal of Public Administration 36(11), 807-819. http://dx.doi.org/10.1080/01900692.2013.791315.

Ebrahim, Z., \& Irani, Z. (2005). E-government adoption: architecture and barriers. Business Process Management Journal, 11(5), 589-611. http://dx.doi.org/10.1108 14637150510619902.

Eidson, L. A. K. (2009). Barriers to e-learning job training: Government employee experiences in an online wilderness management course. Theses, dissertations, professional papers. Paper $86<$ http://scholarworks.umt.edu/etd>

Evaristo, J. R. (2007). Knowledge transfer across borders: A process model. Knowledge and Process Management, 14(3), 203-210.

Ferguson, S., Burford, S., \& Kennedy, C. (2013). Divergent approaches to knowledge and innovation in the public sector. International Journal of Public Administration,

Frank, U. (2006). Towards a pluralistic conception of research methods in information systems research (No. 7). ICB-research report <http://hdl.handle.net/10419 
Gil-Garcia, J. R. Chengalur-Smith, I., \& Duchessi, P. (2007). Collaborative eGovernment: Impediments and benefits of information-sharing projects in (2) European Journal of Information Systems, 16(2), 121-133.

Guri-Rosenblit, S. (2006). Eight paradoxes in the implementation process of ELearning in higher education. Distances et Saviors, 4(2), 155-179. http:// x.doi.org/10.3166/ds.4.155-179.

Hârțescu, I. (2012). A case study of implementing blended learning courses in public administration. In: Leveraging technology for learning: Proceedings of the 497-503). Bucharest, April 26-27, 02 2012.

Hazlett, S. A., Mcadam, R., \& Beggs, V. (2008). An exploratory study of knowledge flows: A case study of public sector procurement. Total Quality Management \& Business Excellence, 19(1-2), 57-66.

Henderson, L. (2007). Chapter VIII theorizing a multiple cultures instructional design model for E-Learning and e-teaching. In A. Edm E-Learning cultural challenges (pp. 130-153). UK: IGI Global. http://dx.doi.org/ 10.4018/978-1-59904-301-2.ch008.

Hilton, J., III, Wiley, D., Stein, J., \& Johnson, A. (2010). The four 'R's of openness and ALMS analysis: Frameworks for open educational resources. Open Learning, 25(1), 37-44.

Kang, Y.-J., Kim, S.-E., \& Chang, G.-W. (2008). The impact of knowledge sharing on work performance: An empirical analysis of the public employees' perceptions in South Korea. International Journal of Public Adm

http://dx.doi.org/10.1080/01900690802243607.
Kennedy, M., \& Burford, S. (2013). A comparative analysis of conceptions of knowledge and learning in general and public sector literature 2000-2009. International Journal of Public Administration, 36(3), 155-167. http://dx.doi.org/ International Journal of Public Adn
$10.1080 / 01900692.2012 .749279$.

Koper, R. (2008). Open source and open standards. In M. J. Spector, D. M. Merrill, J. Merriënboer, van, \& M. P. Driscoll (Eds.), Handbook of research on educational Taylor \& Francis Group.

Lane, A. (2010). Designing for innovation around OER. Journal of Interactive Media in Education <http://www-jime.open.ac.uk/article/2010-2/html>.

angford, J., \& Seaborne, K. (2003). To click or not to click: E-learning for the public sector. Canadian Public Administration, 46(1), 50-75.

Laurillard, D. (2008). Open teaching: The key to sustainable and effective open education. In T. liyoshi \& V. Kumar (Eds.), Opening up education. The collective advancement of education through open technology, open content, and open knowledge (pp. 319-336). London: MIT Press.

Mahler, J. (1997). Influences of organizational culture on learning in public agencies. Journal of Public Administration Research and Theory, 7(4), 519-540.

Maier, R. \& Schmidt, A. (2007). Characterizing knowledge maturing: A conceptual process model for integrating e-learning and knowledge management. In Proceedings: 4th conference professional knowledge management-experiences and visions (WM'07). Germany: Potsdam <http://citeseer.ist.psu.edu/viewdoc/ summary? doi=10.1.1.73.1713

Margetts, H., \& Dunleavy, P. (2002). Cultural barriers to e-government. National Audit Office, UK <http://catedras.fsoc.uba.ar/rusailh/Unidad\%205/ avy\%20Culura

rs\%20to\%20Egovernment.pdf>.

McGrath, O. (2008). Open educational technology: Tempered aspirations. In T, Iiyoshi \& V. Kumar (Eds.), Opening up education. The collective advancement of education through open technology, open content, and open knowledge (pp. 13-26). London: MIT Press.

Moynihan, D. P. \& Landuyt, N. (2009). How do public organizations learn? Bridging cultural and structural perspectives. Public Administration Review, 69(6), 1097-1105.

OECD (2001). Knowledge management: Learning-by-comparing experiences from private firms and public organisations. In HRM working party meeting: Summary
record of the high level forum held in Copenhagen, 8-9 February, 2001. JT00109192.

OECD (2003). The learning government: Introduction and draft results of the survey of knowledge management practices in ministries/departments/agencies of central government. In 27th Session of the public management committee (pp. 154). Original forma

Pawlowski, J. M., Pirkkalainen, H., Gervacios, J. L., Nordin, N., \& Embi, M. A. (2013). Contextualization of open educational resources in Asia and Europe. e-ASEM collaborative research (pp. 99-139) <http://asemlllhub.org/fileadmin/ Whw. hang, C. W., Kankanhalli, A., \& Ang, C. (2008). Investigating organizational learning
in eGovernment projects: A multi-theoretic approach. eGovernment strategies:
ICT innovation in international public sector contexts. Journal of Strategic Information Systems, 17(2), 99-123. http://dx.doi.org/10.1016 j.jsis.2007.12.006.

Pirkkalainen, H. \& Pawlowski, J. M. (2014). Collaborating on ideas: Tackling barriers to open education. In World conference on educational multimedia, hypermedia and telecommunications (pp. 1844-1850). Chesapeake: Association for the Advancement of Computing in Education.

Pirkkalainen, H. \& Pawlowski. J. M. (2010). Open educational resources and socia software in global E-Learning settings, In Sosiaalinen Verkko-oppimine (pp. 23-40). Naantali: IMDL.

Pirkkalainen, H. \& Pawlowski. J. M. (2013). Global social knowledge management: From barriers to the selection of social tools. Electronic Journal of Knowledge Management, 11(1), 3-17.

Pirkkalainen, H., \& Pawlowski, J. M. (2014a). Global social knowledge managementUnderstanding barriers for global workers utilizing social software. Computer in Human Behavior, 30, 637-647.

Punie, Y. (2007). Learning spaces: An ICT-enabled model of future learning in th knowledge-based society. European Journal of Education, 42(2), 185-199.

Rashman, L., Withers, E., \& Hartley, J. (2009). Organizational learning and knowledge in public service organizations: A systematic review of the literature. International Journal of Management Reviews, 11(4), 463-494,

ichter, T. (2014). Kulturorientierte Forschung in der Wirtschaftsinformatik: Entwicklung eines Werkzeugs zur Abgrenzung kultureller Forschungskontexte und zur Ermittlung kontextuell passender Kulturbeschreibungsmodelle: Thesis:

Richter T. \& Adelsberger $H$. (2012). On the myth of a general national culture. In $\mathrm{M}$ Strano, H. Hrachovec, F. Sudweeks, \& C. Ess (Eds.), Cultural attitudes towards technology and communication 2012: Proceedings of the eighth international technology and communication 2012: Preceengs of the eighth internationa Demark. Australia: Murdoch University <http/lissuuticom/catac/docs catac12_proceedings_part_1/3? $\mathrm{e}=0>$
. world? Distance Education, 33(2), 201-219.

Riege, A. (2005). Three-dozen knowledge-sharing barriers managers must consider. Journal of Knowledge Management, 9(3), 18-35.

Sannia, M., Ercoli, G., \& Leo, T. (2009). Evaluation of virtual learning environment fo the professional training in public administration. International Journal of Advanced Corporate Learning (i)AC), 2(1), 50-5.

Schout, A. (2009). Organizational learning in the EU's multi-level governance system. Journal of European Public Policy, 16(8), 1124-1144. http://dx.doi.org

$10.1080 / 13501760903332613$.
Schweik, C. M., Mergel, I., Sandfort, J. R., \& Zhao, Z. J. (2011). Toward open public administration scholarship. Journal of Public Administration Research \& Theory 21(suppl_1), i175-i198.

Specht, M. (2008). Designing contextualized learning. In H. Adelsberger, H. Kinshuk, J. M. Pawlowski, \& D. G. Sampson (Eds.), Handbook on information technologies for education and training (pp. 101-111). Berlin: Springer Heidelber (International Handbooks on Iformation Systems). http://dx.doi.org/10.1007

in the developing virtual communities in the pation s8(2): A local government case stuc (2009). Delivering distance

the education for the service in the The university of chester's foundation for government programme. In S Marshall, W. Kinuthia, \& W. Taylor (Eds.), Bridging the knowledge divide: Educational technology for development (pp. 77-96). Charlotte, NC: 10034/83593; http://chesterrep. Authorrepository.com/cdr//bitstream/10034/ 83593/8/talbot-delivering\%20distance \%20ed\%20book\%20chapter.pdf>.

Van de Walle, S., \& Van Delft, R. (2014). Publishing in public administration: Issues with defining, comparing and ranking the output of universities. Internationa Public Management Journal (in press) Available at SSRN: <http://ssrn.com/ abstract $=2425075>$.

Webster, J., \& Watson, R. (2002). Analyzing the past to prepare for the future: Writing a literature review. Management Information Systems Quarterly, 26(2)

Yang, T.-M., \& Maxwell, T. A. (2011). Information-sharing in public organizations: A literature review of interpersonal, intra-organizational and inter-organizationa

Yunus, Y. \& Salim, J. (2008). Framework for the evaluation of e-learning in Malaysian public sector from the pedagogical perspective. In International
symposium on information technology, 2008. IEEE. ITSim 2008 (Vol. 3, pp. 1-8). 
Barriers to open e-learning in public administrations: A comparative case study of the European countries Luxembourg, Germany, Montenegro and Ireland

by

Stoffregen, J. D., Pawlowski, J. M., Ras, E., Tobias, E., Šćepanović, S., Fitzpatrick, D., ... \& Friedrich, H. 2016.

Technological Forecasting and Social Change vol 111, 198-208.

Reproduced with kind permission by Elsevier. 


\section{Barriers to open e-learning in public administrations A comparative case study of the European countries Luxembourg, Germany, Montenegro and Ireland}

Julia Dorothée Stoffregen $^{\mathrm{a}, \mathrm{b}, *}$, Jan M. Pawlowski ${ }^{\mathrm{a}, \mathrm{b}}$, Eric Ras ${ }^{\mathrm{c}}$, Eric Tobias ${ }^{\mathrm{c}}$, Snezana Šćepanović $^{\mathrm{d}}$, Dónal Fitzpatrick ${ }^{\mathrm{e}}$, Tracey Mehigan ${ }^{\mathrm{e}}$, Petra Steffens ${ }^{\mathrm{f}}$, Christiane Przygoda ${ }^{\mathrm{f}}$, Peter Schilling ${ }^{\mathrm{f}}$, Horst Friedrich ${ }^{\mathrm{f}}$, Sabine Moebs ${ }^{\mathrm{g}}$

${ }^{a}$ University of Jyväskylä, Finland

${ }^{\mathrm{b}}$ University of Applied Sciences Ruhr West, Germany

${ }^{c}$ Luxembourg Institute of Science and Technology, Luxembourg

d University Mediterranean, Montenegro

e Dublin City University, Ireland

${ }^{\mathrm{f}}$ Fraunhofer-Institut für Offene Kommunikationssysteme, Germany

${ }^{g}$ Duale Hochschule Baden Württemberg, Germany

\begin{tabular}{l} 
A R T I C L E I N F O \\
\hline Article history: \\
Received 26 September 2015 \\
Received in revised form 9 June 2016 \\
Accepted 27 June 2016 \\
Available online 16 July 2016 \\
\hline Keywords: \\
Comparative study \\
Public administrations \\
OER \\
e-Learning
\end{tabular}

\section{Introduction}

This paper aims to explore barriers to open e-learning in public administrations at the local government level. Lifelong learning is essential to upgrade performance and innovate work processes in various sectors. To increase organisational learning, training programmes in the public sector are also subject to reform. However, e-learning and the use of open educational resources (OERs) are not widely implemented in public administrations. To advance the understanding of this issue, this article explores which barriers prevent public employees' involvement in open e-learning in selected European countries and provides guidance for the implementation. This study advances the current state of practice and research by conducting a cross-national analysis of administrative barriers to open e-learning (cf. Bimrose et al. 2014:60; Chen 2014:464). ${ }^{1}$ Compared to e-learning in international

\footnotetext{
* Corresponding author.

E-mail address: julia.stoffregen@hs-ruhrwest.de (J.D. Stoffregen).

${ }^{1}$ Given the initial, extensive literature review, only selected articles that offer comprehensive and balanced insights on the respective points are referenced in this paper.
}

educational settings, the results shed light on a unique yet diversified context. Beyond the studies on e-learning in public health and the military sector (Bonk \& Wisher 2000), this study focuses on core administration contexts, which are often severely constrained in terms of time, budget and technical resources.

One notable study on barriers to e-learning of public employees even concludes that the benefits of e-learning might be 'illusionary': flexible learning time, convenience of learning at the workplace and collaborative interactions can hardly be achieved (Eidson 2009: $130 \mathrm{ff}$.). Chen (2014:460) clarifies that these 'innovative characteristics' of elearning are important and shape the perceived effectiveness of programs. Is the situation as difficult as studies suggest? So far, most of the research on e-learning in the public sector focuses on single countries (e.g. Langford \& Seaborne 2003; Yang \& Ruan 2007). Authors therefore doubt the generalisability of the results (Chen 2014:463 ff.; Eidson 2009:154 ff.,157).

This empirical study aims at contributing to close this research gap. The main research question is as follows: What are the similarities and differences in barriers to open e-learning across public administrations? This paper presents the results of several focus group sessions and 
interviews with public employees that were conducted in public administrations in four European countries. The results extend the contextualised barrier framework [CBF] for open e-learning in public administrations (Stoffregen et al. 2015), which can guide future research in the domain. As the involved public administrations participate in the EU project called EnhAnced Government LEarning ${ }^{2}$ (EAGLE), practical implications of the results are also discussed. Overall, this article thus advances both theoretical and practical considerations about the development and use of open e-learning systems in public administrations.

The article is structured as follows. Section 2 introduces the background of the e-learning domain in the public sector. Outlining the current state of approaches to the phenomenon helps define the particular topics to address. Section 3 discusses the research methodology and design. This section includes the empirical context and selection criteria for the countries in this comparative study. Section 4 presents the results of this qualitative study. Both specific and common barriers across administrations and countries are explained. In Section 5, the findings are discussed in view of their practical and theoretical contributions to the field. The conclusion in Section 6 summarises the most important points.

\section{Background of the empirical study: Barriers to open e-learning in} public administrations

2.1. Literature review: Current state of e-learning in the public sector

e-Learning in the public sector often refers to blended information and communication technology (ICT)-supported training, meaning that online sessions are combined with traditional face-to-face seminars (cf. Bere et al. 2013:488; Chen 2014:456; Conci \& Bramati 2007:82; Hârţescu 2012:497). Open e-learning comprises related activities that include the use of open-source technologies and OERs (cf. Stoffregen et al. 2015). Most courses are launched with the aim of enabling lifelong learning (e.g. Langford \& Seaborne 2003:57 ff.), as well as saving costs and increasing competitiveness (Bere et al. 2013:487; Conci \& Bramati 2007:82). e-Learning has been available since 2000 (cf. Langford \& Seaborne 2003). However, studies on e-learning have not systematised the lessons learned so far, for example, discussing implications of the challenges in interventions or the design of programs. The reports are of short length and focus on selected aspects (e.g. Hârtescu 2012; Yang \& Ruan 2007). Some of the challenges and salient topics are presented in this subsection.

From the range of goals for introducing e-learning, it appears that the state and meaning of e-learning have 'interpretative flexibility'. ${ }^{3} \mathrm{Sim}$ ilar to the private sector, both democratic (access to learning) and economic rationales (cost savings and performance) are promoted (cf. Remtulla 2007:10). A challenge is that managers do not seem to assess the implications of these goals. As a result, the required investments for introducing e-learning programs are uncoordinated and their implementation lags behind if expectations are not met (Langford \& Seaborne 2003:66). Phang et al. (2008) highlight the relevance of this challenge for employees. If they have optimistic expectations about reforms, they may take a positive role in the implementation (Phang et al. 2008:111). Phang et al. (2008) focus not only on organisational learning in e-government projects but also on perceived e-learning effectiveness, where expectations play a salient role (Chen 2014). Consequently, the stakeholder expectations and the meaning and state of e-learning should be assessed for the design of a holistic program.

Following Langford and Seaborne's (2003:65) study, another challenge is the lack of knowledge and skills needed to engage in e-

\footnotetext{
${ }^{2}$ www.eagle-learning.eu.

3 'Interpretative flexibility' stems from the social shaping of the technology school of thought and means that multiple perspectives shape the path of evolving (technical) arte-
} facts (Williams \& Edge 1996:869). learning. Familiarity with online practices is more generally a crucial factor for successful adoption (Yang \& Maxwell 2011:173). eLearning programs may aim at increasing digital competencies (Bere et al. 2013:490), but learning contents should address training needs in the form of dedicated curricula (Sannia et al. 2009:50). Programs should concentrate on professional advancement instead of "[...] make[ing] up for knowledge opportunities missed at the time of compulsory school education" (Sannia et al. 2009:50). To advance and compare lessons learned across projects, it is important to obtain information about the employees' familiarity with systems (Yang \& Maxwell 2011), their professional competencies and e-learning curricula (Sannia et al. 2009).

Further challenges relate to introducing digital platforms, which requires institutional changes and resources. One related aspect involves the process of coordinating training offers. Both systematised training and coordination of knowledge-sharing processes in the public sector are typically inadequate (Hazlett et al. 2008:62; Yang \& Ruan 2007:575 ff.). Often, there is neither a dedicated process nor established routines for transferring knowledge (Butler et al. 2008:264). Since elearning is conducted at the workplace, employees have difficulties in balancing work processes and spending time for learning or knowledge sharing due to their workloads (Bere et al. 2013:486; Hazlett et al. 2008:63; Langford \& Seaborne 2003:65 ff.). As a result, how to integrate e-learning into work processes needs further elaboration in different contexts.

Another related challenge is the lack of facilitators and managerial support. Both can have negative influences on the realisation of elearning and knowledge sharing (Hazlett et al. 2008:63; Langford \& Seaborne 2003:68 ff.; Sannia et al. 2009:51). Particularly in selfregulated learning environments, employees need to be trained to become tutors (Hârțescu (2012:497,499). Responsibilities and the roles in collaboration should be designated anew (Bimrose et al. 2014:57,59). Group members need to know the goals and topics of discussions, and they require the means for collaborative activities. Such boundaries offer a space to develop norms on how to share ideas and knowledge.

Why would information be shared? Stefanick and LeSage (2005:245 ff.) indicate that a dominant value in the public sector may be discretion; "[...] one of a municipal official's most unforgivable sins is to 'misspeak' in public" (244). Bureaucracy and hierarchical structures may override the interest to share information and work in teams (Hazlett et al. 2008:61). Moreover, public sector values have recently changed and may emphasise the competition for resources among employees (Amayah 2013:455). Though contrasting with traditional public sector values, competition can impede sharing behaviour as well. Consequently, how and which kinds of collaboration and cultural norms shape the introduction of e-learning today are salient questions to be answered and compared across public sectors.

The last selected aspect is the role of policies. The Organisation for Economic Co-operation and Development's (OECD 2003:3 ff.,15 ff.) report on knowledge sharing supports the importance of regulations for enabling or constraining practices. Legislative mechanisms should be in place to facilitate exchange of ideas in collaborative projects (e.g. Gil-Garcia et al. 2007). Nonetheless, which kinds of policies would constrain (or facilitate) the use of open e-learning platforms remain unclear. Clarity is also needed regarding the role and nature of technologies. Most studies report that e-learning offers are built on open-source products (Bere et al. 2014; Conci \& Bramati 2007:83 ff.; see also Gallego et al. 2008 concerning the diffusion of open-source software), yet it is unclear whether OERs (cf. Pirkkalainen \& Pawlowski 2010) are used. In the cases in Italy, learning objects may be shared and re-used (cf. Bere et al. 2014:466; Conci \& Bramati 2007:83 ff.), but more research is required to find out the technical facilities and (open) principles on which open e-learning is built.

Overall, this brief review of existing studies highlights potential challenges and topics to evaluate when introducing open e-learning. 
Similarities to organisational learning, knowledge management and trends such as e-government can be perceived. However, given the scarcity of generalised findings, the first question to be answered is as follows: What are the similarities and differences in barriers to open elearning across public administrations? Except for a few studies (e.g. Bere et al. 2014), most papers concentrate on single countries and aspects. To conduct a comparative study, the first step is to consider how the findings could be systematically captured. One suitable approach is to review barrier studies, which are introduced in the next subsection.

\subsection{Improvement on current approaches focusing on barriers}

Barrier studies systematically capture and cluster a range of challenges. In the context of public administrations, only a few examples can be cited. One notable approach is used in Eidson's (2009) thesis, which elaborates on a learning theory and practices in an e-learning wilderness class. As a result, several barrier categories to consider for e-learning design, including technical and pedagogical considerations, are provided, among others. Since the study focuses only on a particular program, Eidson (2009:153 ff.) raises doubts on whether the challenges can be generalised to other public administrations. This concern holds true for other approaches (cf. Chen 2014:454 ff.). An exception is Blindenbacher and Nashat's (2010) report about the framework they developed for knowledge creation across public and private sectors on a global scale. However, their framework provides guidelines for planning learning events instead of focusing on open e-learning challenges (Blindenbacher \& Nashat 2010:ch. 9,10).

What can be learned by focusing on barriers? Apart from concentrating on e-learning, the results from related trends can be addressed. Ebrahim and Irani (2005) elaborate on an e-government architecture, with challenges associated with introducing different features at the technical and organisational levels (among others). Regarding e-government and organisational learning, relevant theoretical considerations can also be found (cf. Phang et al. 2008). Emphasising knowledge sharing, Riege (2005) expounds on individual (23-25), organisational (25-29) and technical barriers (29-30) in organisations. Inspired to advance the research approach to elearning in public administrations in this respect, Stoffregen et al. (2015) synthesise lessons learned in various domains through a systematic review. The resulting CBF for open e-learning serves to guide future research. It extends similar work (Pirkkalainen \& Pawlowski 2014) on global collaboration, knowledge sharing and e-learning and provides a reference for comparative studies on related topics. Barrier dimensions in the CBF address the contextual, social and technical levels by providing categories and subcategories of challenges to open e-learning (Stoffregen et al. 2015). In addition to the cited studies, the CBF hints about aspects that have not yet been systematically addressed in e-learning studies, such as the role of rewards, collaboration and the meaning of culture (Stoffregen et al. 2015:9).

Overall, barrier studies thus appear to be suitable for comparing the introduction and use of open e-learning in different public administrations. For the outlined topics (state of e-learning, policies and role of OERs), the similarities and differences are systematically defined and compared. In this regard, the methodological considerations are outlined in the next section.

\section{Research design}

3.1. Research approach and strategy

As stated, open e-learning is understood as involving any situation and activity that include or are related to the use of technologies and OERs in the learning environment (Stoffregen et al. 2015). The OERs are defined as digital artefacts that can be reused, revised, redistributed or mixed with corresponding licences (Hilton et al. 2010:39-43;
Pirkkalainen \& Pawlowski 2010). As the unit of analysis, a barrier is defined as "[...] any challenge [...] related to acting or working in a [specific] setting" (Pirkkalainen \& Pawlowski 2013:5).

The research strategy of the present comparative study follows an abductive approach and is guided by an interpretive paradigm (Carson et al. 2001; Douven 2013). The CBF (Stoffregen et al. 2015) guides the inquiry and analysis as a conceptual, sensitising frame (Blaikie 2010:118-119). However, instead of testing whether predefined barrier categories apply, the goal is to understand different socio-cultural contexts of public administrations and how their characteristics shape the introduction of open e-learning. Correspondingly, the categories and dimensions of the barrier frameworks (BFs) guide the research but may be altered throughout the analysis. In this manner, the abductive approach is also valuable for structuring an exploratory, comparative approach while enabling an indepth analysis of a novel phenomenon (Carson et al. 2001:98 ff. 108 ff.; Yin 2014:59 ff.)

The selection of cases follows the replication logic; selected countries perform as multiple cases and constitute the unit of analysis, instead of considering the roles of multiple respondents within these cases. This approach allows assessing whether the results can be replicated, that is, observed (similar to experimental research) (Carson et al. 2001; Yin 2014). The inclusion of each case relates to its unique aspects and enables an enhanced understanding from different angles (e.g. Carson et al. 2001:102). The countries are introduced with regard to the selection criteria in the following section.

\subsection{Introduction to the empirical context}

To generate generalisable results, this study has included Luxembourg, Ireland, Montenegro and Germany in its sample. Public administrations at the local level are subject to different conditions and characteristics. The state of e-learning ranges from established programs (Luxembourg) to a low developmental level (Germany), emerging (Ireland) and non-existent programs (Montenegro). Correspondingly, the range of core e-learning actors is either clearly defined (Luxembourg and Ireland) or distributed and unclear (Germany and Montenegro). Public administrations in Ireland and Montenegro face changes in training due to reforms, while reforms are modest in Luxembourg and Germany.

More generally, the sample covers both centralised (Luxembourg and Ireland) and federated structures (Germany and Montenegro), with a high autonomy of individual municipalities in Germany. Based on this sample, distinctions in the results can be assessed regarding the state of e-learning, range of actors and state structure. Related considerations are addressed in the discussion (Section 5).

To elaborate on similarities and differences in barriers to open elearning in different public administrations, an exploratory design has been chosen. Conceptual inferences will be drawn. The implications of the findings will also inform current practices, such as the EAGLE project, which aims to improve learning conditions of public administrations at the local level. Compared to existing e-learning platforms, EAGLE develops a collaborative, open-source platform to enable the exchange of experiences and knowledge across public administrations. To highlight this point, EAGLE is planning to introduce OERs in the training of public employees. Hence, learning contents will be open in terms of reusability (cf. Hilton et al. 2010) and may be created by public employees themselves. So far, none of the four countries offers public employees a similar training program. Current training programs appear to be thoroughly prepared and managed by dedicated institutions and consortia (see Table 1 and Blindenbacher \& Nashat 2010:ch. 9; Eidson 2009:19 ff.). The barriers found in this study will thus inform projects for the innovation of training and organisational learning in the public sector. 
Table 1

\begin{tabular}{|c|c|c|c|c|}
\hline Country & Sector characteristics & State of e-learning & Roles of recent reforms & Core actors \\
\hline Luxembourg & $\begin{array}{l}\text { Centralised, traditional } \\
\text { bureaucracy, small staffed } \\
\text { municipalities }(<10) \text { (EFI } \\
\text { 2013b:1,4) }\end{array}$ & $\begin{array}{l}\text { Right to learning, several programs, } \\
\text { e-learning among traditional } \\
\text { courses, e-courses not open (PGDL } \\
\text { 2013, 2014) (EFI 2013b:11,13) }\end{array}$ & $\begin{array}{l}\text { No recent radical reforms, no major changes } \\
\text { in the training sector (EFI 2013b:5 ff.) }\end{array}$ & $\begin{array}{l}\text { Institution National pour Administrations } \\
\text { Publiqué (MGDL 2014), Syvicol, Ministry of } \\
\text { Civil Service and Administrative Reform } \\
\text { Inter-Communal IT Management Association } \\
\text { (EFI 2013b:1; EC 2014b:19 ff.) }\end{array}$ \\
\hline Ireland & $\begin{array}{l}\text { Highly centralised } \\
\text { structures but involve } \\
\text { counties rather than } \\
\text { municipalities (CI 2014; } \\
\text { EFI 2013b:1) }\end{array}$ & $\begin{array}{l}\text { Right to learning (Circular 23/2007 } \\
\text { Government of Ireland, 2007), } \\
\text { e-learning is available, materials are } \\
\text { partly open (CSTDC 2011:17, 2014) }\end{array}$ & $\begin{array}{l}\text { Incredible reforms (EC 2014a; EFI 2013a:6 } \\
\text { ff.), new training framework, new training } \\
\text { methods, flexible work shifts, terms and } \\
\text { conditions of employment changed (e.g. } \\
\text { CSTDC 2011:8,14) }\end{array}$ & $\begin{array}{l}\text { Local Government Management Services } \\
\text { Board; Department of Public Expenditure and } \\
\text { Reform; Civil Service Training and } \\
\text { Development Centre (CSTDC 2011:4; EFI } \\
\text { 2013a) }\end{array}$ \\
\hline Montenegro & $\begin{array}{l}\text { Ministries are } \\
\text { inadequately staffed (EC } \\
\text { 2013:7 ff.,35) }\end{array}$ & $\begin{array}{l}\text { Weak training system, no e-learning } \\
\text { (Dujić et al. 2006:18,32; RESPA } \\
\text { 2008:47) }\end{array}$ & $\begin{array}{l}\text { EU-association process (EC 2013:3), new law } \\
\text { for training (Dujić et al. 2006:16,24,34 ff.; EC } \\
\text { 2013:8; RESPA 2008:45 ff.) }\end{array}$ & $\begin{array}{l}\text { Human Resource Management Authority, } \\
\text { Regional School of Public Administration (EC } \\
\text { 2014c; RESPA 2008:45) }\end{array}$ \\
\hline Germany & $\begin{array}{l}\text { Separation of powers } \\
\text { (BMI 2009:10 ff.) }\end{array}$ & $\begin{array}{l}\text { Federal and state training programs, } \\
\text { federal working groups (FHoeD } \\
\text { 2014), e-learning also available but } \\
\text { not open }\end{array}$ & $\begin{array}{l}\text { No new training laws (BLV §§ 6,46; BMI in } \\
\text { press), increasing demand for flexible, } \\
\text { self-responsible employees in terms of } \\
\text { knowledge improvement (BMI 2009:24 ff.) }\end{array}$ & $\begin{array}{l}\text { Shared responsibilities among ministries or } \\
\text { dedicated institutions (FHoeD 2014) }\end{array}$ \\
\hline
\end{tabular}

3.3. Data collection and analysis

Several focus group sessions and interviews were conducted with public employees and key stakeholders, such as public managers, leaders and representatives of public sector institutions (Kitzinger 1994; Morgan 1997). Specifically, the participants were civil servants, administrative staff, human resource managers, advisors, senior employees, mayors and front-office or technical back-office employees $(n=68)$. On average, there were 6.5 participants in the workshops (focus groups), which lasted about $2.5 \mathrm{~h}$ each. Overall, 32 municipalities, one district in Ireland and one public academy in Germany were involved.

Based on the topics (as defined in the literature review) and the results of a pre-study in the EAGLE project, a set of questions was listed. A coherent structure for conducting the workshops in the countries was prepared to streamline the assessment. Table 2 summarises the overall process and the main questions for the workshop.

Difficulties in scheduling the workshops were experienced in the municipalities in Ireland and Germany. One reason involved personnel constraints in the public sector; thus, public employees had no free time to attend a meeting. Furthermore, the administrations in all four countries were involved in organising elections for local government authorities or the Parliament of the European Union (EU). Nevertheless, the participation rates of public employees across the countries were equally high, except for Ireland. The limitations in this respect are explained in Section 5 (discussion).

Once the workshops were held, the results were documented in four country reports and translated into English. The subsequent analysis can be described as an interpretive content analysis (Mayring 2010:98-101), including a pattern-matching technique (Trochim 1989; Yin 2014:143-147). In this study, the patterns referred to the nature and meaning of the barriers that were found, compared and synthesised among the country results and with regard to the CBF (cf. Yin 2014:188). To secure intercoder reliability, the country reports were analysed separately by workshop leaders and an additional reviewer. Diverging perspectives were discussed and resolved. With this iterative approach of analysing country results regarding the $\mathrm{CBF}$, content validity was strengthened. However, the quality of the findings is reconsidered in the discussion (Section 5). The findings are presented in the following section.

\section{Results of the analysis}

\subsection{Overview of findings and barrier dimensions}

The analysis has led to defining similar and different barriers at the contextual, social and technical levels (see Table 3). Contextual barriers describe the challenges that emerge in time and space from a certain situation, organisation or task, such as e-learning. They are manifested in artefacts such as laws, the workplace environment or sectorial structures. In contrast, social barriers focus on humans as the main subject of inquiry and challenges. They relate to personal and group-related perceptions, behaviours or characteristics from the national to the individual level. Technical barriers constitute another dimension that relates to technology characteristics, focus on artefacts and entities with digital features, and address or require digital and electronic processes.

\subsection{Dimension: Contextual barriers}

In the contextual dimension, four barrier categories describe the main set of differences and similarities among the four countries. The first category relates to the barriers that constitute the lack of resources to establish a learning environment. Beginning with the subcategory lack of financial support, Luxembourg and Germany generally have budgets to invest in training, while in Ireland and Montenegro, resources are scarce. However, investment is generally subject to constraints. For example, in Luxembourg, central learning programs are offered for free, so additional programs may need to be paid for in advance. However, the Institution National pour Administrations Publiqué (INAP) often pays for the costs if evidence for the usefulness and completion of tasks is demonstrated. Except for Luxembourg, financial support from central levels is more likely if a sufficient number of civil servants (a critical mass) will take part in the program. For small local municipalities and special learning needs, this principle poses a constraint to the establishment of learning activities. Two further subcategories are the lack of space and lack of time to dedicate to learning activities. In all countries, the latter point is related to the high workload. The participants highlight the importance of learning at the workplace and being given the time to learn during work hours. Only in Germany do public employees show some interest in e-learning at home (for professional reasons). Another subcategory that constrains the learning environment is the lack of personnel. The turnover and rotation of employees reduce the chance to participate in learning activities; considering the already understaffed situation, another colleague's time off from work to attend the learning program would make the workload unmanageable for the remainder of the employees. The final subcategory that hinders the learning environment is the lack of learning contents in all four countries. Moreover, for the participants in Ireland and Germany, it is unclear what OERs might be and thus whether related resources are available. The lack of resources in Montenegro is further subject to language issues, a point referred to again later.

The second category of contextual barriers refers to policy coordination or management by law. Its first subcategory is a set of constraining regulatory frameworks. The countries share that e-learning has no 
Table 2

\begin{tabular}{|c|c|c|}
\hline Phase & Step & Description/set of questions \\
\hline \multirow[t]{2}{*}{$\begin{array}{l}\text { Welcome and } \\
\text { introduction }\end{array}$} & 1. Awareness building & $\begin{array}{l}\text { Introduce EAGLE. Build awareness of } \\
\text { e-learning and OERs in public } \\
\text { administration. Depending on the } \\
\text { audience, present an introduction to } \\
\text { OER and e-learning. Good practices, } \\
\text { as well as organisational and } \\
\text { individual benefits, could be } \\
\text { presented. }\end{array}$ \\
\hline & $\begin{array}{l}\text { 2. Introduction of } \\
\text { participants }\end{array}$ & $\begin{array}{l}\text { Ask each workshop participant to } \\
\text { briefly introduce his or her } \\
\text { institution/department and describe } \\
\text { his or her expectations regarding the } \\
\text { workshop. Introduce the nature of } \\
\text { focus groups, including ethical and } \\
\text { procedural conditions, to } \\
\text { participants. }\end{array}$ \\
\hline \multirow[t]{8}{*}{$\begin{array}{l}\text { Group } \\
\text { discussion }\end{array}$} & $\begin{array}{l}\text { 3. Understanding the } \\
\text { context }\end{array}$ & $\begin{array}{l}\text { Explain why it is necessary to } \\
\text { understand the general situation of a } \\
\text { public administration } \\
\text { authority/organisation/department } \\
\text { for EAGLE. The main contextual } \\
\text { factors may be policies, guidelines or } \\
\text { incentives, for example. }\end{array}$ \\
\hline & $\begin{array}{l}\text { 4. Requirements/Barrier } \\
\text { analysis }\end{array}$ & $\begin{array}{l}\text { Explain the discussion plan (topics) } \\
\text { and begin asking questions. Ask the } \\
\text { participants to discuss the main } \\
\text { categories of the context (or specific } \\
\text { situations). Ensure that in case a } \\
\text { related project is mentioned, barriers } \\
\text { within this project are discussed. }\end{array}$ \\
\hline & $\begin{array}{l}\text { 5. Set of overall } \\
\text { questions }\end{array}$ & $\begin{array}{l}\text { Status of e-learning - What is the role } \\
\text { of (e-) learning in your organisation? } \\
\text { Policy - What are the key policies and } \\
\text { conditions for (e-) learning in your } \\
\text { organisation? }\end{array}$ \\
\hline & & $\begin{array}{l}\text { Projects - What are the key projects } \\
\text { related to the use of technology in } \\
\text { (e-) learning? } \\
\text { Processes - What are favourable } \\
\text { learning/training methods from your } \\
\text { perspective? }\end{array}$ \\
\hline & & $\begin{array}{l}\text { Roles - Which roles do you and your } \\
\text { colleagues play in the (e-) learning } \\
\text { processes? }\end{array}$ \\
\hline & & $\begin{array}{l}\text { Knowledge - What are the main } \\
\text { skills needed to realise online } \\
\text { learning? }\end{array}$ \\
\hline & & $\begin{array}{l}\text { Curricula - What are the current } \\
\text { schemes for (e-) learning/career } \\
\text { development in your organisation? } \\
\text { Culture and collaboration - Are you } \\
\text { comfortable with sharing knowledge } \\
\text { or discussing questions that arise } \\
\text { during work? }\end{array}$ \\
\hline & & $\begin{array}{l}\text { Technology - Can you describe which } \\
\text { technologies and programs you use in } \\
\text { your workplace? }\end{array}$ \\
\hline \multirow[t]{2}{*}{$\begin{array}{l}\text { Refining } \\
\text { results of } \\
\text { the } \\
\text { discussion }\end{array}$} & $\begin{array}{l}\text { 6. Intervention } \\
\text { prioritisation }\end{array}$ & $\begin{array}{l}\text { For each barrier, solutions } \\
\text { (interventions) should be discussed } \\
\text { and prioritised. Be sure to relate the } \\
\text { barriers/interventions to the } \\
\text { interventions proposed by EAGLE. }\end{array}$ \\
\hline & $\begin{array}{l}\text { 7. Scenario/action } \\
\text { planning }\end{array}$ & $\begin{array}{l}\text { Depending on the available time, } \\
\text { scenarios and actions should be } \\
\text { discussed. Ask for scenarios on how } \\
\text { EAGLE could advance the current } \\
\text { learning situation in the workplace. }\end{array}$ \\
\hline Closure & 8. Outline of follow-up & $\begin{array}{l}\text { Debrief the participants and outline } \\
\text { the follow-up procedure, consisting } \\
\text { of data analysis and upcoming } \\
\text { workshops in the project. } \\
\text { Deepen knowledge through } \\
\text { interviews (following the workshop) } \\
\text { with at least three key stakeholders. } \\
\text { Announce that another event at the } \\
\text { end of the analysis will follow to }\end{array}$ \\
\hline
\end{tabular}

\begin{tabular}{|c|c|c|}
\hline Phase & Step & Description/set of questions \\
\hline & & $\begin{array}{l}\text { show the results and success } \\
\text { stories/examples. }\end{array}$ \\
\hline
\end{tabular}

particular corresponding policy framework. E-learning offers would thus need to be interpreted within the (often unfamiliar) training regulations. Due to the open character of the resources, the participants are concerned about intellectual property rights (IPRs), the authorship regulation of OERs and content reliability. Established laws may counteract reforms, for instance, policies that regulate knowledge management and information exchange, bringing your own device (BYOD) to work (Montenegro and Germany), and accessibility regulations (Ireland). The second subcategory of barriers to the implementation of open elearning constitutes the uncoordinated implementation efforts and related reforms. Research has emphasised that reforms are weakly communicated throughout the countries and administrative sectors. For example, in Ireland, the participants report the perceived lack of policies to coordinate learning. However, due to recent reforms, the policies are actually in place. In Montenegro, the lack of policies for open data is mentioned by the workshop participants as well although the country is about to associate itself with the Open Government Partnership (OGP). ${ }^{4}$ Similarly, the public employees in Germany state that no platforms for e-learning in the public sector are in use yet; however, several applied universities for the public sector offer resources and guidance.

Apart from the lack of communication and awareness about reforms, changes and reforms are handled reactively (e.g. Luxembourg and Germany). Public administrations at the local level have not yet implemented a systematic change management process, which should align the efforts to introduce e-learning in the sector and facilitate the implementation. The lack of systematic change is combined with the subcategory organising training offers. There tends to be no process of informing stakeholders about available training programs (e.g. Luxembourg and Ireland). Information brochures were distributed in Luxembourg, but this medium did not reach the interested learners. Finally, related to the lack of organisation of training offers, training needs assessments are not regularly performed at the local level, and the results are not transferred to the responsible institutions (e.g. Luxembourg and Montenegro). Another subcategory of barriers with the hindsight on training systems is the lack of rewards. In all four countries, the participants perceive a disconnection between learning efforts and career promotion. Except for Luxembourg, there is often no established performance-based reward system, and an accreditation mechanism is absent in all four countries. This subcategory includes providing feedback and recognition to individuals who make the effort of organising and completing a training program.

The third barrier category involves managerial practices in the public sector. Its first subcategory is the role of the hierarchy. For example, in Montenegro, the participants require official approval to share information. In Germany, employees generally welcome the opportunity to share knowledge but show some preference for discussing issues with their superiors instead of colleagues. Hence, centralised communication flows may impede open sharing on platforms. Another subcategory is the lack of leadership in reforms. In Luxembourg, Montenegro and Germany, the lack of tutors and positions is criticised in terms of who would be assigned to coordinate learning programs. The workshop participants in all four countries further claim that political support is important to step up reforms but has not been provided for learning efforts so far.

The final category of barriers involves the perceived technological fit of tasks and reforms, such as e-learning. As its first subcategory, the sustainability of technical artefacts and reforms should be highlighted.

\footnotetext{
${ }^{4}$ When associating with the OGP, its requirements should be fulfilled (www.
} opengovpartnership.org/how-it-works/eligibility-criteria). 
Table 3

\begin{tabular}{ll}
\hline $\begin{array}{l}\text { Overview of barrier categories. } \\
\text { Barrier } \\
\text { dimension }\end{array}$ & Categories \\
\hline Contextual & $\begin{array}{l}\text { Lack of resources, managerial practices, management by law (policy } \\
\text { coordination), perceived technological fit } \\
\text { Cocial } \\
\text { Characteristics at the national level, value of information, digital } \\
\text { divide, characteristics at the organisational level, quality of } \\
\text { information, cognitive backgrounds, individual concerns, ICT skills, }\end{array}$ \\
$\begin{array}{l}\text { lack of knowledge } \\
\text { Technical ability, technical and conceptual differences, perceived } \\
\text { functionality, interoperability, privacy and security, usability and } \\
\text { system quality }\end{array}$ \\
\hline
\end{tabular}

Except for Ireland, all the participants have critical concerns about the maintenance of the platform and learning resources. This issue is especially important in the case of an open platform, which is primarily built from the contributions of its users. The second subcategory is the general aversion to the quest for evidence-based success of e-learning. The participants in Luxembourg and Montenegro outline their reservations in shifting to e-learning. The German and Luxembourgish participants are critical about the additional benefits and have asked to streamline existing offers with a novel training initiative.

\subsection{Dimension: Social barriers}

Several challenges and differences have been found in the dimension of social barriers (see Table 5). For the first category, characteristics at the national level, one major subcategory that appears is the role of language. Luxembourg has three official languages, one of which (German) it shares with Germany. Germany has two regions with two official secondary, minority languages (Danish and Sorbian), but every civil servant in public administration masters German. Ireland and Montenegro have no shared set of languages with the other countries in this study. Collaboration may thus be impeded due to linguistic diversity.

For the category characteristics at the organisational level, three subcategories have been found. One is the role of the common understanding of the meaning of open content, the sharing and conduct of knowledge exchange. Interestingly, the participants across all departments and countries tend to share a similar perspective. This first subcategory reflects a shared learning paradigm. Gathered information should be immediately applicable. Furthermore, learning is less valued than executing daily work tasks and thus less accepted among colleagues. Related to this, the participants tend to similarly describe the relevance of training content for work activities as a requirement to start learning. Relevance is associated with topics (contents) that provide applied and practice-oriented solutions to improve daily work. Norms that shape interactive learning are also considered relevant by the public employees. When they imagine collaborating with foreign civil servants, the participants in Luxembourg wonder whether the same understanding of privacy (ethics) would be shared. Two examples are spamming e-mail accounts and providing feedback (comments) about created learning contents (OERs). The second subcategory is the lack of encouragement to share knowledge and to collaborate with others. Except for the German participants, the others mention the lack of feedback that needs to be remedied. The third subcategory is the role of current organisational routines in collaborating and learning. The participants cite the lack of knowledge sharing within their respective institutions and across the public sector. The current routine is based on informal sharing of information and is a voluntary practice. Correspondingly, the idea of a compulsory e-learning program is rejected. An activity that would allow monitoring and control of performance would not be part of the public sector culture.

Another category is the role of individual concerns. Its first subcategory is socialisation, which describes concerns about losing ties and communication with colleagues (when transferring training activities online). Except for Ireland, the participants mention that personal ties and relationships are essential for exchanging information. Digital exchange is perceived as impersonal, so there is concern about whether e-learning is an appropriate mode of knowledge exchange among individuals. Closely related with this issue is the second subcategory, misunderstanding due to loss of information richness. In Luxembourg, the participants are concerned that clarification of understanding is difficult to communicate; similarly, disagreements in online forums will be difficult to solve via technical means. The participants in Montenegro indicate that they will also feel uncomfortable if they have to openly disclose online that they have misunderstood something. Finally, several individuals express their reservations concerning self-regulated learning. Their perceived required efforts for the new learning trend, such as increased personal discipline and integration of learning sessions into their daily work practices, are met with low motivation or scepticism (Germany and Montenegro).

Last but not least, a category refers to the perceived value of information. The lack of mutual trust in information exchange among colleagues is one subcategory. There is concern about the reliability of the information provided by colleagues. Another subcategory is the concept of information and knowledge as power. In Germany, some participants point out that the perceived competition among municipalities might reduce the willingness to collaborate in a few fields of knowledge.

In Table 5, another category elaborates on the quality of information, which is less oriented towards human interaction and more towards the characteristics of transferring information. This point relates to issues of trust in digital information and virtual contact raised by public employees in Germany and Ireland. The second subcategory comprises the methods to increase trust when assessing information. Germany and Luxembourg require that access to and production of informative resources be regulated. Furthermore, the rating of open contents is demanded to easily assess whether these are valuable (Luxembourg, Ireland and Germany).

The sixth and seventh categories in the social dimension are the role of ICT skills and the lack of knowledge about open e-learning, respectively. The first subcategory of the sixth category refers to the low level of ICT skills and lack of objective assessment of the competencies (all countries). The seventh category addresses the subcategory low familiarity with and awareness about OERs, which includes understanding of the meaning of openness (Ireland, Luxembourg and Montenegro). This barrier appears to reflect the non-coordination of relevant reforms in the sector. The second subcategory is the low familiarity with technical practice. In all four countries, only a few civil servants have ever practised e-learning.

Finally, a category in Table 5 is the role of cognitive backgrounds. One subcategory is the diversity of backgrounds. The participants in Luxembourg and Germany explain that the diversity of administrative processes is a reason for low collaboration, particularly across national boundaries. Moreover, the Montenegrin participants note possible difficulties in collaborating with one of the other three European countries. Another subcategory pertains to the differences in curricula. The German participants argue that collaboration across national boundaries only makes sense if learning topics are broad. Examples are soft skills or EU projects, while specific topics such as administrative processes are perceived as national matters. In Luxembourg and Montenegro, public employees require that contents and learning groups be separated according to job specifications. The Irish participants have a contrasting perspective on this point. They explain that specific learning contents are not helpful since job rotations require transverse skills and general knowledge to cope with varying demands.

Apart from qualifying how backgrounds constrain collaboration, a similarity is found regarding the orientation by experts. Particularly, the participants in Luxembourg and Germany emphasise that learning will succeed if experts convey and share information. Another subcategory that the participants in all four countries mention concerns the geographic boundaries in relation to collaborative learning. Current 
and forthcoming collaborations are shaped by spatial proximity. Physically close municipalities can easily collaborate (Luxembourg and Montenegro), but doing so with more distant municipalities, including those separated by national borders, is considered doubtful. Therefore, the contents in the search process for an e-learning platform should also represent sources according to the spatial proximity between municipalities.

The ninth and final category is the role of the digital divide and its subcategory demographic challenges. In Luxembourg and Germany, the older participants appear to be less interested in learning, due either to their approaching retirement or, as qualified by the Montenegrin participants, not being digital natives.

\subsection{Dimension: Technical barriers}

In the dimension of technical barriers, one category is the availability of technical resources. One subcategory is the shortage of appropriate infrastructure and software. In Luxembourg and Ireland, availability of the Internet depends on the job position. People working outdoors have no fixed workplace and access to the Internet. In Montenegro and Germany, facilities may be shared, depending on the job conditions, so employees have to arrange for their use of the facilities. Only a few participants in Luxembourg have smartphones for official use; phones are neither provided as a general means of communication nor for health and safety purposes (depending on the job profile). Concerning Internet facilities, another aspect is the lack of broadband. The participants in Montenegro and to some degree, in Germany, claim that they only have access to low bandwidth and weak connections, which would hamper the use of e-learning facilities.

Another category involves the interoperability among platforms. In Germany and Ireland, a heterogeneous landscape of multi-platform settings is mentioned as a barrier for integrating shared or coherent systems. As a result, the lack of interoperable applications is named as a barrier, too.

With the subcategory lack of documentation of the digital systems in Luxembourg, another category has been added - the influence of technical and conceptual differences in the public sector. Together with the information about interoperability and bandwidth capacity of municipalities, however, the lack of documentation of the systems should be qualified on behalf of more direct questions and research in the future.

More specific findings have been assigned to the category concerning privacy and security provisions and particularly, the role of reliable and secure networks. The Luxembourgish participants call for the development of a closed system; similarly, the German participants demand allowing e-learning systems to operate on state networks. Otherwise, as cited by the Luxembourgish and Montenegrin participants, Internet Protocol address might be subject to restrictions and thus be inaccessible to employees over the long term. Concerning the security of technical systems, the role of security standards and rules is also mentioned as a potential challenge for the introduction of new open systems.

Another category is the perceived functionality of the systems. One subcategory is the technical restriction of access. The Luxembourgish and Montenegrin participants ask for technical solutions to restrict access to and use of the resources and platform. Another subcategory raised with regard to e-learning is the tracking of data. The German participants express interest in tracking achievements and the time spent in learning. At the same time, there is aversion by other German participants towards evaluation of work performance including how long each person has stayed online.

A final category is the usability of applications and system quality. One subcategory is the perceived interface usability. Both the display of resources and resource allocation should be specified for the relevant (national) context. A further subcategory is the role of bugs in the system. In Germany and Ireland, the workshops show that devoting additional learning efforts to acquire the ability to handle the platform would have a negative influence on taking up a novel system. An overview of the findings is provided in Table 6 .

\subsection{Summary of the comparison}

Beginning with similarities, the first surprising point is that more common barriers are reported than unique ones. Hence, public employees in different administrations and at varying levels perceive similar barriers to the introduction of an open e-learning platform but less country-specific challenges. An important point is that the barriers appear in different administrations despite their distinct characteristics (Table 4), as illustrated in this paragraph. First, irrespective of the role of recent reforms, public administrations at the local level have often not yet established a strategy for providing training. Second, in this regard, having highly centralised (Luxembourg) or federated structures (Germany) or being in constant restructuring processes (Montenegro) seems to make no difference in whether training offers (from dedicated institutions) are well communicated across levels and known by public employees at the local level. Third, despite the small-staffed municipalities in Luxembourg, no lack of personnel for replacing colleagues is highlighted in this context. Due to reforms in Ireland and Montenegro, as well as in Germany, the challenge concerns the perceived barriers to the introduction of open e-learning. Despite these and other similar barriers, simply providing an open e-learning system will not result in collaboration. The perceived barriers may impede the development and use of an open e-learning system across diverse contexts. However, facing a set of shared barriers may allow designing a targeted intervention and a collaborative solution across several public administrations.

In terms of differences, a unique aspect in Germany involves one participating municipality's concerns about collaboration due to the competition among administrative levels. A priority for public employees in Germany is the need for short-term success stories showing the benefits of e-learning to secure political support and financial investment. In Luxembourg, a unique wish is to have OERs validated either by a centralised, government-supported institution or a team of municipal employees. It would ensure the adequate quality of OERs without legal infringements as well. A priority in Luxembourg is to integrate an open e-learning platform (such as EAGLE) technically and conceptually into the existing program and training system. In Ireland, the current job rotation in times of reforms seems to impact the learning needs. Compared to the administrations in the other countries, specific expertise and knowledge are not of interest but general, transverse skills. A priority defined in Ireland is to further establish mechanisms to store knowledge and avoid its loss when employees rotate positions. In Montenegro, insufficient basic infrastructure capacities are perceived as constituting a main barrier to overcome. The role of regulatory

Table 4

Overview of contextual barriers.

\begin{tabular}{|c|c|c|}
\hline \multicolumn{3}{|c|}{ Dimension: Contextual barriers } \\
\hline Category & Lack of resources & Managerial practices \\
\hline - Subcategory & $\begin{array}{l}\text { y Lack of financial } \\
\text { support } \\
\text { Lack of space } \\
\text { Lack of time } \\
\text { Lack of personnel } \\
\text { Lack of contents }\end{array}$ & $\begin{array}{l}\text { - Hierarchy (organisational struc- } \\
\text { ture) } \\
\text { - Lack of leadership in reforms }\end{array}$ \\
\hline $\begin{array}{l}\text { Category } \\
\text { - Subcategory }\end{array}$ & $\begin{array}{l}\text { Management by law } \\
\text { (policy coordination) } \\
\text { Constraining regula- } \\
\text { tory frameworks } \\
\text { Uncoordinated im- } \\
\text { plementation } \\
\text { Lack of organised } \\
\text { training offers } \\
\text { Lack of rewards }\end{array}$ & $\begin{array}{l}\text { Perceived technological fit } \\
\text { - Sustainability of technical arte- } \\
\text { facts } \\
\text { General aversion to the quest for } \\
\text { evidence-based success }\end{array}$ \\
\hline
\end{tabular}


Table 5
Overview of social barriers.

\begin{tabular}{|c|c|c|c|}
\hline \multicolumn{4}{|c|}{ Dimension: Social barriers } \\
\hline Category & Characteristics at the national level & Value of information & Cognitive backgrounds \\
\hline - Subcategory & y Role of language & $\begin{array}{l}\text { Lack of mutual trust } \\
\text { Concept of information and knowledge as power }\end{array}$ & $\begin{array}{l}\text { Diversity of backgrounds } \\
\text { Differences in curricula } \\
\text { Orientation by experts } \\
\text { Geographic boundary }\end{array}$ \\
\hline Category & ICT skills & Quality of information & Individual concerns \\
\hline - Subcategory & $\begin{array}{l}\text { y Low level of ICT skills } \\
\text { Low level of objective } \\
\text { assessments }\end{array}$ & $\begin{array}{l}\text { Characteristics of transferring information } \\
\text { Methods to increase trust when assessing } \\
\text { information }\end{array}$ & $\begin{array}{l}\text { Socialisation } \\
\text { Misunderstanding due to loss of information richness } \\
\text { Reservations concerning self-regulated learning }\end{array}$ \\
\hline Category & Digital divide & Lack of knowledge about open e-learning & Characteristics at the organisational level \\
\hline - Subcategory & y Demographic challenges & $\begin{array}{l}\text { Low familiarity and awareness } \\
\text { Low familiarity with technical practice }\end{array}$ & $\begin{array}{l}\text { Lack of common understanding } \\
\text { Lack of encouragement to share knowledge and collab- } \\
\text { orate }\end{array}$ \\
\hline
\end{tabular}

frameworks for learning is prioritised as a means of introducing an open e-learning platform such as EAGLE. Moreover, the Montenegrin participants admit their lack of interest in contributing to a collaborative platform. Before they would contribute or participate, knowledge should first be transferred from other countries.

Overall, similar barriers are found, but the priorities vary among the four countries. These priorities range from basic technical and legal infrastructure concerns (Montenegro) and the demand to provide more concrete evidence of the need for and benefits of OERs (as means of political argumentation in Germany) to issues of the nature of open contents (such as the kind, quality and validity of contents in Luxembourg, Germany and Ireland). The next section discusses these rich results and implications from different perspectives.

\section{Discussion}

In the public sector domain, previous studies have mostly focused on single countries. Following this present study, various barriers that are perceived in public administrations at different levels, and in several countries can now be assessed. Some priorities are discussed and results are compared with regard to the unique characteristics of the public sector in each country. This approach extends previous findings, for example, about the challenges to collaboration. Public employees wonder whether their peers in other administrations and countries have similar ideas about the quality of contents of open e-learning or the criticism of others regarding their contributions. Quality is related to the adequacy and accuracy of the contents, a principle and a value shared by superiors and experts. Another insight relates to the role of management. Communication about and coordination of available programs are found to be weak across different administrative levels. At the same time, the participants demand that new offerings be integrated into existing training programs to ensure that learning efforts are officially accepted and rewarded. The role of rewards or connecting career and learning efforts has been discussed ambiguously in previous literature (Amayah 2013:463 ff.; Yang \& Maxwell 2011:173). In this present study, rewards appear to constitute a positive, motivating factor as long as the programs are not mandatory or the activities on the platforms are not tracked. The findings encourage further research about this topic. Experimental and exploratory approaches could be used to gain deeper insights, such as the recommendations of Yang and Wu (2008). The authors elaborate from a game-theory perspective how "[...] different organizational incentives [can be used] to promote knowledge sharing in an organization" (Yang \& Wu 2008:1129). The roles of policies, current initiatives and collective capability are modelled and may provide directions for public-sector research.

Following the results of this present study, Yang and Wu's (2008) approach may offer further insights. Several barrier studies were conducted in the domain of international educational contexts (Pawlowski et al. 2014; Riege 2005). This present study allows comparisons of the findings for different (educational, public, private) sectors as well. For example, in public administrations, the role of laws and regulations has gained importance. However, IPR and OER licences raise concerns in educational settings, too (Pirkkalainen \& Pawlowski 2013:12). For example, users said: "I am not sure about the licensing details. I don't want to share resources that someone else own rights to etc. (IPR issues in general (intellectual property rights))" (Pirkkalainen \& Pawlowski 2013:13). The claims to regulate (i.e., allow spending) the time for learning and to resolve potential conflicting policies (such as BYOD) are also mentioned. The importance of regulations for knowledge management-related practices was previously known (OECD 2003), but this present study allows qualifying that legal frameworks at both national and local levels guide public employees and may become perceived barriers. Due to this, further research on the unique effect of red tape in the public sector on open e-learning should be conducted in the future across different public administrations. Another example is the role of responsible persons in coordinating open e-learning activities. Although the use and creation of OERs build on self-regulatory learning activities, the roles of tutors and people who validate the coherence and accuracy of efforts and programs are emphasised as important in most public administrations. However, the coordinating position is either vacant or the responsibilities are not attached to the position, or the person responsible does not perceive coordination as important

Table 6

Overview of technical barriers.

\begin{tabular}{|c|c|c|c|}
\hline \multicolumn{4}{|c|}{ Dimension: Technical Barriers } \\
\hline Category & Availability of technical resources & Technical and conceptual differences & Perceived functionality \\
\hline - Subcategory & $\begin{array}{l}\text { Shortage of appropriate infrastructure, } \\
\text { software } \\
\text { Lack of broadband }\end{array}$ & $\begin{array}{l}\text { Lack of documentation (including concepts, references and } \\
\text { taxonomy) }\end{array}$ & $\begin{array}{l}\text { Availability (visibility) of tracking } \\
\text { data } \\
\text { Technical restriction of access }\end{array}$ \\
\hline Category & Interoperability & Privacy and security provisions & Usability and system quality \\
\hline - Subcategory & $\begin{array}{l}\text { Multi-platform settings } \\
\text { Lack of interoperable applications }\end{array}$ & $\begin{array}{l}\text { Reliable and secure networks } \\
\text { Role of security standards and rules }\end{array}$ & $\begin{array}{l}\text { Perceived interface usability } \\
\text { Bugs in the system }\end{array}$ \\
\hline
\end{tabular}


This situation may reflect that learning in public administrations, compared to educational institutions, is not the primary goal and means of work; correspondingly, learning may be less valued than daily work activities (cf. Eidson 2009:47). As a result, guidelines should be provided to a coordinator in public administration at the local level to shift the coordination of e-learning and advanced education from the sidelines to the main tasks to be fulfilled.

The methodological and theoretical implications of this cross-public administration study address the level of analysis for future studies. Comparisons at both the country level and across administrations have been made. At the country level (as presented in Table 4), variances of responses and perceived barriers can hardly be observed. However, at the administrative level, nuances could be clarified as described in the reported analysis. Both in the educational context (Richter \& Adelsberger 2012) and the public-sector domain, there are discussions about which level of aggregation is best suited to explore differences. For instance, the results indicate that the national level may be appropriate for distinguishing between German and Korean higher education, but variances within sectorial results increase understanding (Richter \& Adelsberger 2012:14). For western European countries and public administrations more specifically, Beuselinck et al. (2007:105) indicate that a more granular approach than the national level is needed. The empirical findings in this present study suggest a granular approach at the administrative level to make meaningful differences, particularly since this study focuses on public administrations at the local level.

Another implication for future studies comes from the experienced use and contextualisation of the BFs (Pirkkalainen \& Pawlowski 2013, 2014; Stoffregen et al. 2015). They were adapted to the context of public administrations and applied in the requirements analysis for the EAGLE project. The rich insights into the challenges in Luxembourg, Montenegro, Ireland and Germany suggest that the BFs guide an exploratory research into the public-sector domain. The categories and subcategories in the CBF have generally been supported by the empirical findings in all four countries. This suggests that the previous categorisation of the CBF can be corroborated. On one hand, both for single and comparative cases, the frameworks thus appear to be suitable for systematically evaluating similarities and differences of barriers in the public sector. The authors have clearly stated that the empirical findings have led to the redefinition of the meaning and relevance of several categories. For example, the finances category indicates not only a limited budget per se, which reduces investment in e-learning, but also restrictive principles to be considered in implementation designs. Hence, the BF (Pirkkalainen \& Pawlowski 2014) and CBF (Stoffregen et al. 2015) serve as sensitising frameworks ${ }^{5}$ that are valuable to guide and be adapted throughout an exploratory approach. On the other hand, the latest methodological recommendations in information system research can be supported. Instead of concentrating on single concepts and factors, a more granular view in terms of subcategories should be sought. For example, Vaccaro et al., 2010 recommend taking different roles, meanings and perspectives of information technology into account instead of understanding ICT as a standalone factor (2010:1086). Since previous studies in the field have not commonly been oriented towards particular concepts or analytical frames, the CBF could be used, corroborated and validated in the future.

In terms of practical implications, the findings allow recommending managerial actions to implement open e-learning. First, the range of subcategories of barriers indicates that interventions need to be designed for overall barrier categories, such as managerial coordination or perceived technological fit. Second, the similarity of perceived barriers across countries indicates that good practices should be shared to see which interventions can be placed across contexts. However, employees in different administrations also differed in their rating of barrier-priorities (i.e., which challenges need to be resolved in the first place). Hence, managers need to be sensible which interventions are

\footnotetext{
${ }^{5}$ The term is further explained by Blaikie (2010:118-119).
}

suitable on site, for example, to distribute responsibilities to coordinate learning programs among colleagues.

In this vein, a third point is that managers have to raise awareness of such (coordinating) roles and learning activities. It is critical for success that employees learn about the possibilities and benefits of e-learning, including its short-term advantages and efforts, In this respect, findings also call public managers to be self-reflective; in different public administrations employees require superiors to provide active support and symbolic encouragement. Public managers should engage with and coordinate activities of employees in the beginning of open e-learning while public employees have to be free in organizing their learning activities independently in the long run. Compared to previous studies about learning and knowledge management in the public sector, these findings generate multiple and rich insights on managerial implications. Before, only separate aspects were addressed such as the distribution of roles or the presence of tutors (e.g. Bimrose et al. 2014; Hârțescu 2012). Altogether, this study advocates taking a holistic, integrated managerial perspective and particularly asks for future exchange about how the different perceived barriers interrelate and may be overcome through a comprehensive approach.

\subsection{Limitations of empirical assessment}

In view of defining interventions, one limitation of this study is that the results and decisions about interventions cannot be further discussed. Moreover, the guidelines for applying the BFs, oriented towards the experiences in the EAGLE project, for example, should be more specifically documented for future research. The goal is to further assess the CBF and offer an empirically validated tool that can inform and structure the research about open e-learning in public administrations.

The evaluation of the findings shows that fewer participants from the Irish context are included in the study. Moreover, the range of German municipalities covers the western part of the country. For the civil servants in Luxembourg and Montenegro, representativeness can be assumed. Overall, however, there is limited generalisability of the results for all public administrations in the four countries. Nevertheless, comparing the findings with the CBF suggests that the assessment unveils a wide range of barriers. The bias in terms of neglecting a number of barriers therefore appears to be limited.

Compared to other studies that focused on single countries (e.g. Chen 2014), this empirical study is more sensitive to the variations of similarities and differences across the four countries. Since the categories of the CBF fit very well and further build on empirical studies in Italy (Colazzo et al. 2009), as well as in Brazil and Romania, among others (e.g. Bere et al. 2014), generalisability across the investigated national borders is assumed. Since the list of barriers differs to those made for global, educational contexts (Pirkkalainen \& Pawlowski 2010), findings appear to be specific for public sector domains. However, further empirical research is clearly required to qualify for the overall representativeness of the findings.

\section{Conclusion}

This article has reported a comparative study of the barriers to open e-learning in public administrations at the local level in Luxembourg. Ireland, Montenegro and Germany. The results from the empirical analysis have been presented and discussed. Both similarities and differences have been highlighted across the administrations of the four countries, as well as for their respective barrier subcategories. Consequently, this study offers a detailed answer to the research question (What are the similarities and differences of barriers to open elearning across public administrations?).

Apart from the preceding discussion, the main findings to highlight are the role of managerial support and coordination of training programs. Despite the available information about existing programs, there is minimal awareness about available e-learning offerings at the 
local level. Another aspect is the linguistic diversity across public administrations at the local level and in the four countries. This finding has practical implications since the tools for collaborative learning activities will need to enable multi-lingual translations. In spatial terms, the distance between communities also emerges as a perceived barrier and should be reconsidered in forthcoming interventions to introduce elearning projects. Not the least, knowledge about benefits and shortterm successes need to be conveyed to public employees and stakeholders to increase their confidence and interest in the innovative and collaborative training mode of open e-learning.

Besides the practical implications, the orientation towards the $\mathrm{CBF}$ has been discussed. Applying the conceptual framework in an empirical context shows that previous categories can be supported. Hence, the $\mathrm{CBF}$ appears to be valuable for systematising the inquiry about the phenomenon of e-learning in the public sector. At the same time, the categories are descriptive and require further explanation and evidence of their representativeness. Project discussions about the application of BFs and related guidelines should also be discussed further. For example, the frameworks do not exhaustively capture detailed technical and pedagogical requirements.

In conclusion, this study has shed some light on the range of barriers to open e-learning in public administrations across different countries. Nonetheless, much work remains to be done. Scaling up the descriptive barrier categories into an explanatory model, as well as answering how the range of shared and distinct barriers can be overcome by interventions, are salient research interests for the future.

\section{Acknowledgements}

This research has been co-funded by the European Union within the Seventh Framework Programme, FP7-ICT, under Grant Agreement Number 619347 (http://www.eagle-learning.eu/).

\section{Appendix A}

\section{List of acronyms}

BF barrier framework.

BLV Bundeslaufbahnverordnung (state professional career regulation).

BMI Bundesministerium des Inneren (Federal Ministry of the Interior).

BYOD bring your own device.

CBF contextualised barrier framework.

CI citizen information (website).

CSTDC Civil Service Training and Development Centre.

EAGLE EnhAnced Government LEarning.

EC European Commission.

EFI European Foundation for the Improvement of Living and Working Conditions.

EU European Union.

FHoeD Fachhochschulen des öffentlichen Dienstes [Universities of applied sciences for public administration].

ICT information and communication technology.

INAP Institution National pour Administrations Publiqué (national institute for public administrations).

IPR intellectual property right.

LGMSB local government management services board.

MGDL Ministère de l'interieur, Grand-Duché de Luxembourg (Ministry of the Interior).

OECD Organisation for Economic Co-operation and Development.

OER open educational resource.

OGP open government partnership.

PGDL Portail de la Fonction publique Grand-Duché de Luxembourg (web portal of the public sector).

RESPA regional school of public administration.
Syvicol Syndicat des villes et communes luxembourgeoises. (association of Luxembourg's cities and communes).

\section{References}

Amayah, A.T., 2013. Determinants of knowledge sharing in a public sector organization. J. Knowl. Manag. 17 (3), 454-471.

Bere, R., Silvestri, C., Nemes, L., 2013. E-learning platform for public administration - case study. The 9th International Scientific Conference on elearning and Software for Edstudy. The 9th International Scientific Conference on
ucation. Bucharest, April 25-26, 2013, pp. 486-492.

Bere, R., Silvestri, C., Nemes, L., 2014. Challenges and opportunities in knowledge sharing in e-learning programs for public administration. The 10th International Scientific Conference on eLearning and Software for Education. Bucharest, April 25-26, 2014, pp. 461-469.

Beuselinck, E., Verhoest, K., Bouckaert, G., 2007. Reforms of central government coordination in OECD-countries: culture as counterforce for cross-national unifying processes? In: Schedler, K., Proeller, I. (Eds.), Cultural Aspects of Public Management Reform (16), (Research in Public Policy Analysis and Management). Emerald Group Publishing Limited, Amsterdam, Elsevier JAI, pp. 77-115 http://dx.doi.org/10.1016 S0732-1317(07)16004-8 (Chapter 4, Available at:)

Bimrose, J., Brown, A., Holocher-Ertl, T., Kieslinger, B., Kunzmann, C., Prilla, M., et al., 2014 The role of facilitation in technology-enhanced learning for public employment services. Int. J. Adv. Corp. Learn. 7 (3), 56-64.

Baikie, N.W.H., 2010. Designing Social Research: the Logic of Anticipation. Polity Cambridge.

Blindenbacher, R., Nashat, B., 2010. The Black Box of Governmental Learning: The Learning Spiral - A Concept to Organize Learning in Governments. World Bank Publications, Washington.

Bonk, C.J., Wisher, R.A., 2000. Applying Collaborative and E-learning Tools to Military Dis. Cince Learnin: A Research Framework United States Army Research Institute for the Behavioral and Social Sciences, Alexandria VA.

Bundeslaufbahnverordnung (BLV) - BLV §6, 2009. Verordnung über die Laufbahnen der Bundesbeamtinnen und Bundesbeamten $\$ 6$. Abschnitt 2 - Einstellung von Bundesbeamtinnen und Bundesbeamten $\$ 6$. Abschnitt 2 - Einstellung von Ref: 2030-7-3-1. Available at https://www.jurion.de/Gesetze/BLV-1/6.

Bundeslaufbahnverordnung (BLV) - BLV §46. (n.d.) Verordnung über die Laufbahnen der Bundesbeamtinnen und Bundesbeamten $\S 46$. Abschnitt 4 - Personalentwicklung und Qualifizierung. Ref: 2030-7-3-1. Available at https://www.jurion.de/Gesetze/ BLV- $1 / 6$.

Bundesministerium des Inneren (BMI), 2009. The federal public service Available at http://www.bmi.bund.de/SharedDocs/Downloads/DE/Broschueren/2009/oed_en. pdf?_blob= publicationFile.

Bundesministerium des Inneren (BMI) (2016). Hiring prerequisites and development opportunities. Available at http://www.bmi.bund.de/DE/Themen/ModerneVerwaltung/Dienstrecht/Beamte/Laufbahnrecht/laufbahnrecht_node.html; jsessionid $=8$ B9645555834F7D58A144918DDB69F70.2

cid287\#doc3358690bodyText2 (in press).

utler, T., Feller, J., Pope, A., Emerson, B., Murphy, C., 2008. Designing a core IT artefact for knowledge management systems using participatory action research in a government and a non-government organisation.

Carson, D., Gilmore, A., Perry, C., Gronhaug, K., 2001. Case-based research. In: Carson, D., Gilmore, A., Perry, C., Gronhaug, K. (Eds.), Qualitative Marketing Research. London, able at:)

Chen, T.-L, 2014. Exploring e-learning effectiveness perceptions of local government staff based on the diffusion of innovations model. Adm. Soc. 46 (4), 450-466. http://dx. doi.org/10.1177/0095399713482313.

Citizen Information (CI), 2014. Local authorities (Aug. 14). (Available at) http://www. citizensinformation.ie/en/government_in_ireland/local_and_regional_government/ local_authorities.html.

Civil Service Training and Development Centre (CSTDC), 2011. Guide to preparing a learning \& development strategy Available at http://hr.per.gov.ie/files/2011/04 Guide-to-Preparing-a-Learning-and-Development-Strategy.pdf.

Civil Service Training and Development Centre (CSTDC), 2014. Resources (Dec. 17). (Available at) www.cstdc.gov.ie/mod/resource/view.php?id=1024.

Colazzo, L., Molinari, A., Villa, N., 2009. Lifelong learning and virtual communities in the public administration: a case study in Italy. Int. J. Adv. Corp. Learn. 2 (3), 5-11.

Conci, A., Bramati, C., 2007. E-learning in public administration. SLOOP: Sharing Learning Objects in an Open Perspective, 2007, pp. 81-85.

Douven, I., 2013. Abduction and inference to the best explanation. In: Kaldis, B. (Ed.), Encyclopedia of Philosophy and the Social Sciences. SAGE Publications, Inc., Thousand Oaks, CA, pp. 3-5 http://dx.doi.org/10.4135/9781452276052.n2 (Available at).

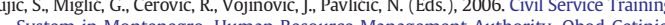
System in Monteng. Podgorica.

Ebrahim, Z., Irani, Z., 2005. E-government adoption: architecture and barriers. Bus. Process. Manag. J. 11 (5), 589-611. http://dx.doi.org/10.1108/14637150510619902. Eidson, L.A.K., 2009. Barriers to E-learning Job Training: Government Employee Experiences in an Online Wilderness Management Cour

European Commission (EC), 2013. Montenegro process report Available at http://ec. europa.eu/enlargement/pdf/key_documents/2013/package/brochures/montenegro 2013.pdf. 
European Commission (EC), 2014a. E-government factsheet. E-government in Ireland (April (Edition 16.0))

European Commission (EC), 2014b. E-government factsheet. E-government in Luxembourg. May (Edition 16.0

European Commission (EC), 2014c. Multi-country programmes: activity report: JanuaryJune 2014. Directorate-General Enlargement: D - Regional Cooperation and Assistance; Turkish Cypriot Community D.3 - Regional Cooperation and Programmes.

European Foundation for the Improvement of Living and Working Conditions (EFI), 2013i. Central Public Administration: Working Conditions and Industrial Relations Ireland (Ireland (EF/13/70/EN 6)).

European Foundation for the Improvement of Living and Working Conditions (EFI), 2013i. Central Public Administration: Working Conditions and Industrial Relations Luxembourg (Luxembourg (EF/13/70/EN 4)

achhochschulen des öffentlichen Dienstes (FHoeD), 2014. AG e-learning (Dec 18), (Available at) http://www.fhoed.de/ag_elearning.htm.

(A.lego, M.D., Luna, P., Bueno, S., 2008. Designing a forecasting analysis to understand the diffusion of open source software in the year 2010. Technol. Forecast. Soc. Chang. 75 (5), 672-686.

Gil-Garcia, J.R., Chengalur-Smith, I., Duchessi, P., 2007. Collaborative e-government: Impediments and benefits of information-sharing projects in the public sector. Eur. J. Inf. Syst. $16(2), 121-133$.

Government of Ireland, 2007. Circular 23/2007. Post entry education - refund of fees, study leave and examination Leave. E109/82/97 Available at http://hr.per.gov.ie/files/2011/04/ Circular-23-of-2007-Post-Entry-Education-Study-Leave-and-Examination-Leave1.pdf.

Hârțescu, I., 2012. A case study of implementing blended learning courses in public administration. The 8th International Scientific Conference on eLearning and Software for Education, pp. 497-503 (Bucharest, April 26-27, 2012).

Hazlett, S.A., McAdam, R., Beggs, V., 2008. An exploratory study of knowledge flows: a case study of public sector procurement. Total Qual. Manag. Bus. Excell. 19 (1/2), 57-66.

Hilton III, J., Wiley, D., Stein, J., Johnson, A., 2010. The four 'R's' of openness and ALMS andysis: frameworks for open educational resources. Open Learn. 25 (1), 37-44.

Kitzinger, J., 1994. The methodology of focus groups: the importance of interaction between research participants. Sociol. Health Illn. 16 (1), 103-121.

angford, J., Seaborne, K., 2003. To click or not to click: E-learning for the public sector. Can. Public Adm. 46 (1), 50-75.

Mayring, P. (Ed.), 2010. Qualitative Inhaltsanalyse, 11th ed. Beltz Verlag, Weinheim and Basel. inistère de l'interieur Grand-Duché de Luyembourg (MGDL). 2014 (May 12). Formation. Available at http://www.mi.public.lu/relations_communes/personnel/
personnel_formation/index.html?highlight=formation. personel_toration.

(and D.t., 1997. Planning and Research Design for Focus Groups. Focus Groups as

Organisation for Economic Co-operation and Development (OECD), 2003C. The learning government: introduction and draft results of the survey of knowledge management practices in ministries/departments/agencies of central government. 27th Session of the Public Management Committee; Original Format.

Pawlowski, J.M., Pirkkalainen, H., Gervacio, J.L., Nordin, N., Embi, M.A., 2014. Contextualization of open educational resources in Asia and Europe. In: Kim, B. (Ed), Open Educational Resources in Lifelong Learning. KNOU Press, Seoul, pp. 96-134.

Phang, C.W., Kankanhalli, A., Ang, C., 2008. Investigating organizational learning in egovernment projects: a multi-theoretic approach. egovernment strategies: ICT innovation in international public sector contexts. J. Strateg. Inf. Syst. 17 (2), 99-123. http://dx.doi.org/10.1016/j.jsis.2007.12.006

Pirkkalainen, H., Pawlowski, J.M., 2010. Open educational resources and social software in global e-learning settings. In: Yliluoma, P. (Ed.), Sosiaalinen Verkko-oppiminen. IMDL, Naantali, pp. 23-40.

Pirkkalainen, H., Pawlowski, J.M., 2013. Global social knowledge management: from barriers to the selection of social tools. Electron. J. Knowl. Manag. 11 (1), 3-17.

Pirkkalainen, H., Pawlowski, J.M., 2014. Global social knowledge management understanding barriers for global workers utilizing social software. Comput. Hum. Behav. 30, 637-647.

Portail de la Fonction publiquie Grand-Duché de Luxembourg (PGDL), 2013g. Formation continue (March 7). [Information post]. Available at http://www.fonction-publique. public.lu/fr/formations/cycles-competences/index.html.

(Pail de la Fonction publiquie Grand-Duché de Luxembourg (PGD), 2014g. Cycles de competences (Nov 25). [Information post]. Available at http://www.fonctionences/index.html. Regional School of Public Administration (RESPA), 2008. Civil service training systems in Training\%20systems\%20in\%20W\%20Balkans\%20countries/index.html.

Training\%20systems\%20in\% $20 \mathrm{~W} \% 20$ Balkans\%20countries/index.html.
Remtulla, K.A., 2007. The knowledge-based economy and e-learning: critical considerations for workplace democracy. Convergence 40, 9-24

on the myth of a general national culture. Making specific cultural characteristics of learners in different educational contexts in Germany visible. In: Richter, T., Adelsberger, H. (Eds.), Proceedings of Cultural Attitudes towards Communication and Technology 2012. Murdoch University, Murdoch, pp. 105-120.

Riege, A., 2005. Three-dozen knowledge-sharing barriers managers must consider. J. Knowl. Manag. 9 (3), 18-35.

Sannia, M., Ercoli, G., Leo, T., 2009. Evaluation of virtual learning environment for the professional training in public administration. Int. J. Adv. Corp. Learn. 2 (1), 50-55.

Stefanick, L., LeSage Jr., E., 2005. Limitations to developing virtual communities in the public sector: a local government case study. Can. Public Adm. 2, 231-250.

Stoffregen, J., Pawlowski, J., Pirkkalainen, H., 2015. A barrier framework for open elearning in public administrations. Comput. Hum. Behav. http://dx.doi.org/10.1016/

Trochim, W.M.K., 1989. Outcome pattern matching and program theory. Eval. Program Plann. 12 (4), 355-366.
Vaccaro, A., Parente, R., Veloso, F.M., 2010. Knowledge management tools, interorganizational relationships, innovation and firm performance. Technol. Forecast. Soc. Chang. 77 (7), 1076-1089.

Williams, R., Edge, D., 1996. The social shaping of technology. Res. Policy 199625 (6), $865-899$

Yang, T.-M., Maxwell, T.A., 2011. Information-sharing in public organizations: a literature review of interpersonal, intra-organizational and inter-organizational success factors. Gov. Inf. Q. 28 (2), 164-175.

Yang, R., Ruan, J., 2007. The e-learning system used in the civil servants' job-training. Integration and Innovation Orient to E-Society 2, pp. 574-581.

ang, H.L., Wu, T.C., 2008. Knowledge sharing in an organization. Technol. Forecast. Soc. Chang. 75 (8), $1128-1156$

Yin, R.K., 2014. Case Study Research: Design and Methods. Sage Publications, Thousand

Julia Dorothée Stoffregen (MSc Res). University of Jyväskylä Finland | University of Applied Sciences Ruhr West; julia.stoffregen@hs-ruhwest.de; + 4920888254828. Julia is $\mathrm{PhD}$. candidate at the University of Jyväskylä with expertise in science and technology studies in the public sector. Experiences and scientific peer reviewed publications are made in the field of open and e-Government and online training of public employees. Dedcated research efforts focus on the development of socio-technical process models of technology implementation processes.

Jan M. Pawlowski (Prof. Dr.). University of Applied Sciences Ruhr West. Mail: jan. pawlowski@hs-ruhrwest.de. Jan. M Pawlowski is Professor Dr. of Digital Media with the specialization "Global Information Systems" (GLIS). Main research interests and numerous scientific peer reviewed publications are in the field of GLIS, E-learning, modeling and - assurance for education and mobile / ambient learning

Eric Ras (Prof.). Luxembourg Institute of Science and Technology, eric.ras@list.lu. Eric Ras

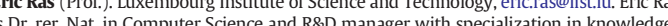
based approaches and ser science and $R \& D$ manager with specialization in knowledgebased approaches and semantic web technologies with innovative human-computer interfaces (e.g., tangible user interfaces, dialogue-based systems). Mr. Ras is national contact
point for the FET flagship project FuturlCT and has authored $>70$ peer reviewed scientific publications.

Eric Tobias (MSc). Luxembourg Institute of Science and Technology; eric.tobias@list.lu. Eric Tobias has a MSc in Information and Computer Sciences, and is R\&D engineer with expertise in science, technology and environmental politics, information technology \& politics and foundations of political theory. Mr. Tobias has experience in educationa assessment of online training and development.

Snezana Šćepanović (PhD. Associate Professor). University Mediterranean, Podgorica; snezana.scepanovic@unimediteran.net. Snezana Šćepanović is associate professor at UNIM in Montenegro. She is expert in instructional design e-tutoring and e-learning technologies. Special interest is in developing and delivering online courses for professionals a well as accreditation of related curriculums.

Dónal Fitzpatrick, (Prof.). School of Computing, Dublin City University, dfitzpat@

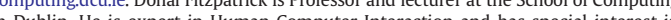
dal interfaces and accessibility.

Tacey Mehigan (Dr.). University College Cork, tm6@cs.ucc.ie. Tracey Mehigan is associated to the University College Cork and has experience in initial planning phases of elearning systems in the public sector. Special interest is in e-learning development and delivery.

Petra Steffens (Dipl.-Inform., M.Phil). Fraunhofer-Institut für Offene Kommunikationssysteme FOKUS, petra.steffens@fokus.fraunhofer.de. Petra Steffens is co-head of the „eGovernment processes and architectures at the renown research institute FOKUS. Her special interest is the design and development of process and businessoriented eGovernment solutions covering consultancy and strategy development.

Peter Schilling (Dr.). Fraunhofer-Institut für Offene Kommunikationssysteme FOKUS, peter.schilling@fokus-extern.fraunhofer.de. Peter Schilling is Professor for Information

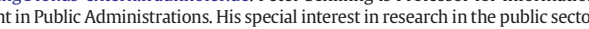
focusing on culture, learning and related change.

Christiane Przygoda (BA). Fraunhofer-Institut für Offene Kommunikationssysteme OKUS, christiane.przygoda@fokus.fraunhofer.de. Christiane Przygoda is research assistant and studies in the field public governance. She is experienced in public sector projects

Horst Friedrich (Dr.). Fraunhofer-Institut für Offene Kommunikationssysteme FOKUS, horst friedrich@fokus fraunhoferde. Horst Friedrich is developer at the institute FOKUS 作 tor.

Sabine Moebs (Prof. Dr.). Duale Hochschule Baden Württemberg, moebs@dhbwheidenheim.de. Sabine Moebs is professor for Business Information Systems at the DHBW. Special interest is in cross-device usability, accessibility, user experiences and learning processes for learners in public administration. 
Identifying Socio-Cultural Factors That Impact the Use of Open Educational Resources in Local Public Administrations

by

Stoffregen, J., Pawlowski, J. M., Ras, E., Scepanovic, S., \& Zugic, D. 2016.

International Journal of Management, Knowledge and Learning vol 5(2), 167-187.

Reproduced with permission of the IJMKL

under the Creative Commons CC BY-NC-ND 4.0 License 


\section{Identifying Socio-Cultural Factors That Impact the Use of Open \\ Educational Resources in Local Public Administrations}

\section{Julia Stoffregen}

University of Jyväskylä, Finland

University of Applied Sciences Ruhr West, Germany

\section{Jan M. Pawlowski}

University of Applied Sciences Ruhr West, Germany

\section{Eric Ras}

Luxembourg Institute of Science and Technology, Luxembourg

\section{Snežana Šćepanović}

University Mediterranean, Montenegro

\section{Dragica Žugić}

University Mediterranean, Montenegro

The goal of this paper is to define relevant barriers to the exchange of Open Educational Resources in local public administrations. Building upon a cultural model, eleven experts were interviewed and asked to evaluate several factors, such as openness in discourse, learning at the workplace, and superior support, among others. The result is a set of socio-cultural factors that shape the use of Open Educational Resources in public administrations. Significant factors are, in this respect, the independent choice of learning resources, the spirit of the platform, the range of available formats and access to technologies. Practitioners use these factors to elaborate on the readiness of public administrations towards the use of open e-Learning systems. To academic debates on culture in e-Learning, the results provide an alternative model that is contextualized to meet the demands of public sector contexts. Overall, the paper contributes to the lack of research about open e-Learning systems in the public sector, as well as regarding culture in the management of learning and knowledge exchange.

Keywords: open educational resources, public administration, mixed-method, expert validation, socio-cultural context, cultural in open e-learning

\section{Open E-Learning in the Public Sector}

The goal of this paper is to elaborate on the cultural factors that shape the exchange of Open Educational Resources (OER) in local public administra- 
tions. The exchange of information and knowledge usually raises concerns about privacy and power relations. Open e-Learning builds upon those activities and beyond, and requires public employees to adapt contents for personal learning means. While the factors that shape the use of OER apart from privacy and power are well known in several contexts, research in the public sector has not advanced. Studies have been conducted on e-learning barriers for single courses (Eidson, 2009) across European countries (Stoffregen et al., 2016) and continuous use intention (Pereira, Ramos, Gouvêa, $\&$ da-Costa, 2015). Yet, no joint theoretical and empirical approach is available that explains which cultural factors are shaping OER activities in the socio-cultural context of public employees.

This paper addresses this research gap and extends adaptive structuration models (DeSanctis \& Poole, 1994) with cultural factors that shape the exchange of OER in open e-Learning systems. Qualitative and quantitative data are used to elaborate on the significance of these factors. The results challenge the use of general innovation or technology acceptance models to explain and explore the phenomenon of open e-Learning in public administrations.

The findings emphasize that open e-Learning is still a 'paradisiacal topic' but that it is about to come to the fore (interview participant 1 ). To secure a sustainable design, use and implementation of E-learning in the future, experiences have to be embedded in theory and practice. The results of this study will contribute to this aim. The findings will allow practitioners to elicit the current state, as well as to organize interaction in open e-Learning systems. Cultural factors such as openness in discourse, support of superiors, and learning at the workplace further instil theoretical discussions, and extend previous conceptual work in public sector research.

The rest of the paper is organized in such a way as to answer the research question: what are the structural gaps shaping the exchange of OER in the public sector, and why? Firstly, background on open e-Learning systems is presented. Subsequently, the methodology is outlined. Thirdly, the findings of the expert validations are presented. The conclusion summarizes the main points.

Introduction to Socio-Cultural Factors in Open E-Learning Systems E-Learning Systems

E-Learning refers to the use of technology to conduct learning activities (Rosenberg, 2001). E-Learning technologies are platforms, authoring, or assessment tools, among others. Activities may include face-to-face sessions or may be performed solely online. Often, learning content and goals are pre-structured; students merely define the pace in which they complete online activities. Open e-Learning differs in at least two respects. Firstly, 
learning materials carry open licences and can be re-used for various learning means. Open licences, such as Creative Commons, distribute rights between learners and original authors. As a corollary, students become creators and contributors to a growing body of knowledge. Secondly, openness refers to the use of open source technology, as can be seen in the platforms OpenScout, EAGLE and Dokeus. Open source technology decreases investment costs while increasing access to knowledge and learning practices.

Open e-Learning systems not only refer to technologies, but also the whole assemblage of learners, open e-Learning technology and learning materials such as OER. They enable users to exchange experiences for personal and professional learning means. In the public sector, Open eLearning systems promise to build effective, efficient and flexible learning networks. They offer collaborative tools for knowledge sharing among colleagues. Yet, these benefits have been realized neither in the public nor in the educational sector (Eidson, 2009; Richter \& McPherson, 2012). Learning is not the first priority at the workplace (Eidson, 2009). Values such as discretion distract learners from learning (Stefanick \& LeSage, 2005). Cultural customs irritate learners and disrupt cognitive processes (Katz \& Te'eni, 2007). Language barriers and 'not invented here syndromes' constrain the exchange of OER (Pirkkalainen \& Pawlowski, 2014). Hence, there is a large range of known, potential barriers to the use of OER. Yet, it is a paramount subject to research: Which factors are relevant in a given sociocultural context? Factors need to be elaborated for a given context in order to provide guidance and technological support to contextualization (Richter \& McPherson, 2012; Richter \& Adelsberger, 2012). In the public sector, the set of relevant cultural barriers to the use of OER still needs to be defined as well. Culture is an ambiguous term and refers to norms, values, artefacts, and dimensional constructs (Jamil, Askvik, \& Hossain, 2013; Keraudren, 1996; Moynihan \& Landuyt, 2009; Mahler, 1997).

The interest in culture is high but recent studies focus on explaining the success of government reforms (Jamil et al., 2013; Bouckaert, 2007). Apart from Weberian and new public management (NPM) values, no dedicated culture model has evolved (Rutgers, 2008). Interestingly, scholars dismiss models from the private sector (Bouckaert, 2007; Beuselinck, Verhoest, \& Bouckaert, 2007). Sector-specific characteristics such as political values are neglected (Bouckaert, 2007; Moynihan \& Landuyt, 2009). Hence, when approaching OER exchange in public administrations, the next question has to be answered anew: which factors are relevant, and why?

The logical starting point to answer this question is to summarize experience, findings and known factors from previous studies in the field. One known approach is the Multiple-Culture Model (MCM) (Edmundson, 2007a; 
2007b). It guides adapting digital learning resources with regard to multiple values, educational activities and world-views (Henderson, 1996; 2007). Another renowned concept is developed by Hofstede. Culture is, according to Hofstede (2001, p. 4), a mental program that 'partly predetermines human behaviour.' For learning, acquiring knowledge or changing routines, a person has to know his/her value (dimensions) and has to unlearn the patterns (pp. 3f.). In the public sector, studies on e-Learning have not thus far built upon these or similar models. Pereira et al. (2015) present the decomposed-expectancy-disconfirmation-theory to explain continuous use intention. Chen (2014) elaborates on e-Learning effectiveness and presents the Diffusion-of-Innovation framework.

Only Eidson (2009) elaborates on the challenges from a psycho-sociological framework. Altogether, the role of flexibility, learner control, socialising opportunities, comfort and acceptance at the workplace seem to be commonly relevant factors. Despite the similarity of factors, the no synthesized model allows the comparison or ranking of relevant factors. This study will fill this research gap and elaborate on cultural factors that shape OER-use from a socio-technical perspective. On the one hand, new insights on relevant factors, including an adaptive structuration model for public administrations, will be generated. On the other hand, cultural research in the public sector has to meet 'quality criteria' (Beuselinck et al., 2007; Bouckaert, 2007). For example, political values of the profession need to be considered to explain knowledge exchange in the sector (Stefanick \& LeSage, 2005). Orienting on these criteria, results of this study promise to advance the current state of research. To provide a generous background, the following chapter summarizes the systematic literature review (Stoffregen \& Pawlowski, forthcoming), which preceded the expert evaluations. Subsequently, the method and design of the expert evaluations that focus on this study is presented.

\section{Open E-Learning Systems}

Open e-Learning systems are assemblages of learners, artefacts like OER and e-Learning technology interacting in a given time and space. OER are digital open knowledge resources carrying a licence that enables learners to re-use, adapt, and share information and knowledge without fees. ELearning technologies are platforms, applications and functionalities that enable multiple learning activities, including the re-use, adaptation, and sharing of information and knowledge. Technologies are an open source and can be deployed and customized by instantiations. Learners are authors (producers) and readers (consumers) of OER at the same time. They can exchange resources synchronously, as well as asynchronously, in forums and chats. This study focusses on asynchronous activities. Asynchronous 
exchanges of open knowledge resources refer to the taking and adapting of OER for own learning means and to the creating and publishing of OER for other's learning means (DeSanctis \& Poole, 1994; Bostrom \& Gupta, 2009; Hollingshead, Monge, \& Fulk, 2005; Giddens, 2001; Orlikowski \& Robey, 1991; Lyytinen \& Newman, 2008; Rosenberg, 2001).

From a socio-technical perspective, cultural influences are paramount in open e-Learning systems. Culture is embedded in basic assumptions, espoused convictions and artefacts (Schein, 1990; 2010; Moynihan \& Landuyt, 2009). For means of analysis, cultural factors can be more closely addressed regarding the 'internal group system,' 'organizational,' 'emergent' and 'technology structures,' as well as 'outcomes' (DeSanctis \& Poole, 1994). An internal group system outlines the "nature of members and assumptions about their relationships' (DeSanctis \& Poole, 1994, p. 130).

For exchanging OER, for example, cultural forces shape the value of knowledge exchange to improve everyday work. Organizational structures are content and constraints in a given position and environment (DeSanctis \& Poole, 1994). Technology structures stand for the 'structural potential which groups can draw on to generate particular social structures in interaction' (DeSanctis \& Poole, 1994, p. 127). They reflect assumptions about learning activities, for instance, the 'spirit' of assessment tests. Culture shapes outcomes such as adapted OER as well as decisions of learners whether or not OER-exchange at the workplace is appropriate. Altogether, culture is a dimensional force: factors both enable and constrain interaction in open e-Learning systems (Lyytinen \& Newman, 2008; Witmer, 1997). Several cultural factors and assumptions for experts to evaluate are addressed more specifically in the following paragraphs.

\section{Culture in Open E-Learning Systems}

To provide a background in cultural factors of open e-Learning systems, we focus on internal group factors in the first step. One cultural factor in the internal group system is openness in discourse. This stands for the perceived appropriateness of innovating routines, and of discussing problems and errors among peers. Knowledge and information are often conceived as power in the public sector and, thus, are not shared (Amayah, 2013; Yao, Kam, \& Chan, 2007). Making an error is seen as a failure as opposed to a chance for improvement (Stefanick \& LeSage, 2005). Structures exist that support the solving of problems with discretion among superiors instead of peers (Barette, Lemyre, Corneil, \& Beauregard, 2012, p. 143). Using OERs successfully for learning, however, requires that discussed experiences, including undesirable developments, alternative problem solving strategies and potential errors, openly improve the quality of everyday work (Pirkkalainen, Jokinen, \& Pawlowski, 2014). 
Cultivating open discussions about problems and errors will thus be more favourable to OER-exchange than discretion. Concerning the appropriateness of innovating routines, another factor is the free space to apply knowledge. Often public employees work according to predefined rules. In such a regulated environment, change is considered inappropriate and similar to personal innovation of everyday work (Hedvicakova, 2013; Eidson, 2009, pp. 106-111; Rahman, Naz, \& Nand, 2013; Ho, Tsai, \& Day, 2010; Arellano-Gault, 2013; Imran, Gregor, \& Turner, 2013; Caron \& Giauque, 2006; Gustavsson, 2009; Hedvicakova, 2013). Using OER, however, requires learners to reflect on their routines and assumptions. They need to innovate daily routines and question whether and how their work, OER and practices might be improved (Pawlowski et al., 2013). Summarising the points, OER exchange faces few barriers if the assumptions are commonly shared and conceived as appropriate:

1. Problems have to be discussed openly within the department.

2. Errors have to be discussed openly within the department.

3. Free space has to be available for innovating routines (apply new knowledge).

Group-identification is another factor in the internal group system. Identifying with a group facilitates mutual understanding; similar backgrounds enable learners to share ideas and knowledge (Gustavsson 2009; Imran et al., 2013; Marschollek \& Beck, 2012; Rahman et al., 2013; Eidson, 2009; Moynihan \& Landuyt, 2009; Barette et al., 2012). Correspondingly, if cognitive boundaries constrain identification, OER exchange might be harmed. One common boundary is the role of geography. Imran et al. (2013) indicate that similarity of language is subject to geography and shapes the choice of collaboration partners (also in Colazzo, Molinari, \& Villa, 2009). Another boundary is the role of the learner's work domains. Working in similar fields offers a shared set of terminologies and topics that facilitates communication (Imran et al., 2013, pp. 600f.). Similar to domains, the sector background appears to be relevant. Differences in the public and private sector, for example, often lead to misunderstandings (Marschollek \& Beck, 2012). Consequentially, decisions on how to apply knowledge, and change routines diverge and constrain collaboration and knowledge exchange (Marschollek \& Beck, 2012; Imran et al., 2013). Summarising the points, OER exchange faces few barriers if the assumptions are commonly shared and conceived as appropriate:

4. Collaboration partners do not have to come from the same country.

5. Collaboration partners do not have to speak the native mother tongue.

6. Collaboration partners do not have to work in the same work domain. 
A third cultural factor in internal group systems is the distribution of roles during learning at the workplace. While open e-Learning requires individual creativity, current courses are developed by dedicated personnel. Assumptions about whether all public employees are allowed to create and exchange learning resources are vague. Related to this, the perceived need diverges whether to evaluate the performance of learners OER-use (Edmundson 2007a, p. 270; Tapanes, 2011; Hedvicakova, 2013; Sannia, Ercoli, \& Leo, 2009). Both the quality and rate of contribution can be of concern. Summarising the points, OER exchange faces a few barriers if the assumption is commonly shared and conceived as appropriate:

7. Learners have to be independent in the choice of learning materials at the workplace.

The fourth cultural factor in internal group systems is superior's support. Superiors play a major role to sustain learning activities, invoke change, training programs and knowledge management initiatives (Schraeder, tears, \& Jordan, 2005; Rahman et al., 2013; Beuselinck et al., 2007; Greiling \& Halachmi, 2013; Yao et al., 2007; Gustavsson, 2009; Yang \& Ruan, 2007). Hence, the question is not whether or not support needs to be provided, but what kind of support is required. On the one side, leaders should encourage employees and live up to the principles of their demands (Schraeder et al., 2005, pp. 500f.). On the other side, supervisors should communicate basic agreement and offer symbolic support (Yang \& Ruan, 2007, p. 76). To foster flourishing OER exchange, supervisors should coordinate instead of determining activities (Gustavsson, 2009, p. 253f; Bimrose et al., 2014). Summarising the points, OER exchange faces few barriers if the assumptions are commonly shared and conceived as appropriate:

8. Superiors have to provide active support as opposed to symbolic support.

To provide background of the cultural factors of open e-Learning systems, we focus on organizational structures in open e-Learning systems in the second step. As organizational structures, content and constraints in the work environment are considered. Reviewing studies, a dominant cultural artefact is assumptions about regulation. Regulation, policies, and strategic documents are codified norms and rules (Barette et al., 2012; Schein, 2010). They provide a normative framework how to understand and judge working activities supported by open e-Learning systems. A regulatory frame allows involvement in learning activities in the public sector. It appears, however, that regulations can be situated at different levels.

Firstly, organizational strategies might be launched on a higher administrative level. Such plans often give birth to subsequent, e-Learning directed 
programs (Chih-Yang, Tsai-Chu, Ping-Teng, \& Chih-Wei, 2011; Yang \& Ruan, 2007) or determine licences to apply for OER (Hilton, Wiley, Stein, \& Johnson, 2010).

Secondly, the launch of policies can respond to a particular barrier, such as a lack of tutors and competences (Imran et al., 2013, p. 602). Thirdly, a normative framework can emerge from a code of conduct. Codes of conduct define the way how to learn, which learning goals and practices are appropriate for public employees (Yang \& Ruan, 2007; Barette et al., 2012; Sannia et al., 2009). Summarising the points, OER exchange faces a few barriers if the assumptions are commonly shared and conceived as appropriate:

9. Organizational strategies have to be defined to frame OER exchange.

10. Policies have to be defined to frame OER exchange.

11. A code of conduct has to be defined to frame OER exchange.

The second factor in organizational structures is environmental artefacts. These are tangible shapes communicating the relevance of an activity or assumption (Schraeder et al., 2005). One major artefact in this respect is a calm space that is assumed to be appropriate to spend time learning. At front desks in public administrations, time is scarce and it is often not acceptable to spend time learning (Eidson, 2009, pp. 58f.). Apart from room and space, another factor is the technical infrastructure. In this respect, learning resources also need to be available to support assumptions that knowledge is to create and share through Open Educational Resources (Barette et al., 2012, p. 143). Hence, considering the following assumptions as appropriate facilitates OER-activities:

12. A quiet room has to be available for OER exchange.

13. Technical infrastructure has to be available for OER exchange.

14. Time has to be available for learning at the workplace. no time.

To provide background in cultural factors of open e-Learning systems, we focus on structure of technology in open e-Learning systems in the third step. Another culturally engrained artefact is the technology used for OERactivities. Cultural assumptions structure certain uses of technology. One cultural factor shaping interaction in open e-Learning systems is the "spirit of open platforms.' The spirit reflects the structural potential, which reflects convictions about the means of using technology for knowledge exchange.

In dimensional terms, enabling cultural assumptions reflects the fact that open platforms are enablers for social, interactive learning (Yang \& Ruan, 2007; Chen, 2014). E-Learning is a space for autonomous, selfdependent advancement of knowledge (Hedvicakova, 2013; Ho et al., 2010). But the spirit may not only express self-realization, but also economic convictions (Remtulla, 2007; Langford \& Seaborne, 2003; Stefanick 
\& LeSage, 2005). E-Learning becomes a monitoring tool for work performance of public employees (Yang \& Ruan, 2007).

15. Spirit of OER activities has to be socially oriented as opposed to performance monitoring

One final cultural factor shaping interaction in e-Learning systems is the format for exchange of OER. Formats for exchange reflect basic assumptions about knowledge, and whether it can be documented. Knowledge can be understood as an intangible resource that is acquired in informal communication, or as a resource that can be transferred and acquired irrespective of the context (Schraeder et al., 2005; Gustavsson, 2009; Sannia et al., 2009; Edmundson, 2007a). Cultural assumptions about appropriateness of media types, as well as content of e-Learning courses, are to be elaborated upon (Tapanes, 2011; Eidson, 2009; Langford \& Seaborne, 2003; Schraeder et al., 2005; Yao et al., 2007).

16. All media types have to be appraised for OER exchange.

17. Content must reflect diversity to available forms as opposed to restricted.

Assumptions from the literature review are presented. In the following, the study design to evaluate the presented claims is defined.

\section{Method}

The expert evaluation is part of a doctoral study oriented on action design research (Sein, Henfridsson, Purao, Rossi, \& Lindgren, 2011; Stoffregen, 2015). It requires the involvement of researchers on site of the phenomenon. The low transparency of data generation is a threat, as it is to the generalisation of results. Steps to avoid this barrier is the explication of linkages to previous studies, as well as discussions with experts and practitioners in the field. This study summarizes links to previous studies in the background section. Results of discussions with experts are subject to the remaining article.

The expert evaluation is semi-structured and based on a mixed-method approach that contributes to inter-subjective understanding (McKenzie, Wood, Kotecki, Clark, \& Brey, 1999; Creswell \& Plano-Clark, 2011). Methodological principles focus on action design research (Sein et al., 2011). Both practitioners and academia were asked to use and evaluate the model. The epistemology and ontology of the approach are interpretative and constructivist (Van de Ven, 2007; Creswell \& Plano-Clark, 2011).

A cultural concept can be evaluated from different perspectives (Van de Ven, 2007). Apart from objectivity, the reliability and validity of a construct (Rammstedt, 2004), as well as the practical relevance and intelligibility for 
users, is to be assessed (Lawshe, 1975; McKenzie et al., 1999; Esposito \& Rothgeb, 1997, Krosnick \& Fabrigar, 1997; Frank, 2006).

The aim of this study is to evaluate the relevance of factors systematically. Comparing quantitative and qualitative approaches, it was decided to follow a mixed-method approach that combines advantages of both designs. A prominent model in this respect is the approach of McKenzie et al. (1999). It is commonly used in the evaluation of research in the public sector (Barette et al., 2012). The steps of this approach will be presented in the following.

\section{Preparation of Analysis and Evaluation Steps}

The expert evaluation according to McKenzie et al. (1999) follows three steps: define selection criteria of experts, pose interview questions, and determine logic of analysis. In this study, selection criteria of experts is meant to determine their level of domain knowledge, experience with the topics and availability during the evaluation phase. Expert selection was balanced regarding nationality (Germany, Ireland, Luxembourg and Montenegro) and gender (Cresswell \& Plato Clark, 2011; McKenzie et al., 1999). The interview questions were semi-structured: Firstly, experts were asked to elaborate on the relevancy of open e-Learning and culture in open e-Learning at the workplace. Experts were then asked to explain their view on certain factors, for instance: how relevant is this factor to explain why OER are exchanged among public employees? Experts choose between 'essential,' 'useful but not essential' and 'not necessary,' and then they explain their rating. The analysis then elaborated on the reason and content-validity ratio based on ratings of a factor:

Based on the calculation, the levels of significance were determined $(N[e]=$ number of experts saying a factor is 'essential;' $N=$ number of experts) (McKenzie et al., 1999). Given the number of experts $(N=11)$, CVR .59 is the significance threshold. Given the convergent research design (Cresswell \& Plano-Clark, 2011), however, both qualitative and quantitative evaluations are presented to appraise cultural factors.

Apart from expert feedback, it is important to assess the emerging model in terms of plausibility and credibility. Plausibility can be obtained if a balance of received supporting assumptions and surprises can be found (Van de Ven, 2007, pp. 110f.). Credibility can be gained by "comparing [a theory] with rival plausible alternative theories at the time of the investigation' (Van de Ven, 2007, p. 126). Assumptions need to be falsifiable and in this respect, generalizable from a particular case. Quality criteria to advance the state of research are: firstly, the cultural model should address meso-levels (organisational level) of interaction (Bouckaert, 2007; Jamil et al., 2013). Secondly, the role of political values and artefacts should be 
integrated (Keraudren, 1996; Jamil et al., 2013). Thirdly, for the means of gaining practical relevance, the model should be easy for non-experts to apply (Tapanes, 2011; Pawlowski \& Richter, 2010). So far, the steps for validating and evaluating the cultural model have been outlined. The findings of expert interviews are outlined in the following.

\section{Results}

Overall, five female and six male experts from public sector administrations in Luxembourg (2), Montenegro (2), Ireland (1) and Germany (6) were interviewed. The duration of the interviews ranged from between thirty and sixty minutes. Currently, e-Learning is a known catchword and gains relevance for training of public employees at the workplace. Open e-Learning complements traditional (face-to-face) training but has not been taken up due to several challenges.

\section{Internal Group System}

Experts judge that openness in discourse is one of the essential cultural factors. Free space to apply knowledge, to discuss problems and fix errors has to be conceived as appropriate within a department. Going into detail, experts largely agree that the space to apply knowledge and innovate work is essential to explain why public employees exchange OER. 'Space to apply knowledge is a suitable nice wording for this construct, there must be space' (participant 2). The content validity ratio (CVR .5) supports this idea and is sufficiently high (Barette et al., 2012). Concerning the discussions of problems, the content validity ratio is low (CVR .1) because experts see it related to discussing errors. The latter is a critical factor since it is often claimed 'we are public officers, we are not doing faults. Hence, we are having no error culture' (participant 3). The quantitative evaluation of this factor reflects this positive and normative evaluation (CVR .5).

For the factor group identification, experts take on a common position. Convictions about work domains make a difference in the choice of collaboration partners. Experts see that mutual preferences and exchange of ideas can be facilitated, thus the content validity ratio of the factor is high (CVR .63) and significant. Yet, experts do not agree whether assumptions about shared work values are essential. The nature of work values is ambiguous, yet, may be the core to define the distance between groups: 'Distance emerges from the common values, nothing else' (participant 4). Given the diverging perspectives, the validity ratio is low (CVR -.09). As regards sector backgrounds, experts have diverging perspectives as well. For some, identifying the sector background enables learners to judge work values and is thus essential. For others, there are restrictions. 'Broadening makes sense unless you do not have to go back to fundamentals [of services for the 
public good]' (participant 5). The quantitative is low (CVR -.64). For geographical distance, experts are critical: 'Relevance of geographical distance depends on the size of the country' (participant 2). However, collaboration is 'not yet exploited' wherefore finally raised attention to this point for future elaboration (CVR -.45).

The factor supervisor support is seen as one of the most important factors to explain why public employees exchange OER. Experts were clear: 'If no support is provided, there is no exchange of OER during work-time' (participant 6). Both active and symbolic support impact exchange activities. Experts largely agree that active support is essential. The content validity ratio is very high (CVR .63) and significant. Symbolic support is less essential than active support. The condition is the hierarchy: "leaders need to have support from the highest level' (participant 1). 'Depending on the level of the supporter, an active, motivating or symbolic role needs to be taken over' (participant 2). Yet, it is not as important as active support and, thus, gains a low rating (CVR .09).

\section{Organizational Structures}

Regulation is a factor that experts see as rather unimportant. However, detailed analysis suggests that it is not important which regulation is provided, but that a regulatory frame is provided. 'If you are regulated, then you know that you are allowed' (participant 3). A general guideline telling when and what knowledge to exchange and with whom is considered useful. It is essential to see that OER activities are welcome in a department. Still, the content validity ratio is low (CVR .09). Concerning regulation by higher institutions, experts have diverging perspectives. One condition is the level of administration performing OER activities.

'The lower the administration, the higher the impact of regulation by higher administrations' (participant 2). At the same time, experts doubt that regulations of higher administrations are visible at lower levels. Hence, the CVR is low (CVR .09). As regards the code of conduct, experts have diverging views. If collaboration activities are central in open platforms, codes of conduct gain relevance. 'Rules could harmonize processes and streamline activities in communities' (participant 2). However, if codes of conduct are too unspecific, then the final rating is very low (CVR -.27). Despite the negative evaluation of regulation, all experts outlined the essential role of regulation as such: "the factor is rather an "on-off type of factor;" regulation must be provided somewhere' (participant 7).

Experts see environmental artefacts as one of the most important factors to explain why public employees exchange OER. The subcategory quiet room appears to be less important as it depends on the area of work, irrespective of the work domain of individuals. A calm physical room appears as a proxy 
for assumptions of having time to rest and concentrate on learning. Thus, the factor is low (CVR -.27).

The experts believe the factor internet infrastructure represents one of the main cultural artefacts, and the CVR is high (CVR 1) and significant. The factor available knowledge resources is perceived as useful. But once implemented, the relevance decreases (participant 1). Correspondingly, the content validity ratio is low (CVR .27). In contrast to this, experts judge that assumptions about available time to learn are critical (CVR .45). It represents how relevant learning at the workplace is within a department. Is is also a measure upon which learning strategies can be evaluated and adapted.

\section{Technology}

Generally, the evaluation of the factor spirit is ambiguous. Experts strongly agree that exchange of OER has to avoid having a monitoring character. 'If it is understood as performance tool, nobody will use it' (participant 3). At the same time, experts agree that exchange of OER needs to have a social character but it must 'be clear that social interaction is made for learning means as opposed to social activities in Facebook' (participant 2). Despite that, experts see social interaction and monitoring as two sides of a continuum; they judge social spirit as not being important (CVR .27), while monitoring is very crucial (CVR .64) and significant.

Regarding the format for exchange, experts largely agree that the format of content is essential to explain why public employees engage in exchange of OER. There are different types of learners: 'some can learn better from theories than from practice [so] [...] all formats need to be provided to accommodate diversity, even if the same learning outcome is achieved' (participant 3). Chosen formats also reflect epistemological values, and how knowledge can be exchanged: 'Not all knowledge can be exchanged online' (participant 10). Hence, the content validity ratio is high and significant (CVR .64). Yet, discussions show that assumptions regarding this factor are diverse, therefore a split of the factor in digital formats and epistemological forms has to be validated in the future. Last but not least, experts agree the media type is a useful factor and a diverse range of media must be available for an exchange: 'All contents should be appraised' (participant 2). Experts infer implications of this factor for learning strategies, for example, which media type is missing? Yet, the content validity ratio suggests declining the category (CVR .09).

\section{Discussion}

The following discussion elaborates on the value of the model and the results. It also touches on considerations such as the quality criteria, includ- 
Julia Stoffregen et al.

Table 1 Overview of Results

\begin{tabular}{|c|c|c|c|c|c|c|}
\hline \multirow{3}{*}{ 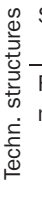 } & Spirit of platform & $\begin{array}{l}\text { Social } \\
\text { means }\end{array}$ & & $\begin{array}{l}\text { Monitoring } \\
\text { means }\end{array}$ & $(.64)^{*}$ & $\begin{array}{l}\text { Perceived monitoring harms } \\
\text { the exchange }\end{array}$ \\
\hline & \multirow{2}{*}{$\begin{array}{l}\text { Format of } \\
\text { media }\end{array}$} & $\begin{array}{r}\text { Multi media } \\
\text { formats }\end{array}$ & & $\begin{array}{l}\text { Single media } \\
\text { formats }\end{array}$ & $(.64)^{*}$ & $\begin{array}{l}\text { Format of media is essential; } \\
\text { both the content and structure. }\end{array}$ \\
\hline & & $\begin{array}{l}\text { Applied } \\
\text { practice }\end{array}$ & & $\begin{array}{l}\text { Abstract } \\
\text { theories }\end{array}$ & $(.64)^{*}$ & \\
\hline \multirow{3}{*}{ 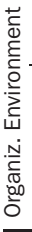 } & Regulation & Any & $\leftrightarrow$ & No & $(.27)$ & $\begin{array}{l}\text { Regulation must be provided, } \\
\text { irrespective of the level. }\end{array}$ \\
\hline & \multirow[t]{2}{*}{$\begin{array}{l}\text { Environmental } \\
\text { artifacts }\end{array}$} & Any time & & No time & (.45) & $\begin{array}{l}\text { Time expresses perceived ac- } \\
\text { ceptance and value learning } \\
\text { activities. }\end{array}$ \\
\hline & & $\begin{array}{l}\text { Any infras- } \\
\text { tructure }\end{array}$ & & $\begin{array}{l}\text { No infras- } \\
\text { tructure }\end{array}$ & $(1)^{*}$ & $\begin{array}{l}\text { Lack of infrastructure prevents } \\
\text { an exchange of OER. }\end{array}$ \\
\hline \multirow{7}{*}{ 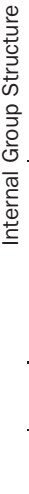 } & \multirow[t]{2}{*}{$\begin{array}{l}\text { Openness } \\
\text { in discourse }\end{array}$} & $\begin{array}{r}\text { Open } \\
\text { discussion }\end{array}$ & & $\begin{array}{l}\text { Discrete } \\
\text { discussion }\end{array}$ & (.45) & $\begin{array}{l}\text { The lack of discussing errors } \\
\text { constrains exchange activities. }\end{array}$ \\
\hline & & Free space & & $\begin{array}{l}\text { Rule } \\
\text { oriented }\end{array}$ & $(.45)$ & $\begin{array}{l}\text { The assumption to be free and } \\
\text { apply knowledge for innovation } \\
\text { is crucial }\end{array}$ \\
\hline & \multirow[t]{3}{*}{$\begin{array}{l}\text { Group } \\
\text { identification }\end{array}$} & Far distance & & $\begin{array}{l}\text { Close } \\
\text { distance }\end{array}$ & $(-.45)$ & $\begin{array}{l}\text { To become salient once collab- } \\
\text { oration is experienced }\end{array}$ \\
\hline & & $\begin{array}{r}\text { Foreign } \\
\text { language }\end{array}$ & & $\begin{array}{l}\text { Native } \\
\text { language }\end{array}$ & $(.-45)$ & \\
\hline & & $\begin{array}{r}\text { Other } \\
\text { domain }\end{array}$ & & $\begin{array}{l}\text { Same } \\
\text { domain }\end{array}$ & $(.63)^{*}$ & $\begin{array}{l}\text { Is significant and essential for } \\
\text { choosing collaboration partners. }\end{array}$ \\
\hline & $\begin{array}{l}\text { Learning at the } \\
\text { work place }\end{array}$ & $\begin{array}{r}\text { Independent } \\
\text { choice }\end{array}$ & $\leftrightarrow$ & $\begin{array}{l}\text { Dependent } \\
\text { choice }\end{array}$ & $(.64)^{*}$ & $\begin{array}{l}\text { Is significant, signals current } \\
\text { assumptions about learning. }\end{array}$ \\
\hline & $\begin{array}{l}\text { Superior } \\
\text { support }\end{array}$ & $\begin{array}{r}\text { Active } \\
\text { support }\end{array}$ & & $\begin{array}{l}\text { Symbolic } \\
\text { support }\end{array}$ & $(.63)^{*}$ & $\begin{array}{l}\text { Without superior support, no } \\
\text { involvement in OER exchange. }\end{array}$ \\
\hline
\end{tabular}

ing credibility and plausibility. Experts evaluated presented factors and used the whole range of rating criteria.

Summarising the evaluation, six cultural factors were judged to be significant in explaining why public employees exchange OER (see Table 1). The strength of the evaluation approach, however, is not the mere quantitative approach, but the further elaboration of why factors are relevant and valid. In this regard, the factors openness in discourse and assumptions about time available for learning need to be included as highly essential.

One highly surprising result is the role of geography as a boundary for group identification. Experts outlined that geography is not a relevant boundary but, at the same time, they raised caution about their rating. Given that collaboration across sectors, countries, and departments is no common, geography is considered a potential factor. Here, the findings shed light on a gap in current learning practices and provide a hint on an opportunity 
for research in the future. The fact that the results provide expected and surprising findings is a quality criterion of emerging cultural models (Van de Ven, 2007). To elaborate further on the credibility and plausibility of the results, the findings can be compared to rival models (Van de Ven, 2007). Does the set of factors and the model suit the context of public employees better than common models in previous studies (Henderson, 2007; Hofstede, 2001; Chen, 2014)?

On the one hand, similarities among factors can be perceived. Edmundson (2007a) sees assumptions about the learner-teacher role (structuring and choosing OER) as a 'critical' factor. The factor 'learning at the workplace' resembles and builds upon this factor, and was also evaluated as significant. On the other hand, the content of cultural factors is more sensible to public sector practices and experiences. Models in higher education address different factors and, moreover, mismatch the required level of analysis (Beuselinck et al., 2007; Jamil et al., 2013; Henderson, 2007).

Further, support is provided by experts, who were asked whether any factors are missing. The experts replied that the model is comprehensive and addresses all salient points. The experts started drawing inferences from the factors; hence, the implications for steering, creating courses, and learning contents can be drawn. Altogether, the plausibility of the idea that factors perform well in practice can be supported. Further, the quality criteria to address are the level of analysis, integration of political values, and ease-of-application. Concerning the level of analysis, the experts judged that most of the factors apply to departments and some are specific to types of learners. While analyzing culture on a micro-level (individual preferences) should be avoided, the importance of subcultures such as learnertypes is seen as valid and insightful (Arellano-Gault, 2013; Rahman et al., 2013; Schraeder et al., 2005). Concerning the role of political values like bureaucracy (Keraudren, 1996, Jamil et al., 2013), evaluated factors show sensibility.

Experts emphasize, for example, that the factor 'learning at the workplace' is well suited to elaborate on whether old or new political values apply (e.g., flexibility; managerial self-responsibility role of innovation). Concerning ease-of-use, experts discuss whether factors are intelligible and applicable in practice (Tapanes, 2011; Pawlowski \& Richter, 2010). As indicated, experts have already started defining implications for their everyday work, which indicates that factors are intelligible and applicable in practice. Yet, given the number of involved experts, more feedback has to be gathered to provide thorough answers. The sampling of experts (diverse countries, positions, gender) contributes to avoid bias. Also, orienting on an established content validation method (McKenzie et al., 1999) helps to avoid over-generalizing the feedback. With caution to these points, the 
ease-of-use aspect can be generally supported but needs to be further assessed.

Altogether, the evaluation, the resulting set of factors, and the research approach appear to meet the quality criteria for the latest research on eLearning from a cultural and socio-technical perspective. It appears to be more sensible for public sector contexts than previously applied models. Future research should empirically validate the model as it is currently planned and executed.

\section{Conclusion}

The goal of this study is to elaborate on the cultural factors that shape the exchange of OER in open e-Learning systems in public administrations. Following a synthesis of previous studies and theories, propositions were defined and presented to experts for evaluation. The result is a set of significant factors that are essential in explaining whether or not public employees exchange OER. Experts in the field appraised the cultural factors and were able to present implications for improving their steering and organization of learning activities. In this regard, the ease-of-use and specificity for public sector contexts can be supported.

Overall, resulting factors can thus be used to elaborate on theoretical and empirical grounds on the phenomenon OER exchange in public administrations. Future research should also elaborate more particularly on surprising results, such as the role of geographical boundaries. Apart from research on particular results, the resulting set of factors highlight the need to conduct comparative studies across countries and cultural models. Initial steps are made to build upon these findings and present a crossadministrative study.

\section{Acknowledgements}

This research has been co-funded by the European Union within the Seventh Framework Programme, FP7-ICT, under Grant Agreement Number 619347.

\section{References}

Amayah, A. (2013). Determinants of knowledge sharing in a public sector organization. Journal of Knowledge Management, 17(3), 454-471.

Arellano-Gault, D. (2013). The dilemma for the new administrative culture in mexican public administration: Esprit de corps or individualist bureaucracy? International Journal of Public Administration, 36(13), 940-952.

Barette, J., Lemyre, L., Corneil, W., \& Beauregard, N. (2012). Organizational learning facilitators in the Canadian public sector. International Journal of Public Administration, 35(2), 137-149.

Beuselinck, E., Verhoest, K., \& Bouckaert, G. (2007). Reforms of central government coordination in OECD countries. In K. Schedler \& I. Proeller 
(Eds.), Cultural aspects of public management reform (pp. 77-115). Amsterdam, The Netherlands: Elsevier.

Bimrose, J., Brown, A., Holocher-Ertl, T., Kieslinger, B., Kunzmann, C., Prilla, M., Schmidt, A., \& Wolf, C. (2014). The role of facilitation in technologyenhanced learning for public employment services. International Journal of Advanced Corporate Learning, 7(3), 56-64.

Bouckaert, G. (2007). Cultural characteristics from public management reforms worldwide. In K. Schedler \& I. Proeller (Eds.), Cultural aspects of public management reform (pp. 29-64). Amsterdam, The Netherlands: Elsevier.

Bostrom, R., \& Gupta, S. (2009). Technology-mediated learning: A comprehensive theoretical model. Journal of the Association for Information Systems, 10(9), 686-714.

Caron, D., \& Giauque, D. (2006). Civil servant identity at the crossroads: new challenges for public administrations. International Journal of Public Sector Management, 19(6), 543-555.

Chen, T. (2014). Exploring e-learning effectiveness perceptions of local government staff based on the diffusion of innovations model. Administration \& Society, 46(4), 450-466.

Chih-Yang, C., Tsai-Chu, C., Ping-Teng, L., \& Chih-Wei, L. (2011, 4-6 August). A study of the civil servants' continuance of using e-learning. Paper presented at the 2011 International Conference on Information Technology Based Higher Education and Training, Izmir, Turkey.

Colazzo, L., Molinari, A., \& Villa, N. (2009). Lifelong learning and virtual communities in the public administration: A case study in Italy. International Journal of Advanced Corporate Learning, 2(3), 5-11.

Creswell, J., \& Plano-Clark, V. (2011). Designing and conducting mixed methods research (2nd ed.) Thousand Oaks, CA: Sage.

DeSanctis, G., \& Poole, M. (1994). Capturing the complexity in advanced technology use: Adaptive structuration theory. Organization Science, 5(2), 121-147.

Edmundson, A. (2007a). The cultural adaptation process (CAP) model: Designing e-learning. In A. Edmundson (Ed.). Globalized e-learning cultural challenges (pp. 267-289). Hershey, PA: IGI Global.

Edmundson, A. (2007b). Addressing the cultural dimensions of e-learning: Where to begin? In C. van Slyke (Ed.), Information communication technologies: Concepts, methodologies, tools, and applications (pp. 22522267). Hershey, PA: IGI Global.

Eidson, L. (2009). Barriers to e-learning job training: Government employee experiences in an online wilderness management course (Thesis, Dissertations, Professional Papers No. 86). Missoula, MN: University of Montana.

Esposito, J., \& Rothgeb, J. (1997). Evaluating survey data: Making the transition from pretesting to quality assessment. In L. Lyberg, P. Biemer, M. Collins, E. de-Leeuw, C. Dippo, N. Schwarz, \& D. Trewin (Eds.), Survey measurement and process quality (pp. 541-571). Chichester, England: Wiley. 
Frank, U. (2006). Towards a pluralistic conception of research methods in ISR (ICT-Research Report No. 7). Duisburg, Germany: University DuisburgEssen.

Giddens, A. (2001). The constitution of society: Outline of the theory of structure. Berkeley, CA: University of California Press.

Greiling, D., \& Halachmi, A. (2013). Accountability and organizational learning in the public sector. Public Performance \& Management Review, 36(3), 380-406.

Gustavsson, M. (2009). Facilitating expansive learning in a public sector organization. Studies in Continuing Education, 31(3), 245-259.

Hedvicakova, M. (2013). Project management in public administration sector. In K. Elleithy, \& T. Sobh (Eds.), Innovations and advances in computer, information, systems sciences, and engineering (pp. 741-749). New York, NY: Springer

Henderson, L. (1996). Instructional design of interactive multimedia: A cultural critique. Educational Technology Research and Development, 44(4), 85-104.

Henderson, L. (2007). Theorizing a multiple cultures instructional design model for e-learning and e-teaching. In A. Edmundson (Ed.), Globalized e-learning cultural challenges (pp. 130-153). Hershey, PA: IGI Global.

Hilton III., J., Wiley, D., Stein, J., \& Johnson, A. (2010). The four R's of openness and ALMS analysis: Frameworks for open educational resources. Open Learning, 25(1), 37-44.

Ho, Y.-Y., Tsai, H.-T., \& Day, J. (2010). Using the theory of planned behaviour to predict public sector training participation. The Service Industries Journal, 31(5), 771-790.

Hofstede, G. (2001). Culture's consequences: Comparing values, behaviors, institutions, and organizations across nations. Thousand Oaks, CA: Sage.

Hollingshead, A., Monge, P., \& Fulk, J. (2005). Knowledge resource sharing in dispersed multinational teams: Three theoretical lenses. In D. Shapiro, J. Cheng, \& M. Von Glinow (Eds.), Managing multinational teams: Global perspective (pp. 159-189). Oxford, England: Elsevier.

Imran, A., Gregor, S., \& Turner, T. (2013). Curriculum design and delivery for e-government knowledge transfer in a cross cultural environment: The Bangladesh experience. In Y. K. Dwivedi, H. Z. Henriksen, D. Wastell, R. De' (Eds.), Grand successes and failures in IT: Public and private sectors (pp. 596-604). New York, NY: Springer.

Jamil, I., Askvik, S., \& Hossain, F. (2013). Understanding administrative culture: Some theoretical and methodological remarks. International Journal of Public Administration, 36(13), 900-909.

Katz, A., \& Te'eni, D. (2007). The contingent impact of contextualization on computer-mediated collaboration. Organization Science, 18(2), 261-279.

Keraudren, P. (1996). In search of culture: Lessons from the past to find a role for the study of administrative culture. Governance, 9(1), 71-98.

Krosnick, J., \& Fabrigar, L. (1997). Designing rating scales for effective measurement in surveys. In L. Lyberg, P. Biemer, M. Collins, E. de-Leeuw, C. 
Dippo, N. Schwarz, \& D. Trewin (Eds.), Survey measurement and process quality (pp. 141-164). Chichester, England: Wiley.

Langford, J., \& Seaborne, K. (2003). To click or not to click: E-learning for the public sector. Canadian Public Administration, 46(1), 50-75.

Lawshe, C. (1975). A quantitative approach to content validity. Personnel psychology, 28(4), 563-575.

Lyytinen, K., \& Newman, M. (2008). Explaining information systems change: A punctuated socio-technical change model. European Journal of Information Systems, 17(6), 589-613.

Mahler, J. (1997). Influences of organizational culture on learning in public agencies. Journal of Public Administration Research \& Theory, 7(4), 519540.

Marschollek, O., \& Beck, R. (2012). Alignment of divergent organizational cultures in it public-private partnerships. Business \& Information Systems Engineering, 4(3), 153-162.

McKenzie, J., Wood, M., Kotecki, J., Clark, J., \& Brey, R. (1999). Establishing content validity: Using qualitative and quantitative steps. American Journal of Health Behavior, 23(4), 311-318.

Moynihan, D., \& Landuyt, N. (2009). How do public organizations learn? Bridging cultural and structural perspectives. Public Administration Review, 69(6), 1097-1105.

Orlikowski, W., \& Robey, D. (1991). Information technology and the structuring of organizations. Information Systems Research, 2(2), 143-169.

Rahman, M., Naz, R., \& Nand, A. (2013). Public sector reforms in Fiji: Examining policy implementation setting and administrative culture. International Journal of Public Administration, 36(13), 982-995.

Rammstedt, B. (2004). Zur Bestimmung der Güte von Multi-ltem-Skalen: Eine Einführung (How-to-Reihe No. 12). Retrieved from http://www.gesis.org/ fileadmin/upload/forschung/publikationen/gesis_reihen/howto/how -to12br.pdf

Pawlowski, J., \& Richter, T. (2010). A methodology to compare and adapt ELearning in the global context. In M. Breitner, M. Lehner, F. Staff, \& U. Winand (Eds.), E-learning 2010: Aspekte der Betriebswirtschaftslehre und Informatik (pp. 3-13). Berlin, Germany: Physica-Verlag.

Pereira, F., Ramos, A., Gouvêa, M., \& M. da-Costa. (2015). Satisfaction and continuous use intention of e-learning service in Brazilian public organizations. Computers in Human Behavior, 46, 139-148.

Pirkkalainen, H., Jokinen, J., \& Pawlowski, J. (2014). Understanding social OER environments: A quantitative study on factors influencing the motivation to share and collaborate. IEEE Transactions on Learning Technologies, 7(4), 388-400.

Pirkkalainen, H., \& Pawlowski, J. (2014). Global social knowledge management: Understanding barriers for global workers utilizing social software. Computers in Human Behavior, 30, 637-647.

Remtulla, K. (2007). The knowledge-based economy and e-learning: Critical considerations for workplace democracy. Convergence 40, 9-24. 
Richter, T., \& Adelsberger, H. (2012). On the myth of a general national culture: Making specific cultural characteristics of learners in different educational contexts in Germany visible. In Cultural Attitudes towards Communication and Technology 2012 (pp. 105-120). Murdoch, Australia: Murdoch University.

Richter, T., \& McPherson, M. (2012). Open educational resources: Education for the world? Distance Education, 33(2), 201-219.

Rosenberg, M. (2001). E-learning: Strategies for delivering knowledge in the digital age. New York, NY: McGraw-Hill.

Rutgers, M. (2008). Sorting out public values? On the contingency of value classification in public administration. Administrative Theory \& Praxis, 30(1), 92-113.

Sannia, M., Ercoli, G., \& Leo, T. (2009). Evaluation of virtual learning environment for the professional training in public administration. International Journal of Advanced Corporate Learning, 2(1), 50-55.

Schein, E. (1990). Organizational culture. American Psychologist, 45(2), 109119.

Schein, E. (2010). Organizational culture and leadership (4th ed.). San Francisco, CA: Jossey-Bass.

Schraeder, M., Tears, R., \& Jordan, M. (2005). Organizational culture in public sector organizations. Leadership \& Organization Development Journal, 26(6), 492-502.

Sein, M., Henfridsson, O., Purao, S., Rossi, M., \& Lindgren, R. (2011). Action Design Research. MIS Quarterly, 35(1), 37-56.

Stefanick, L., \& LeSage, E. (2005). Limitations to developing virtual communities in the public sector: A local government case study. Canadian Public Administration, 48(2), 231-250.

Stoffregen, J. (2015, 4-6 March). Integrated, open e-learning systems in public administrations. Paper presented at the 12. Internationale Tagung Wirtschaftsinformatik Osnabrück, Osnabrück, Germany.

Stoffregen, J., \& Pawlowski, J. (Forthcoming). Culture in public administrations: Caring for the red-headed stepchild in the management of learning and knowledge exchange.

Stoffregen, J., Pawlowski, J., Ras, E., Tobias, E., Šćepanović, S., Fitzpatrick, D., Mehigan, T., Steffens, P., Przygoda, C., Schilling, P., Friedrich, H., \& Moebs, S. (2016). Barriers to open e-learning in public administrations: A comparative case study of the European countries Luxembourg, Germany, Montenegro and Ireland. Technological Forecasting and Social Change, 111, 198-208.

Tapanes, M. A. (2011). Revision and validation of a culturally-adapted online instructional module using Edmundson's CAP model: A DBR study. Retrieved from http://scholarcommons.usf.edu/etd/3376

Van de Ven, A. H. (2007). Engaged scholarship: A guide for organizational and social research. Oxford, England: Oxford University Press.

Webster, J., \& Watson, R. (2002). Analysing the past to prepare for the future: Writing a literature review. MIS Quarterly 26(2), xiii-xxiii. 
Witmer, D. (1997). Communication and recovery: Structuration as an ontological approach to organizational culture. Communications Monographs, 64(4), 324-349.

Yang, R., \& Ruan, J. (2007). The e-learning system used in the civil servants' job-training. In W. Wang, Y. Li, Z. Duan, L. Yan, H. Li, \& X. Yan (Eds.), Integration and innovation orient to e-society (Vol. 2, pp. 574-581). Wuhan, China: Springer.

Yao, L. J., Kam, T. H. Y., \& Chan, S. H. (2007). Knowledge sharing in Asian public administration sector: The case of Hong Kong. Journal of Enterprise Information Management, 20(1), 51-69.

Julia Stoffregen is PhD candidate at the University of Jyväskylä with expertise in science and technology studies in the public sector. Her experiences and scientific peer reviewed publications are made in the field of open and egovernment and online training of public employees. Her dedicated research efforts focus on the development of socio-technical process models of technology implementation processes. julia.stoffregen@hs-ruhwest.de

Jan M. Pawlowski is Professor of Digital Media with the specialization 'Global Information Systems' (GLIS). His main research interests and numerous scientific peer reviewed publications are in the field of GLIS, e-learning, modeling learning-related processes, learning technology, standardization, quality management and assurance for education and mobile/ambient learning.

jan.pawlowski@hs-ruhrwest.de

Eric Ras is Dr. rer. nat. in Computer Science and R\&D manager with specialization in knowledge-based approaches and semantic web technologies with innovative human-computer interfaces (e.g., tangible user interfaces, dialogue-based systems). Mr. Ras is the national contact point for the FET flagship project FuturICT and has authored more than 70 peer reviewed scientific publications. eric.ras@list.lu

Snezana Šćepanović is Associate Professor at UNIM in Montenegro. She is expert in instructional design e-tutoring and e-Learning technologies. Her special interests include developing and delivering online courses for professionals, as well as accreditation of related curricula.

snezana.scepanovic@unimediteran.net

Dragica Zugic is Vice Dean of Academic Affairs at the Faculty of Foreign Languages at the University Meditteranean. Dr Zugic is engaged in the development and implementation of open e-learning systems in local (Montenegrin) public administrations.dragicazugic@gmail.com

cC) $(1$ This paper is published under the terms of the AttributionNonCommercial-NoDerivatives 4.0 International (CC BY-NC-ND 4.0) License (http://creativecommons.org/licenses/by-nc-nd/4.0/). 


\section{Why do relevant structural gaps to the exchange of open knowledge resources change in public administrations}

by

Stoffregen, J., Pawlowski, J., Šcepanovic, S., Zugic, D., Moebs, S., Raffl, C., ... \& Müller, J. 2015.

E-Learn: World Conference on E-Learning in Corporate, Government, Healthcare, and Higher Education, October 2015, 1051-1056.

Reproduced with kind permission by Association for the Advancement of Computing in Education. 


\title{
Why do relevant structural gaps to the exchange of open knowledge resources change in public administrations?
}

\author{
Julia Stoffregen \\ Univ. of Applied Sciences Ruhr West; Univ. of Jyväskylä, Computer Science /Information Systems \\ Germany \\ julia.stoffregen@hs-ruhrwest.de \\ Jan Pawlowski \\ University of Applied Sciences Ruhr West \\ Germany \\ jan.pawlowski@hs-ruhrwest.de \\ Snezana Šćepanović \\ Dragica Zugic \\ University Mediterranean Podgorica \\ Montenegro \\ snezana.scepanovic@unimediteran.net \\ dragicazugic@gmail.com \\ Sabine Moebs \\ Celina Raffl \\ Business Information Systems, Baden-Wuerttemberg Cooperative State University Heidenheim \\ Germany \\ moebs@dhbw-heidenheim.de \\ raffl@dhbw-heidenheim.de \\ Petra Steffens \\ Christiane Przygoda \\ Fraunhofer-Institut für Offene Kommunikationssysteme; Kompetenzzentrum eGovernment und Applikationen \\ Germany \\ petra.steffens@fokus.fraunhofer.de \\ christiane.przygoda@fokus.fraunhofer.de \\ Jeanette Müller \\ accelopment $A G$ \\ Switzerland \\ jmueller@accelopment.com
}

\begin{abstract}
Why do barriers to the exchange of open knowledge resources change in public administrations? Experts in the public sector have been interviewed and outlined antecedents of change to certain barriers. The results are an initial step towards theorizing on barrier change and stepping beyond the current trend of categorizing difficulties to e-Learning and use of open knowledge resources. Categorizing only shows the range of potential challenges. Whether and how the barriers change, however, is seldom addressed in previous literature. The results presented in this study thus provide a new perspective on the phenomenon. Results are part of a longitudinal study about open e-Learning in the public sector across four European countries. They will provide fresh empirical input for discussions at the World Conference on E-Learning how to advance future research and practices in the domain
\end{abstract}

\section{Introduction}

E-Learning and the (re-)use of open knowledge resources is an ongoing trend to innovate education and lifelong learning. Despite considerable challenges, the hope to make knowledge and education more accessible across the globe is not decreasing. Correspondingly, efforts in research and practice are directed to overcome particular barriers to the (re-)use of e-Learning- and open knowledge resources. Familiar contextualization strategies in this respect are localization, adaptation and modularization (Henderson 2007; Edmundson 2007) among others. While inspiring to improve open e-Learning activities in the future, the strategies require further improvement. For example, contextualization models are formulated on a high level (Pawlowski \& Richter 2010) and are difficult to apply in practice (Tapanes 2011). Another point is that they are not accounting for antecedents to barrier change. While research on barriers to e-Learning and OER is increasing (e.g. D'Antoni 2009); there are only few researchers who elaborate on the mechanisms of barrier change (Singh \& Hardaker 2014).

Open e-Learning is still not a mainstream approach in many organizations. To avoid common barriers to eLearning, knowledge about their antecedents is needed to see whether and how they can be identified and, possibly, overcome from the very beginning. Knowing which issues, problems and incidents should be monitored during implementation, for example, would enhance anticipating which barriers are likely to emerge and thus which accommodating strategies would be best to enact. Specifically for public administration this knowledge is invaluable. Despite its potentials, e-Learning and the use of open knowledge resources are not well implemented yet. Research on open e-Learning in the public sector is correspondingly at an infant stage. Studies are mainly 
focusing on the potential range of barriers. Others are just starting to explore e-Learning behavior such as continuous use of platforms (Pereira et al. 2015). Yet, the approaches do not allow answering whether and why difficult situations or failure evolve. Knowing about antecedents of barrier change will thus provide a new perspective how to realize of e-Learning promises and prevent common barriers to unfold.

Altogether, there is a knowledge gap concerning the question why and how barriers to open e-Learning change. This study aims to close this knowledge gap and starts focusing on the public sector where efforts to integrate eLearning in the future could benefit the most of novel insights. The study elaborates on the change of barriers to the creation and adaptation of open knowledge resources for others' and personal learning means. Results will allow making an initial step to answer how and why particular barriers to the exchange of open knowledge resources evolve. The presentation at the World Conference on E-Learning aims at involving peers in the domain to make disciplined imaginaries (Weick 1989) how to improve current research approaches and step beyond current generalized recommendation patterns. Firstly, barrier studies and theoretical approaches in the domain will be resumed. Subsequently, the study and project context including the research design will be outlined. Finally, results of the expert interviews will be discussed. The conclusion will summarize the main points and delimit the focus of the virtual presentation at the conference.

\section{Literature review}

What are challenges to e-Learning and use of open knowledge resources? Why and how do these barriers unfold? Several studies have been moved by the first question and succeeded to provide rich insight on behalf of barrier studies and initial exploratory models. Beginning with barrier studies, Eidson (2009) elaborates on challenges in a wilderness class for public administrations. Barriers relate to the work environment, course design personality trait and preferences including situational, dispositional, epistemological and institutional barriers (synthesized with previous studies, cf. Eidson 2009, pp. 179ff.). Stoffregen et al. (2015) develop a Barrier Framework for the development and use of e-Learning and OER in public administrations. Extending the barrier framework of Pirkkalainen and Pawlowski (2014), authors raise caution that organizational, social and technical barriers are interdependent. Thus, mapping barrier relations and how they evolve is a worthwhile research focus in the future (Pirkkalainen \& Pawlowski 2014). Regarding initial exploratory models, Pereira et al. (2015) elaborate on factors of continuous e-Learning use. They orient on the technology readiness index and disconfirmation expectancy theory to examine relations between satisfaction and continuous use intention among others. Chen (2014) elaborates on e-Learning expectations as well but orients on innovation theory. Results of both studies suggest that expectations towards e-Learning are low in the public sector and shape related activities. Moreover, authors point out that more research is needed to generalize upon findings across public sector contexts. Although various factors are included, the models do not fully represent the phenomenon. Among excluded aspects is that results do not answer whether and how barriers to e-Learning change over time.

Theories and strategies concerning contextualization and e-Learning activities are not much clearer in this respect. Beginning with theories, Bostrom and Gupta (2009) propose that learning contexts, method structures and processes such as appropriation and aptitude explain learning outcomes. Though highlighting the relevance of "processes" in e-Learning theory, the concept puts emphasis on only one of several aspects. Authors refer to learning process which "...is viewed as an appropriation or structuration process where participants learn and adapt the learning method structures" (Bostrom \& Gupta 2009, p.699). The model includes structuration as "the use and adaptation of team and technology patterns' as well (Bostrom \& Gupta 2009, p.700). However, neither the nature nor potential of associated barriers and antecedents to structuration is explained in the concept. Coming to contextualization strategies, a prominent model is the cultural adaptation process (CAP, Edmundson 2007). It builds upon a multiple-culture model (Henderson 2007) and qualifies cultural context factors that shape the creation and adaptation of e-Learning resources. While CAP is strong in determining influence factors, it is weaker in guiding through the processes of adaptation. However, research has resulted in lifecycles (Richter \& Pawlowski 2007) and re-authoring strategies of knowledge resources (Rensing et al. 2005) over time. Overall, the strategies depict particular factors, constructs and steps how creating and adapting culture sensitive knowledge resources may proceed. Yet, they seldom map barriers and antecedents of change during activities. Correspondingly, the question 'why or how the challenges evolve' remains unresolved.

It is stunning that the great interest to improve open e-Learning has not included researching on antecedents of barrier change so far. Singh and Hardaker (2014) come to the same conclusion and promote the relevance of knowing about change factors to adoption and diffusion of e-Learning. While their study supports the call to increase research on mechanisms of barriers change, authors only present a literature review. They do not map results to particular barriers. Moreover, authors do not delimit their focus on particular e-Learning activities. Since Singh and Hardaker (2014) focus on the context of higher education it is furthermore to question how representative findings are for different contexts. Whether antecedents differ in the public sector, for example, cannot be answered at the moment. Overall, this review supports that no sufficient answer to the question 'why and how particular barriers to the exchange of open knowledge resources in public administrations change' is 
provided. The results prepared for the virtual presentation at the World Conference on E-Learning aim to advance knowledge in this respect. The following section will outline the context and research design of the study.

\section{Study context and research design}

The study presented is associated to the project 'EnhAnced Government LEarning' (EAGLE). The project goals include developing a state of the art open source platform for exchange of experiences and open knowledge resources. Target administrations are rural local Governments across Germany, Luxembourg, Ireland and Montenegro. Small public administrations have considerable burdens to invest in digital training systems. The potential to use existing open platforms is further constrained by a perceived lack of suitable knowledge resources which address the specific needs of public employees (Stoffregen et al. forthcoming). To understand requirements and barriers in this context, requirement engineering (Viller \& Sommerville 1999) was conducted. Additionally, empirical data and literature reviews have been compiled across the countries and domains of organizational-, e-Learning and knowledge management. Based on that, a cultural-context model evolved, which aims at explaining why public employees exchange open knowledge resources- that is creating and adapting cultural sensitive open knowledge resources for others and personal learning means. Recently, expert interviews have been conducted to validate the cultural model. Part of the results shall be discussed at the conference and will be described in the following.

The model evaluation follows a mixed-method content validation according to Lawshe (1975) and McKenzie et al. (1999). It is applied in established in the domain (cf. Barette et al. 2012). Firstly, experts were asked about the relevance of the topics e-Learning, use of open knowledge resources and culture respectively. Secondly, a set of nine factors was presented and experts were asked, how important the factors are to explain why public employees exchange open knowledge resources. Together with rating the factors, experts explained conditions, elaborated on experiences and related antecedents to change of critical factors. While the expert's view on factors is published elsewhere, this report is uniquely focusing on the reported antecedents of change. For this means, interviews were analyzed iteratively by semi-structured, thematic content analysis (cf. Mayring 2010): Antecedents are defined as empirical (incident) or abstract (event) moments in time which trigger change of structural gaps within a certain context (Van de Ven 2007). 'Structural gaps' is the theoretical referent for barriers to the exchange of open knowledge resources (orienting on Bostrom \& Gupta 2009; Lyytinen \& Newman 2008). Following an initial coding, the second analysis focused on incidents particularly. Following Van de Ven (2007, p.217), antecedents to change (incident or event, respectively) can be qualified as a 'bracketed string' by providing: (1) a description of the basic elements; (2) notes about discrete occurrences of action or behavior (3) its specific date, situation or consequences, (4) a dedicated memo of the discussion context and finally, (5) a unique code as an indicator of a theoretical event (Van de Ven 2007, p.218). The corresponding results are provided below.

\section{Results: Antecedents to change}

The analysis of results brought several incidents to light. The description of incidents by experts was conceptually dense so that four antecedent constructs could be defined, namely individual and inter-personal, organizational and time related antecedents. In a first, step antecedent constructs and incidents will be described. Subsequently, results will be discussed with regard to findings established in the domain.

Antecedents related to individuals. Antecedents related to individuals stands for age of individuals and moments of change of personnel. The last point can be subdivided into change of positions and change of persons. 'Change of persons' is an event which stands for incidents of personal re-orientation, rotation or retirement of individuals. Personal re-orientation means that employees decide to change positions or change across sectors. Rotation means that employees have to take on a different job task or position given weak personnel force and vacant positions. Retirement means that employees and seniors quit working. The incidents share that people leave their original job task and / or departmental environment. For the original department, the change of colleagues is an antecedent that knowledge about task completion gets lost. As a consequence, the need for leaving persons to create open knowledge resources increases. For leaving employees, the change may offer free space to bring ideas into the new department and / or job task. At the same time, it requires awareness that culturally distinct practices will be present and expected. As a consequence, need for availing of open knowledge resources rises. 'Change of position' is an event which stands for incidents of shifting leader positions; particularly of people who are growing into leadership roles in the public sector. They are politically shaped and / or seek political goals including maturing in their job for promotion. Incidents occur throughout the implementation phase of projects, including knowledge sharing projects. As a consequence, communicating about and realizing e-Learning activities are conditioned by electoral shifts and stability of project agreement by successors. Change of positions may be influenced by age and mindset of individuals including unique dates such as elections.

Age of individuals is an event which stands for incremental incidents of personal prioritization of activities. Age of people shapes personal interest in using internet based social media for learning and personal advancement. Particularly, initial phases including the start of exchanging of open knowledge resources are seen as critical 
phases. Also the importance of being evaluated decreases. While it is difficult to define a common moment in time for individual shifts, the range of critical age was located around forty years.

Antecedents related to inter-personal behavior. Antecedents related to inter-personal behavior stands for a set of moments in time where errors unveil, or leaders and gatekeepers make decisions that are relevant for the involvement in exchange activities. Unveiling errors is an event which stands for the incidents of error occurrence and its recognition. It is a critical moment in time both for employees and superiors. Consequences of errors are unclear and public employees fear to make errors: "We are public employees, we do not make errors" is a common mantra according to interviewees. Associated fear to make errors lead to silencing, influence information sharing, communication across colleagues as well as leadership behavior. The relevance of unveiling errors may be shaped by age, work area of employees. Leader decisions is a moment in time when single leading persons make a decision which applies for all employees. They are higher superiors or general driving individuals. As a consequence of decisions, stronger or weaker involvement of public employees in the exchange can be expected. Pointing towards the incident are activities of others to enroll leaders, if no personal interest is present. Hence, leader decisions are made by a single person but $\mathrm{s} /$ he is not necessary an autonomous leader but shaped in interpersonal behavior with others and interest groups, for example. Additionally, performative decisions such as engaging in the exchange of open knowledge resources may underline the fact that decisions are made. Similarly, the announcement that exchange activities are welcome is an associated incident. Leadership decisions may be conditioned by organizational leadership structures as well as by personal interest and presence of gatekeepers. Gatekeeper decisions is an event when a person or (speaker of an) interest group decides over resources of investment. Similar to leader decisions, stronger or weaker involvement of employees in the exchange can be expected. The incident may occur during use and implementation of online platforms, which serve for learning and training engagement as well as provision of shared services. Gatekeeper decisions may be dependent on resource availability in the respective department.

Antecedents related to time. Antecedents related to time build upon perceived and factual time to spend for the exchange of open knowledge resources. The time for exchange is an event which stands for the perceived time for involving in exchange activities, getting together with others, learning things and preparing to exchange open knowledge resources during work-hours. Incidents appear to be relevant in the initial adoption phase of open e-Learning platforms as well as knowledge management programs given change of personnel. Time for exchange is not a particular date but moment of personal reflection; people decide whether or not to start activities. It may depend on interest in exchange activities and social media. The time window and artifact stands for an event phase which is used to create particular outputs. One incident is that the phase is scheduled in a planner. Furthermore, it is represented by evolving artefacts. Incident appears prior moments of creation, exchange and preparation of collaboration as well as adaptation of contents. The incidents are no single moments in time but perform as re-occurring reminders (to take time and involve in activities). They may be shaped on unique dates, work area, and expertise of individuals. The event unique dates stands for particular dates which are scheduled in time. The dates may stand for regular meetings and assessment dates which are common for all and / or represent dedicated milestones between two persons. As indicated before, elections can be a unique date. It is an antecedent for change of positions, for example. Unique dates are relevant for learning activities, for example, when evaluation deadlines come closer, the relevance to reiterate knowledge contents may rise.

Antecedents related organizational contexts. Antecedents related to organizational contexts stands for incidents of resource allocation and organizational re-structuring. Allocation of resources stands for an event when open knowledge resources are chosen or the choice is checked and agreed upon by superiors. Resources may further refer to calm rooms to spend time for learning, OER for exchange, budget and investment in training programs. The allocation is an incident which expresses power of leaders; correspondingly, a condition is that the allocation is made for an employee who has a predefined task. Allocation of resources shapes interaction and reasoning why to involve in open e-Learning as well as the presence of particular technology programs. Depending on the work domain such as front offices, operational or home offices, the relevance of resource allocation may vary. Organizational re-structuring is an event which stands for incidents of organizational mergers or reforms. Both may be associated to personnel reduction and reduction of training investment. As a consequence, resources for realizing and investing time and effort in the exchange of open knowledge resources are weakened. The antecedent may be associated to resource allocation and change of personnel.

\section{Discussion}

So far, results of expert interviews have been provided. Several points are to discuss including the two questions: to what extent are findings unique and provide a new perspective on the phenomenon (1) and the question: are the findings dependent on the context of experts (2)? Comparing the results with previous studies shows that some findings resemble one another. Age, for example, is included as a factor in in several studies (e.g. (Chen 2014; Moynihan \& Landuyt 2009). Yet, it has not been focused on different age ranges; it may enhance understanding about involvement in e-Learning activities. Another re-occurring point is time-related barriers (Stoffregen et al. 2015; Eidson 2009). Public employees may not have time to involve in learning given 
a high workload or 'competing priorities' (Eidson 2009, pp.44f.). Time related antecedents in this study are distinct because they firstly, differ between phases, unique dates and perceived time for exchange. Secondly, they are no barriers but direct attention to moments in time where barriers start unfolding. In this respect, concrete interventions can be scheduled. To secure taking time for exchange activities, public employees may have to pre-define a specific time phase, for example. This incident raises attention to prepare activities, or remind that it is time for learning. The idea is supported by participants in Eidson's study (2009): "I kind of just moved my schedule, because I knew I was going to have say four half days of free time in the next two weeks...And so rather than having a whole bunch of little half days, I just pushed a couple of things and got them done to make whole days of availability." (student 7 quoted in Eidson 2009, p.45).

A last example addresses individual related antecedents. One barrier reported in previous studies is the perceived lack of socialization in e-Learning (Stoffregen et al. 2015; Eidson 2009). E-Learning students claim that more exchange with colleagues would be beneficial (Eidson 2009, pp.57f.). However, collaboration would be meaningful mainly within national (geographic) borders (Stoffregen et al. 2015; forthcoming). This deficit oriented knowledge is enhanced by antecedents in this study. Incidents related to change of personnel indicate that rotating employees may be more interested in exchange activities. It allows them getting into the new tasks and find out how to accomplish the job. Instead of asking 'which collaboration tools may enable exchange' results in this study suggest asking 'who has recently changed departments?' In this context, it can be shown how results provide a new perspective and input for discussions in the domain.

Coming to the second question; are the results bound to the contexts of experts? (2); the quote of Eidson's study provides an indicative answer. In a first view, results do not appear to be specifically bound to the project context or situation of experts. In particular, findings reported above were mentioned in at least two contexts with the exception of leadership decisions. However, the study from Yang and Ruan provides support that leadership decisions and involvement are critical events: "The government leader themselves should take part in the elearning and admit the new thinking and learning methods." (Yang \& Ruan 2007, p.578). The study is situated in China and refers to Government plans (Yang \& Ruan 2007, p.577). Compared to European contexts this suggests that findings are likely to apply across geographical contexts. While the relevance of findings can thus be supported, it is clear that more efforts are needed to ground the results in empirical observations. More research on e-Learning and the exchange of open knowledge resources is needed to elaborate on mechanisms of barrier change.

\section{Research potentials \& Recommendations}

Based on the results, future research potentials can be defined. On the one hand, research on similarities and differences of barriers across contexts needs to be enhanced. More longitudinal studies need to be implemented which include elaborating on the role of change mechanisms in e-Learning activities and use of open knowledge resources. In the context of higher education, the private and public sector, more in-depth as well as comparative studies should be conducted to advance the current state of research on mechanisms of change. On the other hand, studies should try to include and advance e-Learning theories and models for explanatory research. Focusing on processes in e-Learning and use of open knowledge resources emphasizes the interest to go beyond determining learning outcomes. It is time to go beyond categorizing and regressing factors on learning and innovation performance indices. It needs to be answered first why and how remaining challenges in e-Learning and use of open knowledge resources can be addressed effectively.

Correspondingly to advances in research, implications for practice can be derived. For example, monitoring systems could be developed which report whenever (incidents of) change are noticed. Depending on the associated antecedent, activities to accommodate mechanisms of change can be enacted. For example, if incidents to change of personnel are noticed, guidance how and which open knowledge resources new employees might use can be prepared. Associated to this points, experts have outlined to put more emphasis on the voice of general public employees in research and (practice) of e-Learning. They are at the forefront of change and thus will have needed expertise in evaluating the role of antecedents in their cultural context. These and other implications for future research in the domain shall be presented and discussed in brief at the World Conference on E-Learning.

\section{Conclusion \& Outlook for the World Conference on E-Learning}

The paper has outlined initial results to the question why barriers to the exchange of open knowledge resources change in public administrations. Following the presentation and discussion of results, it becomes clear that the potential of findings is high to open a new perspective on the phenomenon. Correspondingly, the virtual presentation shall not only serve to report the results but also to discuss with the audience. Expecting that the research context of attendants is not concentrated on the public sector, suitable questions for a brief discussion are: how relevant are presented antecedents across (research) contexts (1). Furthermore, ideas to: 'whether and how to advance research on mechanisms of change in the domain?' can be discussed (2). On behalf of these and associated questions, an agenda embracing research questions, -contexts and appropriate 
methods can be constructed for the future. The virtual presentation will provide the audience with some background of the domain and context of research. The main focus will be set on the presentation of results. To facilitate understanding, a graphic of reported antecedents is prepared which goes beyond reported results so far (due to space constrains). The mapping will show relations between the four antecedent constructs and common barriers in the domain.

\section{Acknowledgements:}

This research has been co-funded by the European Union within the Seventh Framework Programme, FP7-ICT, grant agreement no: 619347, (see: http://www.eagle-learning.eu/).

\section{References}

Barette, J.; Lemyre, L.; Corneil, W.; Beauregard, N. (2012). Organizational Learning Facilitators in the Canadian Public Sector. International Journal of Public Administration 35(2), pp. 137-149.

Bostrom, R. P.; Gupta, S. (2009). Technology-mediated learning: A comprehensive theoretical model. Journal of the Association for Information Systems 10(9), pp. 686-714.

Chen, T-L. (2014). Exploring e-Learning Effectiveness Perceptions of Local Government Staff Based on the Diffusion of Innovations Model. Administration \& Society 46(4), pp. 450-466. DOI: 10.1177/0095399713482313.

D’Antoni, S. (2009). Open Educational Resources: reviewing initiatives and issues. Open Learning: The Journal of Open, Distance and e-Learning 24(1), pp. 3-10. DOI: 10.1080/02680510802625443.

Edmundson, A. (2007). The cultural adaptation process (CAP) model: designing e-learning. Chapter XVI. In Andrea Edmundson (Ed.): Globalized e-learning cultural challenges. Hershey, PA: IGI Global, pp. 267-289.

Eidson, L.A.K. (2009). Barriers to E-Learning Job Training: Government Employee Experiences in an Online Wilderness Management Course. Thesis, Dissertations, Prossional Papers.(University of Montana. Paper 86).

Henderson, L. (2007). Theorizing a multiple cultures instructional design model for e-learning and e-teaching. In Andrea Edmundson (Ed.): Globalized e-learning cultural challenges. Hershey, PA: IGI Global, pp. 130-153.

Lawshe, C. H. (1975). A quantitative approach to content validity1. Personnel psychology 28(4), pp. 563-575.

Lyytinen, K.; Newman, M. (2008). Explaining information systems change: a punctuated socio-technical change model. European Journal of Information Systems 17(6), pp. 589-613.

Mayring, P. (Ed.) (2010). Qualitative Inhaltsanalyse. Weinheim und Basel: Beltz Verlag (11 Auflage).

McKenzie, J. F.; Wood, M. L.; Kotecki, J.E., Clark, J.K.; Brey, R. A. (1999). Establishing Content Validity: Using Qualitative and Quantitative Steps. Am J Health Behavior 23(4), pp. 311-318.

Moynihan, D. P.; Landuyt, N. (2009). How Do Public Organizations Learn? Bridging Cultural and Structural Perspectives. Public Administration Review 69(6), pp. 1097-1105.

Pawlowski, J.M.; Richter, T. (2010). A methodology to compare and adapt E-Learning in the global context. In Michael H. Breitner, Franz Lehner, Jörg Staff, Udo Winand (Eds.): E-Learning 2010. Berlin u.a: Physica-Verl, pp. 3-13. Available online at http://dx.doi.org/10.1007/978-3-7908-2355-4_1.

Pereira, F.; Ramos, A.; Gouvêa, M..; da-Costa, M.. (2015). Satisfaction and continuous use intention of e-learning service in Brazilian public organizations. Computers in Human Behavior 46(0), pp. 139-148.

Pirkkalainen, H.; Pawlowski, J.M. (2014). Global social knowledge management-understanding barriers for global workers utilizing social software. Computers in Human Behavior 30, pp. 637-647.

Rensing, C.; Bergsträßer, S.; Hildebrandt, T.; Meyer, M.; Zimmermann, B.; Faatz, A. et al. (2005). Re-Use, Re-Authoring, and Re-Purposing of Learning Resources Definitions and Examples. Technical Report. KOM-TR-2005-02. TU Multimedia Communications Lab. Darmstadt.

Richter, T.; Pawlowski, J.M. (Eds.) (2007). The need for standardization of context metadata for e-learning environments. In Proc. of e-ASEM Conference, Seoul, Korea.

Singh, G.; Hardaker (2014). Barriers and enablers to adoption and diffusion of eLearning: A systematic review of the literature - a need for an integrative approach. Education + Training 56(2/3), pp. 105-121.

Stoffregen et al. (forthcoming). Barriers to Open E-Learning in Public Administrations. A comparative case study across Luxembourg, Germany, Montenegro and Ireland.

Stoffregen, J. et al. (2015). A Barrier Framework for open E-Learning in public administrations. Computers in Human Behavior, http://dx.doi.org/10.1016/j.chb.2014.12.024.

Tapanes, Marie A. (2011). Revision And Validation Of A Culturally-Adapted Online Instructional Module Using Edmundson's CAP Model: A DBR Study. Graduate Theses and Dissertations., pp. 1-283. Available online at http://scholarcommons.usf.edu/etd/3376.

Van de Ven, A. H. (2007). Engaged scholarship: a guide for organizational and social research: a guide for organizational and social research: Oxford University Press.

Viller, S.; Sommerville, I. (1999). Social Analysis in the Requirements Engineering Process: From Ethnography to Method. (Unpublished). IEEE International Symposium on Requirements Engineering (RE '99), pp. 1-8

Weick, K. E. (1989). Theory construction as disciplined imagination. Academy of management review 14(4), pp. 516-531.

Yang, R., Ruan, J., 2007, in IFIP International Federation for Information Processing, Volume 252, Integration and Innovation Orient to E-Society Volume 2, eds. Wang, W., (Boston: Springer), pp. 574-581. 


\title{
V \\ Design for Collaborative Contextualization of Open Educational Resources
}

\author{
by \\ Stoffregen, J.; Pawlowski, J.; Moebs, S.; Traxler, J.; \\ Guerra-Correa, V.; Prakash, A. 2016. \\ Multikonferenz Wirtschaftsinformatik (MKWI) 2016. 1st ed. 1 volume. \\ Ilmenau: Univ.-Verl. Ilmenau, 591-602. \\ Reproduced with kind permission of the MKWI Editors.
}




\title{
Design for Collaborative Contextualization of Open Educational Resources
}

\author{
J. Stoffregen ${ }^{1}$, J. Pawlowski ${ }^{1}$, S. Moebs ${ }^{2}$, J. Traxler ${ }^{3}$, V. Guerra Correa ${ }^{4}$, A. Prakash ${ }^{5}$ \\ ${ }^{1}$ University Jyväskylä and HRW, julia.stoffregen / jan.pawlowski@hs-ruhrwest.de \\ ${ }^{2}$ DHBW Heidenheim, moebs@dhbw-heidenheim.de \\ ${ }^{3}$ University Wolverhampton, John.Traxler@wlv.ac.uk \\ ${ }^{4}$ ZHAW School of Management and Law, guer@zhaw.ch \\ ${ }^{5}$ Fraunhofer FOKUS, Berlin, arun.prakash@fokus.fraunhofer.de
}

\begin{abstract}
The paper presents an evaluation of a prototype design for collaborative adaptation of open educational resources (OER) in e-Learning platforms. Interactive mock-ups are designed for the process of adapting OER collaboratively. The overall research question is: Which functional design allows for a meaningful navigation through collaborative contextualization processes? The analysis focuses on the time (when users like to add peers), which informational needs are required to select peers, and which functions are missing more generally in the prototype. Results provide insights how a well-planned design can increase the use of adaptation tools and how to overcome the important barrier of systems complexity. Findings suggest that participants like to contact peers before having selected the resource and by sending a link or a mail. They do not need to see much information to select their collaboration partner. Furthermore, aspects which need to be added are icons that facilitate identifying collaboration spaces. Based on the results and user feedback, design principles and their adaptation are discussed in this paper.
\end{abstract}

\section{Introduction}

The goal of this paper is to advance understanding of collaborative development and adaptation processes of digital learning resources and its implications for user interface design. Contextualization is a well-known activity in e-Learning and the development of open educational and knowledge resources and stands for the creation and adaptation of cultural sensitive digital knowledge resources for others as well as for personal learning means, preferences or devices. Associated strategies such as 'localization' and 'modularization' are applied and discussed in practice and research (Dunn \& Marinetti2002). Contextualization shall mitigate difficulties given the emerging, global use of educational resources. It was found that the resources are culturally shaped and thus access to knowledge is not opened as intended. OER convey customs of original author's contexts what may disrupt the learning experience. Several studies have elaborated on barriers in this respect, both in private and educational domains (Pirkkalainen \& Pawlowski 2014) as well as in public sector contexts (Eidson 2009). 
Apart from barrier studies, strategies for contextualization have been developed from instructional (Edmundson 2007; Henderson 2007; Dunn \& Marinetti 2002) and technical perspectives (Richter \& Pawlowski 2007). While they provide an overview what aspects are to consider in the development of e-Learning resources, they do not formulate design principles (Tapanes 2011; Pawlowski \& Richter 2010). For designers who are interested in developing appropriate interfaces, the strategies provide no guidance. Design choices cannot be guided by design principles, indicating how to enable learners to navigate through contextualization processes online. What are principles that guide to design usable contextualization screens?

This study will answer the questions by defining and evaluating mock-up designs. The outcome will be a set of generalizable principles and design implications for collaborative context- ualization. The study contributes to close the gap between practical design and theoretical contextualization strategies. In the following, the relevance of collaborative contextualization design is discussed. Subsequently, a set of design principles is defined and applied. Then, the evaluation method is presented. Last but not least, results and implications are discussed.

\section{Background}

\subsection{Approaching culture contextualization}

Culture contextualization is a cyclical process of creating and adapting culture sensitive OER for making them suitable for local uses and means (cf. Dunn \& Marinetti 2002:2). Several models clarify what needs to be created / adapted, but differ in foci and approach. Focusing on learning resources Anand (2005:2f.) suggests to focus on linguistic (textual artefacts), substantive (rules, abbreviations) and cultural aspects (such as customs) in the contents. Adapting terms, icons and examples, however, is just as important as the concept behind. Henderson (2007) criticizes that without a conceptual model, resources are not becoming sensitive to multiple cultures but prone to tokenism and stereotyping. A suitable concept would emphasize standpoint epistemologies, gender, minority, workplace culture and eclectic pedagogical paradigms among others (Henderson 2007:136). As a result, not only the content of a resource but its format, method and learning structure may be subject to contextualization.

Apart from adapting contents, several studies have developed contextualization models which address the re-use of resources (Rensing et al. 2005). Another model suggests steps which users take to adapt OER; they cover the search, re-use validation, adaptation and re-publishing among others (Pawlowski \& Richter 2010). But do models represent adequately how users accomplish contextualization; and how can design interface support the process? For developers, the model provides hints, which functional references must be provided in screens. Otherwise, design principles for contextualization are not developed, especially not for collaborative scenarios. Only a few design heuristics for e-Learning have evolved that may provide guidance. Which functional design allows for a meaningful collaborative contextualization is thus the overall research question of the study.

\subsection{Formulating design principles for culture contextualization}

In the domain of e-Learning several authors have defined design principles to improve the learning experience. Hetsevich (2014) has translated Nielsen's usability design principles (1994) into concrete design guidelines for e-Learning websites. The heuristic to leave user control and 
freedom in the navigation (no.3) resulted in the design of different navigation tools to navigate back and forth in the interfaces (cf. Hetsevich 2014). Lane (2010) addresses a similar aspect, the 'agency of users' in open e-Learning platforms and indicates to be more open which contents can be published and why. Another principle is the heuristic to keep consistency (no.4) by arguing to apply consistent fonts and layouts (cf. Hetsevich 2014). A third example is the translation of the heuristic help and documenting uses of e-Learning platforms (no.10) (Nielsen 1994). Hetsevich (2014) decides to provide tutorials and manuals that are short, simple and informative for learners. Furthermore, the search through the platform and resources must be easy, including the match of wordings (Hetsevich 2014).

Generally, orientation can be gathered by such design heuristics. Often, however, heuristics are too general to guide design activities (Nielsen 1995). Abstract principles may be advanced by providing illustrating examples from practice. Following Shneiderman (2002) and Galitz (2007) abstract principles have to be specified not at last for the use of words and icons (I), the layout (II), in-/output of the system (III) and required training (IV). Aiming to advance the current state of literature about contextualization design, an initial specification of design principles is provided in Table 1 . The first column defines the label and origin of principles. The second column indicates how they are translated into the screen design.

As presented in the table, a set of design principles is defined and discussed. To elaborate whether the resulting design choices enable collaborative contextualization, results have to be tested and improved on behalf of user feedback. Given that contextualization is a comprehensive process, the focus needs to be tailored as well. To begin with, the first contextualization steps can be addressed. They include the steps searching, selection of resources and collaboration partners. Correspondingly, the overall research question can be split into a set of three operational questions: (1) What is the time point of choosing collaboration partners? (2) What informational needs are required to validate the selection of peers? (3) Which functions are missing in the evolving design? These aspects will allow tailoring user feedback to certain aspects.

\section{Methodology and study context}

The study is associated to the project EnhAnced Government LEarning (www.eagle-learning.eu). EAGLE aims at developing an open source platform for the exchange of experiences and OER for training means in the public sector, accompanied by a set of change management guidelines and a pedagogical strategy supporting introduction of online knowledge exchange and learning. The study provides insight on early design sketches. Moreover, they are focused on the contextualization of resources which represents neither the centre nor the whole scope of activities in the EAGLE platform. Yet, the results will inform later design choices as discussed in the last section of the paper.

To enable a test of early sketches and get design principles into screens, a set of interactive mock- ups was designed. The approach followed is LUCID (Logical User-Centered Interactive Design Approach; in Shneiderman 2002; Kreitzberg 2008), suiting the user-centred design perspective (Abras et al. 2004:19; Lowdermilk 2013) of authors. Correspondingly to LUCID, a Goals, Operators, Methods and Selection Rules analysis (GOMS), job-task, context, and needs analysis (incl. scenario development) was made to inform the initial design. The results of analysis suggest to develop five screens including the following contextualization steps as shown in Graphic 1. 


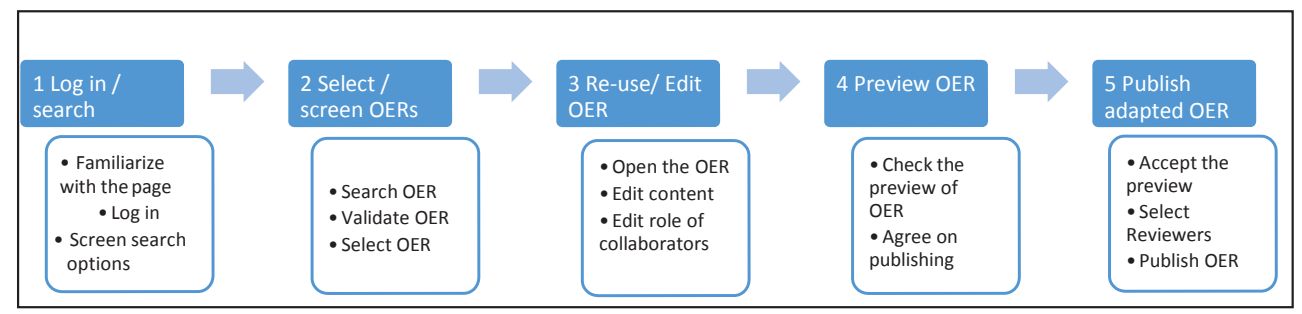

Graphic 1:

How contextualization steps correspond to mockups

Guidance to prepare mock-ups and scenarios is drawn from Galitz (2007) and Benyon (2010) as well as Goodman \& Kuniavsky (2012). Technical tools used are pencil (pencil.evolus.vn) and Umlet (umlet.com ).The resulting mock-ups are presented in the results section (which facilitates following design principles and their evaluation). The evaluation of mock-ups follows a concurrent mixed-method approach (Creswell \& Plano-Clark 2011) to include standardized as well as indepth evaluation techniques that complement each other. To have a representative set of target users of the project, sampling goals were to balance gender, age, and experience levels (in contextualization) of people working in the public sector. To test the usability of the mock-ups, the VisAWIquestionnaire was chosen and taken over from Moshagen and Thielsch (2010;2014b). Being interested to evaluate the navigation (i.e. particular design choices), led to add further questions (orienting on Reeves \& Hedberg 2003:148). To supplement questionnaire results, three qualitative data gathering techniques were conducted. Firstly, observations were made during user test. Secondly, users were asked to think aloud (and explain their thoughts and challenging design aspects) while navigating through the set of mock-ups. Thirdly, semi-structured interviews are made in small focus groups to qualify questionnaire responses (Merton

\& Kendall 1946; Kitzinger 1994; Cohen et al. 2011). The interviews are guided by non-reactive tools such as the semi-structured guidelines and by reactive tools such as stimulus prompts and provocative statements (cf. Merton \& Kendall 1946). All materials can be provided on demand. The approach to analyse questionnaires was oriented on Moshagen \& Thielsch (2014a). Based on the questionnaire results, most negative, positive and surprising responses were noted (as "action points") to tailor the analysis of qualitative data. Subsequently, audio records and notes were analysed. Apart from action points, particular focus was to answer the three operational research questions. Finally, results from both methods were synthesized and related back to design principles. Hence, the analysis can be summarized as an exploratory sequential mixed method approach (Creswell \& Plano-Clark 2011), which is reflected in the following report of results.

\section{Report of results}

\subsection{Sample of participants}

Six women and four men participated in the mock-up evaluation. The age of people ranges between forty and twenty-three, the average age is 29.4 years. Except for one person, participants are employed and work in the public sector (higher education). The time of being employed ranged from a half year to almost eight years. Three participants indicated to never have contextualized OER before (one male and two females). Two participants (two males) indicated that they regularly adapt OERs and are expert in the fields. Other participants were more or less 
familiar with contextualization. Apart from the employment background of participants, the sampling of involved participants is appropriate. The generalizability of results will be addressed in the discussion section.

\subsection{Analysis of Usability / Aesthetic Factors}

The overall rating of the usability and aesthetic-factors of the interface design tends to be rather positive (see Graphic 2- note the scale accumulates responses, expressed in percentages). Concerning the factor simplicity, about $60 \%$ of participants agree (somewhat simply or strongly agree) that the layout is lofty, easy to grasp, well-structured and coherent. Agreement to the factor diversity appears to be less positive. About $48 \%$ somewhat, strongly or simply agree that the design and layout is appealingly diverse. Coming to the factor colourfulness, the assessment shows that about $46 \%$ somewhat, strongly or simply agree that the colourfulness is positive. Furthermore, only about $15 \%$ of participants disagree that colours are negative in the design. Last but not least, the responses to the craftsmanship indicate that about $45 \%$ of participants agree that the layout and design is well made, compared to $25 \%$ participants who disagreed (simple, strongly or somewhat disagree).

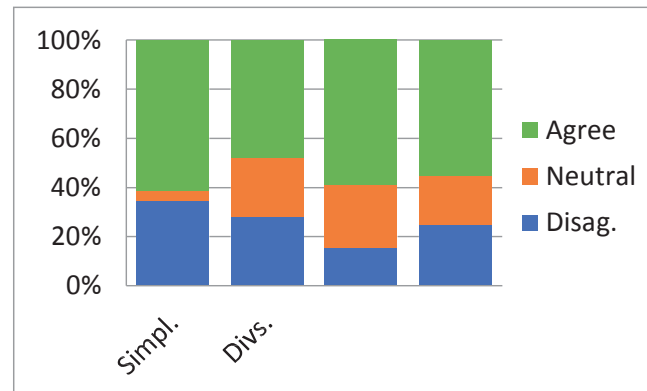

Graphic 2: Overall Evaluation

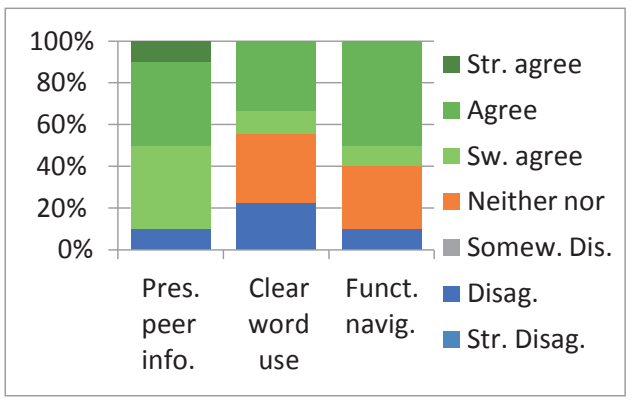

Graphic 3: Evaluating Navigation

Apart from the VisAWI-report, participants were asked to answer additional questions concerning the navigation (see Graphic 3). Aggregating positive (strongly, simple, somewhat agreement) and negative (strongly, simple, somewhat disagreement) responses, nine of ten participants agree the presentation of peer information is clear, followed by the responses that the overall navigation is functional ( six of ten). In contrast, the wording of buttons appears to be unclear; three people did not decide, one did not respond and two participants disagree that the use of words is clear.

So far results suggest that action points address the density of the page, choice of colours, inventiveness, diversity, as well as actuality of the layout. Additionally, the role of linguistic terms needs to be further evaluated. While the questionnaire results do not answer how to go about and improve the design, the results of qualitative data will provide additional hints.

\subsection{Qualitative analysis of mock-up design}

Results of the audio records and observation notes will be presented in the following. In a first step, a descriptive report of the findings will be provided. Findings informing the action points and navigation (highlighted in bold) will be described for each mock-up screen (1-5). In a second step, a brief aggregation of responses to the main research questions will be provided. In a third step, implications for the design (and principles) will be defined. 


\subsubsection{Descriptive results: observing users navigation through contextualization}

Screen (1) Log in: Most participants needed time to familiarize with the first screen which shows several buttons and attention capturing information (such as the link 'what is an OER'). A central picture, which did not matter at all for the testing, captured attention as well and indeed, disrupted the process. Hence, a locale to improve density of the page can be allocated for the forthcoming design. The assumption that density is critical in the first screen can further be supported as users were looking for the log-in sign but could not find it: "... where is the log-in" (participant 3). Concerning the use of words, questions concerning abbreviations such as "OER" were posed. This hint will inform the section 'required training' (IV) of design principles. In the first screen, other action points (diversity, actuality, colours) were not addressed. Concerning the navigation, the most intuitive clicks can be allocated to the "search", "topic" and "find OER" button, as well as on the "play" button of the picture. In fewer cases, participants wanted to login in a first step and search OER afterwards. Only in one case, a participant wanted to look for collaboration partners and click "MyEagle" or the "community" button first. These results suggest that overall, users looked at the higher part of the interface first and oriented on the main navigation buttons.

Screen (2) Search OER: Given the programming of the search process, participants scrolled over the exposed OERs on the second screen. Those who evaluated presented information were very positive about seeing the "author", "last date of adaptation" and the "document type" of the resource. Users stayed only a short amount of time on this screen, wherefore neither design aspects nor action points were addressed. Concerning the navigation, the most intuitive clicks were directed to the OER content. Only few participants clicked the button "use this OER", a drop down menu which allows discriminating between "opening" and "seeing" the OER or opening a dedicated "adaptation space" (a point to be discussed later). Concerning informational needs, users were further interested to see whether this OER has an adaptation history. Hence, whether it was the latest OER or whether (parts of) the OER were re-used is of interest.

Screen (3) Adaptation space: Participants identified that the resource can be adapted 'here' in the third screen given the editor surrounding the OER text. A problem was that the laptop displayed information small wherefore it was mentioned often: “...this is very small” (participant

1). This feedback provides a valuable hint where to improve density of the interface. Concerning the navigation, most intuitive clicks were the buttons "preview", and "communicate with peers". The navigational device on the right hand was perceived and used by two novices. The third novice did not like the navigational device, while others found it non-disturbing when being asked. If the navigational device is not needed, a locale for improving density and simplicity of the layout can be defined. In screen 3, people further hesitated and screened all navigation bars for an option to add peers (to collaborate during contextualization). Not all participants identified the "peer space" button (and link) as the surrogate for this option. On the one hand, the action point choice of linguistic terms leads to a difficulty for users. On the other hand, simplicity of the layout may have to be improved in this respect. When opening the section 'peer space' people were seldom clicking the search button to search and add peers. Output tables appeared to be overloaded since participants were looking only for name, surname and department to identify peers. Apart from informational needs, a surprising note was that participants were looking for icons to "add" friends or to "share" the OER. Here, the action point linguistic terms can be substantiated. Also, actuality and diversity of the layout may be improved regarding the use of icons. Interestingly, participants were looking for other options to inform their collaboration partner, namely by sending a mail, link or an invitation. This informs which functional needs are 
currently missing in the design. Last but not least, participants neither used (found) the 'manage' button nor asked for options to restrict editing rights of collaboration partners. In focused interviews, however, participants supported that such options are important, but the current layout would not point them out intelligibly. In this context, negative results in the questionnaire regarding simplicity may be substantiated.

Screen (4\&5) Preview and publishing space. After taking their time on the adaptation screen, users scrolled past the preview and publishing space without major considerations. Here, metadata for OER are presented by icons. Participants addressed seldom or outlined: “... all these do not tell me anything but I don't know this platform yet-I guess it will work out" (participant 2). In this respect, a point to note for 'required training' (IV) of design principles can be allocated. Concerning the navigation, people both used the top navigation as well as the lower navigation to go back and forth between contextualization steps.

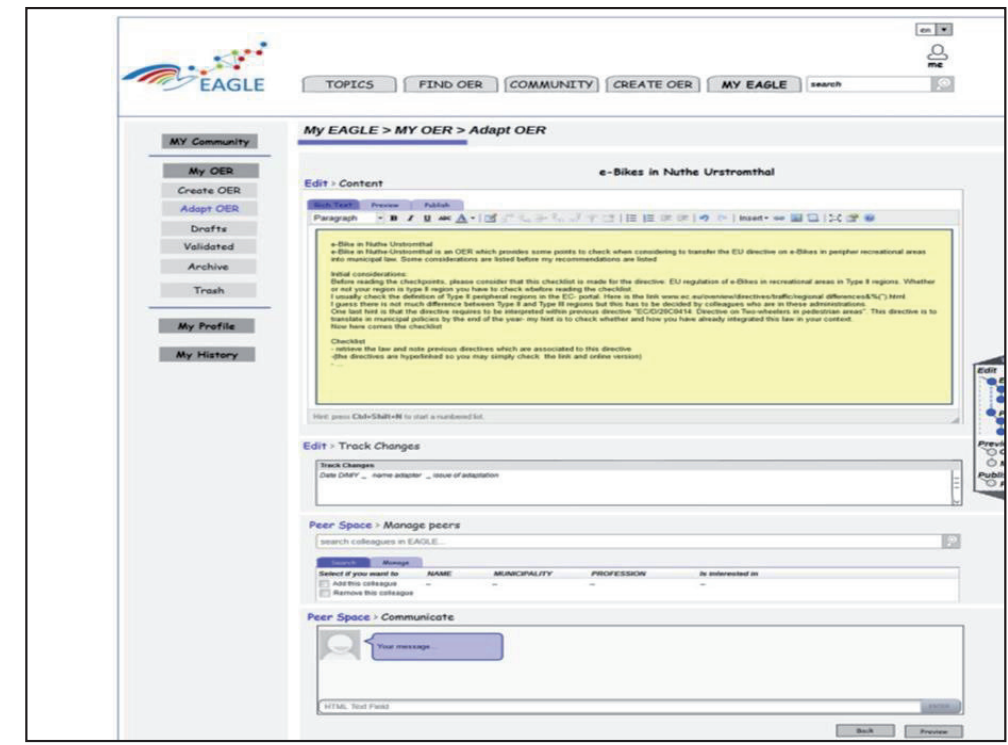

Graphic 4: Mockup screen (3)

\subsubsection{Responses to the research questions}

In the following, an answer to the research questions is sketched: (1) when users like to add collaborative peers in the process; (2) which informational needs users require to validate the selection of collaborative peers; and (3) which functions need to be added to allow collaborators to exchange their knowledge (how and/or what to adapt)?

(1) Concerning the point of collaboration, the test has shown that users like to contact peers before having reviewed the resource, after having selected the resource, by invitation, and sending a link or mail. Users like to be informed when their peer has been informed about the invitation. Users require managing the editing rights of their collaborative peers. They wait for typical icons and wordings of social platforms such as "invite, share, send to" as well as "add". Last but not least, users require seeing collaboration functions directly up front, since collaboration is their central point of concern. (2) Concerning informational needs, the test clearly pointed out, that the current design provides too much information. Users perceive an informational overload. It 
would be sufficient when showing name, surname only. (3) Concerning the third question, functions which need to be added to allow collaborative exchange of knowledge resources are icons for identifying the share functions and for identifying the collaboration space. Kind of media needed are chats, screen-shots, links, video, audio, notifications of changes, app mobiles. Last but not least, signs to differentiate between adapting and viewing spaces of OER should be considered.

So far, results of the questionnaires, audio records and observation notes have been presented. Missing so far is the consideration how findings allow improving and adapting the design and chosen principles in the table. The following section addresses this point.

\subsubsection{Implications for the forthcoming design}

The following table shows an excerpt of chosen design principles and their translation into screens (the full table can be provided on demand). The last column specifies problematic translations and indicates how to change forthcoming design.

\begin{tabular}{|c|c|c|}
\hline design principles & tion of design choice & ons \\
\hline \multicolumn{3}{|c|}{ Use of words and icons } \\
\hline $\begin{array}{l}\text { A.Consistency } \\
\text { O Keep consistency in design } \\
\text { and textual devices (e.g. Het- } \\
\text { sevich 2014) } \\
\text { B.Wording } \\
\text { O Use linguistically clear } \\
\text { elements (e.g. Hetsevich } \\
\text { 2014) } \\
\text { C.Usability in apropriate to } \\
\text { o Language is apability (e.g. } \\
\text { increase use } \\
\text { Nielsen 1994) }\end{array}$ & $\begin{array}{l}\text { Consistency achieved by: consistent fonts, } \\
\text { colour (shades of blue, light yellow, light } \\
\text { red). Navigation is on the top, wordings in } \\
\text { pages labels / fonts /buttons reflect results of } \\
\text { GOMS cf. Galitz 2007:139; Oracle 2010). The } \\
\text { use of words and textual learning con- } \\
\text { tents needs to be low. The platform is used } \\
\text { across countries so several languages are } \\
\text { configured. As linguistically } \\
\text { unambiguous terms are chosen f.e.: "peer } \\
\text { space", "manage" or "communicate", } \\
\text { "trace", "editing", "preview" and "publish". }\end{array}$ & $\begin{array}{l}\rightarrow \text { Linguistic terms: } \\
\text { use more icons and } \\
\text { familiar wordings. F.e. } \\
\text { icons for: share, log in, } \\
\text { save, search; words: } \\
\text { share, invite, add, col- } \\
\text { league, collaborate / chat. } \\
\rightarrow \text { Orient on mobile } \\
\text { phones and social plat- } \\
\text { forms design. }\end{array}$ \\
\hline The layout & & \\
\hline $\begin{array}{l}\text { D.Capabilities } \\
\text { o Capabilities are easy to } \\
\text { grasp (cf. Galitz 2007:47) } \\
\text { o Ongoing representation of } \\
\text { objects and actions } \\
\text { o Fast, incremental, revisable } \\
\text { operations, related effects are } \\
\text { immediately visible on the } \\
\text { screen or object (cf. Shnei- } \\
\text { derman 2002:149). } \\
\text { E.Usability } \\
\text { o Users are informed, enjoy } \\
\text { control, capabilities allow } \\
\text { recognition (Nielsen 1994) }\end{array}$ & $\begin{array}{l}\text { Capabilities are highlighted by bolding (are } \\
\text { bolded, colored cf. Galitz 2007:164,338). } \\
\text { Capabilities of the page are displayed by } \\
\text { buttons and links, they are exposed by the } \\
\text { navigation. Most objects can be clicked, } \\
\text { such as the 'sign in' icon, search, and so } \\
\text { forth. The cursor changes its appearance by } \\
\text { mouse-over, i.e. clickable fields are } \\
\text { highlighted by visual cues (cf. Galitz } \\
\text { 2007:338f.) } \\
\text { Wordings, buttons etc. enable users to recog- } \\
\text { nize functions instead of recalling how func- } \\
\text { tions proceed. The status in the process of the } \\
\text { contextualization process is displayed by } \\
\text { process bars. }\end{array}$ & $\begin{array}{l}\rightarrow \text { Display status more } \\
\text { clearly: when saving } \\
\text { the contents; adding } \\
\text { colleagues; distributing } \\
\text { rights to colleagues; } \\
\text { tracing editing changes. } \\
\rightarrow \text { Simplicity of screen } \\
\text { structure: open (and } \\
\text { highlight) main capabili- } \\
\text { - ties (f.e. adding peers) } \\
\text { - headmost or central in the } \\
\text { screen. } \\
\text { y }\end{array}$ \\
\hline & & \\
\hline $\begin{array}{l}\text { F.Input/ interaction } \\
\text { sequence } \\
\text { o Visible objects can be } \\
\text { clicked (buttons instead of } \\
\text { syntax) (cf. Galitz 2007) } \\
\text { o An appropriate spirit } \\
\text { (emotional effect) is drawn; } \\
\text { intentional and }\end{array}$ & $\begin{array}{l}\text { The design shall be playful yet convey } \\
\text { sense of seriousness for self- and gu } \\
\text { learning activities. To make self-deper } \\
\text { f learning joyful, user control is provide } \\
\text { letting people decide whether or not to c } \\
\text { t borate \& in which navigational paths. T }\end{array}$ & $\begin{array}{l}\rightarrow \text { Highlight input op- } \\
\text { tions: e.g. search bar } \\
\text { for searching peers, log- } \\
\text { in sign. } \\
\rightarrow \text { Configure additional } \\
\text { navigation bar (right } \\
\text { handed) as a }\end{array}$ \\
\hline
\end{tabular}




\begin{tabular}{|c|c|c|}
\hline \multicolumn{3}{|c|}{ 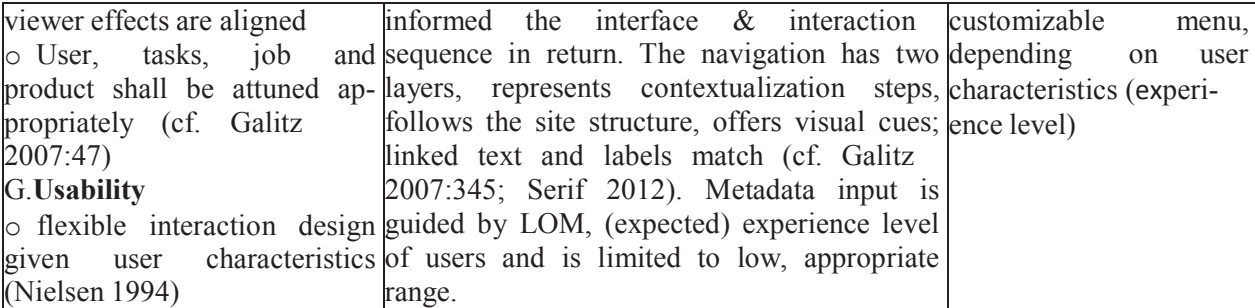 } \\
\hline Required training & & \\
\hline $\begin{array}{l}\text { H.Meaning of words must } \\
\text { be clear } \\
\text { o Abbreviations such as } \\
\text { OER, where to find hints, } \\
\text { use of navigation, familiariza- } \\
\text { tion with the interface }\end{array}$ & $\begin{array}{l}\text { An additional navigation bar guides users in } \\
\text { adaptation screen. (Navigation bar in the right } \\
\text { handed side). Users may need to be advised } \\
\text { about the meaning of acronyms such as OER. }\end{array}$ & $\begin{array}{l}\rightarrow \text { Let people explore } \\
\text { the main interface } \\
\text { before starting the test. } \\
\rightarrow \text { Meaning of LOM } \\
\text { needs to be clarified, } \\
\rightarrow \text { Explain steps of } \\
\text { contextualization }\end{array}$ \\
\hline
\end{tabular}

Table 1:

Design principles and implications from results

\section{Discussion}

So far, the results of the study have allowed answering the research questions. Few points are to discuss, beginning with the quality of results. The results stem from a sound, qualitative research approach to answer: when users like to add peers, which information they need and which functions they aspire in a collaborative contextualization process. The evaluation was conducted with ten participants. It is a small number and limits the generalizability of the results; statistical tests provide no meaningful outputs in this respect. Audio records further indicate that results may be biased by interviewer effects: Participants asked whether interviewers are designers of mock- ups at the same time. Subsequently, interviewers noted in some cases that participants hesitated to evaluate the questionnaire. The depth of qualitative data, however, allows supporting as well as extending the insight of quantitative data. On behalf of the rich responses it was achieved to substantiate questionnaire results, both with regard to action points and responses to the three operational questions. Overall, the quality of results is thus appropriate to discuss the findings and draw further conclusions for e-Learning and Lern-Service Engineering research.

Considering the scenario, that tutors and learners have to select a learning environment for their purposes, recommendations in Table 1 can support the evaluation. For example, findings suggest that additional navigational menus should be designed according to the experience level of users. Tutors could check the level of expertise of their scholars and compare provisions of learning environments respectively. Considering the scenario, that tutors are developing their own learning environment, results of the study facilitate designing contextualization. For example, results suggest placing layout structures centrally in the screen. In this respect, the principle 'focus

\& emphasis' (Galitz 2007:162-165) can be supported and should be taken into account in the design of learning services. Apart from tutors, learners can take the findings into account and check whether a given e-Learning service provides suitable information to identify their peers. Based on the results of the study, the versioning history of a resource would be of interest, for example.

Last but not least, to the systematic learn-service engineering, results of the study further emphasize the role of linguistic terms. Users were looking for particular wordings, cues and related icons. In this respect, a clear link between design and contextualization strategies can be 
found. The role of terminology is mutually emphasized so systematic engineering may benefit from synthesizing strategies from both approaches. Apart from these implications, further emphasis can be placed upon the role of social networks for innovative learn-service engineering. Users' wordings resemble terms commonly used in social network platforms (such as "add", "invite"). Aiming to develop a functional collaborative contextualization process should bear this hint in mind to innovate learning environments.

Apart from considering implications for e-Learning scenarios, the results presented in table one can be used to further integrate future e-Learning concepts: The role of mobile phones needs to be explained a bit more in this point. Looking specifically at interaction design for mobiles, we need to ask how much we know about the mobile digital environment, how much we know about using mobiles whilst being on the move vis-à-vis the knowledge of static computing. Maybe functional design depends on the daytime and location since phones are frequently checked close to getting up or going to sleep, even at Friday and Saturday nights (Perlow 2012). The use of mobile technologies must be understood as no longer a psychological phenomenon but now a sociological one; defining job-task and requirements for design may thus benefit from research on sociology of mobilities (e.g. Nyiri 2007; Urry 2007) in the future. Additional design principles may thus have to be specified and added to table 1 .

Apart from design for mobile learning, pedagogical design implications are not yet addressed in this study. Pedagogical designs depend on the understanding of learning and on the culture and context where this learning process pretends to be fostered. Moreover, the appropriation of any artefacts (technologies, digital resources, tools) it is shaped by the culture and history of the individual user. Hence, how re-design is able to analyse and acknowledge original pedagogical design needs to be further discussed. More generally, a salient question is whether the pedagogical design of an OER should be explicitly highlighted during contextualization processes. In an age where educational innovations are demanded at all levels and sectors, it would be of importance to investigate if this information would allow users to question their own pedagogy and explore new ones, fostering this way the required educational innovations. Following this line, it should be considered which pedagogical dimension should be added to design principles, since a contextualization process could result in a re-conceptualization of the educational resource itself.

\section{Conclusion}

The study has elaborated which functional design allows for collaborative contextualization. The systematic analysis of requirements, design principles and their translation into mock-ups laid a foundation for user evaluations. Based on a mixed-method evaluation, user feedback has allowed discussing appropriateness of design choices. Empirical results suggest that users are looking for linguistic terms which resemble social platforms. Concerning contextualization steps, users like to add collaborators not only after they have selected the resource. Moreover, they would like to send the resource among others by mail and invitation to peers. Apart from insight on contextualization, implications for design principles are defined. Results suggest that general orientation can be gained by e-Learning heuristics. Overall, the results can guide designers who are interested in developing interfaces for collaborative contextualization. In the future, design strategies and contextualization models need to be extended to become more useful for practice. Two future research topics emerging from results are the role of mobile and pedagogical 
principles for interaction design. Implications for design are valuable and inform discussions of development choices in the project EAGLE so far. An interface validation and assessment of subsequent design choices will be addressed in the future. Generally, however, it will be salient to assess the design principles in other context and further elaborate on their generalizability.

\section{References}

Abras C, Maloney-Krichmar D, Preece J (2004) User-Centered Design. In: Bainbridge W Encyclopedia of Human-Computer Interaction. Thousand Oaks, Sage Publications.

Anand P (2005). Localizing E-learning [online]. Knowledge Platform, pp. 1-7. Available at: http://www.knowledgeplatform.com/wp-content/uploads/2014/11/Localizing_E-Learning.pdf

Benyon D (2010) Designing interactive systems: a comprehensive guide to HCI and interaction design. 2nd. London, England: Pearson Education Limited

Cohen L, Manion L; Morrison K (2011) Research methods in education. In: Cohen L, Manion L Morrison K (Eds). 7Ed Milton Park, Abingdon, Oxon, [England]; New York Routledge, 2011.

Creswell JW, Plano-Clark VL (2011) Designing and conducting mixed methods research. 2nded. USA,Sage Publications, Ltd.

Dunn P, Marinetti A (2007) Beyond localization: Effective learning strategies for cross-cultural elearning. In: Edmundson, A (Ed.): Globalized e-learning cultural challenges. Hershey, PA, IGI Global, pp.255-266.

Edmundson A. (2007) The cultural adaptation process (CAP) model: designing e-learning. Chapter XVI. In: Edmundson, A (Ed.): Globalized e-learning cultural challenges. Hershey, PA, IGI Global, pp.267-289.

Eidson LAK (2009) Barriers to E-Learning Job Training: Government Employee Experiences in an Online Wilderness Management Course. Thesis, Dissertation, Paper 86, Univ. of Montana.

Galitz WO (2007) The Essential Guide to User Interface Design. An Introduction to GUI Design Principles and Techniques. Indianapolis, Wiley Pub.

Goodman E, Kuniavsky M (2012) Observing the User Experience, Second Edition: A Practitioner's Guide to User Research. Amsterdam [u.a.]: Elsevier.

Henderson L (2007) Theorizing a multiple cultures instructional design model for e-learning and eteaching. In: Edmundson, A (Ed.): Globalized e-learning cultural challenges. Hershey, PA, IGI Global: 130-153.

Hetsevich I (2014) How To Improve eLearning Course Design Usability By Adopting The 10 Usability Heuristics. eLearning Industry. Available online at $\mathrm{http} / /$ elearningindustry.com/how-to-improve-elearning-course-design-usability-by-adopting- the-10usability-heuristics.

Kitzinger J (1994) The methodology of Focus Groups: the importance of interaction between research participants. Sociology of Health \& Illness, 16:103-121.

Kreitzberg CB (2008) The LUCID Framework. An Introduction. Cognetics Corporation. Princeton Junction, New Jersey. 
Lane A (2010) Designing for innovation around OER. Journal of Interactive Media in Education:1-10.

Lowdermilk, T. (2013). User-Centered Design, 1st Edition: A Developer's Guide to Building User-Friendly Applications, O'Reilly.

Merton R, Kendal PL (1946) The Focused Interview. American Journal of Sociology, 51:541-557

Moshagen M, Thielsch MT (2014a) Manual VisAWI. Version 1.0, Stand 06.10.2014. www.VisAWI.de

Moshagen M, Thielsch MT (2014b) VisAWI Questionnaire- Visual Aesthetics of Websites Inventory. English Version, long version. www.VisAWI.de

Moshagen M, Thielsch MT (2010) Facets of visual aesthetics. International Journal of HumanComputer Studies 68(10):689-709.

Nielsen J (1994) Enhancing the explanatory power of usability heuristics. ACM Human Factors in Computing Systems: 152-158.

Nielsen J (1995) 10 Usability Heuristics for User Interface Design. Nielsen Norman Group (10):1-1. Available at http://www.nngroup.com/articles/ten-usability-heuristics/.

Nyíri K (2007) Mobile Studies: Paradigms and Perspectives, Vienna: Passagen Verlag, Hungarian Academy of Sciences.

Oracle Corporation (2010) Chapter 6: Application Design Principles. Available at https://docs.oracle.com/cd/E19455-01/806-2915/6jc3nftni/index.html.

Pawlowski JM, Richter T (2010) A methodology to compare and adapt E-Learning in the global context. In: Breitner, MH, Lehner F, Staff J, Winand U (Eds.): E-Learning 2010. Berlin u.a: Physica-Verl, pp. 3-13.

Perlow LA (2012) Sleeping with your smartphone: how to break the 24/7 habit and change the way you work. Boston, MA, Harvard Business Review Press.

Pirkkalainen H, Pawlowski JM (2014) Global social knowledge management-understanding barriers for global workers utilizing social software. Comp. in Human Behavior 30: 637-647.

Reeves TC, Hedberg JG (2003) Interactive learning systems evaluation: Educational Technology.

Rensing C, Bergsträßer S, Hildebrandt T, Meyer M, Zimmermann B, Faatz A. et al. (2005) ReUse, Re-Authoring, and Re-Purposing of Learning Resources Definitions and Examples. Technical Report. KOM-TR-2005-02. TU Multimedia Communications Lab, Darmstadt

Richter T, Pawlowski JM (2007) The need for standardization of context metadata for e-learning environments. Procedings of e-ASEM Conference, Seoul, Korea.

Serif Europe Ltd (2012) Inserting navigation bars. Available at http://www.serif.com/ appresources/wpx6/tutorials/en-us/help/navigation_bars.htm\#MT_DynamicNavigationBars.

Shneiderman, B. (2002) User Interface Design. [Deutsche Ausgabe]. Bonn, mitp-Verlag.

Tapanes, Marie A. (2011). Revision And Validation Of A Culturally-Adapted Online Instructional Module Using Edmundson's CAP Model: Graduate Theses and Dissertations.

Urry, J. (2007) Mobilities. London: Polity. 
The Contribution of Agile Open Educational Resources towards Agile Government - an Explorative Study

by

Stoffregen, J.; Pawlowski, J. (submitted 2017).

Government Information Quarterly, nn. 


\title{
The Contribution of Agile Open Educational Resources to- wards Agile Government - an Explorative Study
}

\begin{abstract}
Agile Government leads to many changes regarding policies, processes and technologies. Although those changes are clearly identified, there is a strong need for rapid knowledge acquisition and learning. Our paper elaborates how Open Educational Resource (OER) development and use contribute towards agile government. We present a case study and derive and evaluate a model for agile OER implementation in Public Administration for this aim. Results show that agile OER contribute towards more agile government and governance processes by enculturing open and agile practices from the bottom. Furthermore, we identify main research gaps to address in the future.
\end{abstract}

Keywords: Agile Government; Adaptive Governance; Open Educational Resources; Public Administration

\section{Introduction}

The trends and research disciplines of Agile Government and Adaptive Governance lead to new challenges for technology development and diffusion Public Administration: New processes need to be established, new knowledge and leaning needs occur for citizens and employees. The main goal of this paper is to show how Open Educational Resource (OER) development and use can contribute towards change.

The need for change in Public Administration is manifested in different research trends and corresponding concepts: While the concept of Agile Government is not commonly defined, it relates to the ability of governments to rapidly react to changes including the participation of citizens (cf. Gallop, 2012). These changes can occur on different levels: policies, (work) processes including project management (Crawford \& Helm, 2009) as well as specific software development processes and corresponding technologies (Mergel, 2016). The concept of Adaptive Governance is strongly related: Janssen \& von der Voort (2016) show the different aspects of how to make decisions and handle changes on different levels amongst them organizational governance, governance of programs and governance of software projects. As the overarching concept, Agile Methods (AM) can be defined as 'processes that enable flexibility, forecasting, preparedness, exception handling' in Government (Fishenden \& Thompson 2013:981). Others consider agile methods as a set of steps in technology development that aim at delivering quick, flexible, user-centered results (Arimoto \& Barbosa 2013). As a specialization, agile software development approaches like Scrum or eXtreme programming are well known and applied in practice in the technology domain (Arimoto \& Barbosa 2013). Agile Methods have gained a lot of attention in the domain of Public Administration following the need to create 1) more flexible processes and 2) more stakeholder involvement.

Despite the great increase of publications on agile concepts and principles, only few papers are dedicated how to deal with those rapid and far-reaching changes from a knowledge- and learning perspective. How can employees be prepared for new processes, how can processes be designed to rapidly adapt towards new requirements from society and citizens? Those are just exemplary questions which illustrate the need for learning to adapt towards changes in shorter and shorter periods of time.

A promising solution is the use of Open Educational Resources (OER): digital knowledge resources that can be (re-)used according based on open licenses (Hilton et al. 2010:39-43; 
Pirkkalainen \& Pawlowski 2010). Digitized ways to acquire knowledge was always at stake for Government agencies and administrations (OECD 2001). Yet, reforms aiming at increasing transparency and knowledge sharing processes move slow, both regarding the opening towards citizens and within Government administrations (Stoffregen \& Pawlowski, forthcoming; OECD 2003; Young et al. 2012). One of the main ideas is that public servants create their own materials according to their needs in short periods of time. In times of demographic change, such kind of knowledge can help for example to avoid the brain-drain when experienced colleagues leave their workplace (Stoffregen \& Pawlowski, forthcoming). In an ideal case, every public employee becomes expert for his work and responsible for sharing it adequately with colleagues. Yet, recent studies have shown that OER projects are prone to organizational barriers and conflict with bureaucratic culture (Eidson 2009; Pirkkalainen \& Pawlowski 2013; Stoffregen et al 2015).

Up to now, Agile Methods in Government and OER development have been treated separately in literature. This is stunning since the integration of both streams may bring synergies. On the one hand, OER-lifecycles subsist from the free collaboration of colleagues, an open mindset in practice, liberate search, adaptation and re-use of digital knowledge resources (Butcher 2011). Since public servants are unfamiliar with these practices, agile development may contribute to harvest familiarity as users are continuously involved and become active from the beginning. Once open practices are encultured, sharing digital resources online may spill over and benefit agile approaches and goals of the development team as, for example, yet to be seen for the product source code (cf. Mergel, 2016). Informing OER implementation by agile methods in Government may thus perform as a fruitful bottom-up approach that builds familiarity with open, flexible practices and principles from the beginning of implementation processes. OER development does not only focus on the software development processes but also fosters agile practices of public employees from strategy development to operational, daily work processes.

It remains open how to provide knowledge and learning solutions within agile government processes. Therefore, our aim is to address this research gap and shed light on the research question: How to contribute towards knowledge and learning processes as part of agile government changes utilizing agile Open Educational Resources in public administration?

In our study, we focus on small public administration units which face particular challenges such as restricted resources and high pressure of demographic change. We analyze qualitative material collected over one year during a project to introduce OER. The results contribute conceptually how to implement changes towards Agile Governments from a knowledge and learning perspective. Specifically, we propose a model how to perform Agile OER projects as part of Agile Government processes.

\section{Background: Agile methods in Government}

The chapter background provides background on agile concepts in Government and OER development. The review serves to evaluate the synthesized model resulting from the case study in the discussion.

\subsection{Agile Methods in Public Administration}

Agile Methods follow a clear set of values as described in the Agile Software Development Manifesto : "...individuals and interactions rather than processes and tools; the production of working software rather than extensive documentation; (iii) collaboration with the customer not contract negotiation; and (iv) responding to change rather than following a plan"

${ }^{4}$ Agilemanifesto.org 
(Michaelson 2013:296; Agile Manifesto ${ }^{1}$ ). Stakeholders have to adapt processes and have to be open to incremental, on sight-development phases to succeed with their product and services (Gong \& Janssen 2012; Janssen \& van der Voort 2016; Mergel 2016:518). In view of these points, we define agile methods as a "set of project management and software development processes, adjusted procurement procedures, combined with HR policies, and organizational and managerial approaches to support innovative digital service delivery in Government" Mergel (2016:516). It can be stated that agile methods and principles are about to shape public sector business to address pitfalls such as lack of user involvement (Christy 2016).

Agile methods according to Christy (2016) start with a discovery and needs-analysis phase, continues with a prototyping phase, improvement phase as well as a live-phase "where product becomes operational for all end users" (Christy 2016:14). The goal of is to bring satisfactory products to life. While software development outputs are thus in focus, another goal of the approach is to contribute to change in government services as to make it "analogous to the speed of adaptation that information technology has brought to other parts of society". Hence, Christy considers that agile processes spill over and have a long-term effect both on learning and application of knowledge (Christy 2016).

Similarly, Janssen \& van der Voort (2016:4) consider education and training among the key principles of agile work. They "are the key concepts to provide more leniency towards improvement and adaptation and provide more ability to react". Again, agile approaches shall contribute to innovate overall work processes instead of optimizing technology implementation.

However, agile methods need to be embedded into organizational strategies, culture and processes. Mergel (2016) points out that policy and management pillars of the organization need to be addressed apart from the software development team. She highlights that change should address the mindset, a "culture of prototyping and experimentation" (Mergel 2016:522), that shapes leadership as well as commitment to contribute from employees (Mergel 2016). Clearly, this requires cultural changes and corresponding learning processes. An open question is, how do agile methods inspire culture change while addressing barriers of the current work environment? (Mergel 2016:522). Hence, the behavioral perspective and role of culturecontext-factors have not been sufficiently integrated so far.

Summarizing this brief review, we can state that since agility came into focus of Government reform, its impact was connected to broader goals than software development success. It embeds in the promise of successful digitization, "of a potential transition to a more genuinely integrated, agile, and holistic government, whose organizational operations are visible in detail both to the personnel operating in the fewer, broader public agencies and to citizens and civil society organizations" (Dunleavy et al. 2006).

OER development, as argued out in the next section, has a strong focus on related culture and organizational change processes. Generally, agile methods in Government and OER development share the core steps and outputs from an eliciting phase, planning of releases and sprints, doing sprints, evaluating and iteration orienting on Mergel (2016) and Arimoto et al. (2016).

In this regard, experiences from agile OER development may benefit towards agile processes in Public Administrations as well as cultural change. In our study, we aim at elaborating on this hypothesis. We want to explore, how agile OER development succeeds and how agile government projects can incorporate those for learning and knowledge management aspects. Based on our case study we discuss how the models benefit another and create a synthesized approach. 


\subsection{Agile methods and concepts in OER development}

Open Educational Resources (OER) have emerged as a trend to share teaching, learning, and research materials openly using dedicated licenses (Atkins et al. 2007:4). They are intended to improve speed and quality of knowledge and learning processes which is a key aspect when implementing agile government projects. In the public sector context, OER were often considered as open data-resources and raw materials that are published to the web for citizens (Stoffregen \& Pawlowski, forthcoming). Other than open data, however, OER are shaped by a pre-defined learning goal and present structured information and content. The similarity is the adaptation process which anyone regarding open licenses of the OER can do. A learner can adapt OER for her own learning means similar as an open educator or developer (Nascimbeni \& Burgos 2016) can adapt OER for their target-group (Stoffregen \& Pawlowski, forthcoming). Principles shaping the adaptation and meaningful use for learning means are "users are centerpiece of the processes; previous knowledge, experiences and competences should be accepted and incorporated in the process; the range of OER should be flexible so users can decide where when what how and how fast the can learn." (Butcher 2011).

In this regard, adaptation processes were defined as iterative circles of: searching, validating reuse-ability, adaptation, validation of results, re-publishing and start over with searching relevant OER (Richter \& Pawlowski 2007). To make an OER meaningful to end users, they have to be constantly involved and trained to make the most of the digital learning resource.

Culture and context factors have a tremendous impact on the success of the OER development including creation and adaptation processes (Edmundson 2007c; Henderson 1996; Stoffregen et al. 2016, Pirkkalainen \& Pawlowski 2010). On the one hand, culture mindsets shape the perspective of developers, how the digital resource shall work and be embedded in learning platforms. On the other hand, managers have their own idea about the free-time to use OER, required quality checks and responsibility for publications. End users, at the same time, dream of an easy-to-use, mobile, just-in-time learning solution that works similar to google (Stoffregen et al. 2015). Not to forget, end users do not only use OER for themselves but also for colleagues in administrations. Essentially, an OER is thus iteratively adapted to culturally fit the context of users in a given time and place. Core factors to consider in this culture contextualization are for example, value of errors, learner control, structure (Henderson 1996) but also type of content and format of the media (Edmundson 2007c). Software development for OER use as well as OER adaptation is thus a well elaborated, culturally shaped process (Richter \& Adelsberger 2012, Richter \& Pawlowski 2007). In this respect, a permanent, strong exchange of ideas and progress between these stakeholders is indispensable in order to create a working technical solution. Systematic methods to elicit and document the role of cultural context factors in public administration thus have a strong role in OER development (Richter \& McPherson 2012; Eidson 2009; Edmundson 2007a).

Lately, OER development methods have been inspired by agile principles. Boyle et al. (2006) elaborated on "a light 'agile' development method that is structured but adaptable to local circumstances" in learning resource development. Initially, the goal was "to provide a robust and flexible framework that will support the development of high quality learning objects" (Boyle et al 2006:2). Focus of their work was to improve collaboration between educators and media designers as well as the integration of all organizational members in the overall process of OER use (Boyle et al. 2006:2f.). While Boyle et al. (2006) elaborated on the organization of collaborators to succeed in the creation process, a recent study of Arimoto et al. (2016) focus in depth on the steps to create an agile method for OER (AM-OER). Their result is AM-OER which proceeds over the steps: needs analysis, defining educational objectives, planning, development, validation, iteration, packaging distribution. Later, these steps were refined with considerations about the initial architecture, planning, sprint, design / incremental development, evaluation, iteration, releases. Crucial point of AM-OER is the distribution 
of roles namely the user, development team, coach and IP Expert (Arimoto et al. 2016:212). Users are learners at the same time which is typical for OER-approaches. It means they are gaining knowledge by using OER content as resources for own learning means as well as they are using the resource for own means such as training of colleagues. Developers are media designers, reviewer to check the quality of OER as well as technical embedders in the technical infrastructure and processes of the organization. The IP expert focuses on the correct uses of the materials. Last but not least, the coach works in-between the stakeholders and communicates ideas, challenges and processes. Overall, the distribution of roles contributes to the harvesting of common broad involvement in OER uses and maintenance. Instead of a few end-users and technical developers that run through sprints, the quality of technology infrastructure, outputs and interaction of involved people is addressed in AM-OER.

The approach AM-OER is comprehensive and focuses on the role of social collaboration. It therefore can serve as a base to develop a model which incorporates both, agile government and OER processes to create synergies.

\section{Methodology}

The overarching research question of our study is: How to contribute towards knowledge and learning processes as part of agile government changes utilizing agile Open Educational Resources in public administration? In particular, we elaborated: How does the project trajectory evolve with agile OER uses? as well as: Which model represents an integrated process of agile Government and learning processes? Our research paradigm is associated to the sociotechnical school of thought (Williams \& Edge 1996). The approach follows constructivism and applies an interpretative lens (Myers 1997; Gregor 2006; Bacharach 1989; Whetten 1989). In line with the research paradigm, our research strategy is an interpretative case study (Yin 2014; Carson et al. 2001) oriented on principles and steps of Action Design Research [ADR] (Sein et al. 2011). ADR is a recent approach which assembles principles and practices from action research (e.g., McNiff \& Whitehead, 2009) as well as design science research (Hevner 2007). Outstanding in ADR is the emphasis that technology, knowledge and design principles are shaped from the specific context, while offering a way to generalize upon the situated findings for classes of problems in the field. Furthermore, ADR includes a reflection phase that directs attention for researchers to systemize insight, to reflect and to steer the forthcoming interventionists steps in the project. In this context, ADR suits both the research interest and paradigm of the study. In addition, the approach is valuable for the context specific research question and presented above.

Our data collection bases on focus groups, survey interviews (Yin 2014) as well as semistructured interviews (Myers 1997; Morgan 1997; Kitzinger 1994; Merton \& Kendall 1946). In total, three focus groups were organized with general public employees and trainees (group size $>10$ participants). Authors designed a purposive sample of participants (Yin 2014) and achieved to involve public employees from the IT-Department, e-Government department, personnel and organisational change department, library, fire department, internal service and front offices. The survey interview (Yin 2014) design was oriented on previous studies in the field (cf. Stoffregen et al. 2016). Public employees were asked to participate on a voluntary basis. We recorded and analysed the survey data in SPSS with regard to our research questions. Concerning interviews and focus groups, we took notes and developed protocols of discussions (Myers 1997). The analysis of all data oriented on contextual content analysis according to Mayring 2010). Rules followed are the familiarization with context-specific terminology, definition of material to analyze, contextual analysis (check the relevance and intelligibility for the analysis), develop explicatory paraphrases and validation of explications (Mayring 2010: 89). To validate our explications, we discussed protocols and impressions about the progress with participants and leaders of the administration (cf. Madill et al. 2000; 
Myers \& Klein 2011). Different accounts were noted, discussed and results adapted (see the results section concerning the discussion with leaders).

The case study context is a public administration in western Germany. It is a modern public administration that has an active in e-Government presence and is known for its progressiveness in the public sector landscape. In total, about 32 public employees (13 trainees and 19 public servants and managers) were involved for about one year (November 2015 till November 2016). The project is currently ongoing wherefore we report till the recent point and provide an outlook of next sprints.

The context of our study was a broad OER implementation including a long-term observation as well as strategy development for using OER. However, we avoided to projectizise our focus on "agile" approaches. Instead of insisting to follow steps of agile models presented above (summarized in Figure 1), we aimed at following the process trajectory in context over time. Correspondingly to this, we traced an abductive evaluation strategy (see Douven 2013) and followed an interpretative, in-depth analysis of data (Mayring 2010; Corbin \& Strauss 1990).

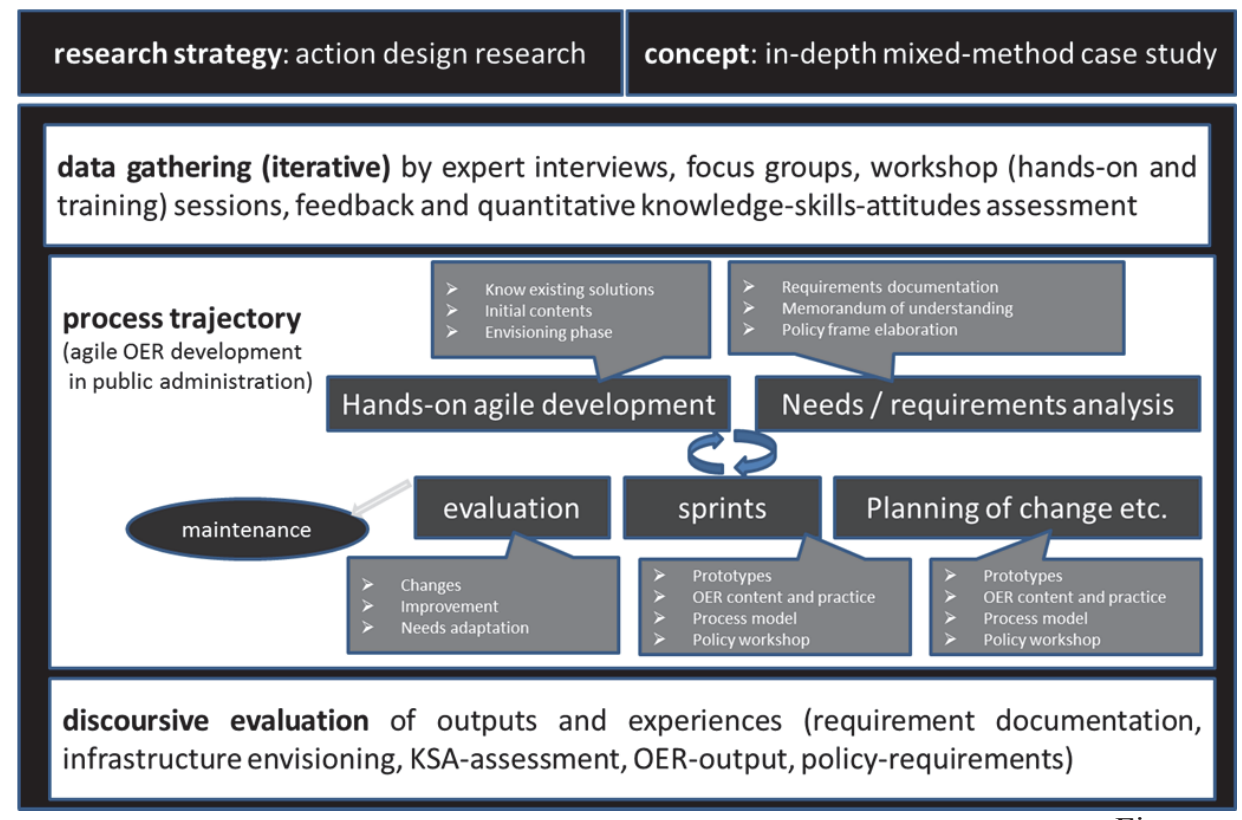

Research Process

Figure 1:

We took notes about discussions (expert and focus-group discussion) for analysis at the workplace. Workshops were recorded but due to privacy concerns, participants aimed at turning down the record. The knowledge-skill-attitudes assessment was distributed on a voluntary basis to all participants. We oriented on a previous approach from the project EAGLE (EAGLE project 2013) as well as guidelines from McNiff \& Whitehead (2009) for documenting observations in the field. Once analyzed, we discussed results and outcomes with participants on site according to principles of ADR (Sein et al. 2011). In the following, the result of this process is presented. 


\section{Results}

In this chapter, we present the results in form of a narrative of landmark happenings, dates and turning points in a first step. In a second step, we will discuss the findings with regard to the main research questions.

\subsection{Narrative of results}

We contacted leaders of the internal services of the municipality and asked whether they are interested in a workshop about "open e-Learning for training of employees in the public sector" which is free of costs. Background of the workshop would be to elaborate individual strategies for sustainable implementation and use of open educational resources. Our suggestion was met with great interest and we were invited for a talk about the workshop-content and overall approach of the implementation strategy.

In the first meeting, two leaders were surprised about the fact that open educational resources are constantly developed and re-used over time. E-Learning was not a common approach to train employees so a lot of time of the first meeting was dedicated to explain what OER are and what they might be. "So it is not e-Learning but our employees actually develop resources- they are free in the choice of topics- how does that work?"

Apart from the meaning of OER, center of discussion was the strategy: who exactly will use the OER and where at the workplace- "how will workshop results be embedded"? The leaders asked which role infrastructure development would play since the municipality was about to elaborate on an integrated approach comprising knowledge management, learning and intranet.

After the meeting, leaders decided to present their ideas to the official meeting of leaders and inform them about the potential workshop and long-term strategy development. During the presentation two further leaders demonstrated great interest and claimed for another meeting for discussion. "The leader of infrastructure and information technology had so many questions and need for explanation-it would be better to meet you again here on spot before going on."

During the second meeting with authors and four leaders of the municipality, it became clear that a long-term involvement after the workshop was of key interest. The workshop should serve as a backup to actually show what OER are in practice and which requirements have to be considered. Furthermore, we noticed the emphasis of one leader. "What is important to me is culture. Its impact is always forgotten. We can sit here and talk and then they don't use it. If they hear it is about anything that is "open" it won't work like that." We outlined our focus on the culture-context approach validated in public administrations before in which culture factors are of central interest. We agreed to discuss about results and decide about further steps subsequently.

The initial workshop followed soon and was attended on a voluntarily basis. Information about the workshop was published in the intranet: "Inhouse Workshop: It is your turn! How do I adapt OER for my on learning means? And how do I generate support of leaders for this...? Both skeptics who do not like to learn online as well as employees who are busy at the info-station and have little time are invited. We elaborate how you can make OER work for your context. We elaborate on your learning and context profile and discuss about barriers that a future strategy has to address." An excerpt of relevant results is presented in the following.

In total, six male and eleven women about 48years old participated in the workshop. Overall, people introduced themselves, elaborated on exemplary OER and discussed about case studies how to use OER in their contexts and positions. Furthermore, what participants knew before and expected of OER development and used was asked. Last 
but not least, individual, culture values were alleviated by a semi-structured questionnaire.

The questionnaire showed that $82,4 \%$ aimed at using OER for own learning means at their workplace. Reading OER gained interest (82,4\% agreement) while less than 50\% $(47,1 \%)$ aimed at adapting OER actively for themselves. Based on questionnaire results, the role of their daily work and context in this regard was very important. Most important factor is 'time' that is officially allowed to spend for developing OER. Over $50 \%$ of participants reject that the must spend time regularly for OER uses while they welcome to use OER according to own means. However, 94,4\% agreed that they need some dedicated space in terms of place to sit, infrastructure and light to actually use OER.

Another key outcome was the role of OER to generate social ties. While some participants $(16,7 \%)$ saw potential that OER will be miss-used for surveillance of employees learning involvement, $83,3 \%$ agreed OER are useful media to get in contact with people. Another key result was the role of policies. About $34,4 \%$ of participants wish for a binding policy that is dedicated to OER development and uses and more than $50 \%$ disagree that no policy shall be developed. Concerning details of policy content, 46,9\% participants agreed that the policy shall elaborate how to behave in OER collaboration. The questionnaire showed furthermore that the role of leaders gained importance. Leaders shall stand for the idea of OER and help using them at their workplace $(94,4 \%)$ users. At the same time, participants were keen to experiment how to actually develop OER at their workplace (55,6\% agreement).

Concerning the role of openness in discourse, results show that $50 \%$ disagree while $22,7 \%$ agree to the claim "information is power and thus not shared". Interestingly, failing in progress or better to say, discussing with peers about errors in content and difficulties is acceptable $(90,9 \%)$. However, only $59,1 \%$ participants that this discussion involves leaders.

The results and researchers notes were discussed with leaders from the first two meetings. In this context, further essential results were noted down: The distribution of responsibilities during the process appeared as a barrier to leaders. Also the setting of quality standardswhether OER uses and development runs as planned, was seen as important factor to elicit. Last but not least, it was principle to develop practice-oriented examples and best-practices regarding OER content and development. Internally, leaders noticed that the workshop did not succeed to actually convey experience in OER uses. Thus, another results oriented step should succeed before deciding about infrastructure designs.

Apart from the workshop with public employees, envisioning of the infrastructure development evolved. At this point of time, leaders from the internal service started to dissociate their involvement. More and more, the two technical administration leaders took over. During meetings, requirements for the technical solution were: embedded interface, building upon the existing technical solutions as well as integrate a wiki. The solution should integrate principles of a social intranet, such as connecting with others, writing in private and public with colleagues. Yet, leaders were not finished with the envisioning phase regarding radical new platform integration. Thus, we decided to start with the wiki as is (infrastructure of the media-wiki) and build upon it. Furthermore, one of the authors developed a prototype skeleton for authoring OERs. As a result, we decided to develop around the existing solution. Two main relevant OER topics were defined for the sprints, digital security at the workplace and wiki for trainees.

Afterwards, another workshop with public employees (trainees) was scheduled soon after. Participants were not corresponding with previous ones. Also the layout of the workshop was 
radically different given the interest in results oriented practice and training. On the one side, we scheduled weekly meetings to see how the OER development is actually progressing in their practice context. On the other side, it was much more flexible since the agenda provided space for participants to develop own OER. Essentially, the workshop addressed further barriers elicited in the first context. Participants were trained in: giving feedback concerning errors and problems; how to write OERs; how OER uses and this project is supported by leaders, that they can form wiki-teams with older colleagues or trainees, that their feedback is welcome- both personally and online in a reflection tool that one author prepared. Furthermore, we elicited the knowledge-skills-attitude questionnaire on a voluntary base (anonymously with personal sign for recognition).

During and after the workshop, participants were totally exhausted. They considered their knowledge as replaceable and unimportant. "It is a good idea. But why should we as trainees start with this project?" Despite that they liked their OER-results produced in the workshop, they did not see the relevance of their involvement. In other words, trainees supported very much the development of the wiki but did not understand how they should contribute to the kickoff.

The second and third meeting with trainees unveiled that only one person managed to actually register to contribute OER. Others mentioned:

"I have no time and actually my superior did not know about the project.

Yes, I agree. Moreover, I cannot login from my pc-it is not connected to the internal network.

Yeah, well, my superior seemed to know but how can I spend time when my colleagues is next to my talking to clients - I cannot afford that as a trainee."

Discussing their experiences, participants outlined that they had no time to create OER. Their leaders were hardly informed about the project. Trainees had no ideas what to write apart from topics discussed in the initial workshop. Furthermore, infrastructure barriers did not allow particular users to contribute to the process.

While the authors collected and analyzed results for the next development and prototyping phase, one author was invited by one of the technical leaders. It came out that she was about to integrate new ideas from a working group outside our project and their administration. She had some ideas about video-learning and that everything could be produced by screenshots developed internally as well as by providers she got to knew a few months ago. Interestingly, she had not discussed with the other technical leader so far. Instead she wanted to know our ideas about it and how we could connect with the other team.

We decided to integrate this suggestion in our next report that is about to be discussed and focuses on the infrastructure integration and future training sessions of trainees and involved participants.

\subsection{OER Reference Model for Public Administration}

In the following, we discuss the results with regard to experiences with the concept phases, outcomes and key turning points as well as roles emerging in the process. From this, we derive the main articfact as part of the ADR process: a reference model of agile OER implementation with the goal to support knowledge and learning processes as part of Agile Government projects.

The case study results reflect a process trajectory which runs up till the first sprint. In a first step (hands-on agile development) we had to inform involved stakeholders about our approach, what OER means and what to expect regarding infrastructure development. In a second step (needs / requirements analysis), we elicited requirements during the workshop and 
noticed major barriers that are subject to change. Subsequently, we discussed with leaders about initiating change processes (planning of change). In this regard, we prepared OER prototypes, decided about the content and training modules. Also we discussed about the process including the importance of regular meetings on the spot. Next step was the first sprint which was realized in form of the second workshop. For participants, it was the first workshop so they were trained to create OERs and get their way through the infrastructure platform. Based on the results, we are about iterate the planning and start the second sprint.

The reflection suggests that the steps (hands-on until the first sprint) suit the overall process trajectory (see Figure 1). Important point to notice is that we have not insisted on running through each step or phase but instead, discussed and followed leaders and participants in how to move on. In this regard, key turning points and overlapping of phases can be noticed from our report.

First notice is that we had to explain extensively over a long time "what OER and development processes are". Leaders were not so much interested existing OER solutions but the question how to integrate solutions into a running system. Furthermore, they asked whether other municipalities are involved in OER development and which experienced they have made. End users paid more attention to the question which running OER solutions actually exist. Central concern, in this regard, was that social ties may be disconnected, for example, personal exchange of experiences during coffee is supplemented by searching for OER. Overall, results indicate that interests and concerns deviated in-between the two groups and suggest re-designing the hands-on phase individually for stakeholder concerns. Interests of leaders tended to address the overall running infrastructure system while end-users rather addressed compatibility of practices during work. Both groups were interested how others handle OER development. Leaders were interested who else in the public sector context experienced the processes while end-users asked for best-practices and how to collaborate and evaluate quality of their peers' results. Accordingly to this, similar frames (system integration and benchmarking) but different perspectives have to be addressed.

Second note concerns the role of culture in discussions with leaders as well as with end-users. Since we did not emphasize our dedicated research interest, leaders did not know about our interest in culture factors. Once the leader indicated that we have to pay attention to culture factors we were able to discuss about different culture concepts and which factors might be relevant. During the workshop, these factors raised emotions. Asking about how to behave in discussions (whether and with whom to share problems at the workplace), which role leaders ought to have in OER development among others raised discussions. Important to note, however, the collaboration also created solution space that, for example a common objective must be found for collaborative OER development in form of a binding policy. Furthermore, we noticed the sociality of OER development regarding collaboration with peers, friends and developers was welcome and central concern to participants. Requirements for the OER development process can be derived on this base, such as: the authoring tool must be collaborative, no option for anonymity, quality review process, strategy with wiki-teams (one developer, one experienced public employee) that meet in person, chat and create technical solutions. Yet, these requirements need to become more detailed throughout sprints and reflections. So far, we notice that exploring and reflecting on culture factors supports eliciting major requirements as well as policy needs (such as binding agreements how to behave).

Thirdly, we saw that our regular and constant communication with public employees and leaders was not enough to build a bridge to "internal, open communication". For example, leaders outlined that we did not succeed to offer a hands-on experience in agile OER development. They knew from internal talk and indicated to us that OER development is not understood in practice. Participants who were invited to comment personally or anonymously how they experienced the development process did not report this opinion to us. Consequen- 
tially, we radically redesigned our workshop-approach and succeeded initial OER prototypes. However, results indicate that more clarity needs to conveyed, how open and flexible our development team is to their feedback. Designing a memorandum of understanding (what agile OER development processes require and offer in terms of communication, flexibility and on the spot support) should involve all stakeholder groups.

This last note points out to the important role of stakeholder involvement. More particularly, results point out to the importance of role-sensitive communication to participants involved in the overall agile OER-development process. Firstly, information and sensitizing strategies in the 'hands-on' phase should be individualized according to the position and daily work of stakeholders. Secondly, central outcomes from individual communication must be streamlined. For example, leaders knew about our commitment to work on the spot, adapt to changing requirements and ideas and, beyond, also confronted us constantly with new ideas such as the video-learning approach (see last paragraph of the report). End users were welcome to give free feedback, ask anything they want and that we will adapt to their ideas. However, this might be seen as an offer limited to the workshop-session instead of a dedicated memorandum of understanding. Accordingly to this, we come to the following synthesized model for agile OER development in Government.

1. Hands-on agile development: get into practice

a. Stakeholder: Demonstrate existing agile / open source solutions on the market; therein facilitate benchmarking and check of system integration

b. End users: Offer space to test existing solutions and develop initial contents

c. Envisioning phase of the needs and barriers (related to the next step)

2. Needs / requirements analysis

a. Requirements documentation

i. Technical: Architecture envisioning (infrastructure, user stories, prototypes)

ii. Socio-cultural: Elaborate which culture factors shape the context, elaborate the culture profile of end users (see Stoffregen et al.)

b. Memorandum of understanding, important: to all stakeholders

i. Explain the given policy frame

ii. Create confidence that needs and requirements may change (and this process is welcome)

iii. Create awareness agile development is time (and collaboration)- intensive

iv. Create confidence that employees may become multiplicators of the practices

3. Planning of change, releases and sprints

a. Technology prototypes (e.g. OER authoring tools, repositories, interfaces etc.) OER content and practice (train users in creating / contextualizing OER and being multiplicators))

b. Socio-technical process model (elaborate how culture barriers change and evaluate processes with involved in the practice context)

4. Sprints

c. Policy-workshop: securing formative long-term change

a. Technology prototypes (e.g. OER authoring tools, repositories, interfaces etc.)

b. Training in OER content and practice (extended hands-on phase)

c. Reports about discussion to evaluate releases

5. Evaluation

a. Identify changes, improvements and needs

i. Prototype evaluation 
ii. Hands-on evaluation

iii. Evaluation of discussions

iv. Policy changes for the organization

6. Back to sprint OR maintenance.

In the next step, we will discuss the model and our key findings with regard to existing agile concepts in Government.

\section{Discussion}

The aim of our study aimed at elaborating how agile government projects can benefit from agile OER development in public administration? Elaborating on differences in the background chapter, we showed that potential synergies can be derived from the focus on culture and behavioral change in OER development. Also, the strong role of users and citizens may be a beneficial point to agile methods.

Relating our results to Adaptive Governance strategies and influence factors (Janssen \& von der Voort, 2016), we can state that our approach contributes towards many of those: Both, Agile Government / Adaptive Governance as well as OER include phases to analyze and engage stakeholders. Furthermore, agile OER contributes towards Agile Government by providing solutions for education and training as well as shortening training and correspondingly decision making times. These conceptual synergies clearly show that Agile OER contribute conceptually and practically towards Agile Government.

Specifically, we can state that our results imply that agile development concepts in Government need to be more elaborated regarding the involvement of particular stakeholders. In our case, stakeholders were internal service leaders, infrastructure and information technology leaders as well as end-users. According to the concept of Arimoto \& Barbosa (2013); Arimoto et al. (2016), these roles can be matched with for example, roles of coaches and IT-experts among others. For future research, we suggest to elaborate more on the development of roles in agile processes, which types of roles emerge and which requirements their new position evolves. For practice and with regard to our on-going case study, we will adapt the model and individualize agile steps according to these roles. Moreover, we will validate with stakeholders, how useful they consider a training to meet these or similar roles (being expert for IT and OER publishing, for example).

Secondly, while building upon the previous step, an additional principle to agile concepts in Government should be the common involvement of all stakeholders in the development of the memorandum of understanding. While that stakeholder communication should be individualized as suggested before, main principles such as flexibility, collaboration and agile responsiveness to changing needs should be formulated, communicated manifested intelligibly in the overall development process.

Thirdly, OER models focus on behavioral practice in agile development. Interestingly, we experienced that our idea of realizing this "hands-on" experience phase failed requirements of our target group. There was an even greater demand to start with practical OER development than to merely demonstrate existing solutions and explain how it works. We had to radically redesign the first phase so that participants actually developed their initial OERs in the first meeting. It can be argued that this result is weakened given the fact that we contacted our case-study partner with the offer of a practice oriented workshop. Indeed, future research has to elaborate on the design and placement of step in agile development processes in Government. Yet, the results outline the importance of a hands-on phase in the beginning of agile processes in Government. Furthermore, results show that we actually underestimated the importance of practicing OER development processes from the beginning as shown. In this re- 
gard, we consider that a synthesis of agile concepts in Government suggests to emphasize collaborative, results oriented sprints to the starting phase of agile processes..

Related to the previous point is the role of change processes within the whole organization. Based on the constant feedback of leaders, employees and trainees, results indicate that actually practicing OER use at the workplace brings barriers to light, that would otherwise have not been considered important. First, elaborating on common concepts like culture contextualization or the barrier framework has helped to elicit socio-culture and organizational barriers. In our current work, this knowledge informs our work on suitable policies that frame a common and secure frame for development process and use of OER for public employees. In this regard, an extended agile development concept in Government should be extended to elicit culture- contextual barriers. This finding supports the claim of Mergel (2016) and suggests a way how to elaborate and integrate barrier development in agile processes. Second, the role of allowed time (by rule) as well as involvement of leaders in other departments turned out as crucial barriers. Another example is the interest in social interaction during development processes, for example, that trainees collaborate with developers or employees in a wiki-team. Conflicting with this, the discussion outlined low selfidentification of trainees as multiplicators and knowledgeable peer in the wiki-team. Based on that, we consider that training that helps to reflect the worth of one's knowledge and ideas will benefit agile processes. The last point directs attention to the previous interest of Janssen and van der Voort (2016:4) about the role of education and training as a principle for agile methods. Results support this claim. Furthermore, we suggest that OER may benefit agile Government approaches in this respect as OER perform as medium for training (conveying knowledge about OER, familiarizing users with their role of multiplicator) and artifact of success and progress (product of agile software development and use) at the same time.

Overall, we argue that results of study contribute to answer the research questions in a positive way. Results stem from a single case study which is "work in progress". Generalization of findings has to be seen with caution. At the same time, our aim was to see in depth-context how agile processes evolve in practice. We designed a sensible research design that suits to develop context-sensitive solutions which can be transferred to overall cases (Sein et al. 2011). Furthermore, we did not "projectize" our focus on agility (by labelling or praising agile principles from the beginning) which provides ground to generalize findings to technical development processes more generally. In this regard, we argue that results present a practical, rich and multi-faceted insight how agile development processes work in Government and how to enrich them prospectively in research and practice.

\section{Conclusion}

The paper provides in-depth case study how first phases of agile OER development succeed in Public Administration and how this contributes towards Agile Government processes. Results suggest that main steps of agile projects such as needs, requirements phase, sprints, planning of change and evaluation are followed. More focus should be laid on a hands-on (results oriented) phase that conveys how technical artifacts work in contexts. During development steps, the developing team will have to design and communicate agile processes rolesensitive according to involved stakeholders. In this regard, role and culture-sensitive requirements elicitation will contribute to sensitize about challenges as well as solution spaces for socio-technical barriers. Compared to previous agile concepts in Government, the importance of education and training during development steps can be strongly supported. The role of OER in this respect can be emphasized as OER perform as medium for training and artifact of success and progress at the same time. Among other findings, the results suggest that agile OER development contributes to reach fundamental goals of agile Government such as open interaction, sense for individual and shared culture, social interaction, worth and 
responsibility of knowledge sharing among colleagues. We suggest elaborating further on the suggested synthesis of agile concepts in order to harvest agile mind and processes from the bottom up.

\section{Acknowledgement}

This research has been co-funded by the European Union within the Seventh Framework Programme, FP7-ICT, grant agreement no: 619347, (see: http://www.eagle-learning.eu/).

\section{References}

Arimoto, M. M., \& Barbosa, E. F. (2013, October). Towards the establishment of an agile method for OERs development and delivery. In 2013 IEEE Frontiers in Education Conference (FIE). 541-547.

Arimoto, M.; Barroca, L.; Barbosa, E. (2016). AM-OER: An Agile Method for the Development of Open Educational Resources. Informatics in Education 15(2), 205-233.

Atkins, D. E.; Brown, J. S.; Hammond, A. L. (2007). A review of the open educational resources (OER) movement: Achievements, challenges, and new opportunities: Creative common $\quad 1-54 . \quad$ Available online at http://www.hewlett.org/uploads/files/ReviewoftheOERMovement.pdf.

Bacharach, S. B. (1989). Organizational Theories: Some Criteria for Evaluation. The Academy of Management Review 14(4), 496-515. DOI: 10.2307/258555.

Boyle, T., Cook, J., Windle, R., Wharrad, H., Leeder, D., \& Alton, R. (2006, December). An agile method for developing learning objects. In Paper presentation, ASCILITE conference, Sydney, Australia, December, 3-6.

Butcher, N. (2011). Was sind OER? Übersetzung von Commonwealth of LEarning und UNESO 2011, 1-22.

Carson, D.; Gilmore, A.; Perry, C.; Gronhaug, K. Case-based Research (2001). In : Qualitative Marketing Research. SAGE Publications, Ltd., 92-113. Available online at http://dx.doi.org/10.4135/9781849209625.

Christy, A. (2016). Government goes agile. Stanford Social Innovation Review Spring, 2016. Corbin, J. M.; Strauss, A. (1990). Grounded theory research: Procedures, canons, and evaluative criteria. Qualitative sociology 13(1), 3-21.

Crawford, L. H., \& Helm, J. (2009). Government and governance: The value of project management in the public sector. Project Management Journal, 40(1), 73-87.

Douven, I. (2013). Abduction and Inference to the Best Explanation. Encyclopedia of Philosophy and the Social Sciences. Ed.s Kaldis, B. Thousand Oaks: SAGE Publications, Inc.Print ISBN: 9781412986892 Online ISBN: 9781452276052,3-5. Available online at DOI: http://dx.doi.org/10.4135/9781452276052.n2.

Dunleavy, P.; Margetts, H.; Bastow, S.; Tinkler, J. (2006). New public management is dead-long live digital-era governance. Journal of Public Administration Research and Theory $16(3)$, pp. 467-494.

EAGLE project (2013). EAGLE EnhAnced Government Learning. Accelopment (2013). Available online at http://www.accelopment.com/en/projects/eagle.

Edmundson, A. (2007a). The cultural adaptation process (CAP) model: designing e-learning. Chapter XVI. In Andrea Edmundson (Ed.): Globalized e-learning cultural challenges. Hershey, PA: IGI Global, 267-289.

Edmundson, A. (Ed.) (2007b). Globalized e-learning cultural challenges. Hershey, PA: IGI Global. 
Edmundson, A. L. (2007c). Addressing the Cultural Dimensions of E-Learning: where to Begin? ch 5.2. eWorld Learning, USA; (In C. van Slyke: Information Communication Technologies: Concepts, Methodologies, Tools, and Applications. Information Science Reference, e-book: 159904949X), 2252-2267.

Eidson, L.A.K. (2009). Barriers to E-Learning Job Training: Government Employee Experiences in an Online Wilderness Management Course. Thesis, Dissertations, Professional Papers .(University of Montana. Paper 86).

Fishenden, J.; Thompson, M. (2013). Digital government, open architecture, and innovation: why public sector IT will never be the same again. Journal of Public Administration Research and Theory 23(4), 977-1004.

Gallop, G. (2012). Agile Government. In: Gallop, Geoff (2012). Politics, Society, Self. Nedlands, W.A.: UWA Publishing, 2012, 185-193.

Gong, Y.; Janssen, M. (2012). From policy implementation to business process management: Principles for creating flexibility and agility. Government Information Quarterly 29, 61-71.

Gregor, S. (2006). The Nature of Theory in Information Systems. Management Information Systems Quarterly 30(3), 611-642.

Henderson, L. (1996). Instructional design of interactive multimedia: A cultural critique. Educational technology research and development 44(4), 85-104.

Hevner, A. R. (2007). A three cycle view of design science research. Scandinavian Journal of Information Systems 19(2), 87-92.

Hilton, III.J.; Wiley, D.; Stein, J.; Johnson, A. (2010). The four 'R's of openness and ALMS analysis: frameworks for open educational resources. Open Learning 25(1), 37-44.

Hofstede, G. (Ed.) (2001). Culture's consequences. comparing values, behaviors, institutions, and organizations across nations. Thousand Oaks [u.a.]: Sage, Thousand Oaks, CA.

Janssen, M.; van der Voort, H. (2016). Adaptive governance: Towards a stable, accountable and responsive government. Government Information Quarterly 33, 1-5.

Kitzinger, J. (1994). The methodology of focus groups: the importance of interaction between research participants. Sociology of health \& illness 16(1), pp. 103-121.

Madill, A.; Jordan, A.; Shirley, C. (2000). Objectivity and reliability in qualitative analysis: Realist, contextualist and radical constructionist epistemologies. British Journal of Psychology 91(1), pp. 1-20.

Mayring, P. (Ed.) (2010). Qualitative Inhaltsanalyse. Weinheim und Basel: Beltz Verlag (11 Auflage).

McNiff, J.; Whitehead, J. (2009). You and Your Action Research Project: Routledge. Available online at http://dx.doi.org/10.4324/9780203871553.

Mergel, I. (2016). Agile innovation management in government: A research agenda. Government Information Quarterly 33, 516-523.

Merton, R K.; Kendall, P L. (1946). The Focused Interview. American Journal of Sociology 51(6), pp. 541-557. Michaelson, R. (2013). Is Agile the Answer? The Case of UK Universal Credit. IFIP AICT 4ß2, 295-309.

Morgan, D. L. (1997). PLANNING AND RESEARCH DESIGN FOR FOCUS GROUPS. Focus Groups as Qualitative Research. SAGE Publications, Inc. Edited by Inc. SAGE Publications. 
Myers, M. D. (1997). Qualitative Research in Information Systems. Management Information Systems Quarterly / MISQ Discovery, archival version 21(2), 241-242. Available online at http://www.qual.auckland.ac.nz/.

Myers, M. D.; Klein, H. K. (2011). A Set of Principles for Conducting Critical Research in Information Systems. MIS Quarterly 35(1), pp. 17-36.

Nascimbeni, F., \& Burgos, D. (2016). In Search for the Open Educator: Proposal of a Definition and a Framework to Increase Openness Adoption Among University Educators. The International Review of Research in Open and Distributed Learning, 17(6).

OECD (2001). Knowledge management: Learning-by-comparing experiences from private firms and public organisations. [Public Management Service, Public Management Committee]. HRM Working Party meeting Paris, 25-26 June 2001. Summary Record of the High Level Forum held in Copenhagen, 8-9 February 2001. JT00109192.

OECD (2003). The Learning Government: Introduction and draft results of the survey of knowledge management practices in ministries/departments/agencies of central government. 27th Session of the Public Management Committee; original format, 1-54.

Pirkkalainen, H.; Pawlowski, J.M. (2010). Open educational resources and social software in global e-learning settings. Sosiaalinen Verkko-oppiminen. IMDL, Naantali, 23-40.

Pirkkalainen, H.; Pawlowski, J.M. (2013). Global Social Knowledge Management: From Barriers to the Selection of Social Tools. Electronic Journal of Knowledge Management 11(1), 3-17.

Richter, T.; Adelsberger, H. (Eds.) (2012). On the myth of a general national culture. Making Specific Cultural Characeristics of Learners in Different Educational Contexts in Germany Visible. Proceedings Cultural Attitudes Towards Communication and Technology 2012. Murdoch University, Murdoch: 105-120.

Richter, T.; McPherson, M. (2012). Open educational resources: education for the world? Distance Education 33(2), 201-219.

Richter, T.; Pawlowski, J.M. (Eds.) (2007). The need for standardization of context metadata for e-learning environments. In Proc. of e-ASEM Conference, Seoul, Korea.

Sein, M. K.; Henfridsson, O.; Purao, S.; Rossi, M.; Lindgren, R. (2011). Action Design Research. MIS Quarterly 35(1), 37-56.

Stoffregen, J. Pawlowski, J.M. Ras, E., Tobias, E., Šćepanović, S., Fitzpatrick, D., Mehigan, T., Steffens, P., Schulling, P., Przygoda, C., Friedrich, H., Moebs, S. (2016)., Barriers to Open E-Learning in Public Administrations. A comparative case study of the European countries. Luxembourg, Germany, Montenegro and Ireland. Technological Forecasting and Social Change, 111, 198-208.

Stoffregen, J., Pawlowski, J.M., Ras, E., Tobias, E., Friedrich, H., Schilling, P., Steffens, P., Moebs, S. (2015). EAGLE Project - Deliverable No. D2.2.A. Requirements documentation and recommendations with Accessibility Guidelines. Authors Available online at http://www.eagle-learning.eu/.

Stoffregen, J.; Pawlowski, J.M. forthcoming. Concept of a knowledge ecosystem for the public sector. Consolidating open e-Learning, knowledge management and open data concepts.

Whetten, D. A. (1989). What Constitutes a Theoretical Contribution? The Academy of Management Review 14(4), 490-495. DOI: 10.2307/258554.

Williams, R.; Edge, D. (1996). The social shaping of technology. Research Policy, 1996(6), 865-899. 
Yin, R. K. (2014). Case study research: Design and methods: Sage publications.

Young, Mei-Lien; Kuo, Feng-Yang; Myers, Michael D. (2012). To share or not to share: a critical research perspective on knowledge management systems. European Journal of Information Systems 21(5), 496-511. 